Prepared in cooperation with the U.S. Army Corps of Engineers

\title{
Sediment Lithology and Borehole Erosion Testing, American and Sacramento Rivers, California
}

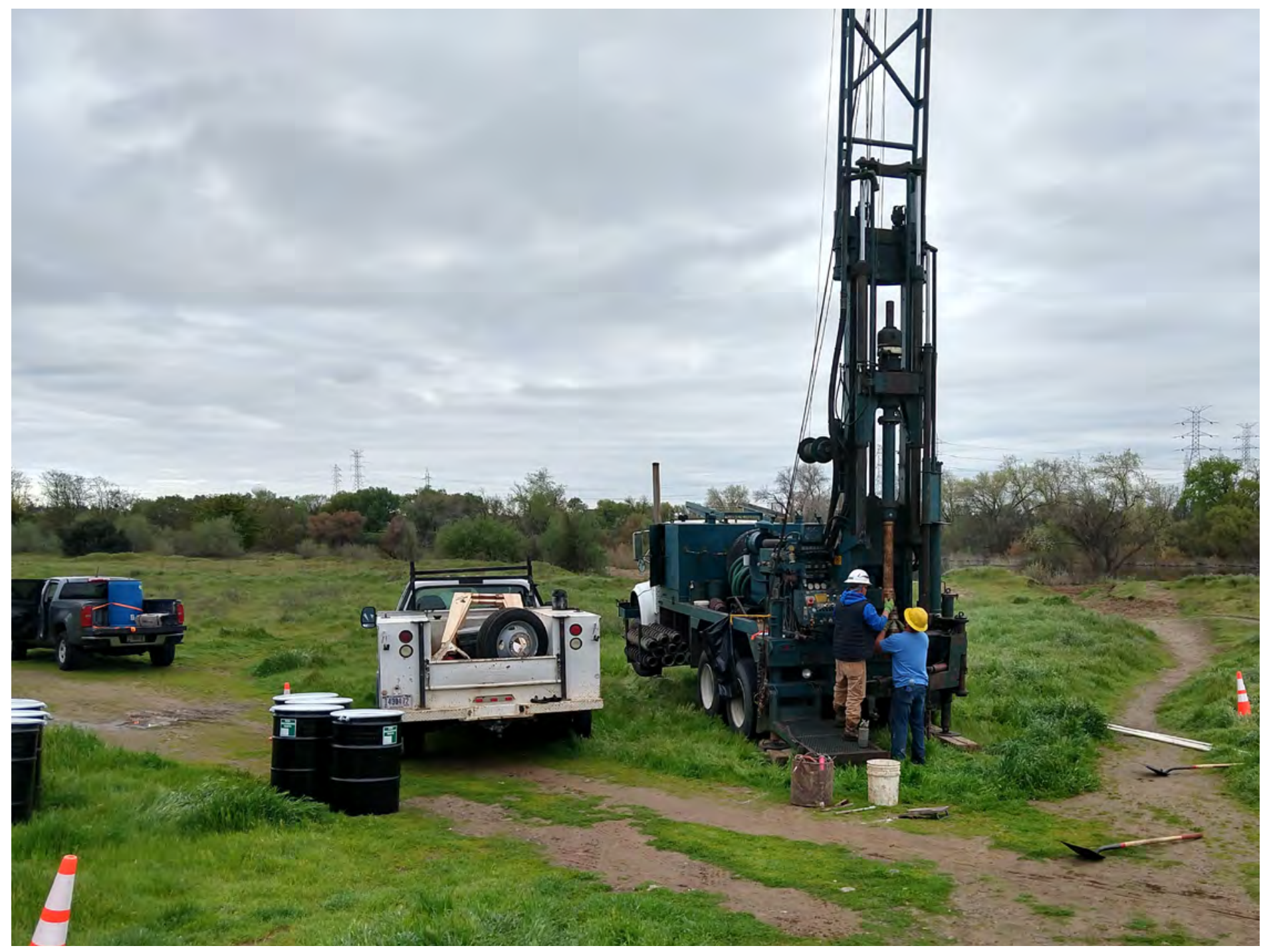

Scientific Investigations Report 2020-5063 
Cover Photo: U.S. Geological Survey drilling rig at site on American River. Photograph by Paul Work, 2019. 


\section{Sediment Lithology and Borehole Erosion Testing, American and Sacramento Rivers, California}

By Paul Work and Daniel Livsey

Prepared in cooperation with the U.S. Army Corps of Engineers

Scientific Investigations Report 2020-5063 


\title{
U.S. Department of the Interior \\ DAVID BERNHARDT, Secretary
}

\author{
U.S. Geological Survey \\ James F. Reilly II, Director
}

U.S. Geological Survey, Reston, Virginia: 2020

For more information on the USGS - the Federal source for science about the Earth, its natural and living resources, natural hazards, and the environment-visit https://www.usgs.gov or call 1-888-ASK-USGS.

For an overview of USGS information products, including maps, imagery, and publications, visit https://store.usgs.gov/.

Any use of trade, firm, or product names is for descriptive purposes only and does not imply endorsement by the U.S. Government.

Although this information product, for the most part, is in the public domain, it also may contain copyrighted materials as noted in the text. Permission to reproduce copyrighted items must be secured from the copyright owner.

Suggested citation:

Work, P., and Livsey, D., 2020, Sediment lithology and borehole erosion testing, American and Sacramento Rivers, California: U.S. Geological Survey Scientific Investigations Report 2020-5063, 92 p., https://doi.org/10.3133/sir20205063.

Associated data for this publication:

Work, P.A., and Livsey, D.N., 2019, Borehole erosion test data, lower American and Sacramento Rivers, California, 2019 (ver. 3.0, July 2020): U.S. Geological Survey data release, https://doi.org/10.5066/P96MCT20.

ISSN 2328-0328 (online) 


\section{Acknowledgments}

The authors would like to acknowledge financial support from the U.S. Army Corps of Engineers and assistance in the field from personnel from the U.S. Army Corps of Engineers, Sacramento, California, particularly Patricia Flanders and Richard Harvey. 



\section{Contents}

Acknowledgments …........................................................................................................................

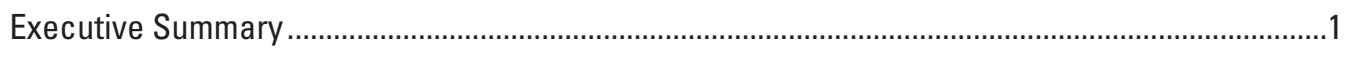

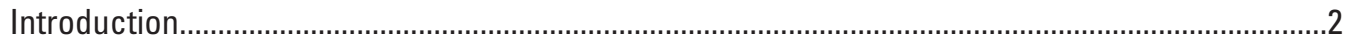

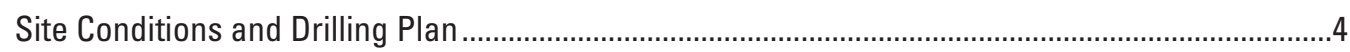

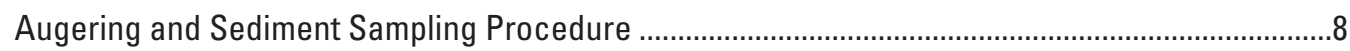

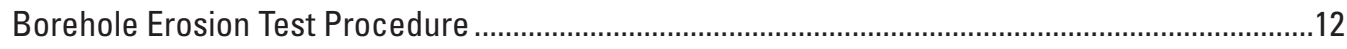

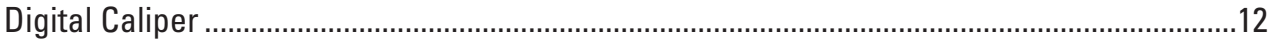

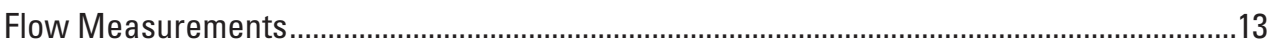

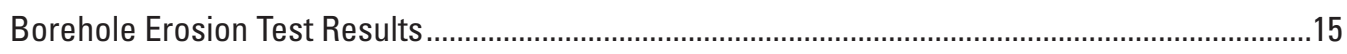

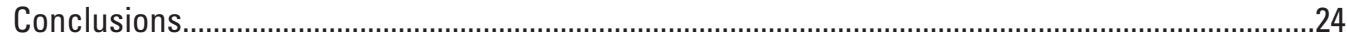

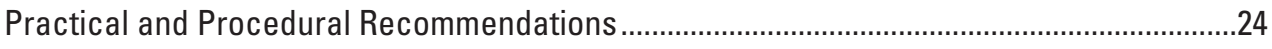

Site and Project Specific Conclusions ....................................................................................2

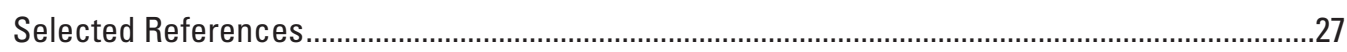

Appendix 1 Individual Borehole Erosion Test Plots and Notes......................................................29

Appendix 2 Flowmeter and Water Level Logging …….............................................................8

\section{Figures}

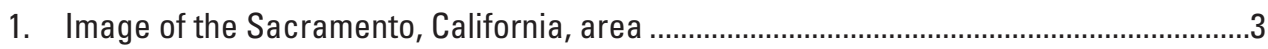

2. Map showing drilling sites on the American River, California ..........................................

3. Map showing drilling sites on the Sacramento River, California.......................................7

4. Images showing a mobile drilling rig deployed at site SAC5 and a bit on a hollow-stem auger..........................................................................................................

5. Images showing a split spoon sampler being disassembled for access to a sediment sample and the shoe of a split spoon sampler and a sand catcher ..................9

6. Images showing a Calmod sampler before disassembly and after disassembly ..............9

7. Image showing a disassembled split spoon sampler, with the core nose and bottom of the core at the upper right ............................................................................

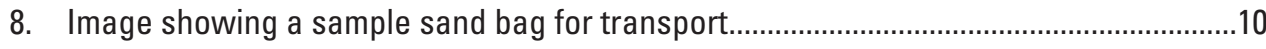

9. Image showing a Munsell soil color chart.................................................................11

10. Image showing the start of a test for the fraction of fines in a sediment sample ...........11

11. Images showing a digital caliper and winch and a detail of the caliper in the

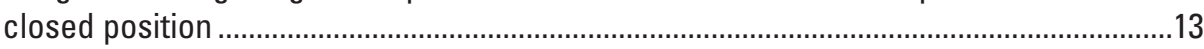

12. Graph showing time dependence in measured discharge on April 19, 2019, for site LAR7 with data logged at 1 hertz ............................................................................14

13. Graph showing evolution of the hole radius in a test at site LAR7 on April 19, 2019.......15

14. Graphs showing frequency of occurrence of flow speed, erosion rate, and ratio of erosion rate to flow speed for all available data ........................................................

15. Plot showing borehole erosion test results at site SAC1 ..............................................19

16. Plot showing borehole erosion test results at site SAC1 with erosion rates below 0.3 inch per hour discarded ...............................................................................20

17. Plot showing computed erosion rate versus flow speed and sediment classifications at site SAC1. 
18. Plot showing erosion rate versus flow speed by sediment type, using all available data from all test sites

19. Plot showing erosion rate versus flow speed and sand fraction, for samples from all sites containing greater than 50 percent sand based on visual observations.

\section{Tables}

1. Approximate locations, elevations, and hole depths for drilling sites on the lower American River

2. Approximate locations, elevations, and hole depths for drilling sites on the Sacramento River.

3. Summary of borehole erosion tests completed, presented in chronological order, and depth-averaged erosion rates.

\section{Conversion Factors}

U.S. customary units to International System of Units

\begin{tabular}{|c|c|c|}
\hline Multiply & By & To obtain \\
\hline \multicolumn{3}{|c|}{ Length } \\
\hline inch (in.) & 2.54 & centimeter $(\mathrm{cm})$ \\
\hline foot $(\mathrm{ft})$ & 0.3048 & meter $(\mathrm{m})$ \\
\hline \multicolumn{3}{|c|}{ Volume } \\
\hline gallon (gal) & 3.785 & liter (L) \\
\hline gallon (gal) & 0.003785 & cubic meter $\left(\mathrm{m}^{3}\right)$ \\
\hline gallon (gal) & 3.785 & cubic decimeter $\left(\mathrm{dm}^{3}\right)$ \\
\hline Cubic feet $\left(\mathrm{ft}^{3}\right)$ & 0.0283 & Cubic meter $\left(\mathrm{m}^{3}\right)$ \\
\hline \multicolumn{3}{|c|}{ Flow rate } \\
\hline foot per second (ft/s) & 0.3048 & meter per second $(\mathrm{m} / \mathrm{s})$ \\
\hline gallon per minute (gal/min) & 0.06309 & liter per second $(\mathrm{L} / \mathrm{s})$ \\
\hline inch per hour (in/h) & 0.0254 & meter per hour $(\mathrm{m} / \mathrm{h})$ \\
\hline \multicolumn{3}{|c|}{ Weight Mass } \\
\hline ounce (oz) & 28.35 & $\operatorname{gram}(\mathrm{g})$ \\
\hline pound (lb) & 0.4536 & kilogram $(\mathrm{kg})$ \\
\hline \multicolumn{3}{|c|}{ Pressure } \\
\hline pound per square foot $\left(\mathrm{lb} / \mathrm{ft}^{2}\right)$ & 0.04788 & kilopascal (kPa) \\
\hline pound per square inch $\left(\mathrm{lb} / \mathrm{in}^{2}\right)$ & 6.895 & kilopascal (kPa) \\
\hline \multicolumn{3}{|c|}{ Density } \\
\hline pound per cubic foot $\left(\mathrm{lb} / \mathrm{ft}^{3}\right)$ & 16.02 & kilogram per cubic meter $\left(\mathrm{kg} / \mathrm{m}^{3}\right)$ \\
\hline pound per cubic foot $\left(\mathrm{lb} / \mathrm{ft}^{3}\right)$ & 0.01602 & gram per cubic centimeter $\left(\mathrm{g} / \mathrm{cm}^{3}\right)$ \\
\hline \multicolumn{3}{|c|}{ Viscosity at 70 degrees Fahrenheit to Viscosity at 20 degrees Celsius } \\
\hline Pound-seconds per square foot & 268 & centipoise, or milliPascal-seconds \\
\hline
\end{tabular}




\section{Datum}

Vertical coordinate information is referenced to the North American Vertical Datum of 1988 (NAVD 88).

Altitude and elevation, as used in this report, refers to distance above the vertical datum.

\section{Abbreviations}

$\begin{array}{ll}\text { ASTM } & \text { American Society for Testing and Materials } \\ \text { BET } & \text { borehole erosion test } \\ \mathrm{Hz} & \text { hertz } \\ \mathrm{mA} & \text { milliampere } \\ \text { PVC } & \text { polyvinyl chloride } \\ \text { 01 } & \text { flowrate in flow event 1 } \\ 02 & \text { flowrate in flow event } 2 \\ \text { 03 } & \text { flowrate in flow event } 3 \\ \text { Q4 } & \text { flowrate in flow event 4 } \\ \text { SPT } & \text { standard penetration test } \\ \text { USACE } & \text { U.S. Army Corps of Engineers } \\ \text { USGS } & \text { U.S. Geological Survey }\end{array}$





\title{
Sediment Lithology and Borehole Erosion Testing, American and Sacramento Rivers, California
}

\author{
By Paul Work and Daniel Livsey
}

\section{Executive Summary}

A field investigation intended to measure the potential for erosion of sediments beside the American and Sacramento Rivers near Sacramento, California, is described. The study featured two primary components: (1) drilling and soil sampling to reveal lithology, down to depths matching the local river thalweg, where possible, and (2) borehole erosion tests (BETs) as described by Briaud and others (2017) at many of the same locations. The latter test involved drilling a vertical hole, measuring its diameter profile, inserting a hollow drilling rod to almost the bottom of the hole, and pumping fluid through the drilling rod at a known discharge for a chosen time interval. The hole was then resurveyed to establish an erosion rate (change in borehole radius divided by duration of flow event) as a function of depth, and the test was repeated. This test was performed with water as the erosive fluid at 12 locations, with 1 test repeated with drilling mud. Lithology holes were drilled at these same locations and an additional five locations. Drilling operations took place on river left and river right on the American River and river left (left bank, when looking downstream) on the Sacramento River.

The drilling to acquire sediment samples and reveal lithology involved the use of a mobile drilling rig equipped with a 6-inch (in.) auger, a 140-pound pneumatic hammer to drive split spoon and Calmod samplers, and a piston to push Shelby tube samplers to obtain samples of clayey material. Blow count (hammer blows per 6-in. sampler advance) was recorded while sampling, and the process was logged using standard U.S. Army Corps of Engineers (USACE), Sacramento District procedures. Sediment samples were identified and described in the field per ASTM D2488 and then delivered to a USACE laboratory and to Texas A\&M University for additional laboratory analysis.

The BETs were performed with the same drilling rig that performed the drilling for definition of lithology. In most instances, tests were limited to regions above the water table, to avoid slumping of the borehole and heaving sands pushing into the hole. Most of the tests featured sediments that were primarily silty sand or sandy silt.

The testing procedure involved comparing borehole profiles before and after passing an assumed constant discharge through a drilling rod to the bottom of the drilled hole. Discharge and water losses were logged during the testing procedure, and water losses into the walls of the drilled hole were typically less than 5 percent of the introduced volume. For the tests performed with water, the coefficient of variation of the discharge ranged from 4.5 to 28 percent, with a mean of 13 percent, but the mean discharge appeared to be reasonably steady over the typical test duration of 10-30 minutes. It was thus assumed that discharge was constant and water losses during the tests were neglected. Coefficients of variation of the discharge for the three tests performed with drilling mud were much higher (20-50 percent), but erosion rates were much smaller.

Resolution of the borehole caliper-reported diameter was $0.1 \mathrm{in}$. and several of the tests lasted for 10 minutes. With boreholes measured twice, before and after each test, and averaged, these numbers correspond to an apparent erosion rate (radius change divided by test duration) of 0.3 inches per hour (in/hr), which is a theoretical lower bound on what could be measured with this approach and equipment. In practice, $0.5 \mathrm{in} / \mathrm{hr}$ appears to be a more realistic lower bound on the detectable erosion rate, based on inspection of computed changes and erosion rates.

Three flow speeds $(5,8$, and 12 feet per second; $\mathrm{ft} / \mathrm{s})$ were targeted for the tests. Because of equipment limitations, it was not possible in the field to reach an average of $12 \mathrm{ft} / \mathrm{s}$ throughout any given borehole, although much higher flow speeds were reached locally in some cases. Most tests featured at least two different flow rates, and the borehole was typically surveyed at least twice for each condition, to allow averaging to reduce the influence of random diameter measurement errors. Errors arising from out-of-round boreholes appeared to be uncommon.

Briaud and others (2017) recommend stepped increases in the flow rate during a borehole test. This approach was taken during initial testing but proved to be problematic. The drilled hole would be enlarged by the first (smaller) discharge, and then it would be difficult to reach the desired higher flow speed because of the larger annulus between the drilled hole and the drilling rod that supplied the water for testing. This was largely solved by starting with a high discharge and, in many cases, maintaining it for subsequent tests with the average flow speed decreasing as the hole enlarged. 
Several different measures of erosion rate were computed and investigated by comparison to lithological profiles. The vertically averaged erosion rate for each hole was computed, but this result does not reveal vertical variability of erodibility; and the mean flow speed within the hole is not a good representation of the speed when attempting to determine a relationship between erosion rate and flow speed. Instead, for each 6-inch layer within the hole, vertically averaged erosion rates and local flow speeds were computed and plotted. Where possible, the soil type for each layer was identified. For later laboratory analysis, project protocol dictated collection of Shelby tube samples whenever clay was encountered.

Plots of erosion rate versus flow speed displayed scatter that indicate that several other factors influence the erosion potential of the soil. Blow count was not a good predictor variable; it is better correlated with soil type than erodibility.

Soils were classified as sand, silt, or clay, depending on which soil type dominated within a sample. In general, those classified as sand and silt did not reveal clear patterns allowing erosion rate to be computed directly from flow speed, but the test results define the range and bounds on the erosion rate. Results for clay were slightly clearer with the erosion rate increasing with flow speed, once a threshold had been reached. In this case, the erosion rate appeared to change near a speed of $7 \mathrm{ft} / \mathrm{s}$; above this threshold, erosion rates jumped from less than $2 \mathrm{in} / \mathrm{hr}$ to greater than $3 \mathrm{in} / \mathrm{hr}$.

Even for soils with similar classifications, large differences in erodibility were observed between sites and in different layers within an individual hole. One potential means of dealing with this problem would be to perform more tests at each site to allow establishment of relationships between flow speed and erodibility for individual layers within a borehole. The maximum number of tests performed at a site in this study was four, but in some cases, results are available for only one or two flow events. Comparison of data to a set of Erosion Function Apparatus tests that provide better resolution of the vertical variation in the erosion rate versus flow speed relationship would allow further investigation of this idea.

It was hypothesized that drilling mud could expand the utility of the test in soft sands by reducing the likelihood of slumping that would be interpreted as erosion. The one test that was performed with drilling mud indicated that it greatly reduced the erosion rate of the soils encountered. It yielded very different results from the test performed at the same site with water.

Erosion rate is often expressed as a function of shear stress applied to a soil. In order to compute shear stress on the walls of the drilled hole, one must assume a form for the relationship between flow speed and shear stress and select a friction factor that is often estimated empirically from head loss, observed water-surface profiles, surface roughness, or other data not available in this report. One methodology for computing shear stress from flow speed is discussed in this report, but the test results have been presented in terms of erosion rate versus flow speed to avoid assuming values that are not verifiable via the field data collected in this study. Erosion rate was computed from directly measured values (sequential borehole profiles) and flow speed was computed directly from measured quantities (discharge and borehole geometry).

The BET has seen limited application, primarily in clayey soils, whereas most of the soils encountered in this study were primarily sand or silt. The objective of the BET is to determine the erodibility of in situ soil below the ground or riverbed surface. The BET is simple in principle and has the advantage of revealing erodibility of in situ sediments below the ground or riverbed surface; it appears to be very useful in clayey soils, based on previously published work, but is more difficult to apply in sandy soils where slumping and water losses within the hole during testing are more likely to occur. The BET did reveal a large variation in the results both laterally and vertically, even for the same soil-type classification. It is thus recommended that the results be applied considering these spatial variations rather than attempting to universally assign an erosion-rate relationship to a particular soil type. Results have been provided showing the results by site and by sediment classification (sand, silt, and clay), to allow either approach. Where possible, it is important to rely on site-specific results because the erosion-rate relationship for a given soil type varied by site.

Data collected during this project have been made publicly available online via the U.S. Geological Survey (USGS) Sciencebase database. The measured borehole profiles, discharge, lithology log sheets, and photos are available in the data release that accompanies this report (see Work and Livsey (2019) in the "Selected References" section for the appropriate link).

\section{Introduction}

Much of the city of Sacramento, California, sits on flood plain near the confluence of the American and Sacramento Rivers (fig. 1), making the city vulnerable to floods. Both rivers feature man-made levees and major dams that provide protection from flood events; but in a major flood event, flows released from reservoirs could potentially cause the river to meander or cause the river cross-section to enlarge, eventually threatening the integrity of the protecting levees. The likelihood and magnitude of any resulting erosion is dependent on the erodibility of the sediments subjected to the overlying flow. 


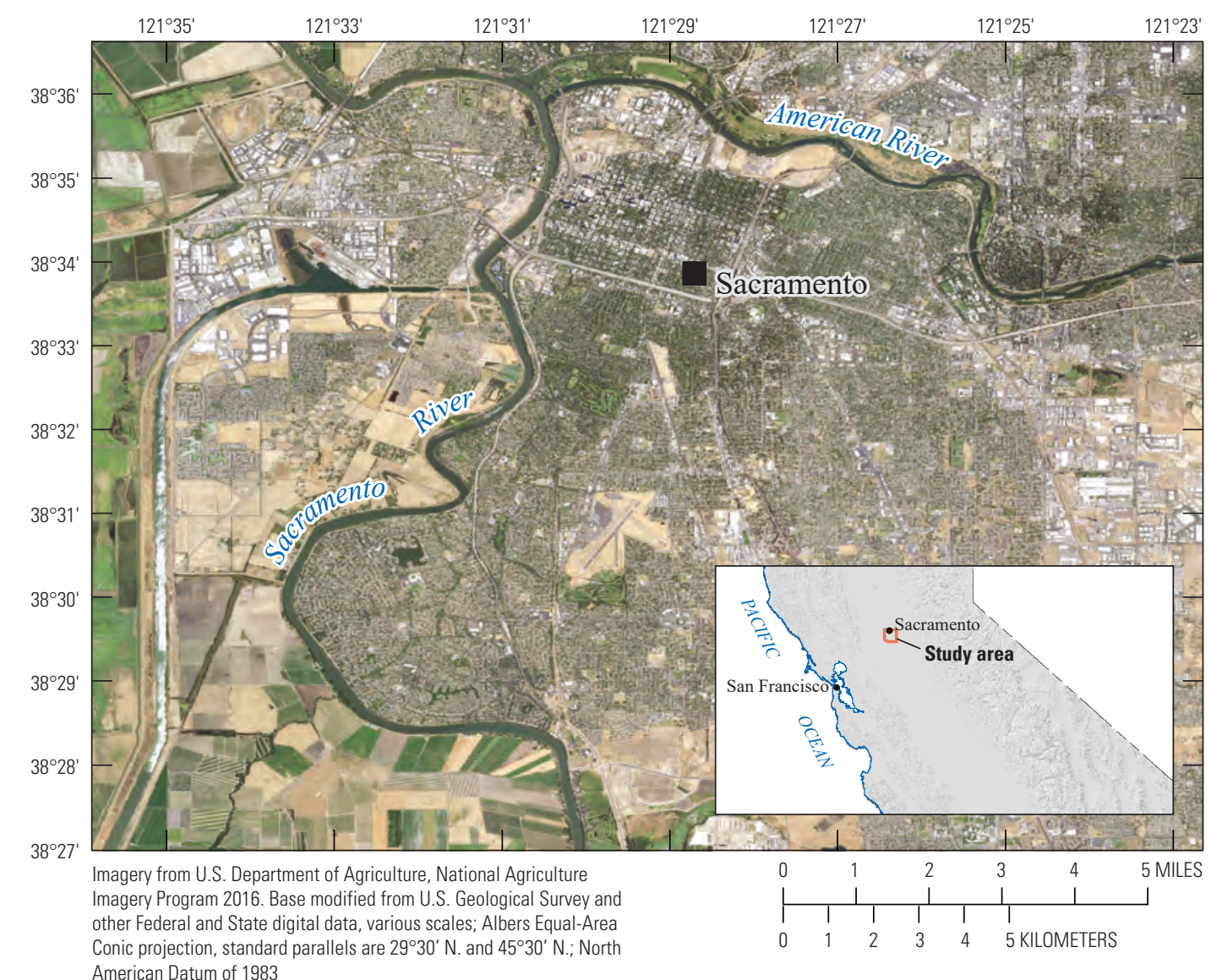

Figure 1. The American River flows from right to left, joining the Sacramento River near downtown Sacramento, California. The Sacramento River flows from top to bottom and eventually enters San Francisco Bay (north is at the top of the image).

A variety of methods have been designed to measure the erodibility of soils subjected to flows of overlying surface water. Because sampling can alter sediment strength and behavior, several methods involve either in situ testing or testing of minimally disturbed cores in either field or laboratory settings (Maa and others, 1993; McNeil and others, 1996; Tolhurst and others, 2000; Briaud and others, 2001; Roberts and others, 2003; Hanson and Cook, 2004; Borrowman and others, 2006; Ravens, 2007; Jones and Gailani, 2009; Work and Schoellhamer, 2018). Erosion rates are typically expressed as a mass or volume eroded per unit surface area, per unit time as a function of either flow speed or bed shear stress. Most approaches involve testing only the top few inches of the soil column, at the most.

Briaud and others (2017) developed a borehole erosion test (BET) to characterize the erosion potential of soils at, theoretically, any depth that can be reached by drilling. The test involves drilling and profiling a hole, inserting a drilling rod through which water or another drilling fluid is pumped at a known rate for a known duration, re-profiling the hole, and computing erosion rates as a function of depth for the chosen flow rate. Erosion rates are computed as the change in borehole radius divided by the duration of the flow event. A local flow speed can be computed from the geometry observed before and after each flow event. In addition to the advantage of being able to resolve erosion potential at greater depths than other approaches, this approach also involves testing of the soils without removal.

The U.S. Army Corps of Engineers (USACE) identified 21 sites along the American and Sacramento Rivers at which sediment lithology information was desired, and 18 of these sites were to include BETs. Most sites fell between the levees and a few were on the levee crown. In most cases, sediment samples and lithology data were desired down to a vertical position matching that of the river thalweg. The plan was modified during the project and ultimately 17 lithology holes were drilled and 13 BETs performed, including one test that was repeated with drilling mud. The major tasks performed in the project are listed below:

1. Auger to acquire sediment samples and document sediment lithology at each site.

2. Provide sediment samples acquired by split spoon and Calmod samplers to USACE and colleagues from Texas A\&M University for subsequent laboratory analysis to define sediment characteristics. 
3. Provide undisturbed sediment cores acquired with Shelby tubes to Texas A\&M for laboratory testing of erodibility.

4. Perform BETs and interpret resulting data to describe erosion rate versus flow speed and depth below grade.

At most sites a hole was drilled to the specified depth, acquiring samples during the process, until the target depth was reached. The BET was performed in a separate hole drilled as close as possible to the first.

The BET is relatively new and has seen limited application; it is more readily applied to cohesive sediments because of the reduced likelihood of borehole collapse and loss of pumped water compared to non-cohesive sediments. Most of the coring done for this project revealed sandy soil over most of the drilled hole. Some difficulties arose during drilling because of the tendency for unsupported sands to slump, particularly below the water table. As a result, most of the BETs were limited to regions above the local water table, which typically meant the top 10-15 feet (ft) of the soil column. One test was repeated using drilling mud to see if this yielded different results for erosion rate compared to a test done with water at the same site, and to see if the mud facilitated testing below the water table.

Two other companion efforts related to the erodibility of American and Sacramento River sediments were undertaken by others as part of the project that led to this report:

1. Mini-Jet erosion tests were performed on surficial riverbank sediments by a team from the U.S. Department of Agriculture's National Sedimentation Laboratory in Oxford, Mississippi.

2. Erosion Function Apparatus tests were performed in a laboratory in the civil engineering department at Texas A\&M University, using cores obtained via a Shelby tube as part of the work discussed in this report. Where Shelby tube sampling was not feasible, samples were collected with Calmod and split-spoon samplers to be packed into a Shelby tube for laboratory testing.
This report is divided into five major sections:

1. The study plan;

2. Discussion of the augering and sediment sampling procedure to reveal lithology and sediment characteristics versus depth below sediment surface;

3. The BET procedure, test results, and lessons learned;

4. Conclusions based on the above;

5. Supporting appendices.

\section{Site Conditions and Drilling Plan}

Despite being nearly 100 miles from the Pacific Ocean, the region considered is less than 50-ft above sea level, and the slopes of the land and riverbed are mild. For each site chosen for drilling, a target depth for the drilled hole was identified, typically to place the bottom of the hole at the elevation of the deepest point in the local river cross-section (that is, the river thalweg; tables 1, 2). Target hole depths ranged from 24 to $62 \mathrm{ft}$-below grade. In some cases, refusal was met before the target depth was reached.

The locations of the drilling sites are shown in figures 2 and 3 and tables 1 and 2. Two sites (SAC5 and SAC8) were within the levee prism, where the USACE prohibited BETs. In some cases, debris (for example, buried waste, such as metal wire) encountered during drilling prohibited test completion. Test sites for which data are not available are shown as NA in the tables below. At many sites, because of experience with slumping of sands within the drilled hole below the water table, the BETs were limited to regions above the water table.

Sites were chosen on the river left and river right banks to reveal longitudinal variations in erosion rates, in addition to vertical variations. But the sampling strategy did not provide for resolution of cross-channel variability in erosion rates or lithology. 
Table 1. Approximate locations, elevations, and hole depths for drilling sites on the lower American River.

[Latitude and longitude are based on the World Geodetic System of 1984 datum and were provided by the U.S. Army Corps of Engineers, along with ground elevation data. Abbreviations: ft, feet; NAVD 88, North American Vertical Datum of 1988; BET, borehole erosion test; NA, results not available because testing was not performed or was halted because of debris]

\begin{tabular}{lllcccc}
\hline $\begin{array}{c}\text { Site } \\
\text { name }\end{array}$ & Latitude & Longitude & $\begin{array}{c}\text { Ground } \\
\text { elevation } \\
\text { (ft NAVD 88) }\end{array}$ & $\begin{array}{c}\text { Target hole } \\
\text { depth } \\
\text { (ft) }\end{array}$ & $\begin{array}{c}\text { Lithology } \\
\text { hole depth } \\
\text { (ft) }\end{array}$ & $\begin{array}{c}\text { BET hole } \\
\text { depth } \\
\text { (ft) }\end{array}$ \\
\hline LAR1 & 38.567043 & -121.37287 & 39 & 24 & 24.5 & NA \\
LAR2 & 38.567505 & -121.382367 & 44 & 29 & 28.5 & 9 \\
LAR3 & 38.565279 & -121.392356 & 43 & 35 & 35 & 17 \\
LAR4 & 38.560523 & -121.411922 & 38 & 31 & 30.5 & NA \\
LAR5 & 38.560627 & -121.416983 & 37 & 30 & 30.5 & 12 \\
LAR6 & 38.561914 & -121.418805 & 41 & 34 & 35 & 16 \\
LAR7 & 38.56643 & -121.421602 & 38 & 35 & 34.5 & 15 \\
LAR8 & 38.572297 & -121.423641 & 39 & 36 & NA & NA \\
LAR9 & 38.584124 & -121.425739 & 38 & 35 & 34.5 & 26 \\
LAR10 & 38.589901 & -121.454501 & 32 & 39 & 36.5 & 15 \\
LAR11 & 38.601747 & -121.491249 & 28 & 35 & 34.5 & NA \\
LAR12 & 38.580259 & -121.425334 & 39 & 36 & 36.5 & 20 \\
\hline
\end{tabular}

Table 2. Approximate locations, elevations, and hole depths for drilling sites on the Sacramento River.

[Latitude and longitude are based on the World Geodetic System of 1984 datum and were provided by the U.S. Army Corps of Engineers, along with ground elevation data. Borehole erosion tests (BET) were performed twice at site SAC3, first with water to 10 feet ( $\mathrm{ft}$ ) and then with drilling mud to $15 \mathrm{ft}$. Abbreviations: ft, foot; NAVD 88, North American Vertical Datum of 1988; NA, results not available because testing was not performed or was halted because of debris]

\begin{tabular}{ccccccc}
\hline $\begin{array}{c}\text { Site } \\
\text { name }\end{array}$ & Latitude & Longitude & $\begin{array}{c}\text { Ground } \\
\text { elevation } \\
\text { (ft NAVD 88) }\end{array}$ & $\begin{array}{c}\text { Target hole } \\
\text { depth } \\
\text { (ft) }\end{array}$ & $\begin{array}{c}\text { Lithology } \\
\text { hole depth } \\
\text { (ft) }\end{array}$ & $\begin{array}{c}\text { BET hole } \\
\text { depth } \\
\text { (ft) }\end{array}$ \\
\hline SAC1 & 38.595986 & -121.507081 & 29 & 39 & 29 & 28 \\
SAC3 & 38.548766 & -121.511313 & 21 & 39 & 31 & 10,15 \\
SAC5 & 38.51774 & -121.525996 & 37 & 62 & 62 & NA \\
SAC7 & 38.474598 & -121.531639 & 22 & 47 & 47 & 13 \\
SAC8 & 38.475533 & -121.515974 & 34 & 59 & 58.8 & NA \\
SAC9 & 38.464399 & -121.502893 & 18 & 43 & 45.5 & 17 \\
\hline
\end{tabular}




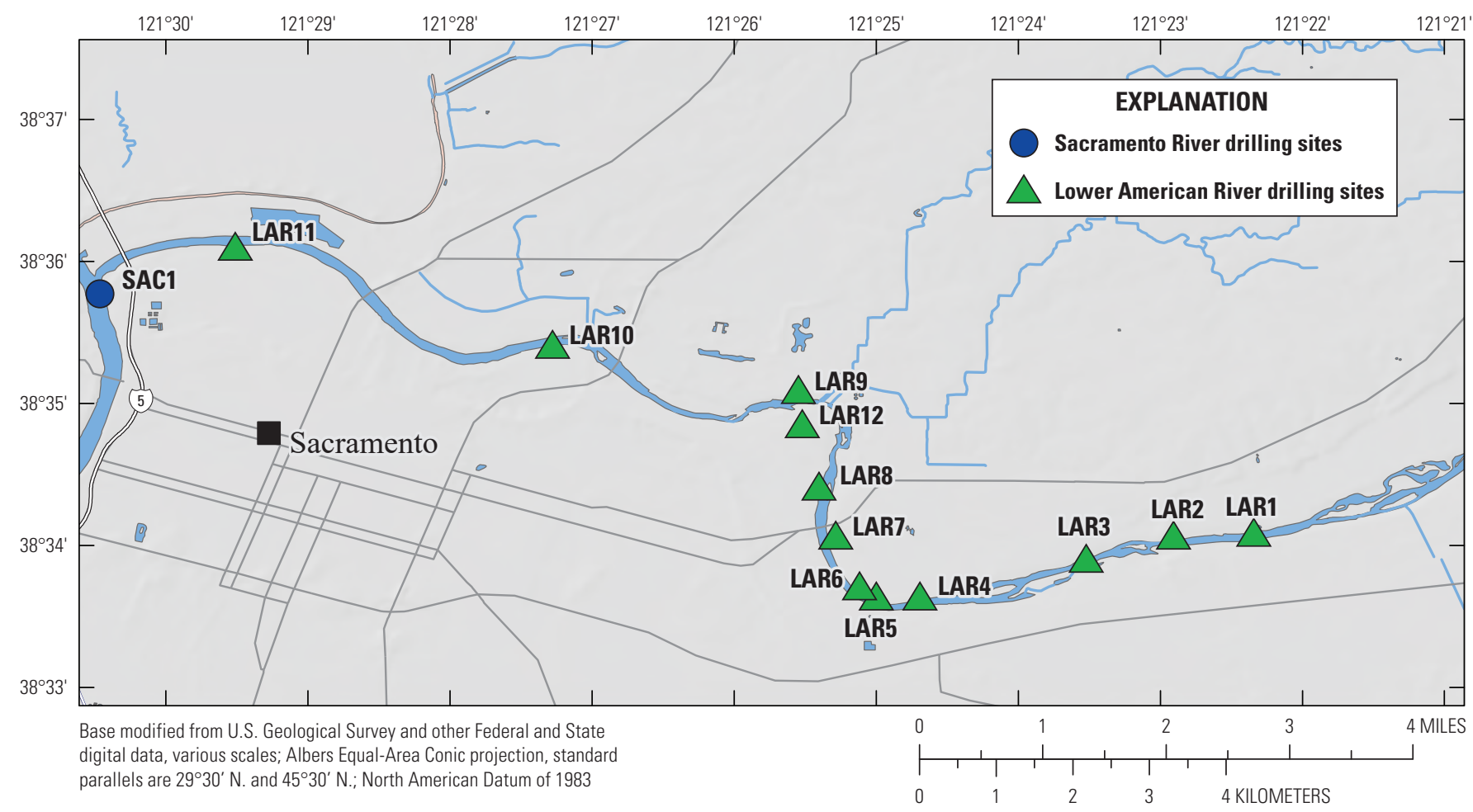

Figure 2. Drilling sites on the American River, California. Coordinates, elevations, and hole depths are shown in table 1. 


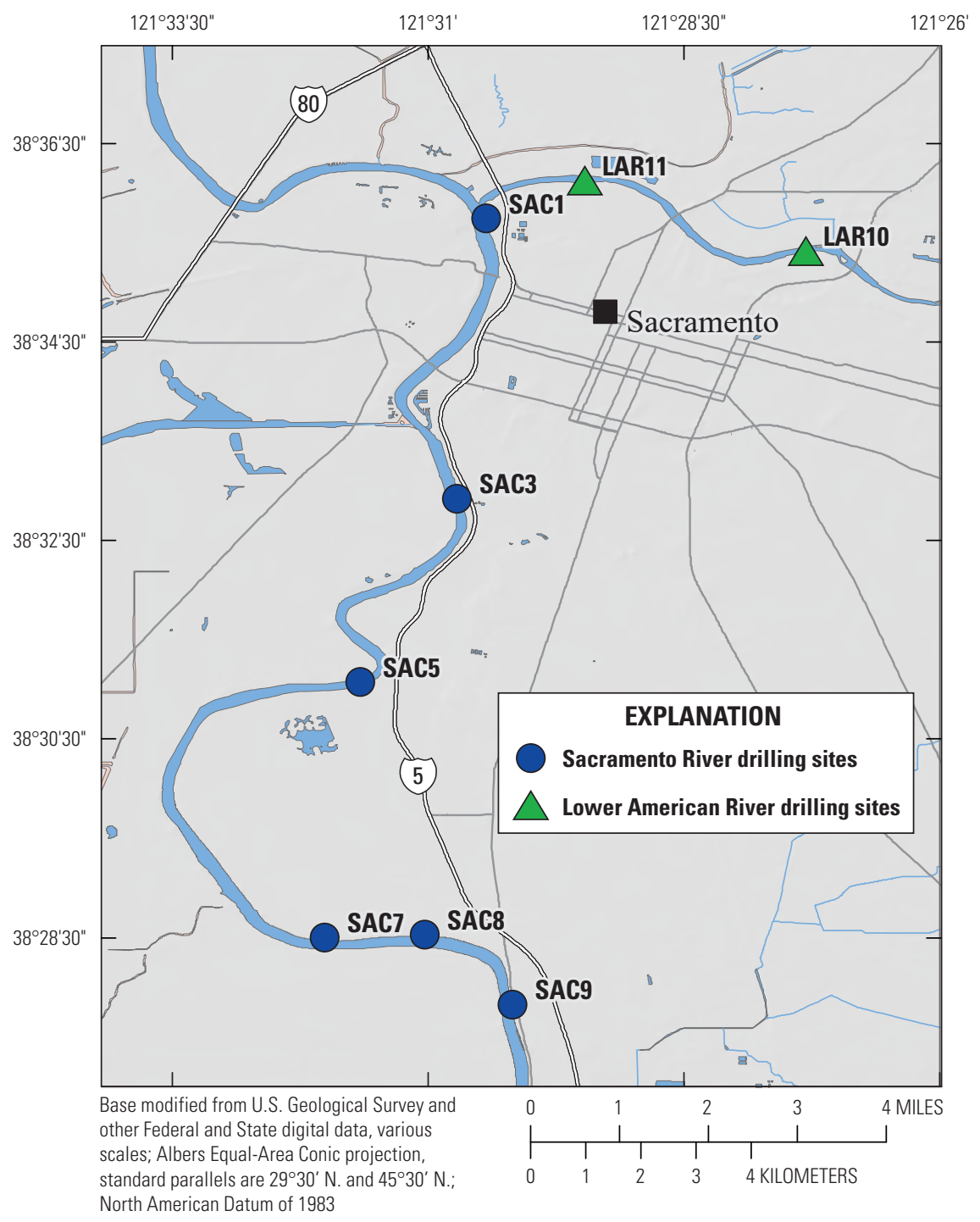

Figure 3. Drilling sites on the Sacramento River, California. Coordinates, elevations, and hole depths are shown in table 2. 


\section{Augering and Sediment Sampling Procedure}

Sediments were collected to define vertical variations in soil characteristics and to provide samples for two types of subsequent laboratory testing: (1) grain-size analysis to characterize sediment grain-size distributions and (2) erosion rate versus water flow speed, using an erosion function apparatus in a flume at Texas A\&M University. Grain-size analysis can be done on either disturbed or undisturbed samples, whereas the erosion-rate tests are ideally performed on minimally disturbed samples.

A mobile drilling rig was deployed at each site (fig. 4). Drilling proceeded as listed below:

1. Installed a hollow stem auger (fig. 4) and drilled through first 12 inches (in.) of soil.

2. Installed a split spoon (fig. 5) or Calmod (fig. 6) sampler, hammered 18 in., and recorded blow counts every 6 in.; stopped if the target maximum depth or refusal were met. Refusal of a sediment sampling tool was defined when blow counts exceeded 50 blows for a 6-in. interval.
4. If cohesive sediment was found, a Shelby tube was pushed for later laboratory analysis of the erosion rate. The pressure and time required to push the Shelby tube 24 in. was noted.

5. Repeated steps 1-4 until target depth or auger refusal were met.

Midway through the project, calibration tests were performed on the drilling rig hammer. Calibration reveals the energy transferred from the hammer to the tool being struck.

The characteristics of the bottom 18 in. of sediment found in each split-spoon or Calmod sample were logged using a standardized form utilized by the U.S. Army Corps of Engineers (2012; fig. 7). The numerous American Society for Testing and Materials (ASTM) standards that dictated sample collection, documentation, and handling are cited in the list of references at the end of this report.

Following soil description and classification, the sediment was placed in a labeled bag for subsequent grain-size analysis (fig. 8). At times more than 18 in. of soil were recovered in the sampler; this likely resulted from the weight of the sampler and rod pushing into loose or soft soils before driving the sampler.

3. Removed the sampler, logged and saved the sample for laboratory sampling.

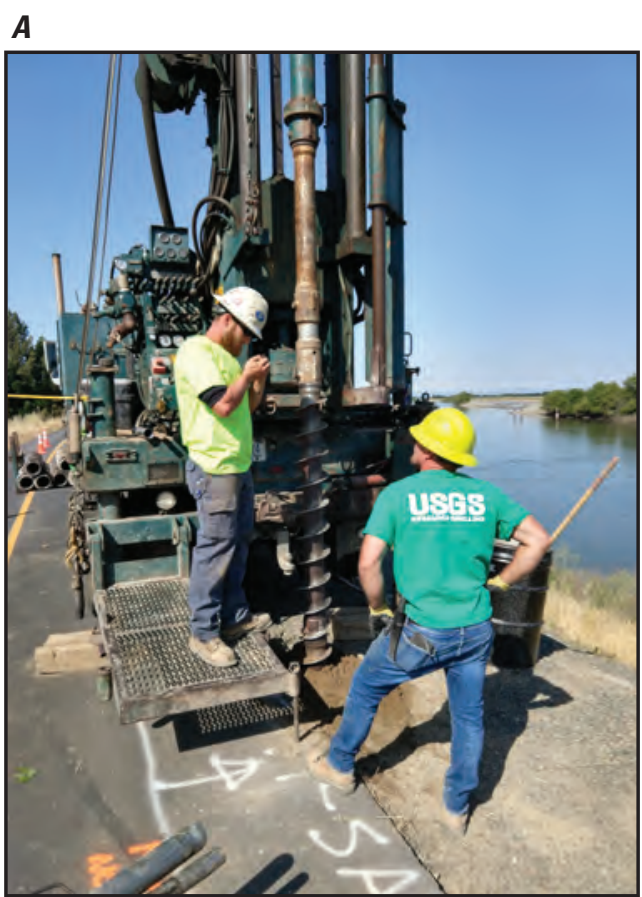

\section{$\boldsymbol{B}$}

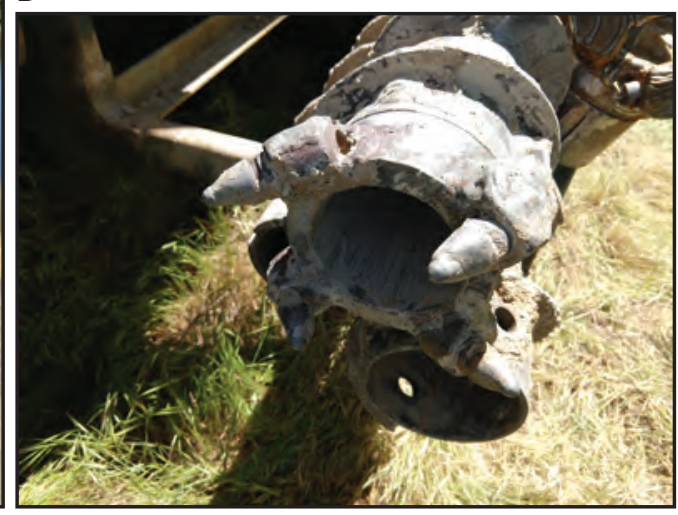

Site SAC5A, coordinates are in table. (Photographs taken on May 7, 2019, by Paul Work, U.S. Geological Survey.)

Figure 4. A, Mobile drilling rig deployed at site SAC5, beside a bike trail on top of the levee overlooking the Sacramento River; and $B$, a bit on a hollow-stem auger. 


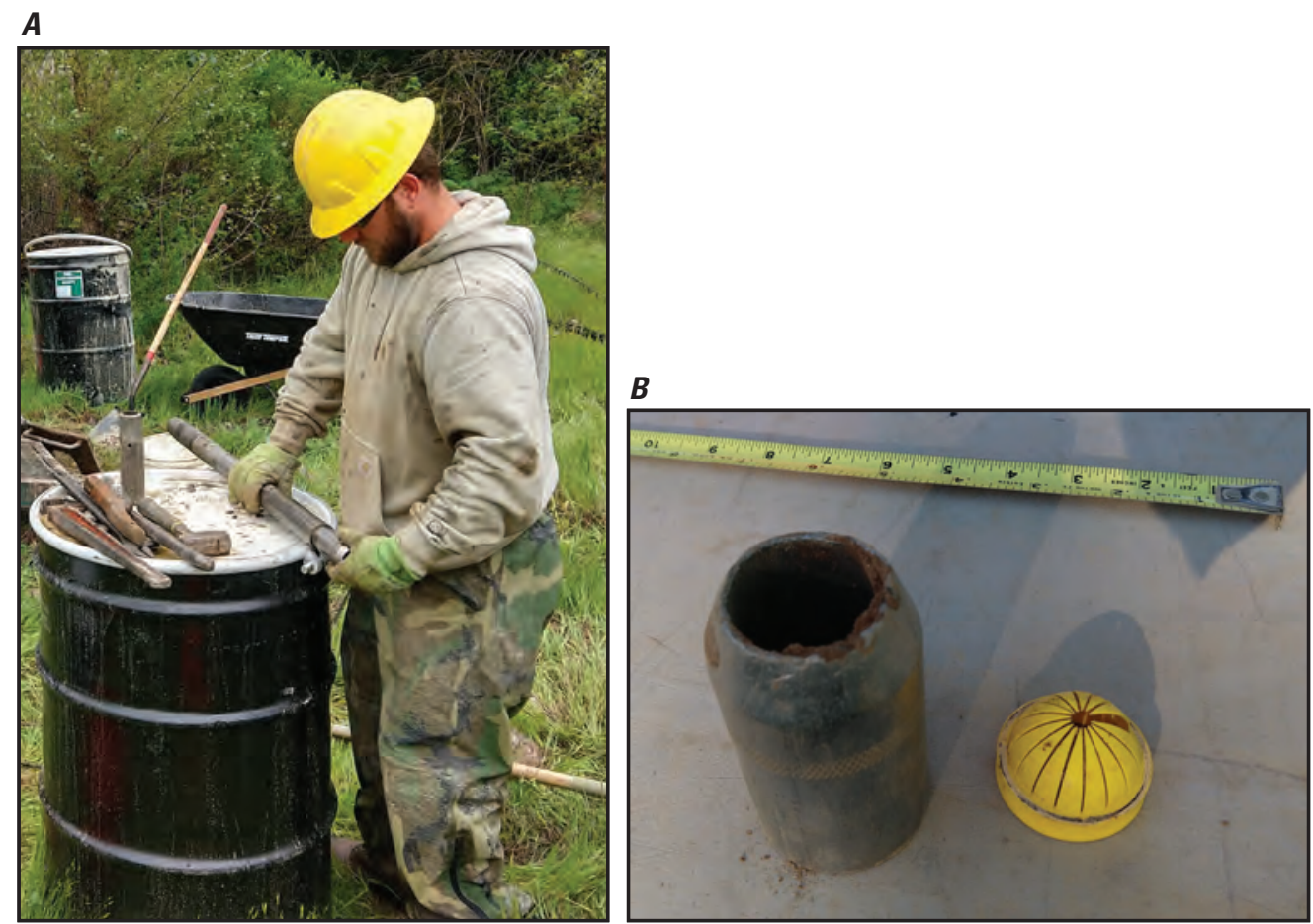

Photographs taken by Paul Work, U.S. Geological Survey.

Figure 5. A, A split spoon sampler being disassembled for access to a sediment sample; and $B$, the shoe of a split spoon sampler and a (partially broken) sand catcher.

$\boldsymbol{A}$

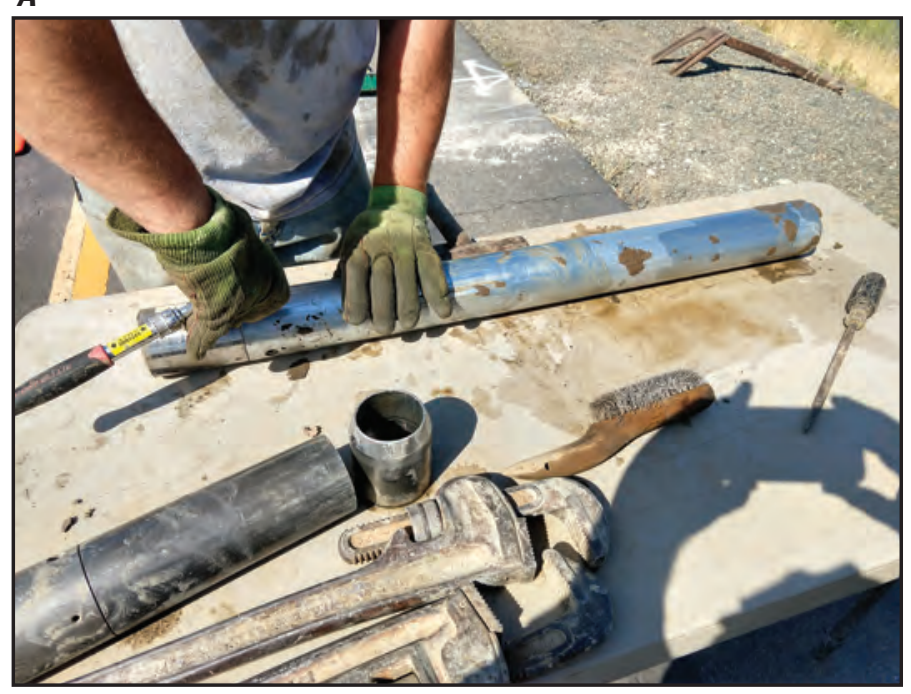

Site SAC5A (Photographs taken on May 7, 2019, by Paul Work, U.S. Geological Survey.)
B

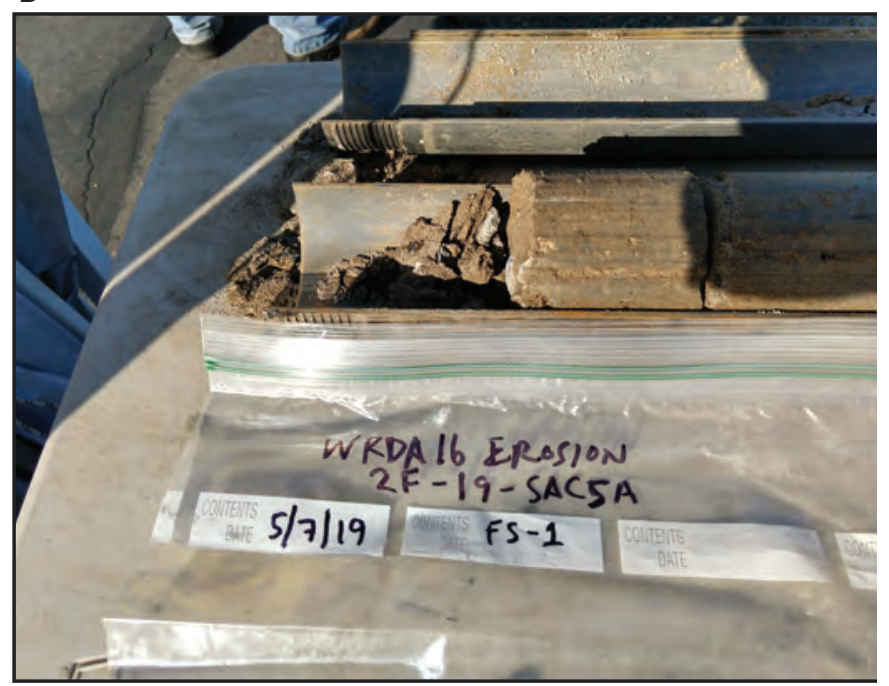

Figure 6. A, A Calmod sampler before disassembly; and $B$, after disassembly. 


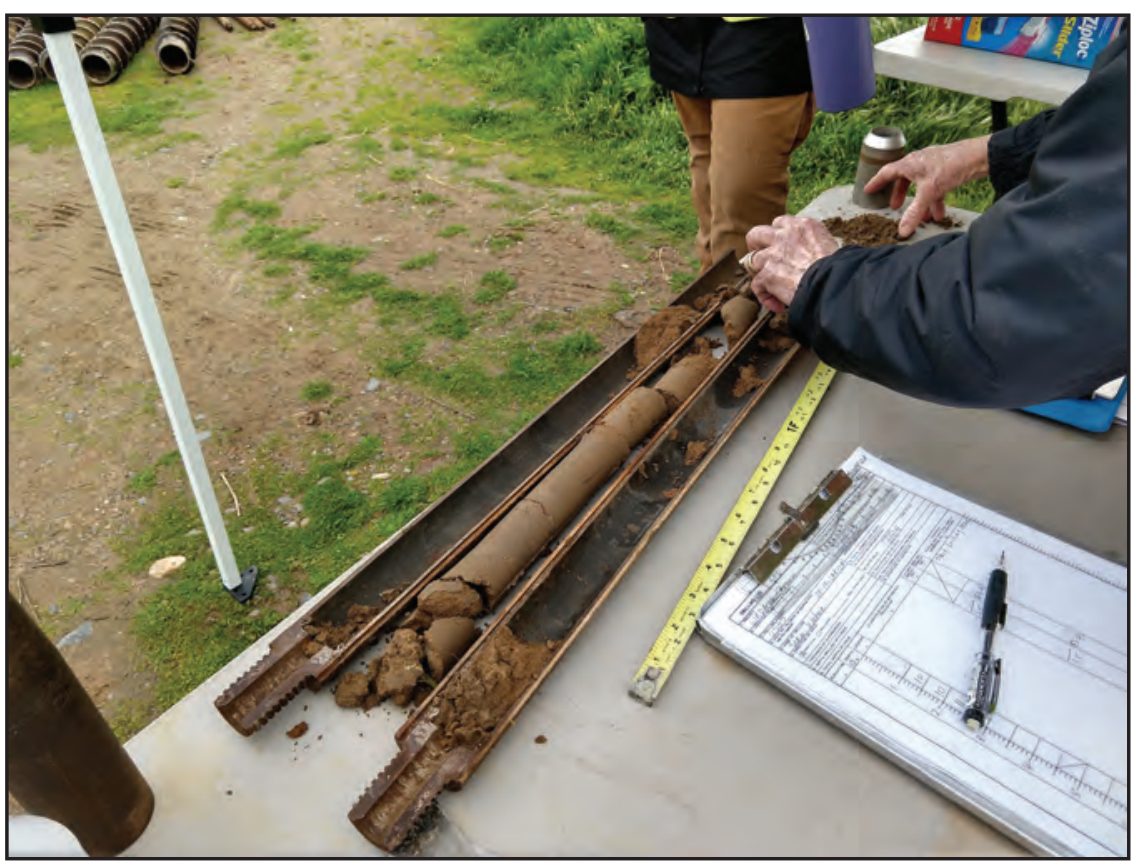

Photograph taken by Paul Work, U.S. Geological Survey.

Figure 7. A disassembled split spoon sampler, with the core nose and bottom of the core at the upper right. A standardized core logging form (ENG Form 1836) is shown at the lower right.

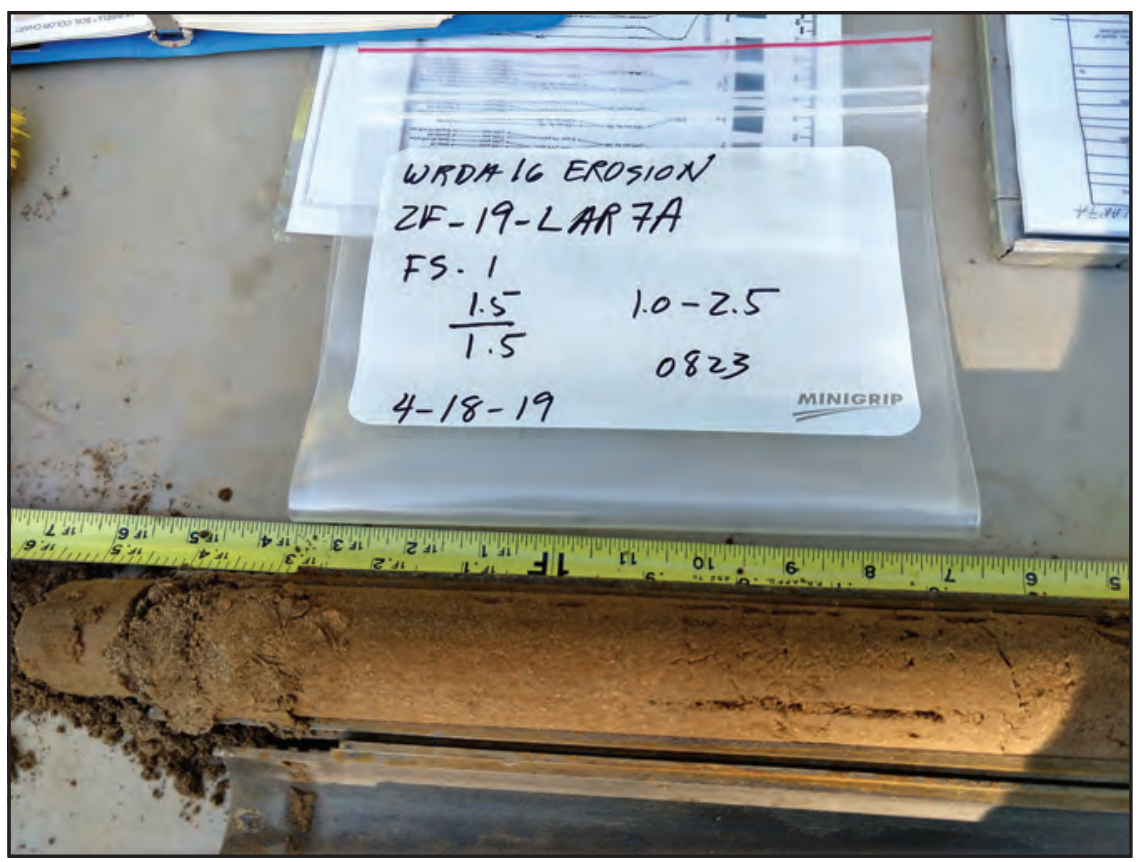

Site LAR7 (Photograph taken on April 18, 2019, by Paul Work, U.S. Geological Survey.)

Figure 8. A sample sand bag for transport and at the top of the bag label is the project name, followed by the core code (19 for the federal fiscal year, LAR7 for the site name, and $A$ for sediment sampling). The meaning of $1.5 / 1.5$ is that the entire 1.5 -foot (ft) sample interval was recovered, 1.0-2.5 shows the depth range sampled (in $\mathrm{ft}$ below the local ground surface), and 0823 is the local time (all times Pacific Daylight Time). 
The log sheet included size and color classification, based on the Munsell soil color chart (fig. 9). A simple test was performed to approximate the fraction of fines in the sample. A small spoonful of sediment was placed at uniform thickness on a grid that was on a cutting board (fig. 10). Half of the sample was cut away and placed in a bowl, and fines were washed from the sample with water. The remaining sediment was placed back on the grid at the original thickness and the area reduction noted. A qualitative assessment of the plasticity was made to assess the fraction of clay in the sample.

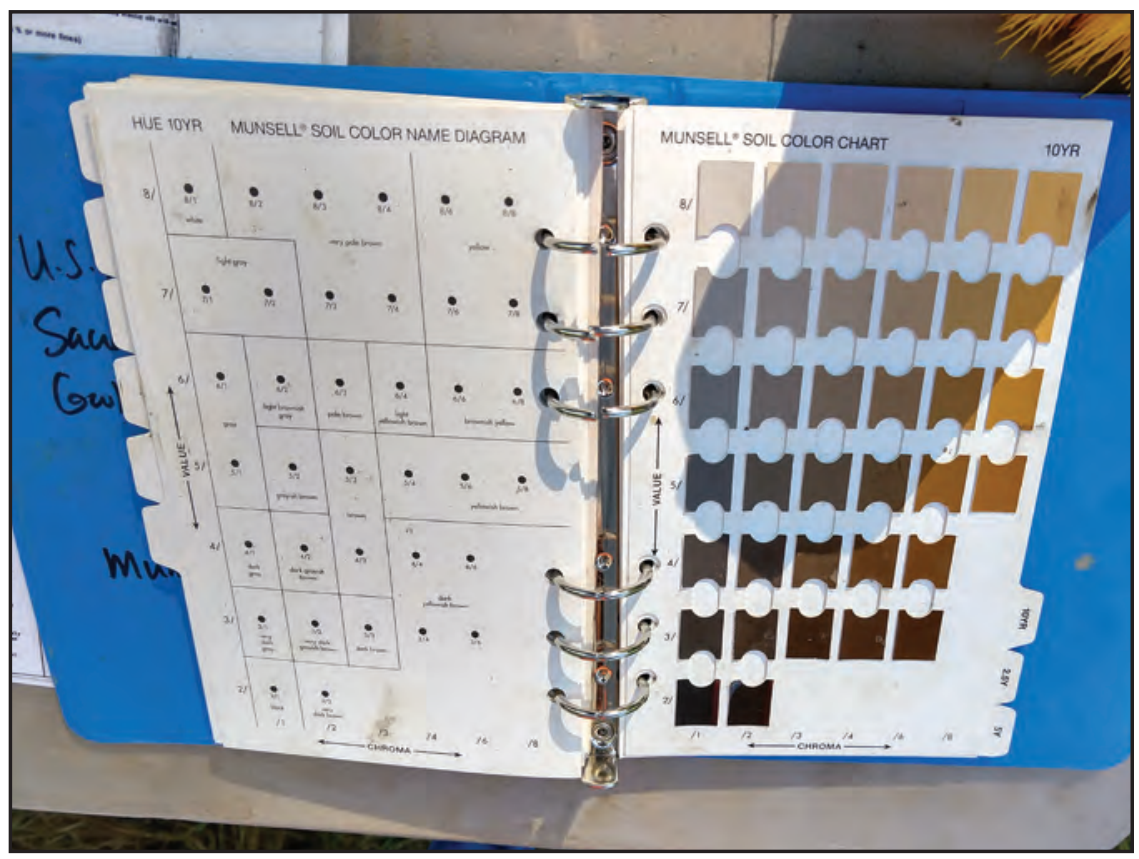

Site LAR7 (Photograph taken on April 18, 2019, by Paul Work, U.S. Geological Survey.)

Figure 9. A Munsell soil color chart.

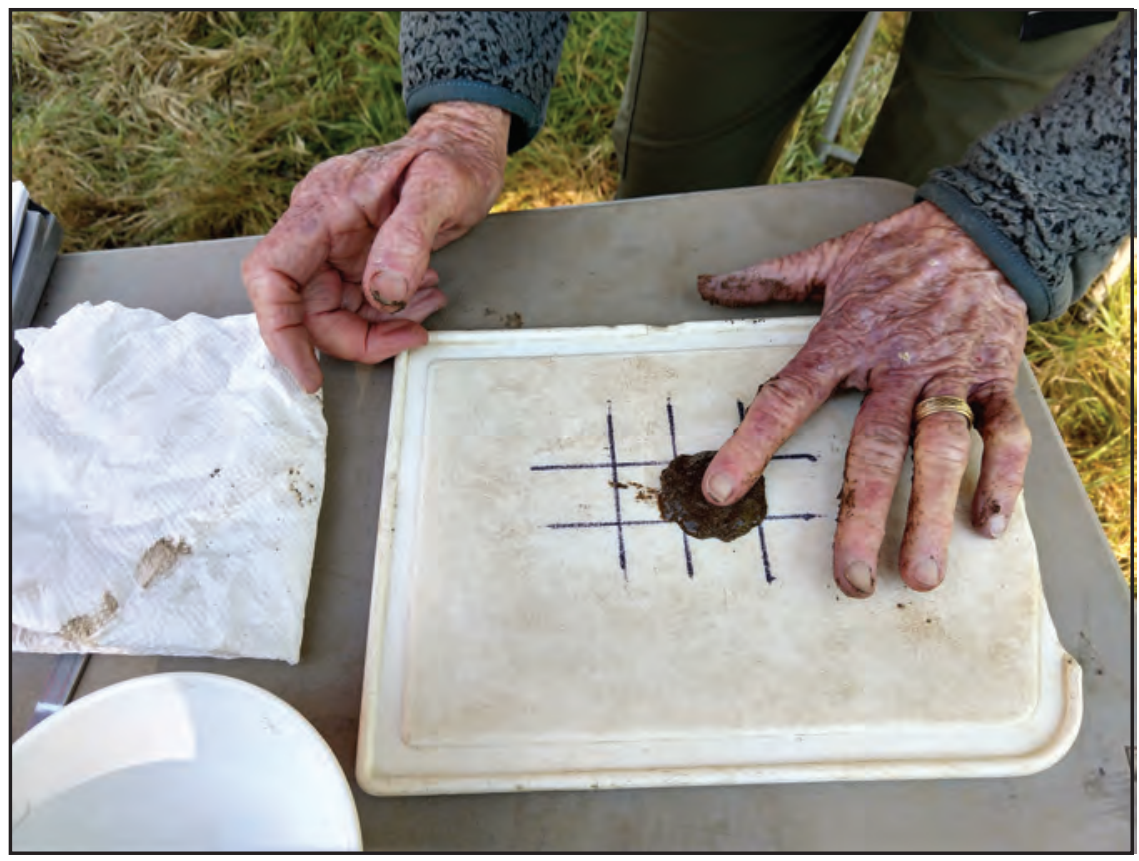

Site LAR7 (Photograph taken on April 18, 2019, by Paul Work, U.S. Geological Survey.)

Figure 10. The start of a test for the fraction of fines in a sediment sample. 


\section{Borehole Erosion Test Procedure}

The BET (Briaud and others, 2017) is conceptually simple, and it involves the steps listed below:

1. Drill a vertical hole to the depth of interest. The smallest diameter possible is preferable, as it helps reduce required water discharges later.

2. Profile the hole with a caliper to establish the diameter as a function of depth below grade. Repeat as desired, to allow averaging of results, which helps reduce random measurement errors and the influence of out-of-round sections.

3. Insert the hollow drilling rod back into the hole, extending to within 12 in. or so from the bottom.

4. Pump water at a known flow rate for $X$ minutes through the drilling rod, with $\mathrm{X}$ chosen subjectively based on experience and knowledge of local sediment characteristics. Typical durations of these flow events were 10-30 minutes.

5. Profile the hole with the caliper again, multiple times.

\section{Repeat steps 3-5 with additional flow rates.}

Water flows down the hole within the drilling rod, exits, and flows vertically upward through the annulus between the drilling rod and the earthen hole. The flow speed in the annulus is controlled by the flow rate $(Q)$ and the area of the annulus $(A)$. In practice, the borehole profile was inspected to estimate a mean diameter of the hole and the mean area of the annulus between the drilling rod and the hole wall was computed. For a given target flow speed $(V)$, it is then possible to compute a target flow rate, $Q$ :

$$
Q=A V=V\left[\frac{\pi}{4}\left(d_{h}^{2}-d_{p}^{2}\right)\right]
$$

where

$$
\begin{array}{ll}
Q & \text { is the flow rate, } \\
A & \text { is the area of the annulus, } \\
V & \text { is flow speed, } \\
d_{h} & \text { is the mean diameter of the hole, and } \\
d_{p} & \text { is the outside diameter of the drilling rod } \\
& \text { (constant), which is the inner diameter of } \\
\text { the annulus. }
\end{array}
$$

As the hole erodes the annulus area increases, which means that higher discharges are required to achieve any given target flow speed. For this reason, in most cases, the test with the largest target flow speed was performed first. Target flow speeds of 5,8, and $12 \mathrm{ft} / \mathrm{s}$ were requested by the USACE for this study based on expectations of conditions likely in the flooding and storm events of interest.

The temporal change in hole diameter, which varies with the altitude within the hole, can be used to compute local erosion rates, and local flow speeds also can be computed for each depth. One result of the collection of tests was then a plot of erosion rate versus flow speed. Given the uncertainty in each dataset and the nature of depositional soils, some vertical averaging of erosion-rate results was appropriate, but ideally the length scale of this averaging was short enough that each section has uniform sediment characteristics. There also was temporal variation of the erosion rate during any given flow event. When the test first started, the annulus was smaller and then it grew as the test proceeded, which reduced the flow speed that was eroding the wall of the hole. Without any data to reveal the temporal variability in erosion rate during a flow event, it was assumed to be constant during the flow event, with the flow speed represented by an average value for that event: that is, the discharge divided by an area that was halfway between the initial and final annulus areas. In reality, the initial rate of erosion during a test interval would exceed the rate of erosion at the end because of the higher flow speed at the beginning of a flow event.

Ideally there was no slumping of material within the hole; it was assumed that all observed changes were because of erosion caused by the water flowing through the annulus between the drilling rod and the hole. The test was continued for a long enough period to achieve measurable erosion, and the time span varied with soil type and conditions. Experience is required to know how long to run a test.

\section{Digital Caliper}

The borehole caliper used in the tests (fig. 11) was deployed using an electrically powered winch equipped with an encoder to report cable position. The cable was braided stainless steel for load carrying and includes conductors to carry power and transmit data. A laptop computer was used to control the equipment and log the data.

The borehole caliper was calibrated before each day's use. This involved placing the measurement end of the instrument inside a ring of known diameter and instructing it to open and report the diameter. The calibration coefficient was changed to force the reported value to match the known diameter within $0.1 \mathrm{in}$., which is the resolution of the reported output. This was done with rings of two sizes to produce a two-point calibration. The calibration also was checked at the end of the day. In each case, the calibration remained close enough to its initial result that no subsequent corrections to reported diameters were deemed necessary.

The cable for the caliper extended from the winch to the drill rig, where it passed through a pulley to suspend the caliper within the borehole. The caliper was lowered to a designated elevation above the ground surface and the reported cable extension zeroed so that all subsequent distances would represent the depth of the caliper below the ground surface. Once near the bottom of the borehole, the caliper was opened. 
A

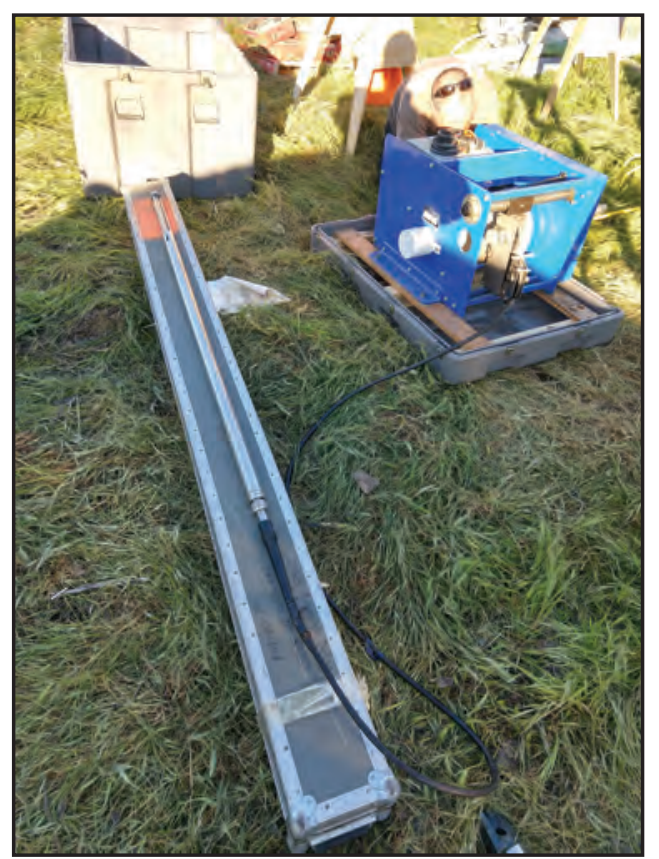

B

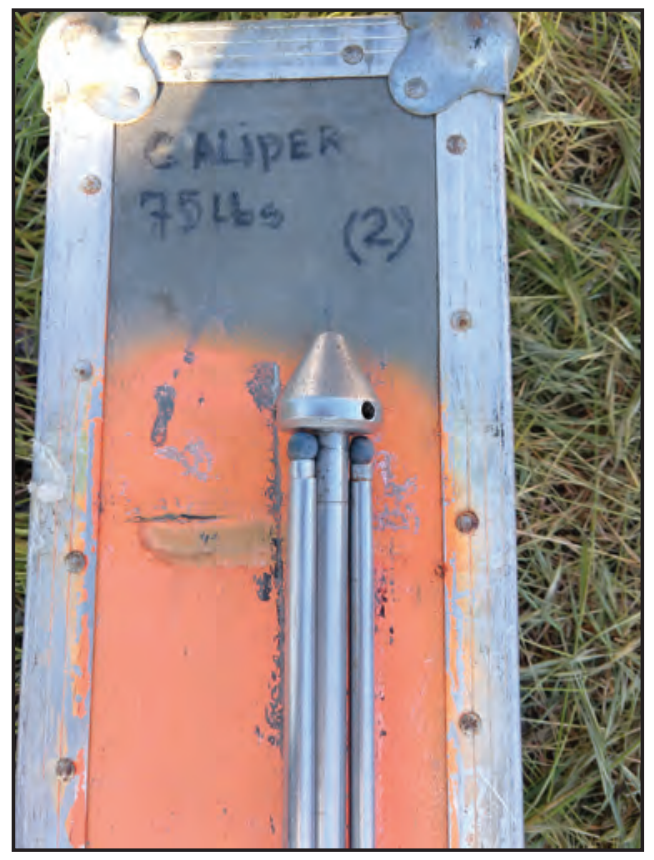

Site LAR9 (Photographs taken on April 12, 2019, by Paul Work, U.S. Geological Survey.)

Figure 11. A, a digital borehole caliper and winch; and $B$, a detail of the caliper in the closed position.

The open caliper was pulled up at speeds in the $2-5 \mathrm{ft} / \mathrm{s}$ range, logging borehole diameter with a resolution of 0.1 in and vertical position of the caliper with a resolution of $0.02 \mathrm{ft}$. The arms on the caliper are spring loaded and move in and out to follow the contours of the borehole. The caliper had some freedom to rotate because it was suspended from a cable, so repeated profiles of the same hole sometimes differed slightly, particularly if the hole was not round. At least two profiles were performed for each condition, and the results averaged over the vertical region represented by all profiles.

\section{Flow Measurements}

The test procedure depends on accurate measurement of borehole geometry and water discharge. During each test, water was pumped from a 1,000-gallon (gal) tank with a centrifugal pump powered by a dedicated diesel engine. The water then passed through an electromagnetic flowmeter to the top of the drilling rod; from there it traveled to the bottom of the hole, then up the walls of the hole into a 70-gal receiving tank, from which it was pumped back into the larger tank with a second pump.

The manufacturer of the flowmeter (Tactical Flowmeter, model TFM-LDT50033410110122) reports that the error in the flowmeter is less than 0.5 percent over its rated range of 200 gallons per minute (gal $/ \mathrm{min})$, or $1 \mathrm{gal} / \mathrm{min}$. Observed fluctuations during each test were typically much higher than the rated uncertainty. Data were acquired by reading the flowmeter display visually, every minute, during the typical 10-15 minute run time. Later in the study a data logger was designed, assembled, and employed to digitally record flow rates every second. The analog direct current output of 4-20 milliampere ( $\mathrm{mA}$ ) from the flowmeter was converted to a $0.88-4.4$ voltage with a 220 -ohm resistor and the output was digitized at 1 hertz (Hz) using an Arduino-based microprocessor data logger. In the example shown in figure 12, after the first minute, the mean and standard deviation of the discharge were 56 and $1.2 \mathrm{gal} / \mathrm{min}$, respectively. Standard deviation typically increased with the mean value.

Water depth in the supply tank was monitored using a submersible pressure logger during five of the later experiments. Detailed analysis of the discharge and depth measurements can be found in appendix 2, and all of the test data collected for this study can be found in Work and Livsey (2019).

Despite time-dependence in discharge and observed water losses, it was concluded that it was reasonable to neglect the water that was lost into the borehole during tests, and to assume there was a constant discharge during each flow event. However, this does not mean that flow speed was constant because hole diameter varied over time and depth below grade. Flow speed variations will be discussed further in the next section. 


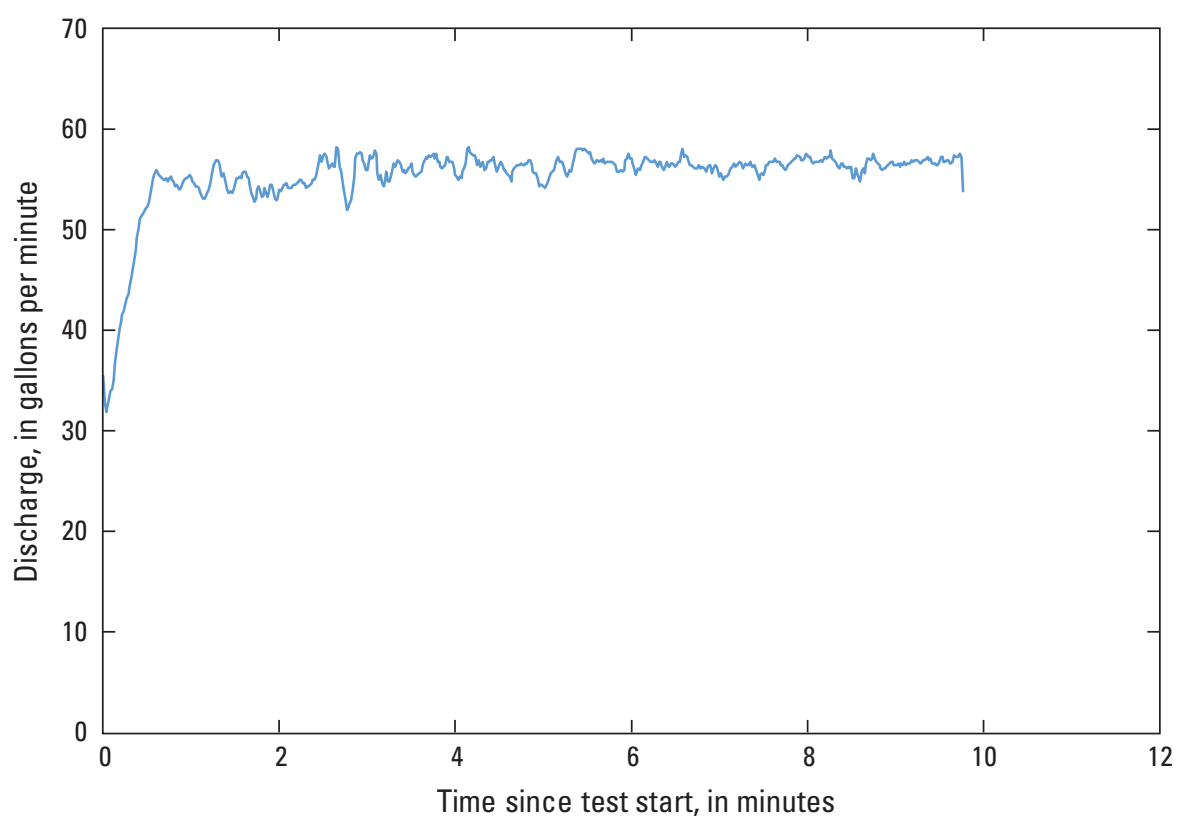

Figure 12. Time dependence in measured discharge on April 19, 2019, for site LAR7 with data logged at 1 hertz. Typically, the data logger was launched, the pump started to flow water in a closed loop including the flowmeter, and a valve opened to send water down the borehole. This last step would reduce the discharge by increasing head loss in the plumbing loop.

Figure 13 shows the evolution of the hole during a test with two different discharges in a sandy layer above the water table. The hole was profiled twice for each condition, and the two results were averaged. The resolution of the diameter was $0.1 \mathrm{in}$., and the vertical resolution was $0.02 \mathrm{ft}$. The blue curve represents the initial condition before pumping. A 6-in. polyvinyl chloride pipe served as the casing down to a depth of approximately $3 \mathrm{ft}$; the drilling auger was used to increase the hole diameter in this region to allow insertion of the casing before drilling operations, and bentonite sealant was introduced between the outside of the casing and the drilled hole. The first flow test was performed with a small diameter drilling rod ( $d_{\text {rod }}$ of 1.77 in.) and an average low flow rate of $56 \mathrm{gal} / \mathrm{min}$ (fig. 12). The red curve shows the result after the first flow interval of 10 minutes; some erosion was evident over most of the profile. A larger drilling rod ( $d_{\text {rod }}$ of $2.64 \mathrm{in}$.) was then inserted to reduce the size of the annulus and the head loss of the pumping system, which doubled the flow rate to $112 \mathrm{gal} / \mathrm{min}$. The gray curve reveals, surprisingly, very little change during the second flow event except for just below the bottom of the casing. 


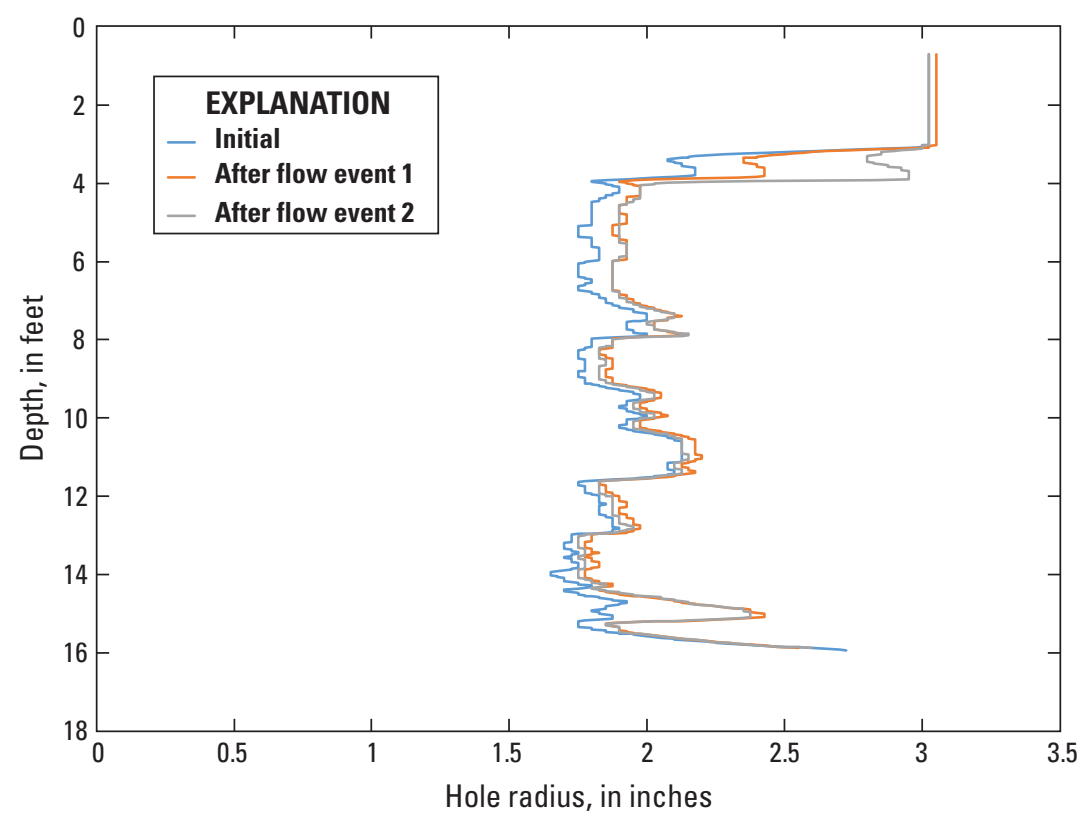

Figure 13. Evolution of the hole radius in a test at site LAR7 on April 19, 2019. Note the slight offset at the top of the profile where the caliper passed through the polyvinyl chloride casing of constant diameter. Where possible, the profiles were adjusted by applying a constant correction to the diameter to force them to match in this region before further analysis. No such correction was applied when making this plot.

\section{Borehole Erosion Test Results}

The goal of the BETs was to determine, for a given site and sediment type, the relationship between the erosion rate (expressed as a length per unit time) and speed of the flow passing the walls of the hole. Shear stress applied on the hole walls can be estimated from the estimated flow speed, but this requires the introduction of additional assumptions, so flow speed was used as the predictor variable. The analysis made use of the assumptions listed below:

1. The borehole profile was everywhere circular, but with a diameter that varies vertically, and this profile was accurately resolved by the profiling caliper. Radius, used to compute erosion rate, is half of the measured diameter.

2. The effect of random errors can be reduced by averaging repeated borehole profiles.

3. Bias can be reduced by forcing borehole profiles to match within the PVC casing. Where data inside the casing were available in repeated surveys, later surveys were shifted systematically by applying a constant correction to the radius to force them to match the initial condition within the casing. This correction was typically no more than 0.05 in., which is the caliper resolution for diameter $(0.1 \mathrm{in}$.) divided by 2 to convert to radius.

4. All observed changes to the borehole were because of water-induced erosion. One test (site LAR12) was discarded because the diameter of the borehole changed considerably between repeated borehole profiles. This was concluded to be caused by slumping below the water table during an extended delay arising from equipment problems.

5. The mean discharge during a flow event was steady and did not vary over the length of the borehole (that is, water losses during a test were negligible). The time-averaged discharge for a flow event is representative of that event.

6. Average flow speed at a given location is given by the mean discharge for the test interval divided by the area of the local annulus between the drilling rod and the borehole wall.

7. Representative flow speed at a given elevation for a given flow event is the time-averaged discharge for that event divided by the average of the starting and ending annulus areas for that location and event. This will yield a single erosion-rate flow speed pair for that elevation and flow event. 
Borehole profiles for each test are provided in appendix 1. A summary of the BETs, with results averaged over the entire hole, is provided in table 3.

Table 3 shows BET results that are vertically averaged over the entire boreholes, which reveals some interesting results. The observed mean erosion rates ranged from 0 to $3.6 \mathrm{in} / \mathrm{hr}$. The peak target flow speed of $12 \mathrm{ft} / \mathrm{s}$ was not reached over any entire borehole, but inspection of the plots in appendix 1 reveals that it was exceeded locally in several tests. Mean hole diameters were typically $4-5.0$ in., but inspection of the profiles shows diameter exceeding $10 \mathrm{in}$. in some cases, locally.

Some tests featured similar mean flow speeds in subsequent flow events at the same site, with very different results. For example, the first test at site LAR3 yielded a mean erosion rate of zero, yet the subsequent flow event, at a slightly reduced mean flow speed, yielded a mean erosion rate of $0.5 \mathrm{in} / \mathrm{hr}$. The test at site LAR6 featured four flow events, with three of them having nearly the same mean flow speed. Computed erosion rates for these three events were $0.48,0$, and $0.28 \mathrm{in} / \mathrm{hr}$. Inspection of the borehole plots (appendix 1) shows that the borehole profiles in both cases were complicated because of very different erosion rates within different vertical layers of the borehole; so a more detailed investigation of the erosion rates as a function of vertical position within the borehole is warranted. The fact that erosion rate is expected to be a nonlinear function of the overlying flow speed makes it more important to consider the actual local flow speed eroding a given portion of the borehole; but these results also help reveal the magnitude of uncertainty in the testing process. Caliper precision for diameter measurement is $0.1 \mathrm{in}$., and some tests were as short as 10 minutes. If $0.1 \mathrm{in}$. is taken as the estimated uncertainty in a single measurement of diameter, and the profile is measured twice and results averaged, the resulting uncertainty in diameter becomes 0.07 in., if no bias exists and errors are Gaussian. The uncertainty in the change in diameter is then $0.1 \mathrm{in}$. A change in the diameter of $0.1 \mathrm{in}$. in 10 minutes corresponds to an erosion rate of $0.3 \mathrm{in} / \mathrm{hr}$, so a result of this magnitude or less would be considered to be within the measurement uncertainty. Empirically, it appears that the measurement uncertainty is closer to $0.5 \mathrm{in} / \mathrm{hr}$. Many of the results in table 3 are below this threshold, but recall that table 3 shows only depth-averaged results. The results that reveal local erosion rates are more important and informative.

To proceed further, the lithology information was integrated with the borehole erosion data, which involved the steps below:

1. Starting and ending depths were identified for each borehole to exclude the regions near the casing in the top of the hole and the hole bottom. In both locations, hydrodynamics are more complicated and do not satisfy the assumption of flow parallel to the hole walls. Typically, the top and bottom $1 \mathrm{ft}$ of the profiled hole were excluded from analysis.
2. The high-resolution borehole data describing the diameter at $0.02 \mathrm{ft}$ intervals were divided into 6-in. layers, with average values of diameter and flow speed determined for each layer. Justification of the 6-in. averaging interval is provided below.

3. For each 6-in. layer, the percentages of sand, silt, and clay were assigned based on the lithology logs.

Averaging over intervals larger than 6 in. would remove some of the random errors in the original data, without losing the resolution of the most substantial vertical variations within the borehole. This approach also allows investigation of the differences in erosion rates between sands, silts, and clays. Although gravel was found near the bottom of some holes, none of the BET data used for analysis included regions classified as gravel.

After subdividing all profiles into 6-in. layers, computing erosion rates and flow speeds for each, and tabulating results, the histograms shown in figure 14 result. Thirteen percent of the computed erosion rates were negative, but most of these were small enough that they were likely a result of measurement error rather than actual sediment accumulation. Most of the rest were less than $2.5 \mathrm{in} / \mathrm{hr}$, and many were below the theoretical detection limit of $0.3 \mathrm{in} / \mathrm{hr}$.

Even though erosion rate is expected to be a nonlinear (but increasing) function of flow speed, the ratio of erosion rate to flow speed can be considered a measure of erodibility of a soil layer. Eighty-two percent of the values of this ratio fall between 0 and 0.5 . The mean value of this parameter, excluding negative values, is $0.17 \mathrm{in} / \mathrm{hr}$ per ft/s.

Figure 15 provides results from the test at site SAC1. The borehole at this site extended 28-feet-below grade, and the bottom two-thirds of this zone was clay. Most of the region upstream from this was silty sand or sandy silt. Many predictive equations for erosion of cohesive sediments make use of the idea of a critical velocity or shear stress for erosion. The plot indicates a nonlinear relationship between flow speed and erosion rate, as expected, but there is enough noise in the data collected that it is difficult to identify a critical velocity.

The overall trend in figure 15 is as expected, in that the erosion rate appears to increase with increased flow speed. But there is much scatter, and some of the computed erosion rates are negative. Each borehole included sediments with a range of compositions, densities, organic contents, water contents, and other factors that were expected to result in some of the observed scatter. The negative values resulted from either measurement error or slumping of soil within the borehole. Slumping that is not accounted for leads to overestimated erosion rates in areas that lose sediment and underestimated or negative erosion rates in areas that receive the material that slumps. One test (site LAR12) was excluded from consideration because of observed slumping, but elsewhere it was not obvious from inspection of the measured profiles that slumping was substantial. 
Table 3. Summary of borehole erosion tests completed, presented in chronological order, and depth-averaged erosion rates.

[All tests were performed with water, except the last test (SAC3B2) which was completed with drilling mud at the same site as test SAC3. All tests performed with a 2.64 inch (in.) outside diameter drilling rod, except the first flow event at LAR7, which utilized a $1.77 \mathrm{in}$. outside diameter rod. Abbreviaitons: Q, mean discharge in gallons per minute (gal $/ \mathrm{min})$ for a flow event, and its duration is given in minutes; $\mathrm{ft} / \mathrm{s}$, feet per second; in/hr, inch per hour; $\mathrm{V}$, flow speed; - , not applicable]

\begin{tabular}{|c|c|c|c|c|c|c|}
\hline $\begin{array}{l}\text { Flow } \\
\text { event }\end{array}$ & $\begin{array}{c}\text { Hole } \\
\text { diameter } \\
\text { (in.) }\end{array}$ & $\begin{array}{c}\text { Standard deviation } \\
\text { of diameter } \\
\text { (in.) }\end{array}$ & $\frac{0}{\text { (gal/min) }}$ & $\begin{array}{l}\text { Duration } \\
\text { (minute) }\end{array}$ & $\begin{array}{c}\text { Mean } \\
(\mathrm{ft} / \mathrm{s})\end{array}$ & $\begin{array}{c}\text { Mean } \\
\text { erosion rate } \\
\text { (in/hr) }\end{array}$ \\
\hline \multicolumn{7}{|c|}{ LAR9 } \\
\hline- & 6.5 & 0.0039 & - & - & - & - \\
\hline 1 & 6.5 & 0.012 & 96 & 10 & 1.7 & 0.23 \\
\hline 2 & 6.6 & 0.0018 & 141 & 10 & 2.4 & 0.12 \\
\hline \multicolumn{7}{|c|}{ LAR12 } \\
\hline - & 6.6 & 0.0 & - & - & - & - \\
\hline 1 & 6.7 & 0.0068 & 155 & 10 & 2.0 & 0.27 \\
\hline \multicolumn{7}{|c|}{ LAR7 } \\
\hline - & 4.1 & 0.0021 & - & - & - & - \\
\hline 1 & 4.2 & 0.0016 & 56 & 10 & 1.9 & 0.42 \\
\hline 2 & 4.3 & 0.0021 & 112 & 10 & 5.3 & 0.20 \\
\hline \multicolumn{7}{|c|}{ SAC1 } \\
\hline - & 3.8 & 0.00064 & - & - & - & - \\
\hline 1 & 4.1 & 0.0012 & 121 & 10 & 7.0 & 0.95 \\
\hline 2 & 4.3 & 0.00093 & 127 & 15 & 5.6 & 0.33 \\
\hline 3 & 4.4 & 0.00074 & 110 & 15 & 4.4 & 0.25 \\
\hline \multicolumn{7}{|c|}{ SAC7 } \\
\hline - & 3.9 & 0.0027 & - & - & - & - \\
\hline 1 & 4.4 & 0.0044 & 145 & 10 & 7.7 & 1.6 \\
\hline 2 & 5.1 & 0.0023 & 151 & 15 & 4.6 & 1.2 \\
\hline 3 & 5.5 & 0.0026 & 150 & 20 & 4.1 & 0.60 \\
\hline \multicolumn{7}{|c|}{ SAC3 } \\
\hline - & 4.3 & 0.0021 & - & - & - & - \\
\hline 1 & 4.8 & 0.0034 & 148 & 10 & 6.1 & 1.3 \\
\hline 2 & 5.1 & 0.0024 & 154 & 10 & 6.0 & 0.85 \\
\hline 3 & 5.3 & 0.0024 & 157 & 10 & 3.9 & 0.75 \\
\hline \multicolumn{7}{|c|}{ LAR2 } \\
\hline- & 3.9 & 0.0077 & - & - & - & - \\
\hline 1 & 5.1 & 0.0030 & 153 & 10 & 5.9 & 3.6 \\
\hline 2 & 5.5 & 0.0029 & 152 & 20 & 3.2 & 0.60 \\
\hline 3 & 5.5 & 0.0032 & 152 & 20 & 2.8 & 0.07 \\
\hline \multicolumn{7}{|c|}{ LAR5 } \\
\hline- & 4.1 & 0.0044 & - & - & - & - \\
\hline 1 & 4.8 & 0.0016 & 150 & 10 & 5.4 & 1.8 \\
\hline 2 & 4.8 & 0.00098 & 131 & 11 & 3.9 & 0.17 \\
\hline
\end{tabular}


Table 3. Summary of borehole erosion tests completed, presented in chronological order, and depth-averaged erosion rates.-Continued

[All tests were performed with water, except the last test (SAC3B2) which was completed with drilling mud at the same site as test SAC3. All tests performed with a 2.64 inch (in.) outside diameter drilling rod, except the first flow event at LAR7, which utilized a $1.77 \mathrm{in.} \mathrm{outside}$ diameter rod. Abbreviaitons: Q, mean discharge in gallons per minute (gal $/ \mathrm{min}$ ) for a flow event, and its duration is given in minutes; $\mathrm{ft} / \mathrm{s}$, feet per second; in $/ \mathrm{hr}$, inch per hour; $\mathrm{V}$, flow speed; - , not applicable]

\begin{tabular}{|c|c|c|c|c|c|c|}
\hline $\begin{array}{l}\text { Flow } \\
\text { event }\end{array}$ & $\begin{array}{l}\text { Hole diam- } \\
\text { eter } \\
\text { (in.) }\end{array}$ & $\begin{array}{l}\text { Standard deviation } \\
\text { of diameter } \\
\text { (in.) }\end{array}$ & $\underset{\text { (gal/min) }}{0}$ & $\begin{array}{l}\text { Duration } \\
\text { (minute) }\end{array}$ & $\begin{array}{c}\text { Mean } \\
\text { V } \\
(\mathrm{ft} / \mathrm{s})\end{array}$ & $\begin{array}{c}\text { Mean ero- } \\
\text { sion rate } \\
\text { (in/hr) }\end{array}$ \\
\hline \multicolumn{7}{|c|}{ LAR6 } \\
\hline- & 3.8 & 0.0017 & - & - & - & - \\
\hline 1 & 4.0 & 0.0011 & 62 & 11 & 5.5 & 0.48 \\
\hline 2 & 4.0 & 0.0011 & 61 & 15 & 5.2 & 0 \\
\hline 3 & 4.8 & 0.0017 & 184 & 10 & 9.2 & 2.4 \\
\hline 4 & 5.0 & 0.0019 & 153 & 20 & 5.5 & 0.28 \\
\hline \multicolumn{7}{|c|}{ LAR10 } \\
\hline - & 3.4 & 0.0045 & - & - & - & - \\
\hline 1 & 4.4 & 0.0076 & 150 & 10 & 9.2 & 2.0 \\
\hline 2 & 4.7 & 0.012 & 114 & 15 & 5.0 & 0.45 \\
\hline \multicolumn{7}{|c|}{ LAR3 } \\
\hline- & 4.2 & 0.0053 & - & - & - & - \\
\hline 1 & 4.2 & 0.0018 & 127 & 10 & 5.6 & 0 \\
\hline 2 & 4.5 & 0.00062 & 134 & 15 & 5.3 & 0.50 \\
\hline 3 & 4.6 & 0.0 & 123 & 45 & 4.2 & 0.06 \\
\hline \multicolumn{7}{|c|}{ SAC9 } \\
\hline- & 4.5 & 0.0044 & - & - & - & - \\
\hline 1 & 5.1 & 0.0037 & 138 & 20 & 4.5 & 1.0 \\
\hline \multicolumn{7}{|c|}{ SAC3B2 } \\
\hline - & 3.7 & 0.0016 & - & - & - & - \\
\hline 1 & 3.9 & 0.0018 & 115 & 10 & 7.5 & 0.48 \\
\hline 2 & 4.0 & 0.0012 & 109 & 30 & 6.0 & 0.16 \\
\hline 3 & 4.1 & 0.0010 & 75 & 30 & 3.7 & 0.07 \\
\hline
\end{tabular}

Measurement uncertainty and error bounds should be considered in any experimental investigation. The primary input variables controlling the results presented in this study are the measured borehole profiles and the measured discharge through the drilling rod. It was not feasible to investigate the accuracy of the flowmeter in the field, but the rated uncertainty is less than the typical standard deviation (5-10 percent) of the observed discharge. Note that time dependence in discharge will yield a mean shear stress that is greater than the square of the mean flow speed. For example, if the flow includes a sinusoidal component superimposed on the mean, and the periodic component has an amplitude that is 10 percent of the mean, the true mean shear stress will be 1.05 times what would be computed using just the mean flow speed.

Each borehole condition was profiled more than once to allow averaging that should remove some of the random error inherent in any measurement. Repeated profiles typically agreed well (appendix 1), but there were some exceptions that were likely caused by the caliper following different paths within a borehole with a non-circular cross-section or slight slumping of the soil. Repeated profiles at site LAR12 (omitted from consideration because of suspected slumping) showed more than a 1 in. difference in diameter, but $0.1-0.2$ in. was a more typical local difference. 


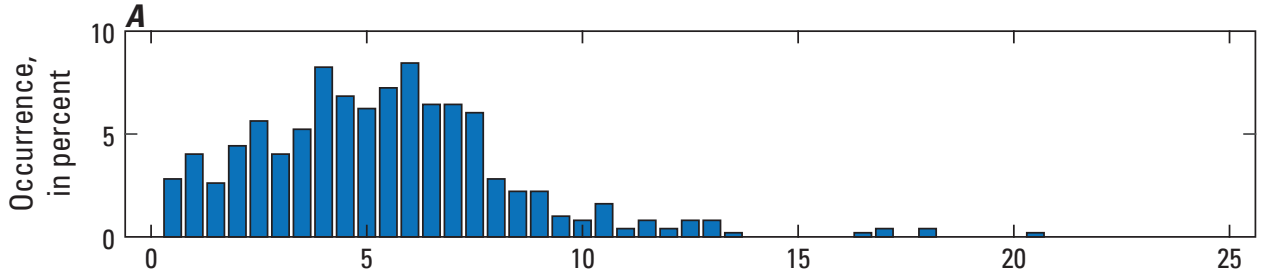

Flow speed, in feet per second
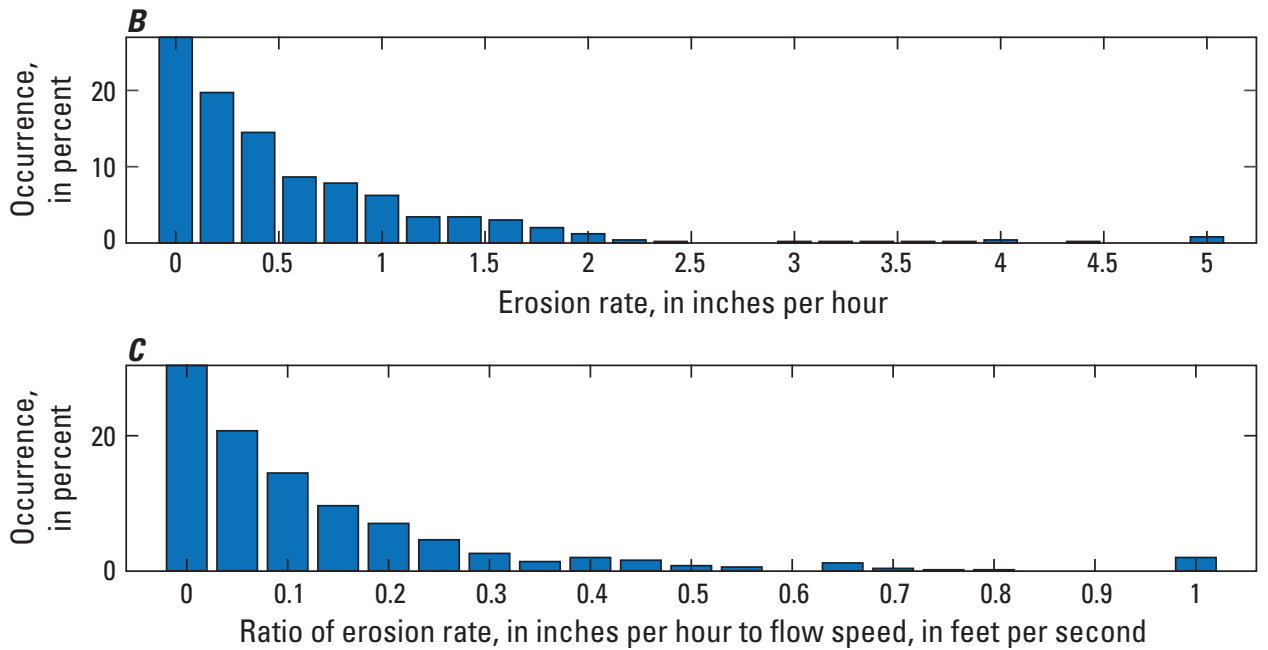

Figure 14. Frequency of occurrence of $A$, flow speed, $B$, erosion rate, and $C$, ratio of erosion rate to flow speed for all available data. Each value used to create this plot is representative of a 6 -inch-tall section of the borehole. Erosion rates less than 0.3 inch per hour are within measurement uncertainty.

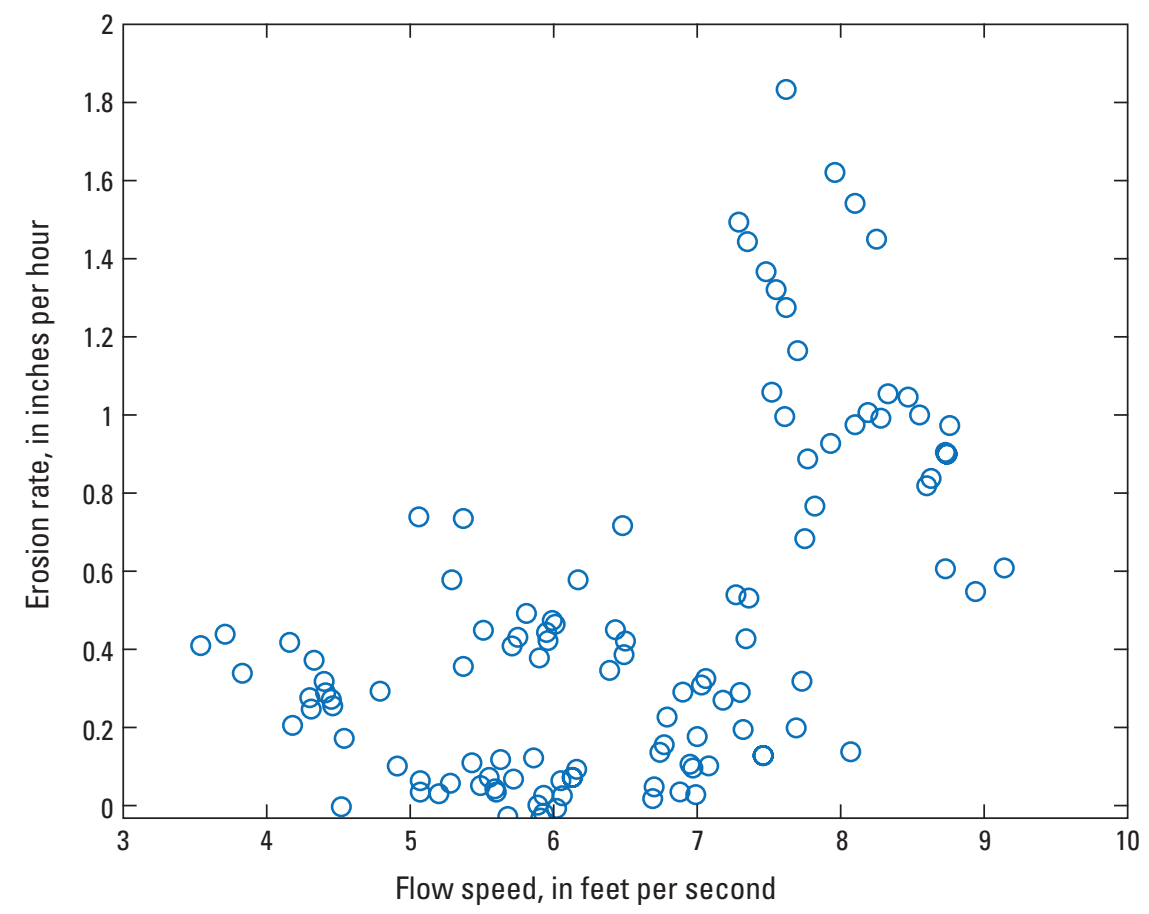

Figure 15. Borehole erosion test results at site SAC1. Each datapoint represents a result for a 6-inch-tall layer within the borehole. This plot includes results from three different flow events. 
Averaging of the repeated borehole profiles should remove much of the random error in the measurements and provide a better definition of the effective diameter of the hole, but limits on caliper resolution and calibration drift can introduce what appears as measurement bias. This was dealt with by applying a constant diameter correction to borehole profiles to force them to match within the PVC casing, where possible. This adjustment was typically no more than $0.1 \mathrm{in}$., which was the resolution of the caliper.

The potential for measurement bias to influence computed results highlights the importance of very careful measurements. A mean error of only $0.1 \mathrm{in}$. in diameter-the resolution of the caliper output-for a 10-minute duration test results in an error in the computed erosion rate of $0.3 \mathrm{in} / \mathrm{hr}$. Of the 32 results presented in table 3, only 19 exceed this threshold. The only practical means of improving this situation is to run tests for longer duration, but this would mean that changes in flow speed during a test are increased.

For the reasons discussed above, it was decided to exclude results corresponding to less than $0.3 \mathrm{in} / \mathrm{hr}$ for erosion rate. Any computed erosion rate less than $0.3 \mathrm{in} / \mathrm{hr}$ should be considered to be within measurement uncertainty. The result at site $\mathrm{SAC} 1$, with erosion values below $0.3 \mathrm{in} / \mathrm{hr}$ discarded, is shown in figure 16.

Many different equations have been presented to relate erosion rates to flow speeds or to bed shear stresses (Partheniades, 1965; Chien and Wan, 1998; Roberts and others, 1998; Winterwerp and van Kesteren, 2004). Most equations relating shear stress to flow speed in turbulent flows feature an exponent of 2 on flow speed and include a drag coefficient that also is a function of the flow speed via a Reynolds number. Some equations for sediment transport assume that it is proportional to power of the flow, which indicates an exponent of 3 on flow speed. In any case, the erosion rate becomes a nonlinear function of flow speed with an exponent in the range 2-3. In this report, rather than assume a relationship between flow speed and shear stress, or flow speed and flow power, flow speed was utilized by itself because it is the controlling variable and the one that was computed directly from observations.

Wall shear stress on a pipe is often estimated making use of the Moody Diagram to estimate an empirical friction factor (Munson and others, 2013). This friction factor depends on wall roughness and the Reynolds Number, but dependence on the Reynolds Number vanishes once the flow becomes highly turbulent. Wall shear stress can be related to this friction factor and mean flow speed as follows:

$$
\tau=\frac{1}{8} \rho f V^{2}
$$

where

$\rho$ is the fluid density,

$f \quad$ is the empirical friction factor, and

$V \quad$ is the average flow speed in the pipe.

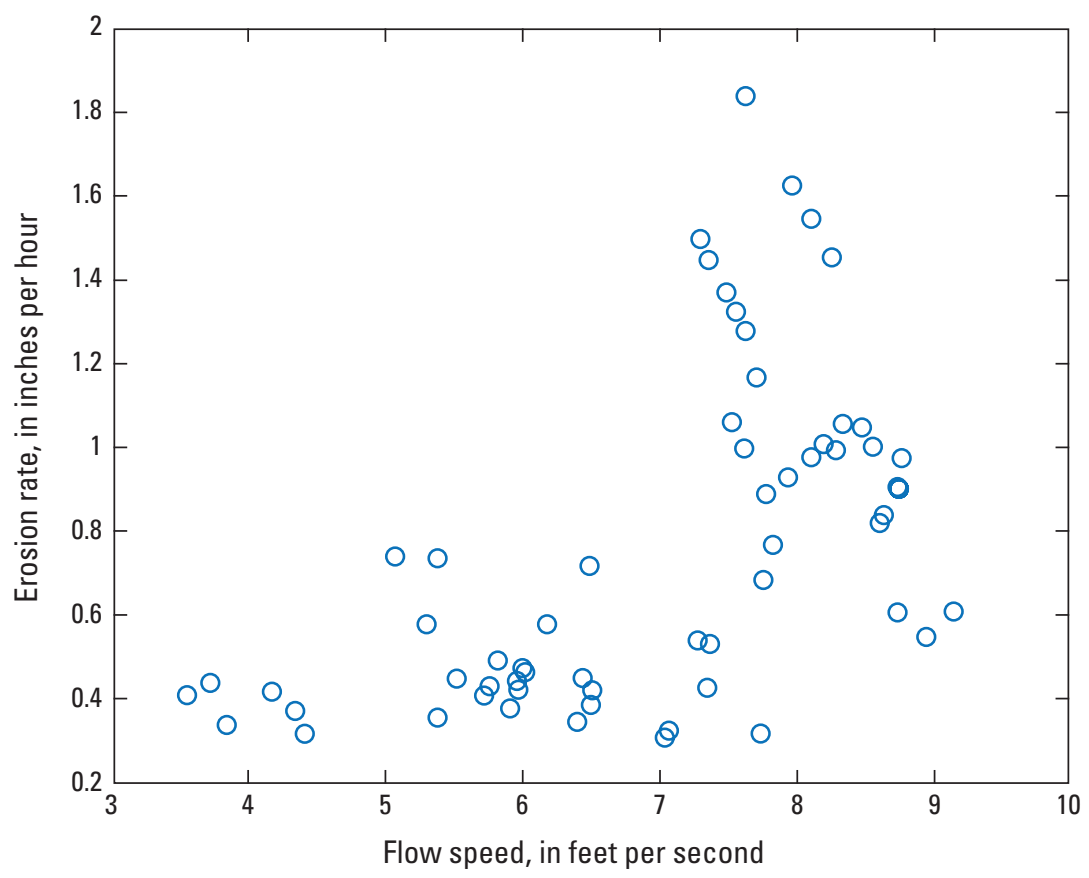

Figure 16. Borehole erosion test results at site SAC1 with erosion rates below 0.3 inch per hour discarded. Each data point represents a result for a 6 -inch-tall layer within the borehole. 
Many equations have been proposed to describe the dependence of the friction factor $(f)$ on the Reynolds Number and relative roughness of a pipe; but in most cases they assume full flow through a pipe and do not consider the scenario in the BET, which features flow through an annulus between a circular pipe (the drilling rod) and a nominally circular larger conduit (the drilled hole). Lyons and others (1996) recommend the following for this scenario.

$$
f=\left[\frac{1}{2 \log _{10}\left(\frac{D_{h}-D_{p}}{e_{a v}}\right)+1.14}\right]^{2}
$$

where

$$
\begin{array}{ll}
D_{h} & \text { is the diameter of the drilled hole, and } \\
D_{p} & \text { the outer diameter of the drill pipe. }
\end{array}
$$

The hole and the pipe will typically feature different roughness, so an average roughness is used:

$$
e_{a v}=\frac{e_{o h} D_{h}^{2}+e_{p} D_{p}^{2}}{D_{h}^{2}+D_{p}^{2}}
$$

where

$$
\begin{gathered}
e_{a v} \quad \begin{array}{c}
\text { is the average roughness height, } e_{o h} \text { is the } \\
\text { representative roughness height for the } \\
\text { wall of the drilled hole, and }
\end{array} \\
e_{p} \quad \text { the roughness height for the drilling rod. }
\end{gathered}
$$

Values for relative roughness are typically not measured in practice, but instead are obtained from reference publications. Unfortunately, the roughness height for the drilled hole is not easily measured and will vary by location and over the length of the hole. Some of the drilled holes featured very large vertical gradients in diameter that would enhance turbulence and are not accounted for in the equations above. For these reasons, in this report, the focus is on the measured or readily derived quantities of diameter, discharge, flow speed, and observed soil characteristics, without relying on assumed values of quantities that were not measured or cannot be derived, such as roughness of the walls of the hole. Plots are provided showing erosion rate versus flow speed; converting the $\mathrm{x}$-axis to shear stress could be done and would stretch the axis horizontally because of the parabolic dependence of shear stress on flow speed. But this would introduce additional uncertainty into the results.

When using the lithology data paired with the BET data it is possible to investigate the differences in erodibility of sediments dominated by sand, silt, or clay fractions. Borehole erosion rates were computed at 6-in. intervals, and lithology was described in 1.5-ft intervals with some gaps. Gaps in the lithology data appeared following each standard penetration test (SPT) or Calmod sample as the auger is advanced 6 in. deeper after each SPT or Calmod sample per ASTM 2011 guidelines. There also were gaps where Shelby tube samples were collected.

For each computed borehole erosion rate, the corresponding sediment type was looked up in the lithology $\log$, where available. It was then possible to plot erosion rates for different sediment types. These are very broad classifications, however, with any sample featuring greater than 50 percent sand classified as sand, for example. Even the samples classified as sands will have different amounts of organic material, silt, clay, and water in them.

Figure 17 shows the result at site SAC1. It was not possible to assign a sediment classification to each 6-in. layer, so the number of points was reduced compared to the previous figure. Each sediment sample was assigned estimated percentages of clay, silt, and sand in the field, and this was used to distinguish the samples. Samples with more than 50 percent sand are classified as sand, and so on. It would be possible to subdivide samples further, but then the number of results per class drops to the point where it is too few to infer any meaningful results. The result shown here indicates that erosion rate increases with flow speed, as expected, but no attempt was made to fit curves through the results because of the limited number of data points and large scatter in the results. Similar plots for other sites revealed mostly similar results, although in some cases, dependence on flow speed is not clear (see the "appendix 1" section for plots for each site).

The complete set of results from all test sites was considered to look for correlation between erosion rate and sediment type (fig. 18). The results for clay and silt exhibited the expected increase in erosion rate with flow speed. Recalling that uncertainty is in the range of $0.5 \mathrm{in} / \mathrm{hr}$, the behavior of the clays appeared to change near a flow speed of $7 \mathrm{ft} / \mathrm{s}$, where the erosion rate increased past $1.5 \mathrm{in} / \mathrm{hr}$. Below a flow speed of $7 \mathrm{ft} / \mathrm{s}$, all computed erosion rates for clay were less than $1 \mathrm{in} / \mathrm{hr}$.

The samples classified as sand exhibited more complicated behavior. Remember that these included samples containing anywhere from 50 to 100 percent sand and also were consolidated to different degrees, as revealed by highly variable blow count data. The dependence on the predominance of sand was considered next.

Figure 19 shows erosion rate as a function of flow speed and sand fraction for those samples classified as predominantly sand. Note that this included silty sands and clayey sands, which likely erode differently. It does not appear that sand fraction is a suitable predictor variable for estimating erosion rate.

The plot for the samples classified as silt is similar to figure 19, although with fewer results. The result for clay samples does not reveal the influence of the clay fraction because most of the samples classified as clay had very high fractions of clay.

Blow count and erosion rate were not well correlated. Some samples with a blow count of zero had erosion rates below detection limits, and this also was true for some samples with higher (greater than five) blow counts. 


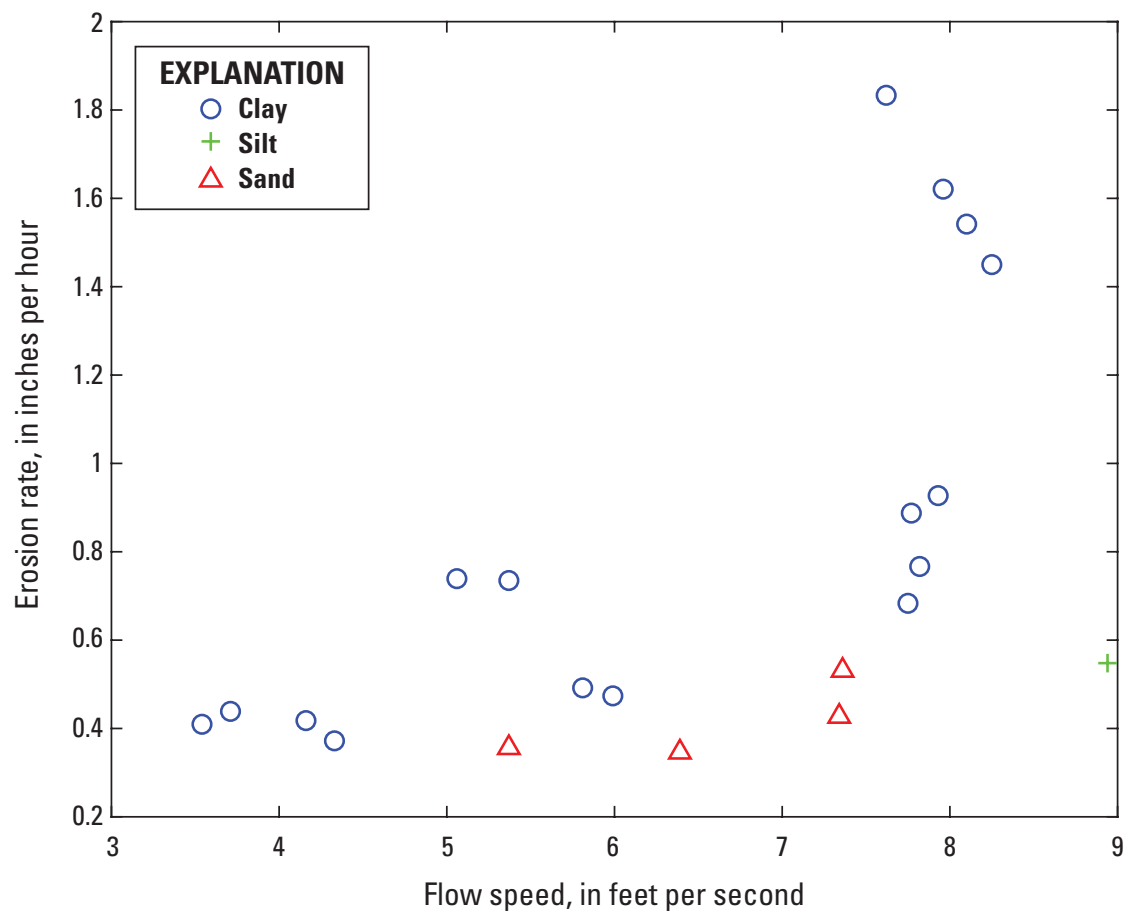

Figure 17. Computed erosion rate versus flow speed and sediment classifications at site SAC1. Each datapoint represents a result for a 6-inch-tall layer within the borehole.

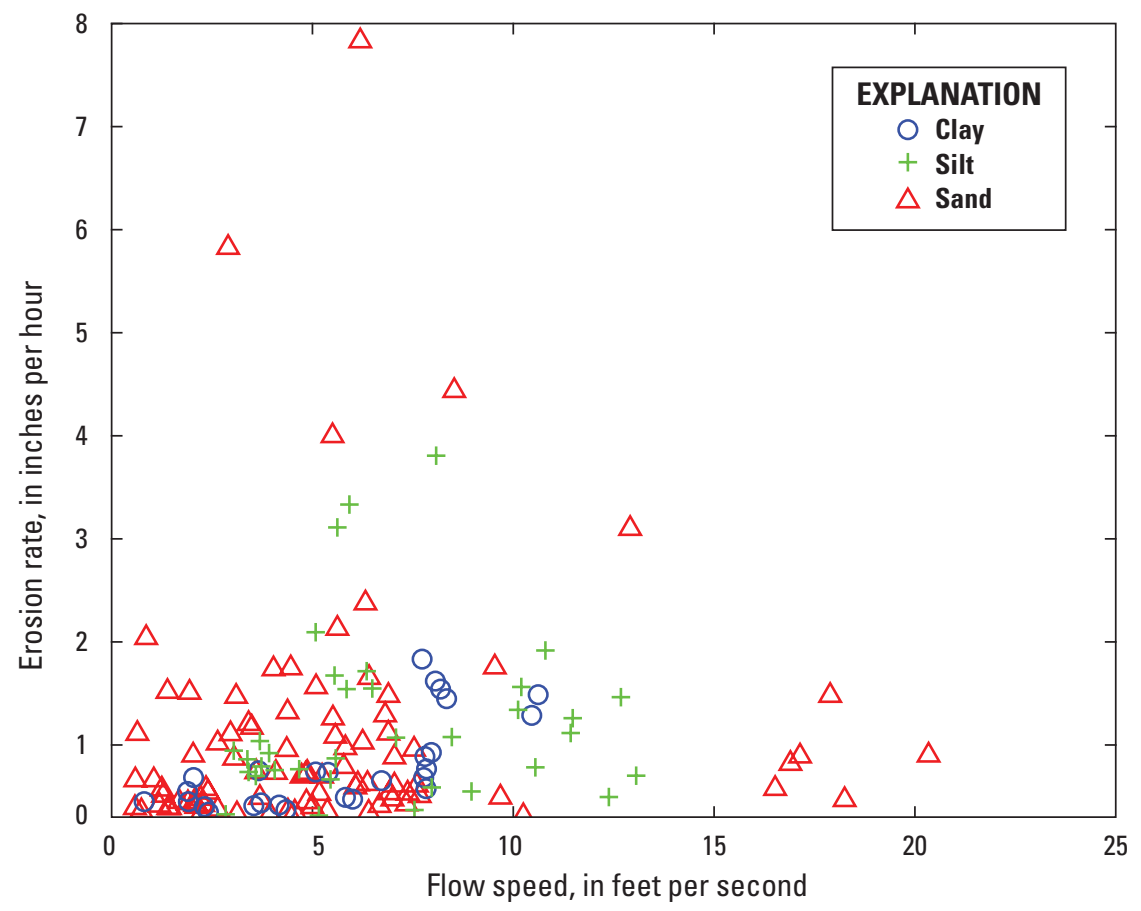

Figure 18. Erosion rate versus flow speed by sediment type, using all available data from all test sites. Each datapoint represents a result for a 6 -inch-tall layer within the borehole. 


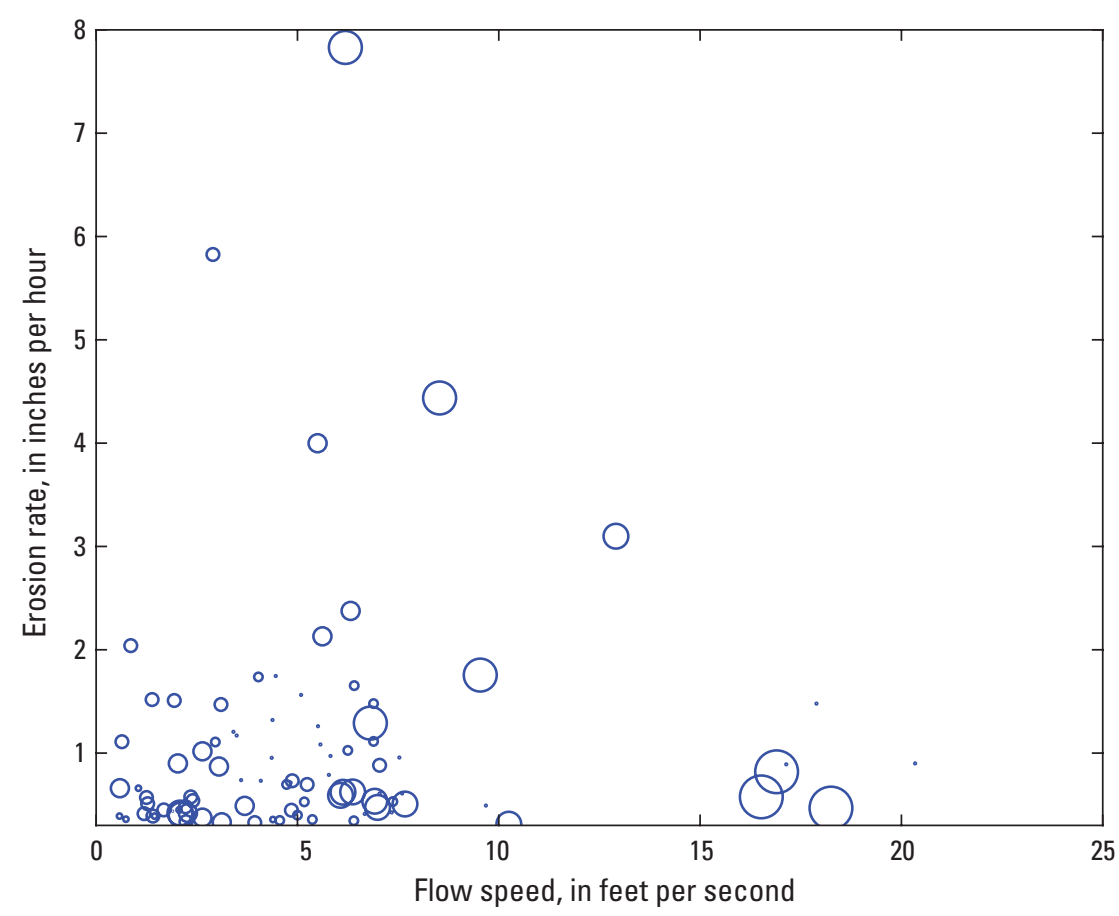

Figure 19. Erosion rate versus flow speed and sand fraction, for samples from all sites containing greater than 50 percent sand based on visual observations. The largest circle represents 100 percent sand, and the smallest, 50 percent.

All of these results make it clear that erosion is a complicated function of many parameters, including the soil composition and its degree of consolidation. This is one argument for performing in situ tests, such as described here, to reveal erodibility and to resolve vertical variations.

One goal of the work described here was to provide quantitative estimates of erodibility versus depth for the various sites and soil types considered. For modeling of sediment transport driven by surface-water flows, one typically uses an empirically derived equation relating sediment transport rate to either flow speed or shear stress. Given the limited number of data points for each soil type at the individual sites and the high degree of variability between sites, it appears that the most appropriate approach, if such an equation is desired, would be to fit an equation through all of the erosion versus flow speed data at a given site (fig. 16). This would mean that as the flow cuts through the more erodible layers, the erosion rate would be underestimated and then overestimated once the less erodible layers were reached. But there were not enough data at most sites to derive a suitable equation for a specific, thin sediment layer. Regions featuring predominantly clay appeared to behave differently than those with silty and sandy soils, but most of the subsurface layers were dominated by the looser soils.

As noted earlier, one test at site LAR12 was omitted from consideration because of apparent slumping of the borehole. Because of equipment problems, there was an extended delay between the drilling of the initial borehole and the start of the first flow event. Repeated caliper profiles revealed that the hole was evolving during this delay period. It also had been observed that sand was flowing into the auger during the drilling of the initial hole. Because of this, subsequent tests were limited to regions above the water table, but one test also was performed with drilling mud to see if it would reduce problems with heaving and collapsing sand. Site SAC3 was chosen for a repeat test with drilling mud.

The additive used to create the drilling mud was Baroid Quik-Gel Gold, described by the manufacturer as a high-yield sodium bentonite viscosifier. Compacted density is stated as $69-74$ pounds per cubic foot $\left(\mathrm{lb} / \mathrm{ft}^{3}\right)$, typically added at a rate of $15-25$ pounds (lb) per 100 gal. In practice, $250 \mathrm{lb}$ of viscosifier was added to $105 \mathrm{ft}^{3}$ of water in order to yield a mixture with the specific gravity of 1.04 . The viscosity was measured using a Marsh funnel (Pitt, 2000). Estimated effective viscosity in centipoise was computed as indicated below.

$$
\mu=\rho(t-25)
$$

where

$\mu \quad$ is viscosity in centipoise,

$\rho \quad$ is fluid density in grams per cubic centimeter $\left(\mathrm{g} / \mathrm{cm}^{3}\right)$, and

$\mathrm{t}$ is Marsh funnel time in seconds. 
The effective viscosity of the drilling mud was 25.9 centipoise. The same test performed in the field with water yielded 1.7 centipoise.

The test with drilling mud was performed after drilling into the water table, and the resulting surveys of the boreholes indicate that slumping was minimal. But the results shown in table 3 indicate that the drilling mud greatly reduced erosion rates, compared to the test performed at the same site with water. Test flow speeds were similar, but erosion rates with drilling mud were substantially reduced. Although this observation applies to only one test at one site, it appears that the use of drilling mud can substantially reduce estimated erosion rates and yield results not representative of erosion rates expected when natural flows of water pass over the same soil.

\section{Conclusions}

There were two major goals of the project described in this report:

1. Perform drilling to reveal lithology at up to 21 sites along the banks of the Sacramento and American Rivers in California, and to acquire sediment samples for later laboratory analysis.

2. Perform borehole erosion tests (BETs) following the methodology of Briaud and others (2017) to ascertain erosion rates and their dependence on sand, silt, and clay composition along the lower American and Sacramento Rivers in California.

The first of these tasks was performed without any major problems, in cooperation with USACE personnel who are archiving the results within a larger geotechnical database. Drilling was performed to define lithology and acquire sediment samples, which were delivered to a USACE laboratory and a Texas A\&M University laboratory.

The BETs were attempted with water at 12 sites, with 1 test repeated with drilling mud. These tests proved more challenging than the drilling for lithology, but revealed some interesting results and lessons learned. In principle, it is a simple test, but the data must be collected and interpreted very carefully, and the test is better suited to some soils than others.

\section{Practical and Procedural Recommendations}

Some practical recommendations for borehole erosion tests are stated first:

1. Loosely consolidated, sandy soils may be heavily eroded simply by the initial drilling process that creates the required borehole. This can lead to a convoluted initial borehole shape that is likely to lead to flow that has large convective accelerations and direction changes that are unaccounted for during the interpretation of BET results and may enhance erosion. Drilling with mud may reduce the development of a convoluted initial borehole, but (based on one test) the drilling mud appears to substantially reduce erosion rates.

2. An overly large, initial mean diameter for the drilled hole requires very high pumping rates to reach high in-hole flow speeds. Pumping capacity was not sufficient to reach the highest (12 ft/s) target flow speed throughout any of the drilled holes; although, this speed was exceeded locally in several tests, and the other target flow speeds of 5 and $8 \mathrm{ft} / \mathrm{s}$ were reached in most cases.

3. Drilling with the slimmest possible drilling rod reduced initial diameter bore sizes in loosely consolidated, sandy soils from roughly 10 to 4 in., compared to what had been obtained with a larger diameter rod. It also allowed drilling fluid to flow up the borehole with reduced flow speed, compared to using a larger drill rod. Soil characteristics may dictate a minimum size for the drilling rod; if too thin, the rod can shear or the bit may wander, resulting in an irregular hole that is difficult to profile accurately and has large vertical gradients in diameter or centerline position.

4. Attempting to test below the water table in loose, sandy soils will often lead to heaving sands and collapse of the borehole. For boreholes consisting entirely of loose sandy soils, erosion tests can be done roughly $2-4 \mathrm{ft}$ above the water table to prevent upward movement of water and sediment via capillary pressure, saturation of dry soils, and borehole collapse. A minimum of $2 \mathrm{ft}$ above the water table for erosion testing is recommended because erosion tests resulted in roughly $1 \mathrm{ft}$ of downward erosion caused by water exiting the drill rod.

5. It appears best to attempt the highest flow speed tests at a site first, although Briaud and others (2017) recommend the opposite. As erosion progresses, the annulus between the drilling rod and the wall of the borehole gets larger, making it more difficult to achieve high flow speeds. An alternative would be to switch to progressively larger drilling rods, but this is logistically difficult.

6. Head losses within the plumbing system must be considered. The system used in this report was modified at one point to reduce the length of plumbing and it led to a notable increase in flow rate. The head loss problem would have been more severe if deeper holes had been drilled. 
7. To allow high flow speeds, the drilling rods used for the test should be only slightly smaller than the drilled hole. But then this would mean that as the hole erodes, the percent change in the annulus area during a flow event is larger than it would be if a smaller diameter rod were used. The optimal duration of a test depends on the erodibility of the soils, which is not known before testing; how the erodibility of the soils varies vertically (also unknown); measurement uncertainty for the caliper; and allowable percent change in the annulus area. In practice, most of the initial tests were performed over 10-minute intervals. With experience, this time was increased to $30-45$ minutes.

8. It is important to monitor water volumes and time dependence in flow rates. Ultimately, it was concluded that water losses during testing could be neglected and that the mean discharge for a flow event could be used to compute flow speeds. However, it is important to know how reasonable these assumptions are, and the best way to evaluate them is with high-frequency data describing discharge and supply-tank depth or volume.

9. Although conceptually simple, the test is logistically complicated and expensive. Each day in the field, one employee was devoted to making on-the-fly decisions about how to proceed and deal with problems, in addition to operating an expensive digital caliper, a datalogger to capture flow time-dependence, and another datalogger to monitor holding tank water depth. Much of the data also were logged manually, for redundancy, in case of a failure elsewhere. One BET per day was the maximum possible, including the site cleanup after completion of the tests, which made many days very long. The crew typically consisted of three drillers, a U.S. Geological Survey (USGS) scientist, USACE employees (geologist and biological expert), a tribal representative, and an archaeological expert. Sites also had to be evaluated for potential impacts on infrastructure and recreation. Of course, many of these tasks would be required regardless of test methodology.

10. To reduce random measurement errors, it is advantageous to profile each hole multiple times and to average the results. A three-pronged caliper was used for all tests and appeared to be adequate in most instances based on observed differences between repeated profiles; it was suspended on a cable so it could rotate within the hole. If the hole was not circular, different results may have been obtained.

11. Tests need to be run long enough to display measurable and meaningful erosion. The caliper used had a resolution of $0.1 \mathrm{in}$. in diameter, so it was desirable to see at least 0.5 in. of change in diameter for computing erosion rates. But the only way to know if this condition was reached was to stop the test and survey the hole. Experience and judgment are required for this test.

12. It is important that the changes in diameter that are documented are only a result of the flow through the drilling rods, as opposed to slumping. The borehole should be profiled immediately before commencement of a test.

13. To avoid problems with saturated sand slumping in the hole, tests were limited to regions above the water table, in most cases. A test performed with drilling mud in primarily sandy soil indicates that it substantially reduces erosion rates, indicating that it should not be used for the BET in this circumstance.

14. Three flow speeds were targeted in this study. In retrospect, a larger number is preferable, bracketing the (unknown) critical velocity for initiation of erosion, because it could allow the development of sediment-layer specific relationships between erosion rate and flow speed, similar to what is obtained in most cases using an erosion function apparatus for laboratory testing of extracted sediment cores.

\section{Site and Project Specific Conclusions}

The statements above are primarily related to how the BETs should be performed. A similar list of conclusions based on the test results is presented below:

1. Eighteen holes were drilled to define lithology and collect sediment samples; one site had to be abandoned because of near-surface debris. The methodology included the use of hollow augers, split spoon samplers, Calmod samplers, and Shelby tubes.

2. Borehole erosion tests were performed successfully near 11 of the lithology holes. One other test had to be repeated because of observed slumping between tests, two tests failed because of interference from submerged debris, and one test was repeated with drilling mud. The drilling mud appeared to substantially reduce erosion rates.

3. Discharge through the drilling rod was monitored digitally at $1 \mathrm{~Hz}$, and visually each minute. Standard deviation of the discharge was typically $5-10$ percent of the mean value. Mean flow speed at a given location for a given flow event was taken as the mean discharge divided by the mean of the initial and final annulus areas for the test of interest at that location. 
4. Water lost during a test was typically less than 10 percent of the volume that entered the borehole. It is difficult to know precisely how much is lost during the test as opposed to after completion of the test. If losses into the wall of the hole had been markedly higher, it would have been necessary to model discharge as a function of elevation within the hole.

5. Results were averaged over 6-in. vertical intervals to help eliminate the effects of random errors. This resulted in an erosion-rate flow speed pair for each 6-in. interval. Where possible, soil characteristics were assigned to each layer.

6. Target flow speeds for testing were 5,8 , and $12 \mathrm{ft} / \mathrm{s}$. The maximum computed flow speed in the collection of tested 6-in. intervals was $20 \mathrm{ft} / \mathrm{s}$; for most 6-in. intervals, tested flow speeds fell between 0 and $10 \mathrm{ft} / \mathrm{s}$.

7. Computed erosion rates ranged from -2.0 to $7.8 \mathrm{in} / \mathrm{hr}$. Negative values arise due to slumping or caliper errors and should be considered as unrepresentative. It was concluded that any value less than $0.3 \mathrm{in} / \mathrm{hr}$ should be considered to be within measurement error bounds. This is based on a caliper resolution of $0.1 \mathrm{in}$. for diameter and a test duration of 10 minutes. Empirically, $0.5 \mathrm{in} / \mathrm{hr}$ appears to be a better definition of measurement uncertainty.

8. Most of the drilling that was performed was through soils containing more than 50 percent sand. No examples of archaeological or cultural significance were found. In some cases, relic construction materials forced relocation or abandonment of drilling operations.

9. Separate holes were drilled to reveal lithology and to perform BETs. At most test sites, the lithology of the two holes appeared to match well; however, this was not true at site LAR6. Spatial variability in lithology must be considered when interpreting results.

10. Given the size of the dataset and the variability in results, it was difficult to assign trends or equations relating flow speed and erosion rate to different soil types. For each of the soil types considered (sand, silt, and clay), some evidence of erosion rate increasing with flow speed was evident, but spatial (longitudinal and vertical) variations in erosion rate for similarly classified soils masked these trends.
11. Given the prominence of sandy soils in the dataset, it was not realistic to calculate separate erosion rates for different sediment types. Instead, what is recommended is to consider results lumped together by location. This means slight underprediction in erosion rates for part of the soil column and overprediction in other portions, but this approach provides one relationship between flow speed (or shear stress) per location, regardless of depth of erosion. There are considerable differences between sites, which would be resolved this way. An appendix to this report provides plots of erosion rate versus depth that could be utilized in this manner.

12. Soils encountered were categorized very broadly when attempting to interpret the BET data. Anything classified as greater than 50 percent sand was considered sand. An examination into whether sands classified as fine or coarse had different erosion rates was inconclusive, probably because even these can have a very large range of clay or silt fractions. There were not enough data to subdivide further.

13. Whereas the concept of a critical velocity for erosion is commonly invoked in the modeling or prediction of sediment transport, the available data did not allow clear identification of critical erosion speeds. However, the erosion of the clay layers did appear to increase once a flow speed of $7 \mathrm{ft} / \mathrm{s}$ had been reached.

14. It is likely that the methodology works best for cohesive sediments, if long flow durations are applied. In this case, the assumption of a round borehole is likely better, slumping is less of a concern, the borehole would likely be more uniform over the vertical, and the amount of water lost during a test more likely to be negligible.

Plots of erosion rate versus flow speed are provided for each site in appendix 1 . There are several different ways that this data could be utilized to facilitate modeling applications. Any of a number of regression equations could be employed, a constant erosion rate above a chosen flow speed threshold could be assumed, or a conservative curve that falls above the computed results could be chosen. The best option will depend on the application and the risk involved with under- or over-predicting the response. 


\section{Selected References}

American Society for Testing and Materials, 2009, Standard test method for Marsh funnel viscosity of clay construction slurries: West Conshohocken, Pa., American Society for Testing and Materials, International, ASTM D6910/ D6910M-09, 3 p.

American Society for Testing and Materials, 2011, Standard test method for standard penetration test (SPT) and split-barrel sampling of soils: West Conshohocken, Pa., American Society for Testing and Materials, International, ASTM D1586-11, 9 p.

American Society for Testing and Materials, 2014, Standard practice for preserving and transporting soil samples: West Conshohocken, Pa., American Society for Testing and Materials, International, ASTM D4220/D4220M-14,11 p.

American Society for Testing and Materials, 2015a, Standard practice for thin-walled tube sampling of soils for geotechnical purposes: West Conshohocken, Pa., American Society for Testing and Materials, International, ASTM D1587/D1587M-15, 4 p.

American Society for Testing and Materials, 2015b, Standard practice for using hollow-stem augers for geotechnical exploration and soil sampling: West Conshohocken, Pa., American Society for Testing and Materials, International, ASTM D6151/D6151M-15, 14 p.

American Society for Testing and Materials, 2016, Standard practice for soil exploration and sampling by auger borings: West Conshohocken, Pa., American Society for Testing and Materials, International, ASTM D1452/D1452M-16, 6 p.

American Society for Testing and Materials, 2017, Standard practice for description and identification of soils (visual-manual procedure): West Conshohocken, Pa., American Society for Testing and Materials, International, ASTM D2488-17, 12 p.

American Society for Testing and Materials, 2018, Standard guide for use of direct rotary drilling with water-based drilling fluid for geoenvironmental exploration and the installation of subsurface water-quality monitoring devices: West Conshohocken, Pa., American Society for Testing and Materials, International, ASTM D5783-18, 8 p.

Borrowman, T.D., Smith, E.R., Gailani, J.Z., and Caviness, L., 2006, Erodibility study of Passaic River sediments using USACE Sedflume: Vicksburg, Miss., U.S. Army Engineer Research and Development Center, 44 p., https://doi.org/doi:10.7282/T38W3DB4.
Briaud, J.-L., Ting, F.C.K., Chen, H.C., Cao, Y., Han, S.W., and Kwak, K.W., 2001, Erosion function apparatus for scour rate predictions: Journal of Geotechnical and Geoenvironmental Engineering, v. 127, no. 2, p. 105-113, https://doi.org/10.1061/(ASCE)10900241(2001)127:2(105).

Briaud, J.-L., Chedid, M., Chen, H.-C., and Shidlovskaya, A., 2017, Borehole erosion test: Journal of Geotechnical and Geoenvironmental Engineering, v. 143, no. 8, 12 p., https://doi.org/10.1061/(ASCE)GT.1943-5606.0001712.

Chien, N., and Wan, Z., 1998, Mechanics of sediment transport: Reston, Va., American Society of Civil Engineers, 913 p., https://doi.org/10.1061/9780784404003.

Hanson, G.J., and Cook, K.R., 2004, Apparatus, test procedures, and analytical methods to measure soil erodibility in situ: Applied Engineering in Agriculture, v. 20, no. 4, p. 455-462, https://doi.org/10.13031/2013.16492.

Jones, C., and Gailani, J., 2009, Discussion of "Comparison of Two Techniques to Measure Sediment Erodibility in the Fox River, Wisconsin" by T. Ravens: Journal of Hydraulic Engineering, v. 135, no. 5, p. 432-434, https://doi.org/ 10.1061/(ASCE)HY.1943-7900.0000002.

Lyons, W.C., Plisga, G.J., and Lorenz, M., eds., 1996, Standard handbook for petroleum and natural gas engineering, 3rd edition: Elsevier, 1822 p., https://www.elsevier.com/books/standard-handbook-ofpetroleum-and-natural-gas-engineering/lyons/978-0-12383846-9.

Maa, J.P.-Y., Wright, L.D., Lee, C.-H., and Shannon, T.W., 1993, VIMS sea carousel-A field instrument for studying sediment transport: Marine Geology, v. 115, no. 3-4, p. 271-287, https://doi.org/10.1016/0025-3227(93)90056-2.

McNeil, J., Taylor, C., and Lick, W., 1996, Measurements of erosion of undisturbed bottom sediments with depth: Journal of Hydraulic Engineering, v. 122, no. 6, p. 316-324, https://doi.org/10.1061/(ASCE)07339429(1996)122:6(316).

Munson, B.R., Okiishi, T.H., Huebsch, W.W., and Rothmayer, A.P., 2013, Fundamentals of fluid mechanics, 7th edition: Wiley, 796 p., http://roneducate.weebly.com/ uploads/6/2/3/8/6238184/fundamentals_of_fluid_ mechanics_7e_textbook.pdf.

Partheniades, E., 1965, Erosion and deposition of cohesive soils: Journal of the Hydraulics Division, v. 91, no. 1, p. $105-139$. 
Pitt, M.J., 2000, The Marsh funnel and drilling fluid viscosity - A new equation for field use: Society of Petroleum Engineers, v. 15, no. 1, 4 p., https://doi.org/10.2118/62020-PA.

Ravens, T.M., 2007, Comparison of two techniques to measure sediment erodibility in the Fox River, Wisconsin: Journal of Hydraulic Engineering, v. 133, no. 1, p. 111-115, https://doi.org/10.1061/(ASCE)07339429(2007)133:1(111).

Roberts, J., Jepsen, R., Gotthard, D., and Lick, W., 1998, Effects of particle size and bulk density on erosion of quartz particles: Journal of Hydraulic Engineering, v. 124, no. 12, p. 1261-1267, https://doi.org/10.1061/(ASCE)07339429(1998)124:12(1261).

Roberts, J., Jepsen, R., and James, S.C., 2003, Measurements of sediment erosion and transport with the adjustable shear stress erosion and transport flume: Journal of Hydraulic Engineering, v. 129, no. 11, p. 862-871, https://doi.org/ 10.1061/(ASCE)0733-9429(2003)129:11(862).
Tolhurst, T.J., Black, K.S., Paterson, D.M., Mitchener, H.J., Termaat, G.R., and Shayler, S.A., 2000, A comparison and measurement standardisation of four in situ devices for determining the erosion shear stress of intertidal sediments: Continental Shelf Research, v. 20, no. 10-11, p. 1397-1418, https://doi.org/10.1016/S0278-4343(00)00029-7.

U.S. Army Corps of Engineers, 2012, SPK - Sacramento Geotechnical Branch-Field Manual: Sacramento, Calif., U.S. Army Corps of Engineers.

Winterwerp, J.C., and van Kesteren, W.G.M., 2004, Introduction to the physics of cohesive sediment dynamics in the marine environment: Elsevier, v. 56, 576 p.

Work, P.A., and Livsey, D.N., 2019, Borehole erosion test data, lower American and Sacramento Rivers, California, 2019 (ver. 3.0, July 2020): U.S. Geological Survey data release, https://doi.org/10.5066/P96MCT2Q.

Work, P.A., and Schoellhamer, D.H., 2018, Measurements of erosion potential using Gust chamber in Yolo Bypass near Sacramento, California: U.S. Geological Survey Open-File Report 2018-1062, 17 p., https://doi.org/10.3133/ofr20181062. 


\section{Appendix 1. Individual Borehole Erosion Test Plots and Notes}

A series of plots is provided to display results from each borehole erosion test (BET). Results are presented in the order in which they were collected.

No corrections were applied to depth data, except for one profile at site LAR9, which is discussed below. The tests all featured polyvinyl chloride (PVC) casing extending through several feet (ft) of the top of the borehole. Because this casing has a constant 6-inch (in.) diameter, if necessary, caliper-measured diameters were shifted by a constant to force them to match at the top. This correction was applied to all

\section{Site LAR9}

This was the first test performed, and it differed from others in a couple of ways. Vertical resolution of the caliper output was only $0.1 \mathrm{ft}$, whereas it was $0.02 \mathrm{ft}$ for all subsequent tests. The profiles after flow event 1 appear to have been taken without correctly setting the vertical datum. A $0.8 \mathrm{ft}$ correction was applied to force these profiles to match the others within the section of the profile that features PVC casing. This correction also was applied to the data files being released through a formal U.S. Geological Survey (USGS) data release (Work and Livsey, 2019).

Mean profiles were computed only for the regions that were represented in the initial condition and in all post-flow conditions. In this case the initial condition survey did not include the PVC casing, so it was not possible to apply a diameter correction to force profiles to match within the casing.

The surveyed profiles are presented in fig. 1.1. The bottom right panel in this figure shows the evolution of the mean profiles, with a mean computed for the initial condition and for each flow event. Figure 1.2 shows the cumulative change in radius, with in an increase in radius shown as positive. The curve labeled "After flow event 1" shows the mean profile after flow event 1 minus the mean initial profile. The curve labeled "After flow event 2" shows the mean profile after flow event 2 minus the mean initial profile. Because erosion rate is computed as the change in radius divided by the duration of the flow event that caused the change, and erosion rate also will be plotted, the cumulative radius changes will not be presented for the remaining cases.

Figure 1.3 shows erosion rate versus depth in the left panel and flow speed versus depth in the right panel. Mean flow speed is computed as discharge for a flow event divided by the local mean annulus area; so, for flow event 1 , for example, at every depth there was an initial value of the annulus area and then a new value at that location after the flow event. The mean of the two computed results is the mean annulus area. At the start of a flow event, flow speed will be higher than this computed mean flow speed, and by the end measured diameters for a given caliper run, where possible, as an attempt to correct for small calibration errors or drift. The resolution of the diameter as reported by the caliper is $0.1 \mathrm{in}$., and the diameter correction applied was, in all cases, $0.2 \mathrm{in}$. or less. A $0.1 \mathrm{in.}$ error in diameter during a typical 10-minute experiment corresponds to an error of $0.3 \mathrm{inch}$ per hour (in/hr) in erosion rate (with erosion rate defined as the change in radius divided by the duration of the flow event), so results below this threshold were considered within the noise and not plotted. of the flow event, flow speed will be lower. Peak flow speed during the test was near 6 feet per second $(\mathrm{ft} / \mathrm{s})$; target flow speeds of 5,8 , and $12 \mathrm{ft} / \mathrm{s}$ were obtainable only by starting the test procedure with the highest possible discharge.

Figure 1.4 shows the surveyed profiles; lithology based on field notes (obtained on a different day in an adjacent hole); and computed erosion rate, with erosion rates below the detection limit of $0.3 \mathrm{in} / \mathrm{hr}$ screened out. Most of the profile consists of sandy soils. Project protocol dictated that Shelby tubes be pushed whenever clays were encountered. Sections sampled by Shelby tubes are shown as white boxes in the lithology plots. At site LAR9, a clay layer appeared to lie between 8 and $13 \mathrm{ft}$, and the computed erosion rate was low in this region. Two thinner, clay layers appeared further down. Gravel was found at the bottom of the lithology hole, but the hole for the BET did not extend into the gravel layer.

Figure 1.5 shows erosion rate plotted against flow speed for 0.5 -ft intervals of the test hole. To create these plots, the 1 -foot intervals of the profile below the casing and above the bottom of the drilled hole were excluded, and data for each 0.5 -ft section in between were averaged; so for every $0.5-\mathrm{ft}$ section, one pair of erosion-rate and flow-speed data exist. Some erosion rates fell below the measurement-uncertainty threshold of $0.3 \mathrm{in} / \mathrm{hr}$ and were excluded.

Figure 1.6 features a subset of the data points shown in the previous figure, classified by sediment type. The number of data points was fewer because of the lack of lithology information where Shelby tube samples were taken, and the fact that only $1.5 \mathrm{ft}$ out of every $2 \mathrm{ft}$ of the soil column was sampled with Calmod and split spoon samplers.

The field logs revealed only clayey and sandy soils at this site. Only two data points were available defining the clay, and the sand results did not reveal a clear trend with flow speed. The field logs provided finer resolution of the soil classification (silty sand, clayey sand, and so on), but given the qualitative nature of the classification and the number of data points, the decision was made to use broader classifications when plotting. 

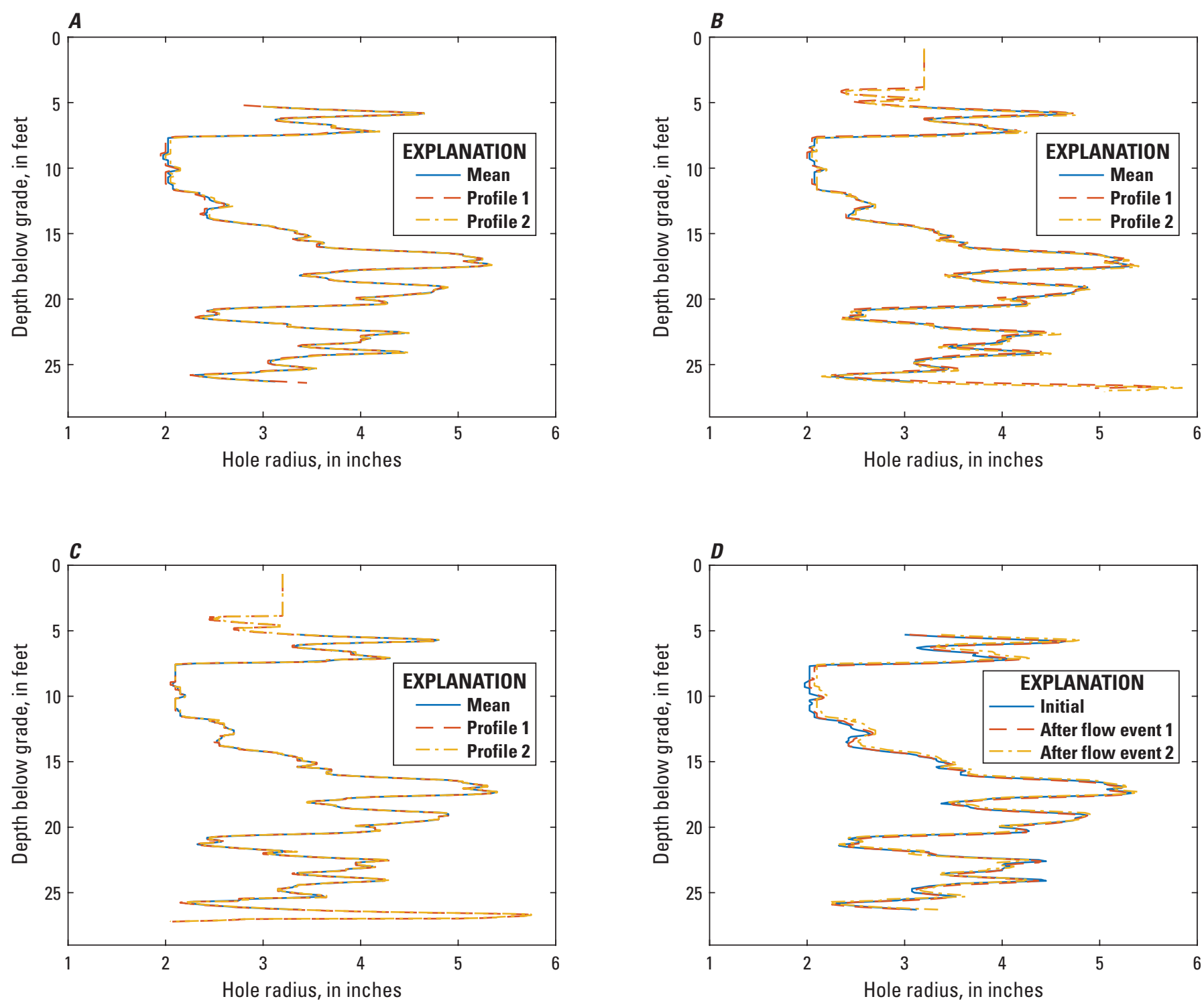

Figure 1.1. Results at site LAR9: $A$, shows the two profiles acquired before testing and the mean of the two results; $B$, shows the condition after flow event $1 ; C$, shows the condition after flow event 2 ; and $D$, shows the evolution of mean profiles for each condition. The mean was computed only for depths represented in all surveyed profiles.

This result illustrates one of the problems that was encountered in many of the tests. Even for sediments that fell within the same general broad categories (sand, silt, and clay), the erosion rates at a given site varied widely. One layer classified as sand eroded at $2 \mathrm{in} / \mathrm{hr}$ at a flow speed of less than $1 \mathrm{ft} / \mathrm{s}$, whereas another layer also classified as sand, eroded at approximately $0.3 \mathrm{in} / \mathrm{hr}$ (the detection limit) at a flow speed of more than $3 \mathrm{ft} / \mathrm{s}$. 


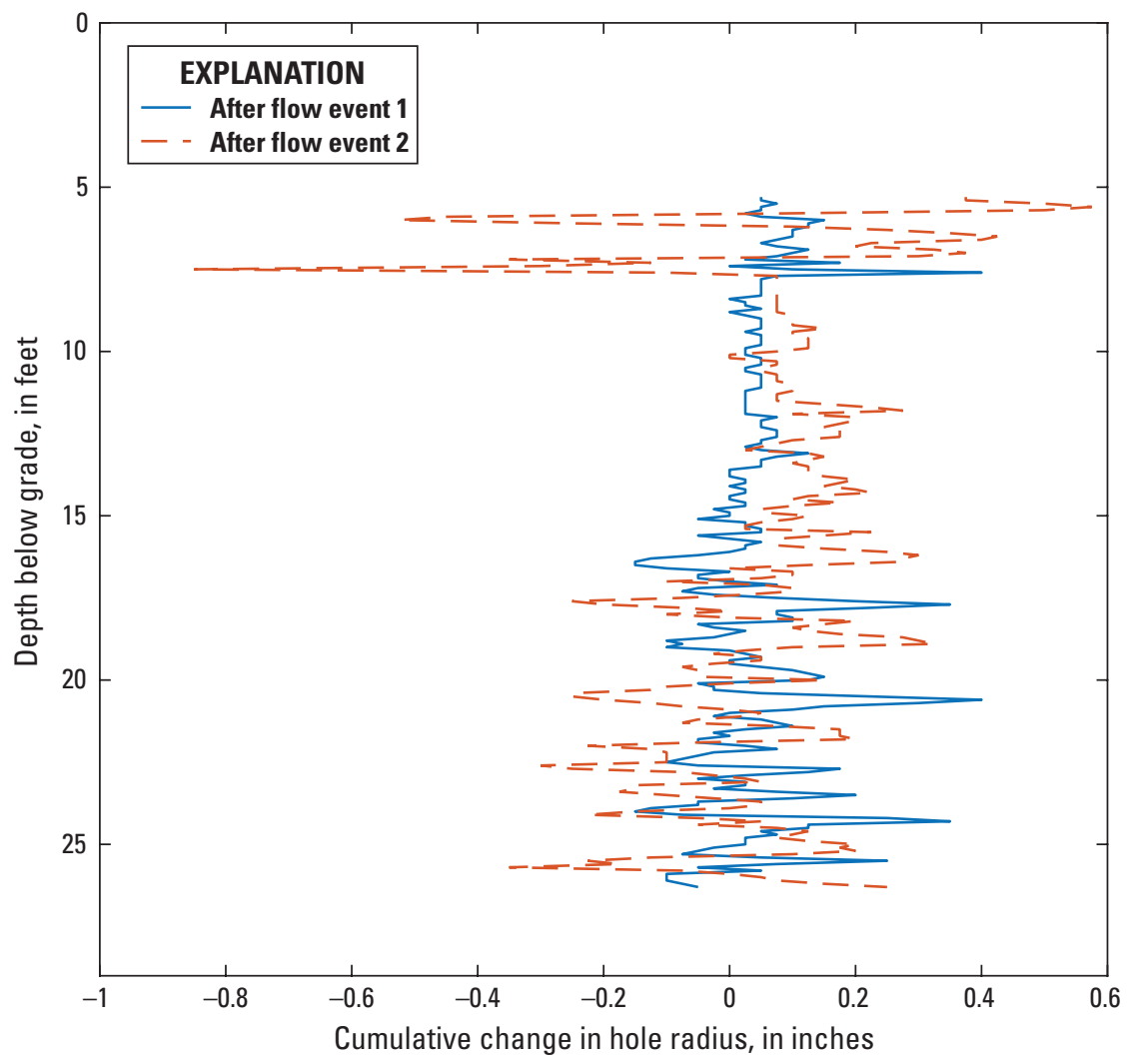

Figure 1.2. Cumulative change in hole radius versus depth below grade at site LAR9. Each result represents the mean of all profiles surveyed at a given time. Positive change means radius has increased. 

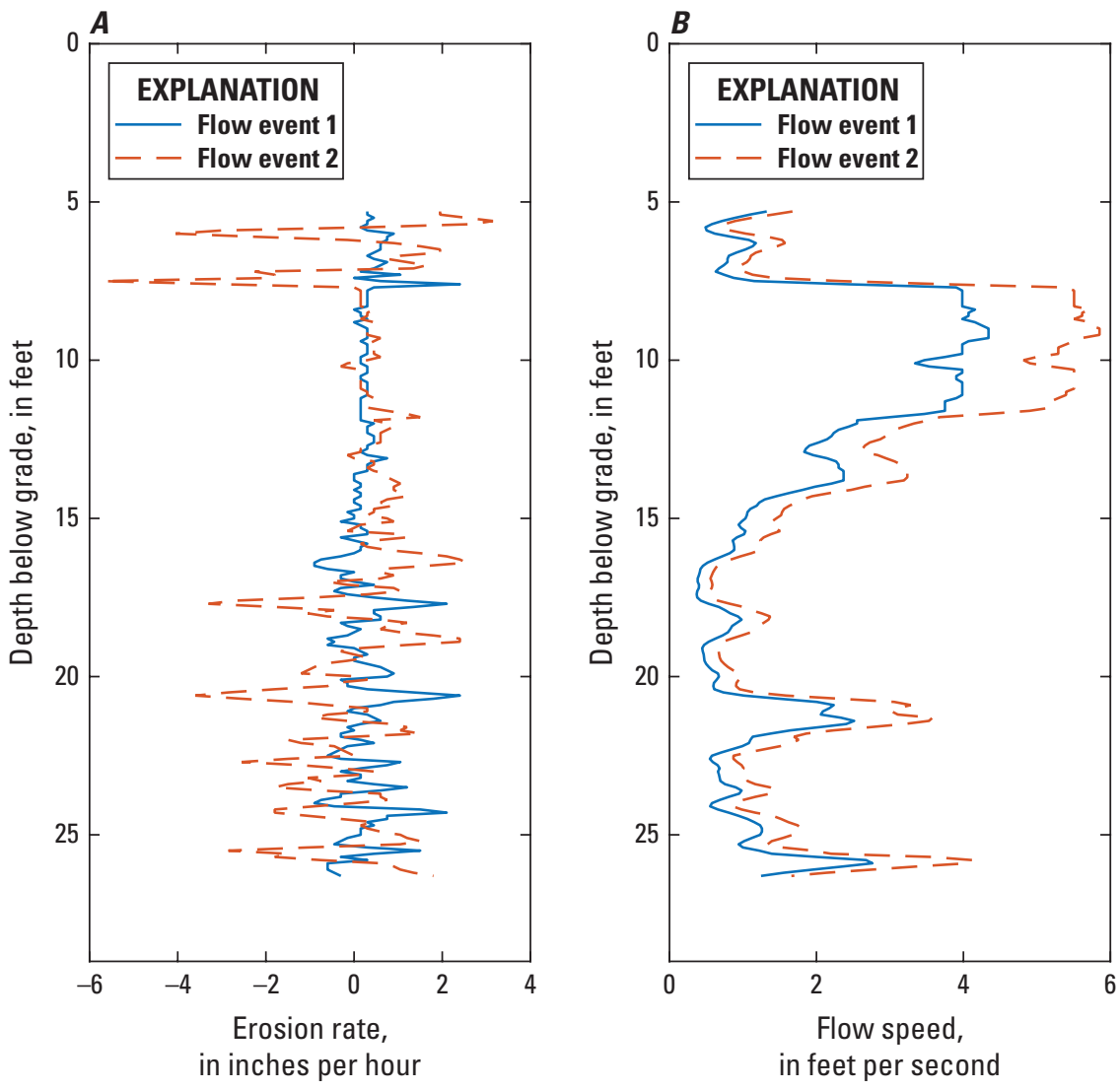

Figure 1.3. Site LAR9: $A$, computed erosion rate versus depth below grade; and $B$, mean flow speed versus depth below grade. 

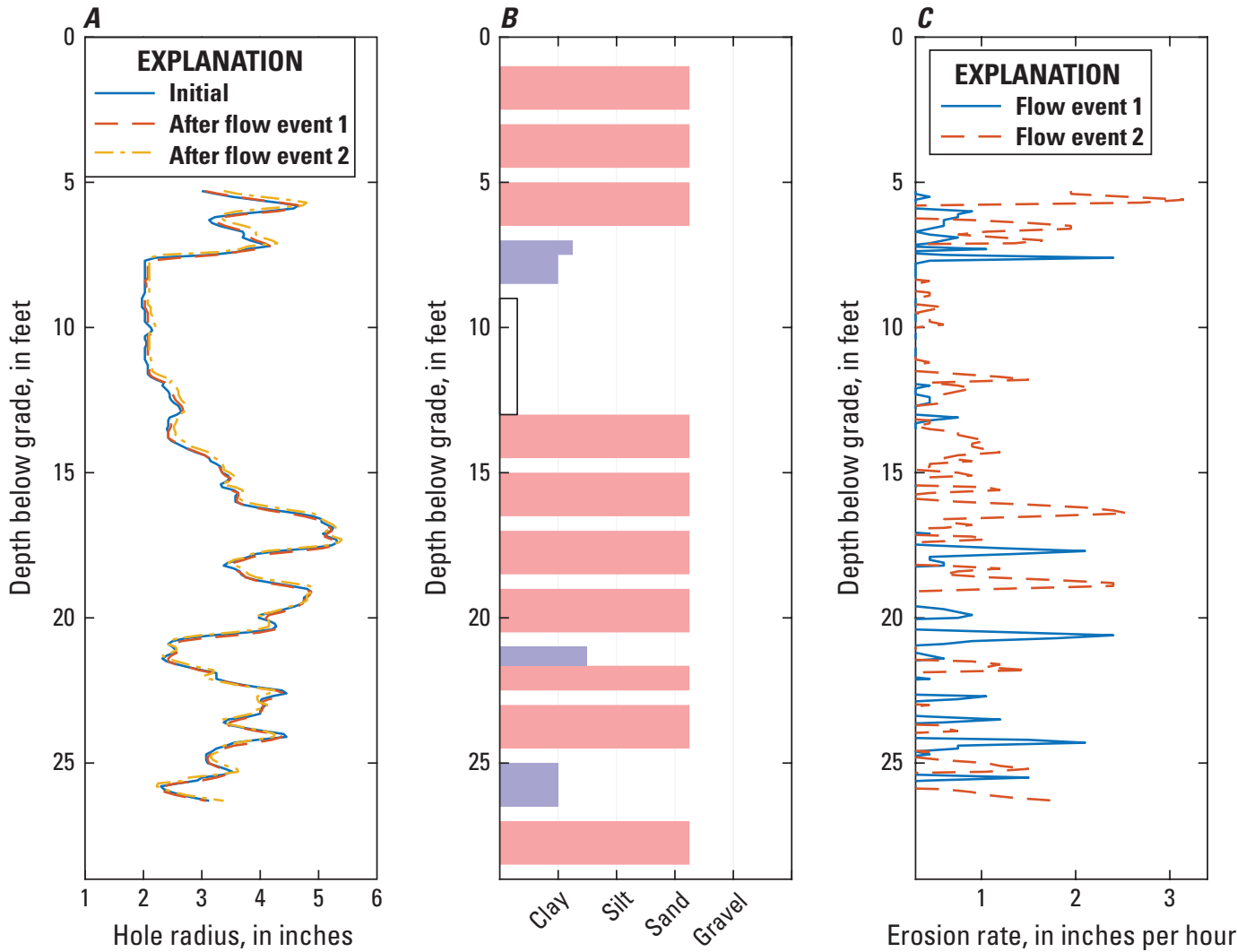

Figure 1.4. Site LAR9 borehole: $A$, mean profiles, $B$, lithology, and $C$, erosion rate. In the lithology plot, a white box indicates a Shelby tube sample. Clays are purple, silts are green, sands are red, and gravels are black. 


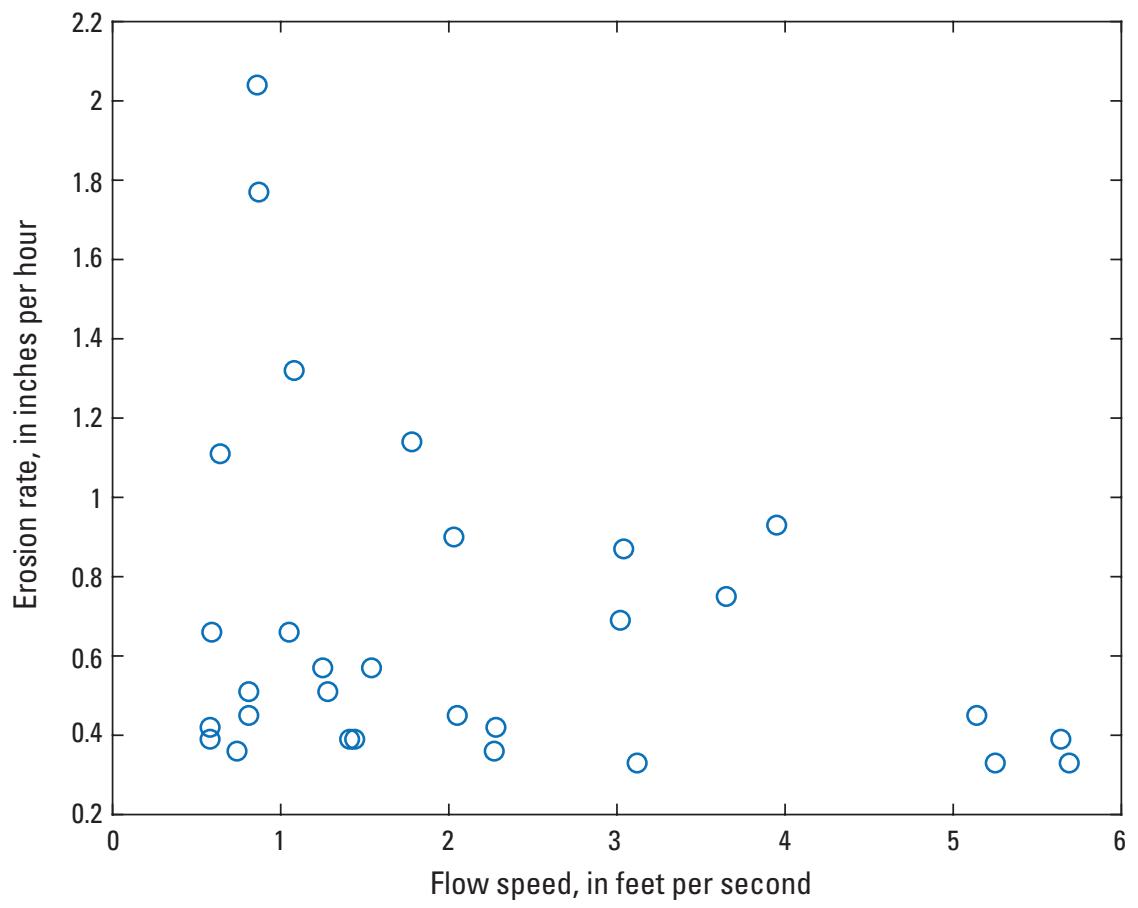

Figure 1.5. Erosion rate versus flow speed at site LAR9 based on data collected between 5.5- and 24-feet-below grade. Each point represents one 6-inch layer of soil. Computed erosion rates less than 0.3 inch per hour (measurement resolution for a 10-minute test) were excluded.

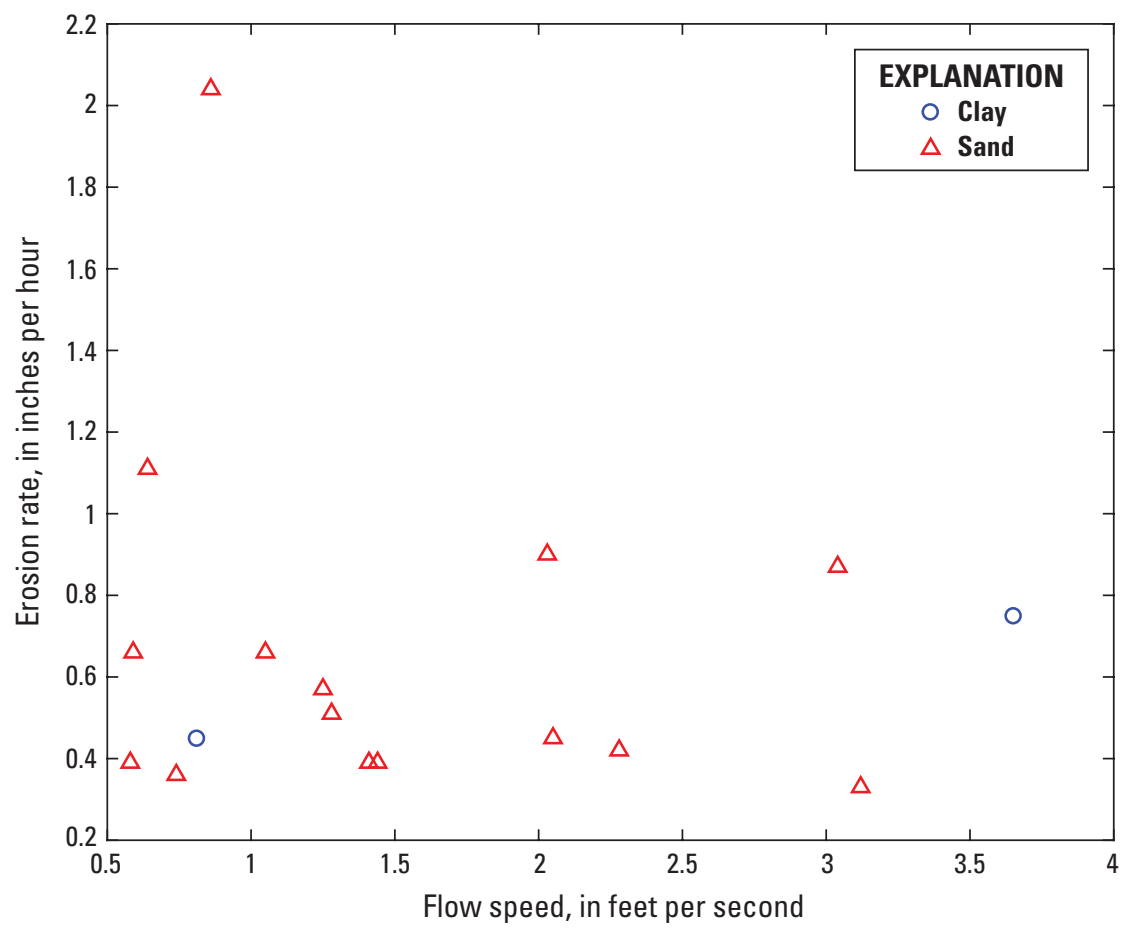

Figure 1.6. Erosion rate versus flow speed and sediment classification based on data collected between 5.5- and 24-feet-below grade, at site LAR9. 


\section{Site LAR12}

A test was conducted at only one discharge at this site because of a hydraulic line failure at the end of the first test. The initial profile was surveyed four times over a period of 2.5 hours while equipment problems were being addressed, and there was some evidence of slumping during this period; because of this, the test at site LAR12 was removed from

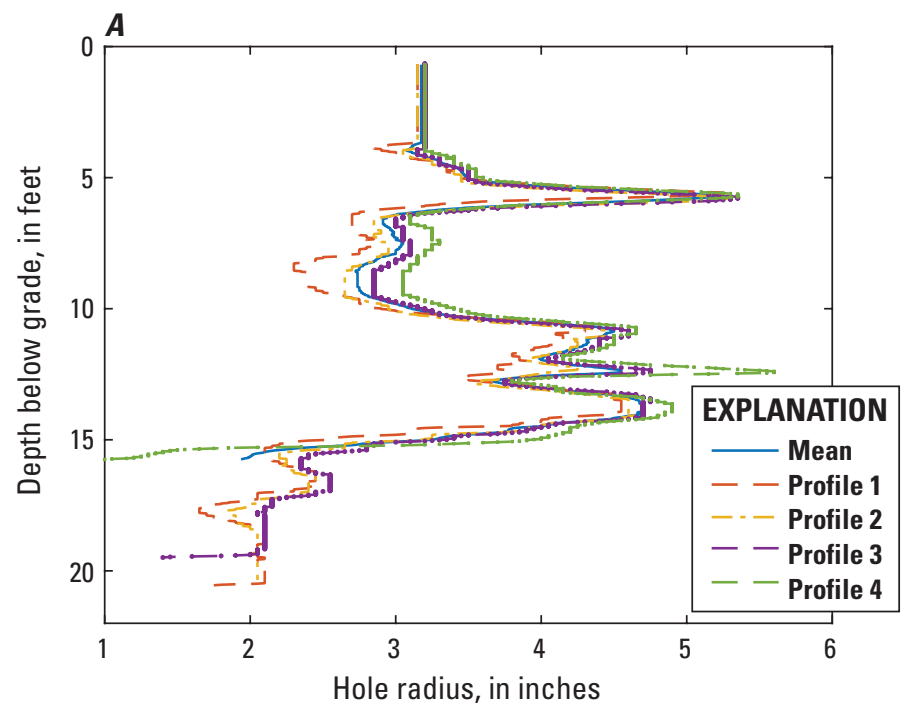

further consideration, and the test strategy was modified to focus on regions above the local water table, to reduce slumping within the drilled hole.

The lithology log for this site shows sand throughout the region that was drilled for the BET. Gravel was found deeper into the soil column.

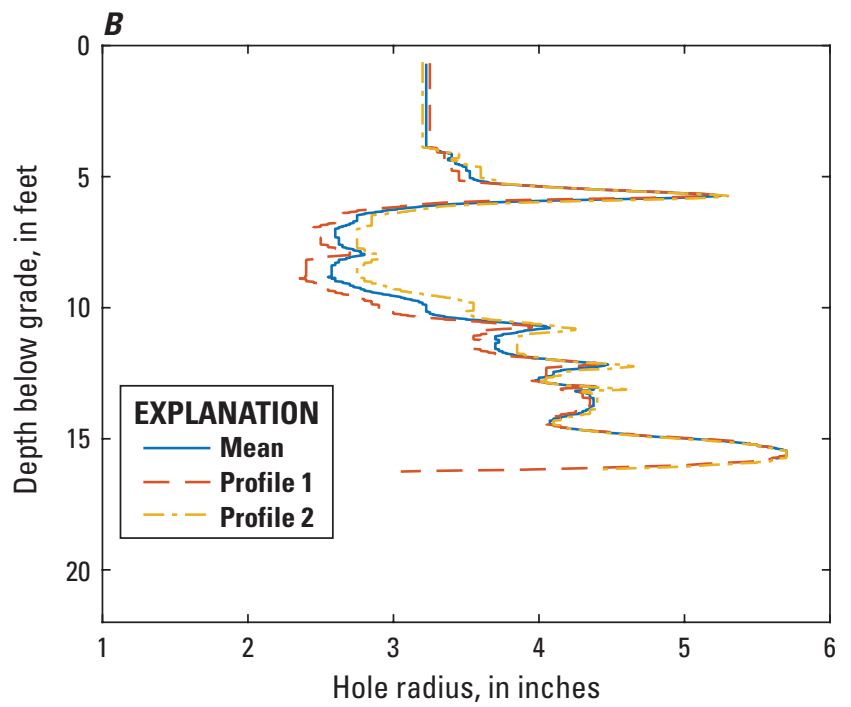

Figure 1.7. Results from site LAR12: $A$, shows the four profiles acquired before testing and the mean of the four results; and $B$, shows the condition after the first flow event, which was surveyed twice. The mean was computed only for depths represented by all surveyed profiles. 


\section{Site LAR7}

This test was performed with two discharges in sandy soils, with the first discharge being smaller than the second. Maximum velocity in the second flow event was $9.3 \mathrm{ft} / \mathrm{s}$, but this flow produced almost no measurable erosion. The most substantial erosion was immediately below the casing and immediately above the hole bottom, where the test water exits the drilling rod. Because the flow in these regions is not parallel to the hole walls, those regions were excluded from calculations when computing erosion-rate velocity pairs. Erosion rates were low (less than $0.5 \mathrm{in} / \mathrm{hr}$ ) during the first flow event in most of the remaining hole, and despite the higher discharge, the erosion rates were unmeasurable (less than $0.3 \mathrm{in} / \mathrm{hr}$ ) during the second flow event, except at depths just beneath the bottom of the casing. The erosion-rate
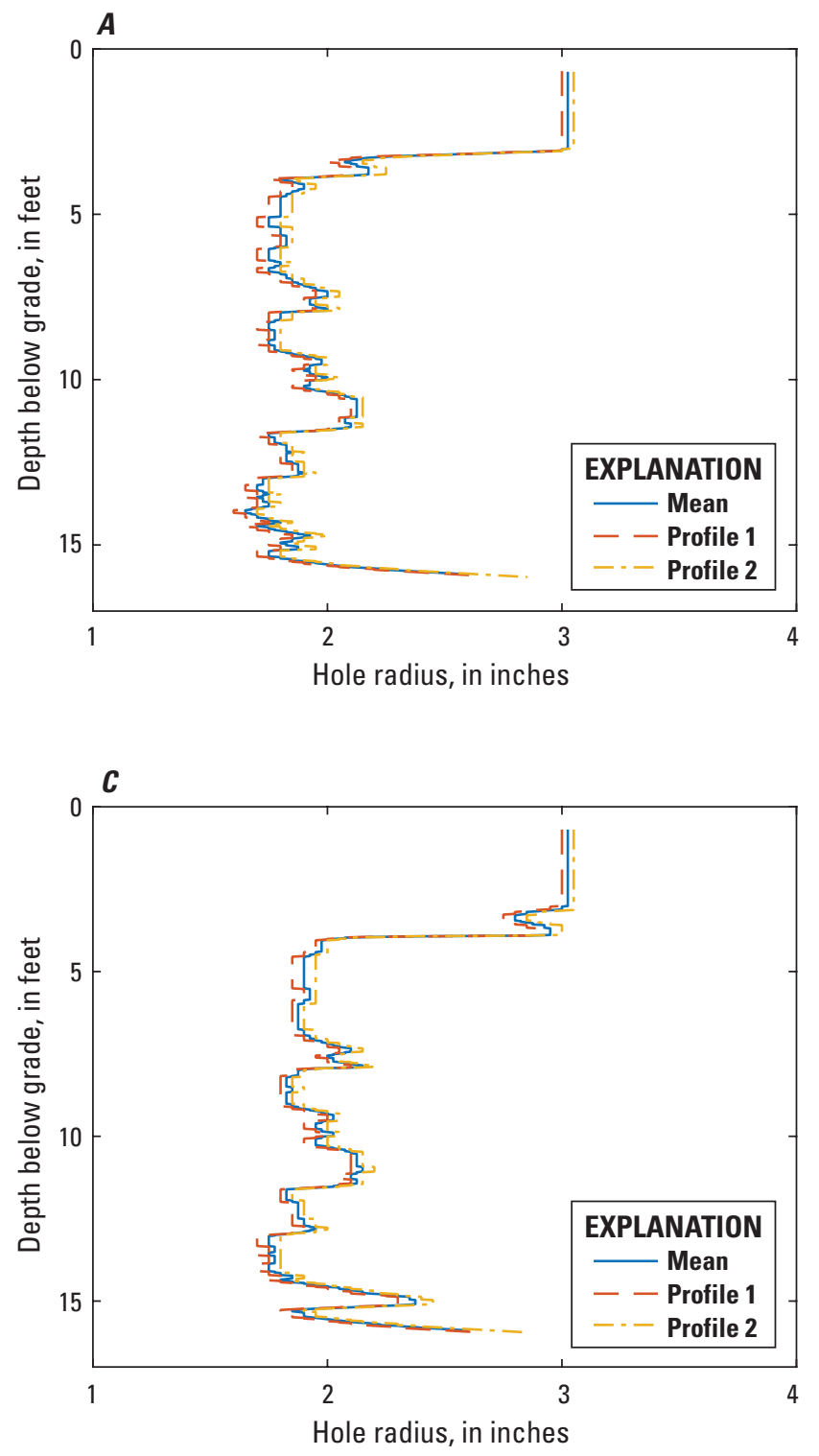

profile is fairly uniform, as is the lithology, other than a thin clay layer.

It is not clear why the second test, with much higher flow speeds, exhibited lower erosion rates than the first test. A few hypotheses were considered: (1) the first test selectively eroded the walls of the hole, leaving it armored against further erosion, (2) the drilling process loosened a thin layer of soil that was eroded during the first test, leaving more durable soil behind for the second test, or (3) the first test introduced additional water into the soil and modified its strength. It is not possible to investigate these ideas conclusively with the available data, but the second hypothesis seems the most likely of the three.
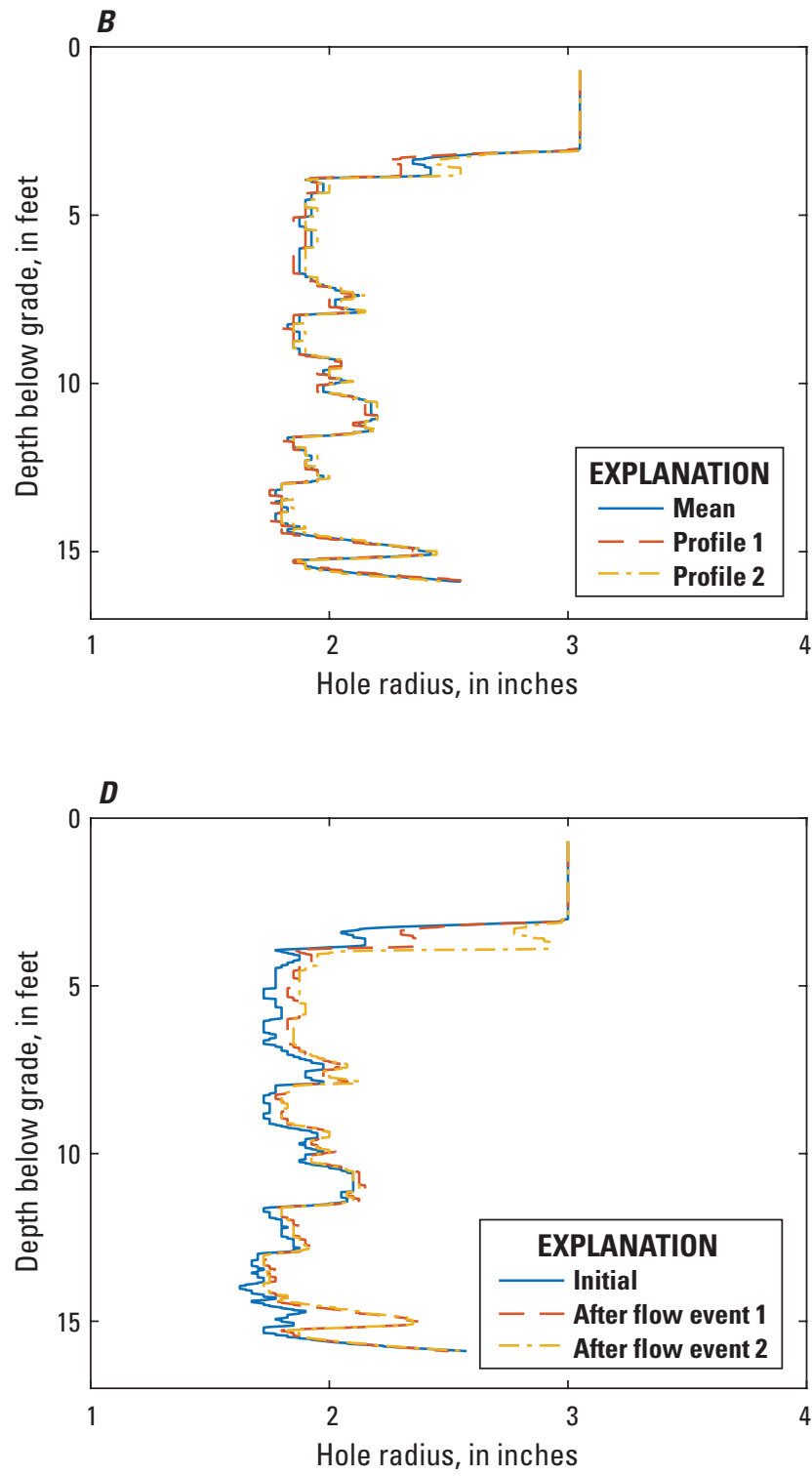

Figure 1.8. Results at site LAR7: $A$, shows the two profiles acquired before testing and the mean of the two results; $B$, shows the condition after the first flow event; $C$, shows the condition after the second flow event; and $D$, shows the time series of the mean profiles with radius correction, which were computed only for depths represented in all surveyed profiles. 

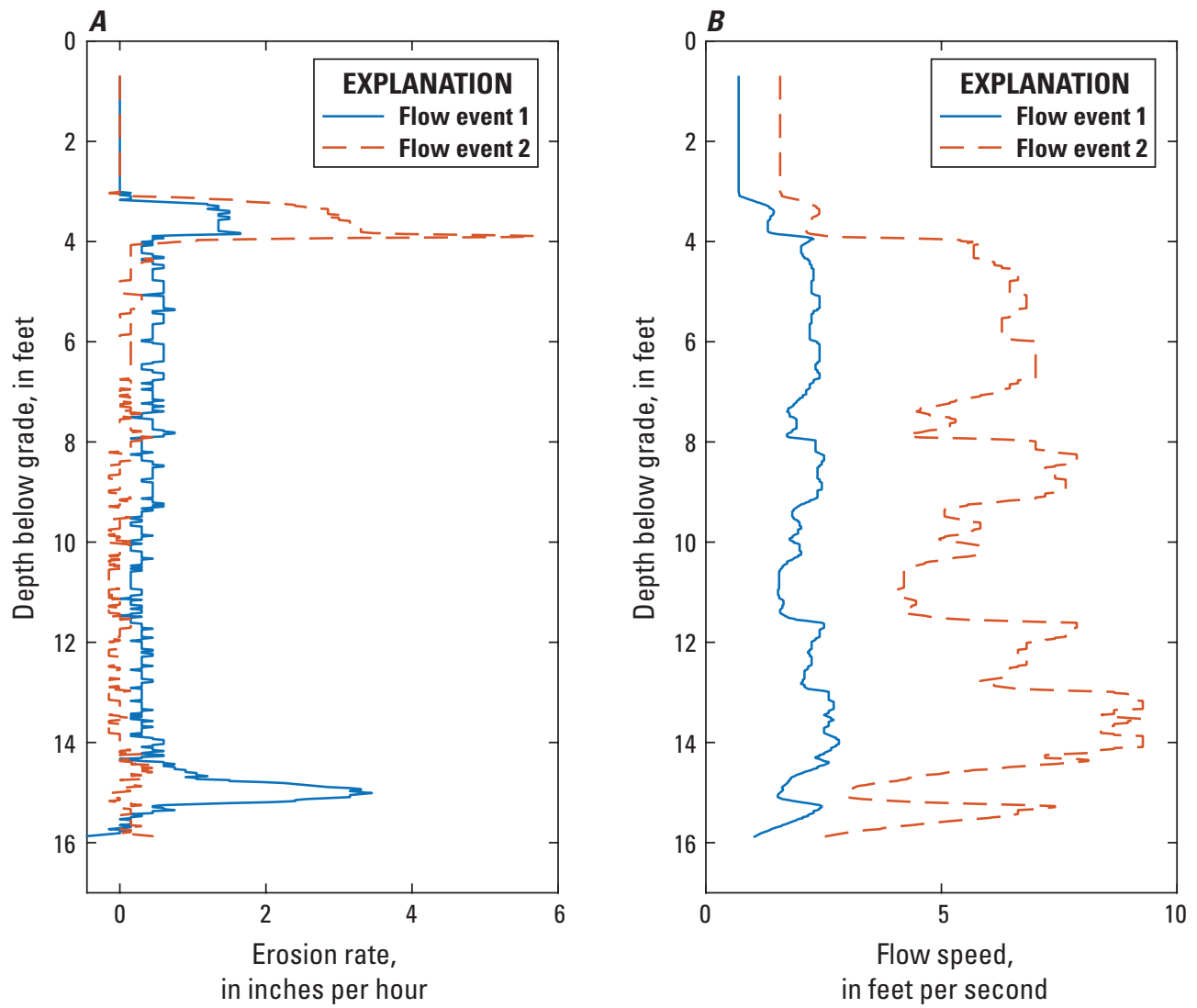

Figure 1.9. Site LAR7: $A$, computed erosion rate versus depth below grade; and $B$, mean flow speed versus depth below grade. 

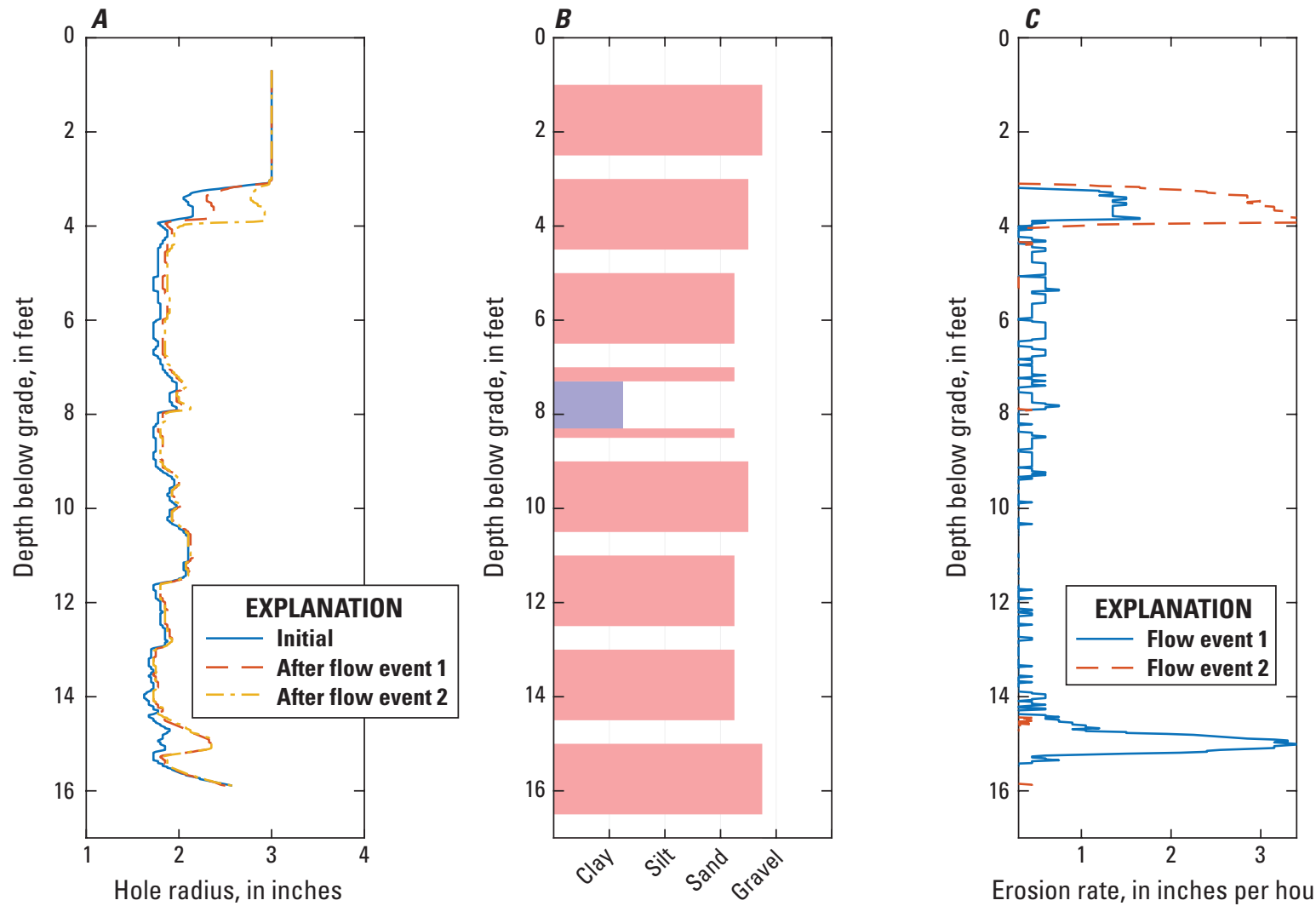

Figure 1.10. Site LAR7 borehole: $A$, mean profiles, $B$, lithology, and $C$, erosion rate. Clays are purple, silts are green, sands are red, and gravels are black. 


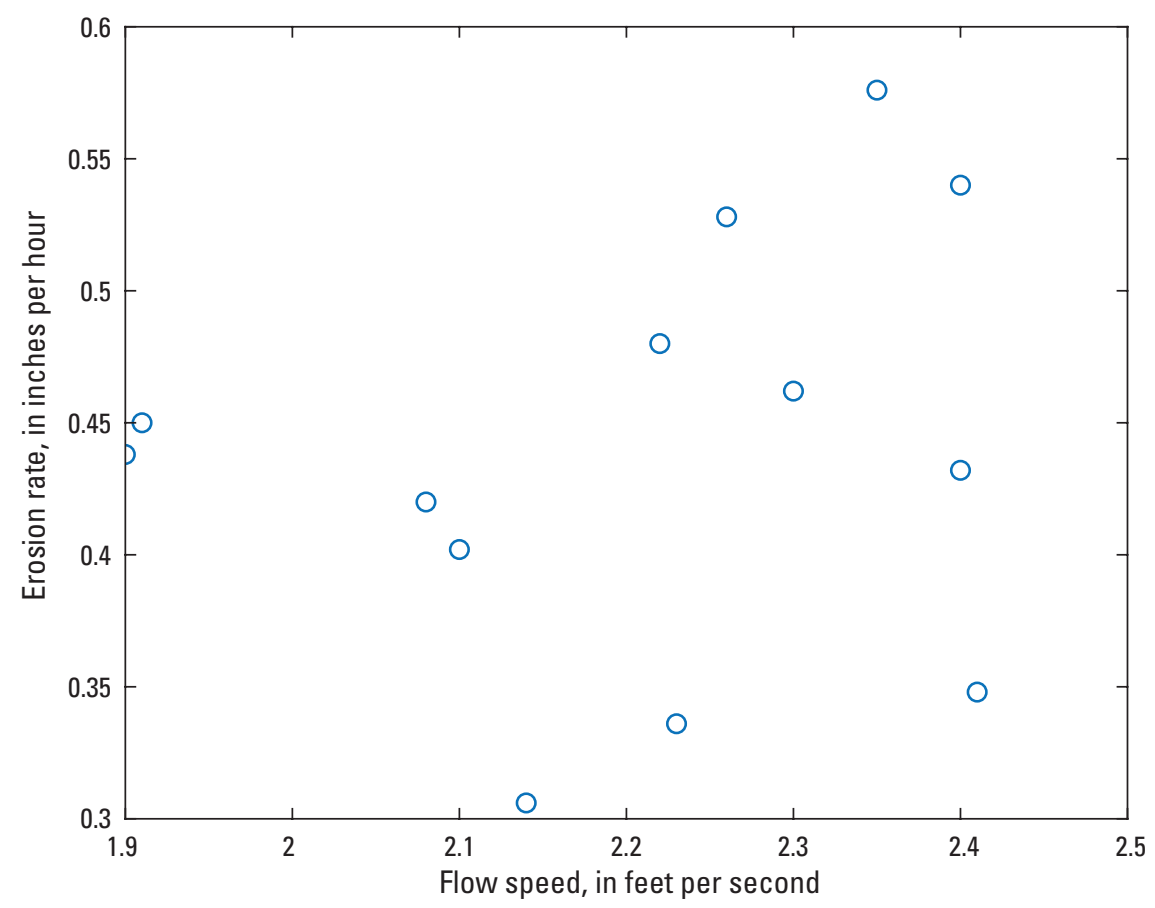

Figure 1.11. Erosion rate versus flow speed at site LAR7 based on data collected between 4- and 14-feet-below grade. Each point represents one 6-inch layer of soil. This plot shows only results from the first of the two flow events, because there was no measurable erosion in the second test, despite much higher flow speeds.

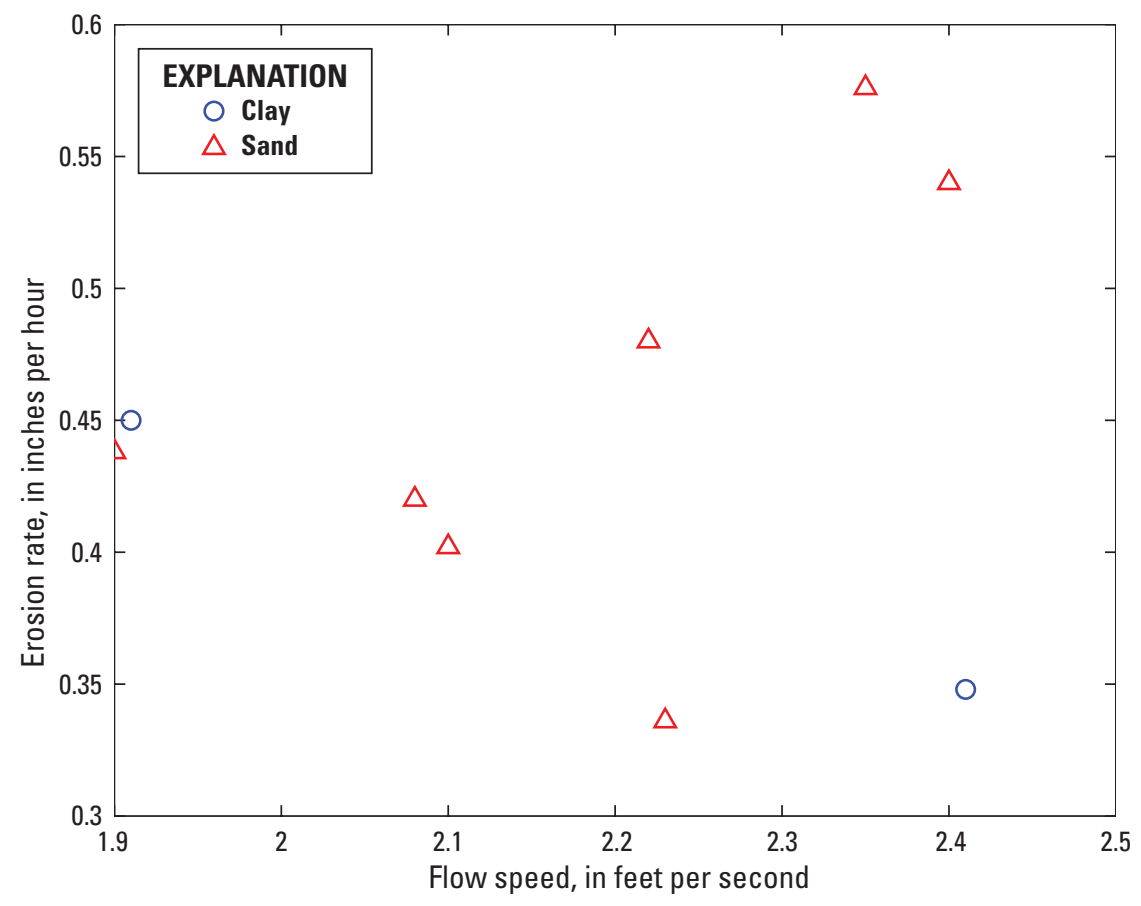

Figure 1.12. Erosion rate versus flow speed and sediment classification based on data collected between 4- and 14-ft-below grade, at site LAR7. This plot shows only results from the first of the two flow events, because there was no measurable erosion in the second test, despite much higher flow speeds. 


\section{Site SAC1}

This site featured approximately $10 \mathrm{ft}$ of sandy soil overlying what is likely a thick clay layer. The order of operations was reversed, compared to previous tests, such that the highest discharge test was done first, resulting in peak-flow speeds above $9 \mathrm{ft} / \mathrm{s}$. This strategy was used for subsequent tests as well. Erosion rates were computed between 6- and 25 -ft-below grade, so most of the available erosion-rate data are for clayey soils. Erodibility increased with depth below grade, in general.
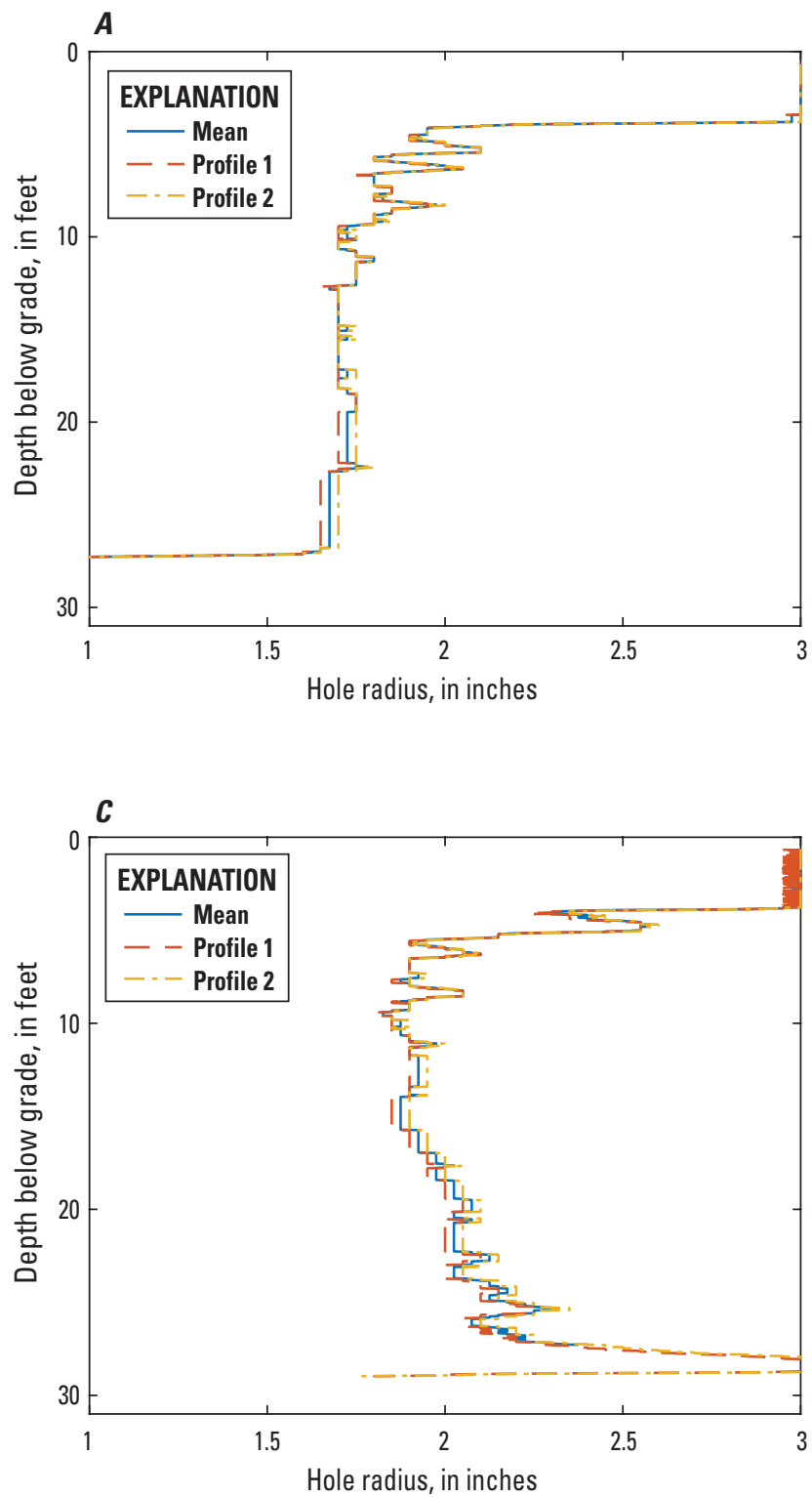

Although there is still considerable scatter, this test revealed clearer trends than the plots from other tests. Data for the clay and sand layers revealed an increase in erosion rate with flow speed and, as expected, the increase appears to be nonlinear based on the nonlinear relationship between velocity and shear stress. However, also note that there was much variability in the clay layers: at flow speeds near $8 \mathrm{ft} / \mathrm{s}$, erosion rates varied by a factor of 3 , from approximately 0.6 to $1.8 \mathrm{in} / \mathrm{hr}$.
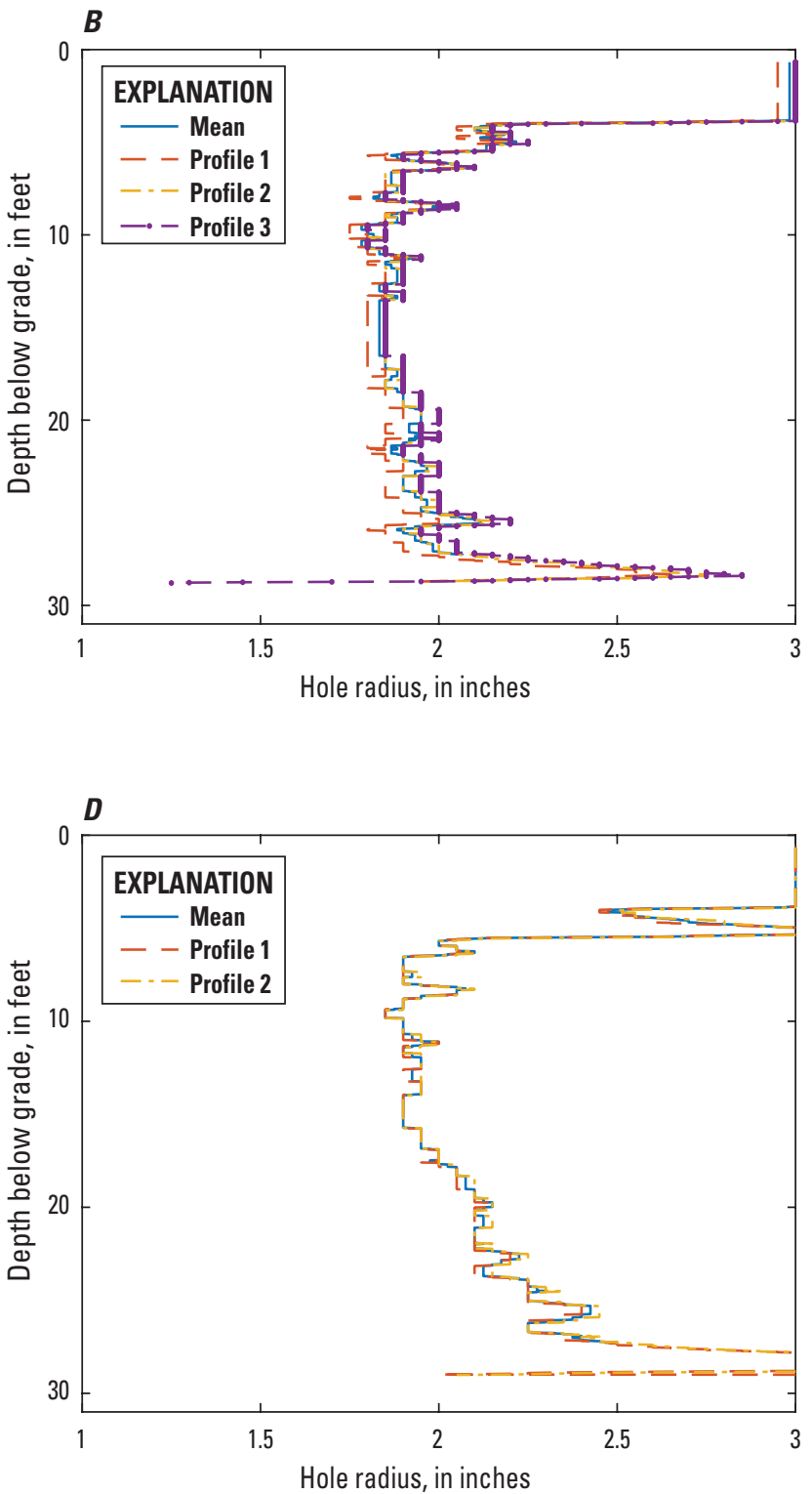

Figure 1.13. Results at site SAC1: $A$, shows the two profiles acquired before testing and the mean of the two results; $B$, shows the condition after flow event $1 ; C$, shows the conditions after flow event 2 ; and $D$, shows the conditions after flow event 3 . The mean was computed only for depths represented in all surveyed profiles. 


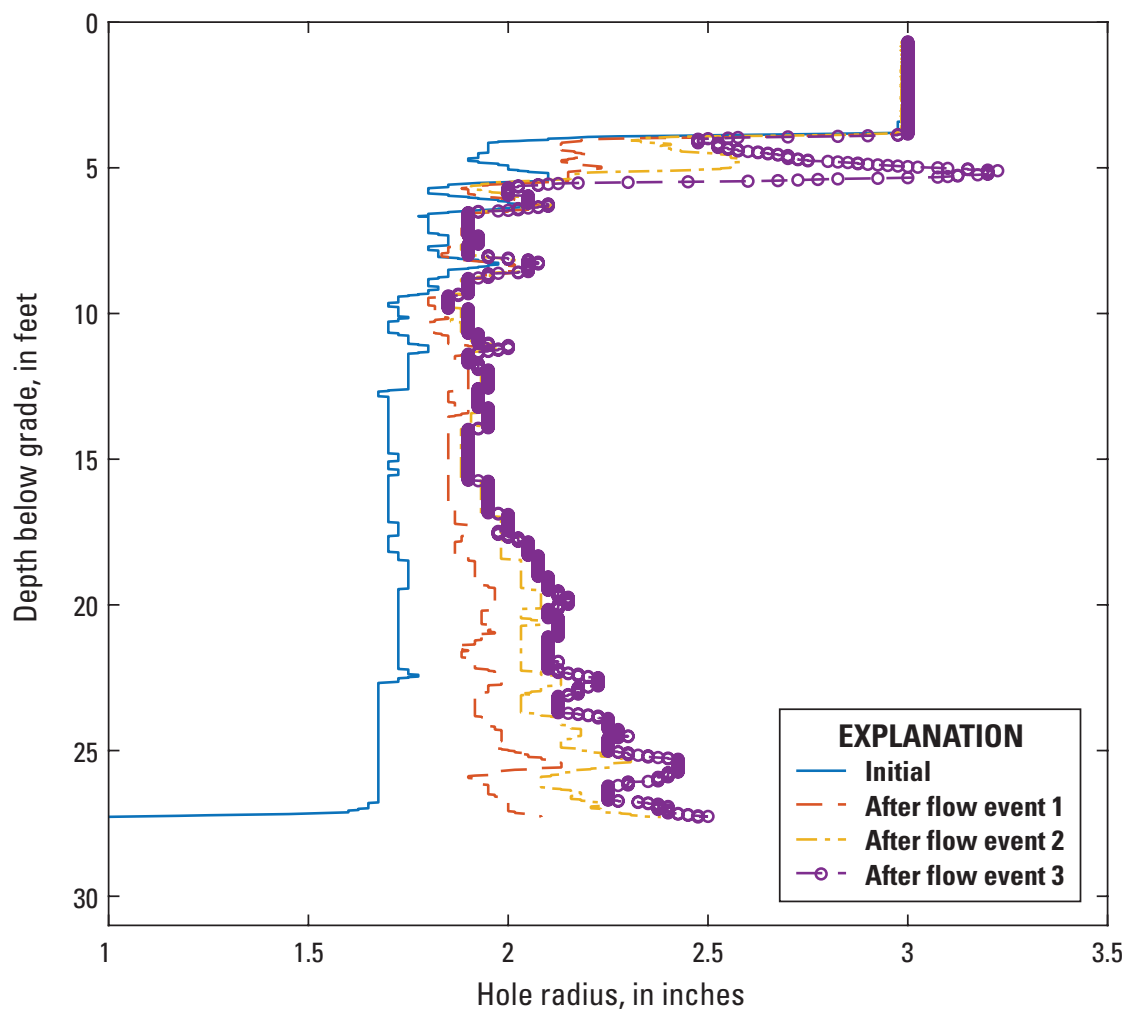

Figure 1.14. The evolution of mean profiles, with radius correction, for each condition at site SAC1: Initial and after flow events 1,2, and 3. The highest discharge test was done first. 

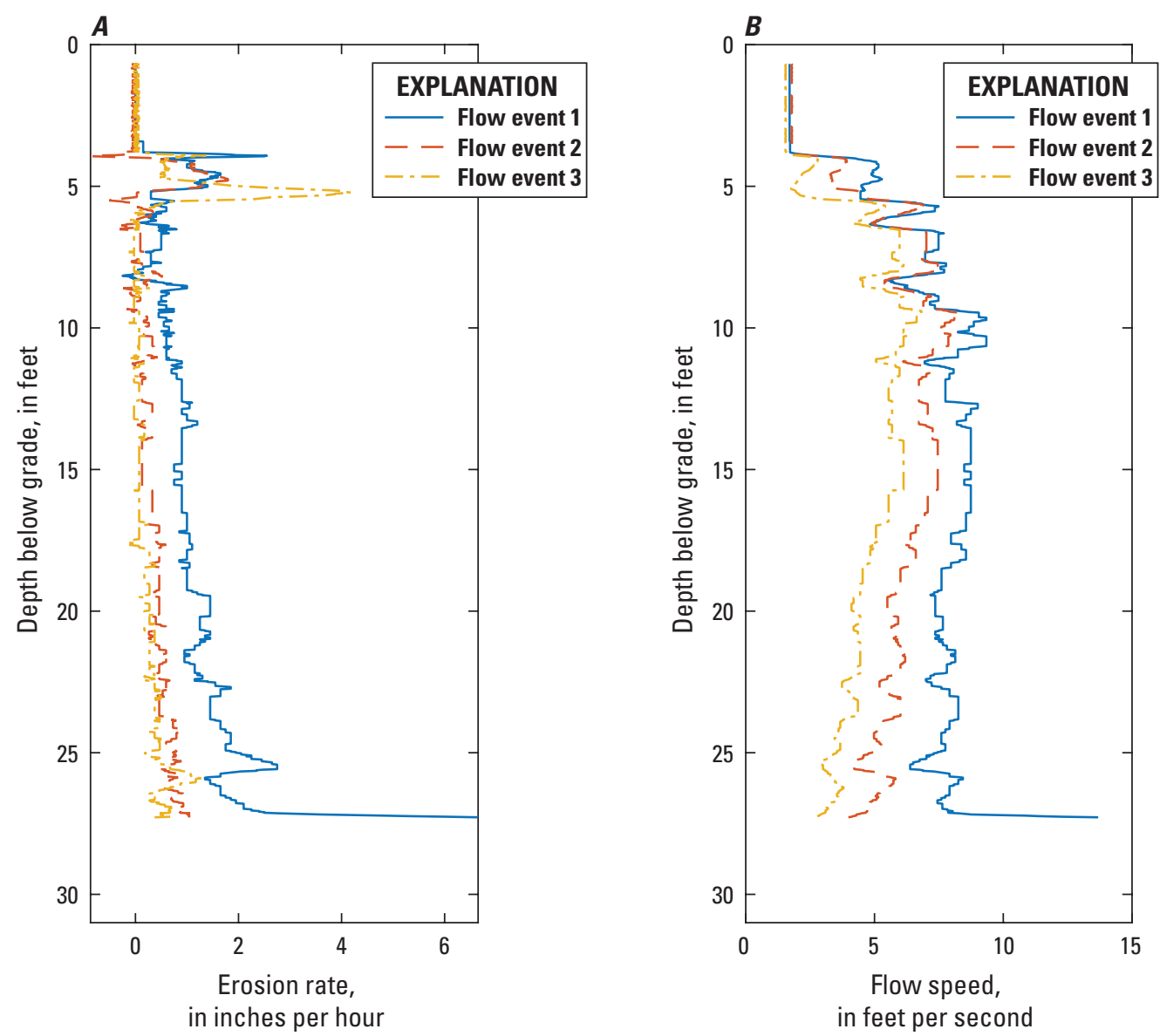

Figure 1.15. Site SAC1: $A$, computed erosion rate versus depth below grade; and $B$, mean flow speed versus depth below grade. 

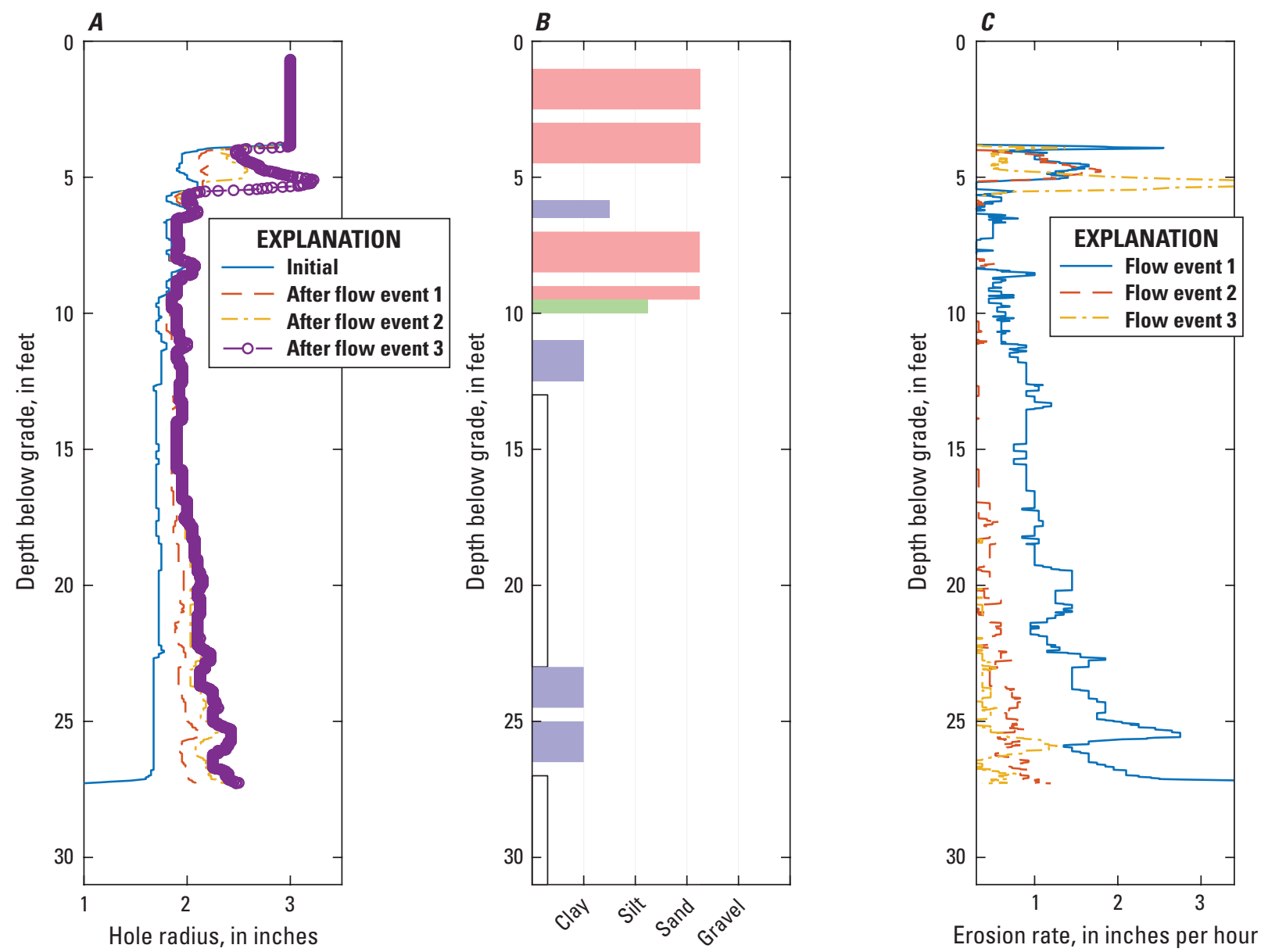

Figure 1.16. Site SAC1 borehole: $A$, mean profiles, $B$, lithology, and $C$, erosion rate. In the lithology plot, a white box indicates a Shelby tube sample. Clays are purple, silts are green, sands are red, and gravels are black. 


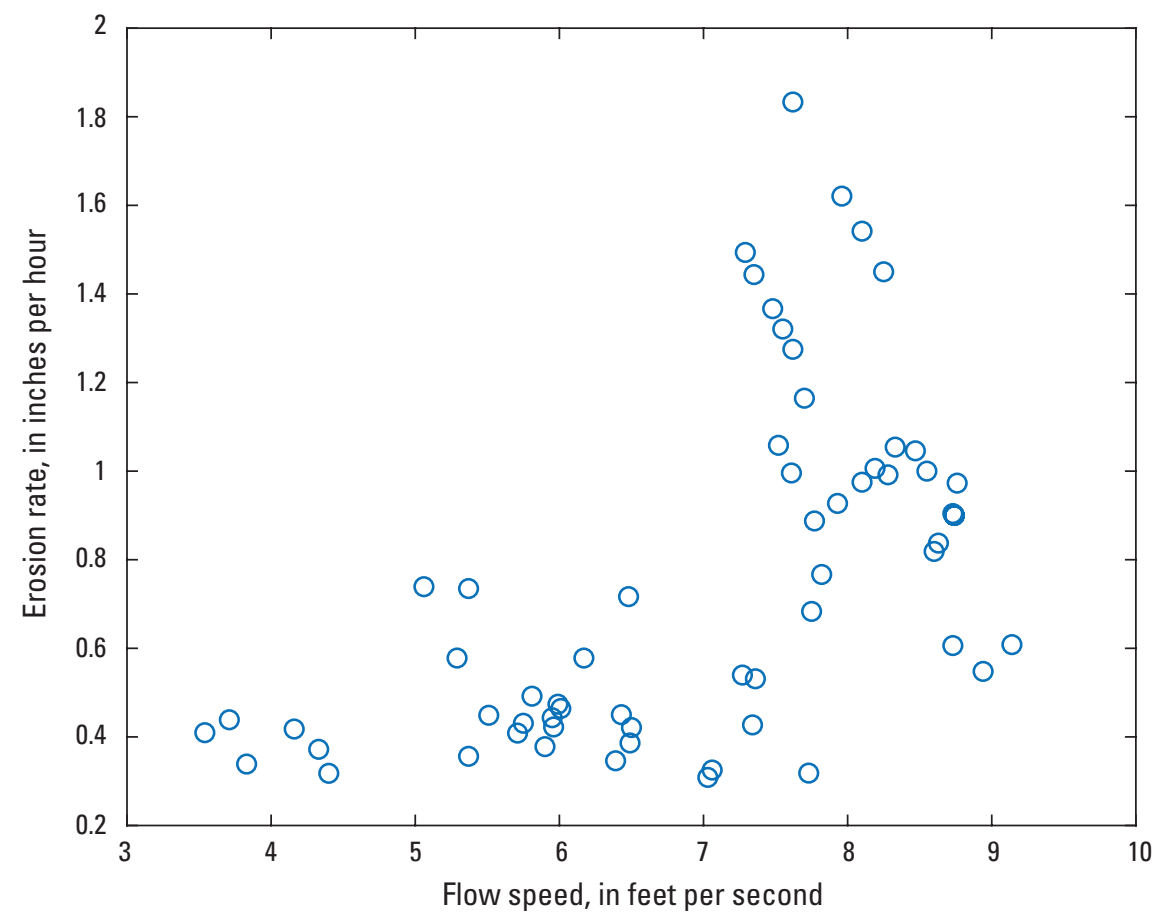

Figure 1.17. Erosion rate versus flow speed at site SAC1 based on data collected between 6 - and 25 -feet-below grade. Each point represents one 6 -inch layer of soil.

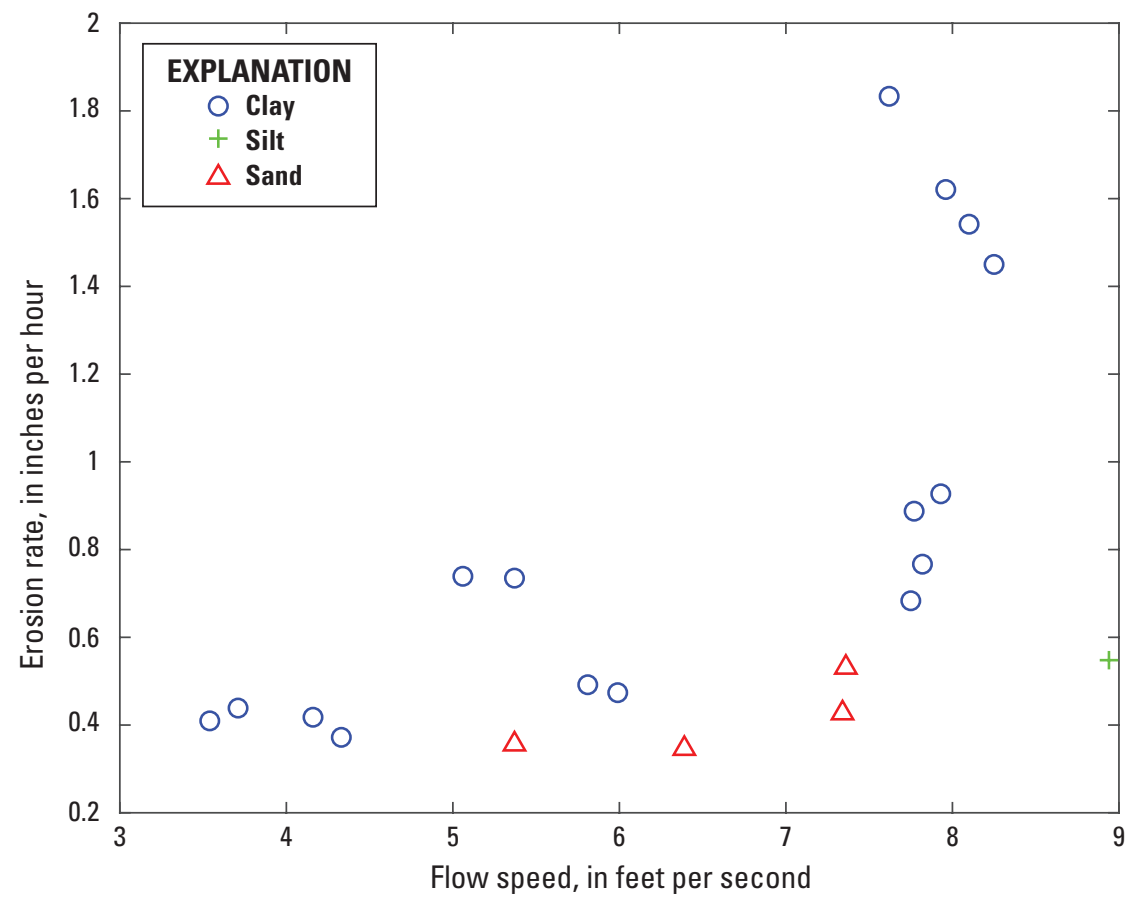

Figure 1.18. Erosion rate versus flow speed and sediment classification at site SAC1 based on data collected between 6- and 25-feet-below grade. 


\section{Site SAC7}

This test was performed in sediments that were primarily sandy silts. Aside from very high erosion just below the bottom of the casing section, there was little vertical structure to the erosion profile. Peak velocity passed the $12 \mathrm{ft} / \mathrm{s}$ target in one section of the hole.

The site LAR7 and site SAC7 test results are quite different. At site LAR7, the higher (second) discharge
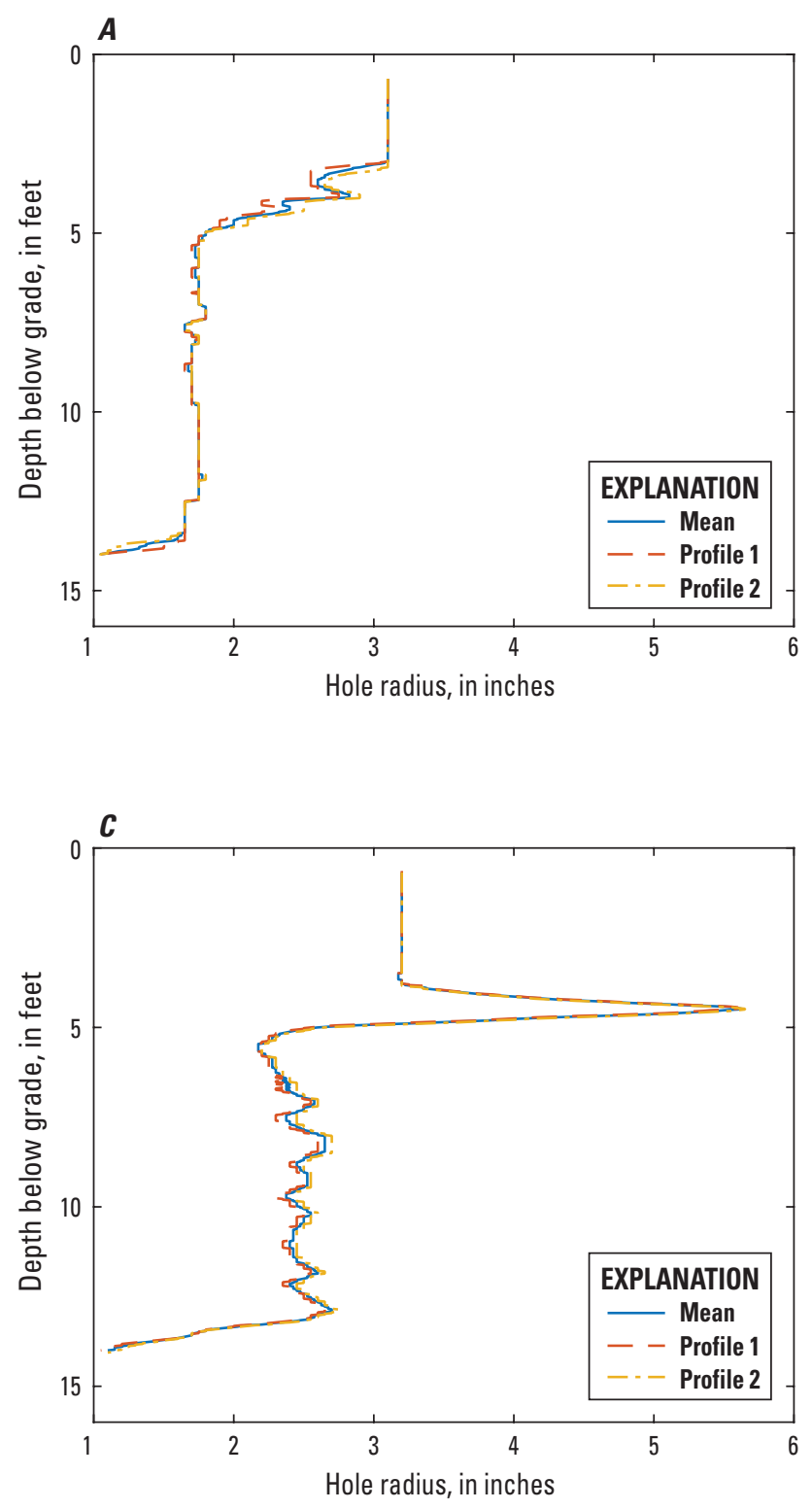

resulted in lower erosion rates than the first test with lower flow speeds. At site SAC7, erosion rates displayed very little sensitivity to flow speed. In fact, in portions of the hole, the second (lower) discharge resulted in greater erosion rates than the first, despite the flow speed being cut nearly in half. The lithology at the two sites is quite different (sands at site LAR7 and silts at site SAC7) but is relatively uniform at both.
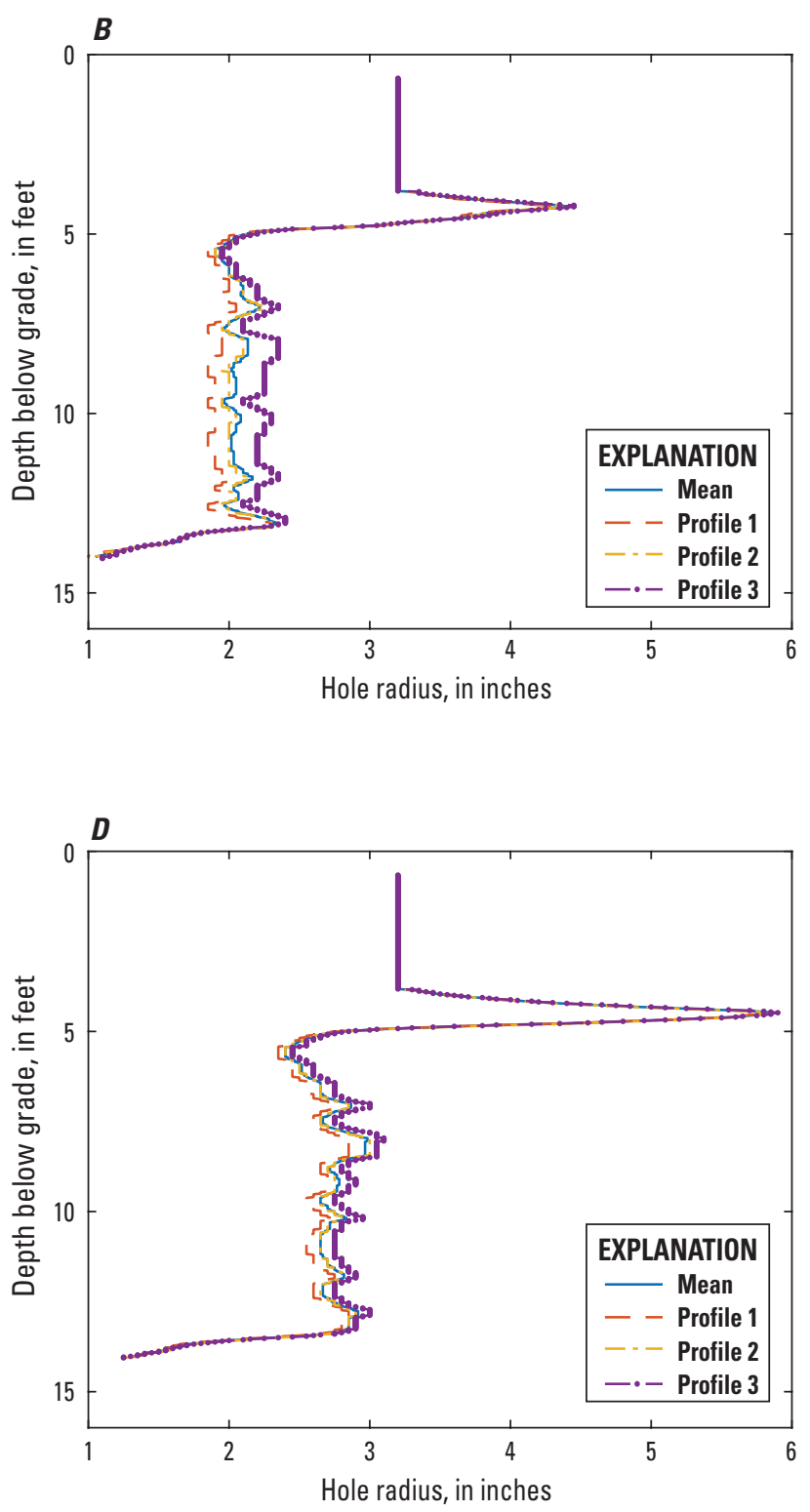

Figure 1.19. Results at site SAC7: $A$, shows the two profiles acquired before testing and the mean of the two results; $B$, shows the condition after flow event $1 ; C$, shows the condition after flow event 2 ; and $D$, shows the condition after flow event 3 . The mean was computed only for depths represented in all surveyed profiles. 


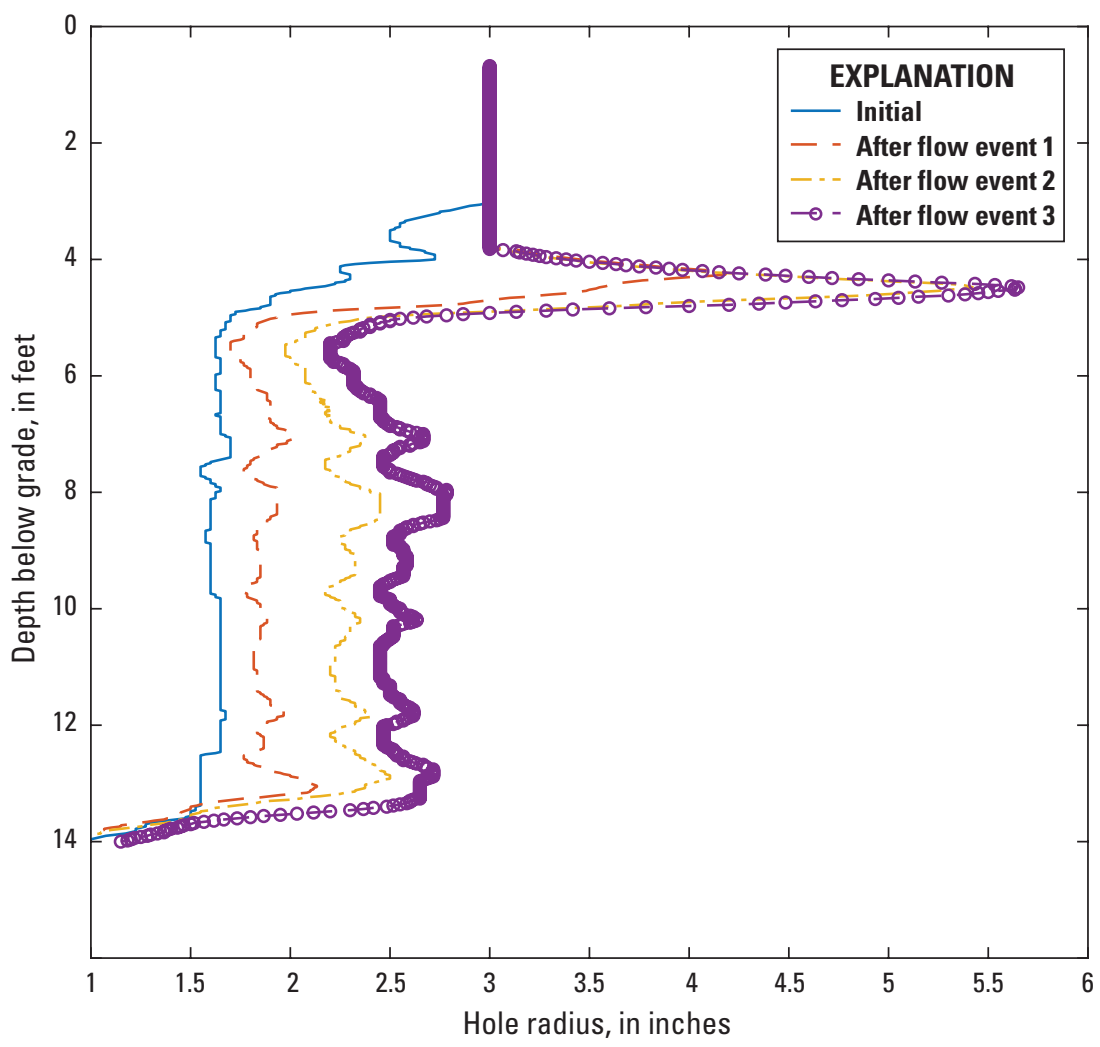

Figure 1.20. The evolution of mean profiles with radius correction for each condition at site SAC7: Initial and after flow events 1, 2, and 3. 

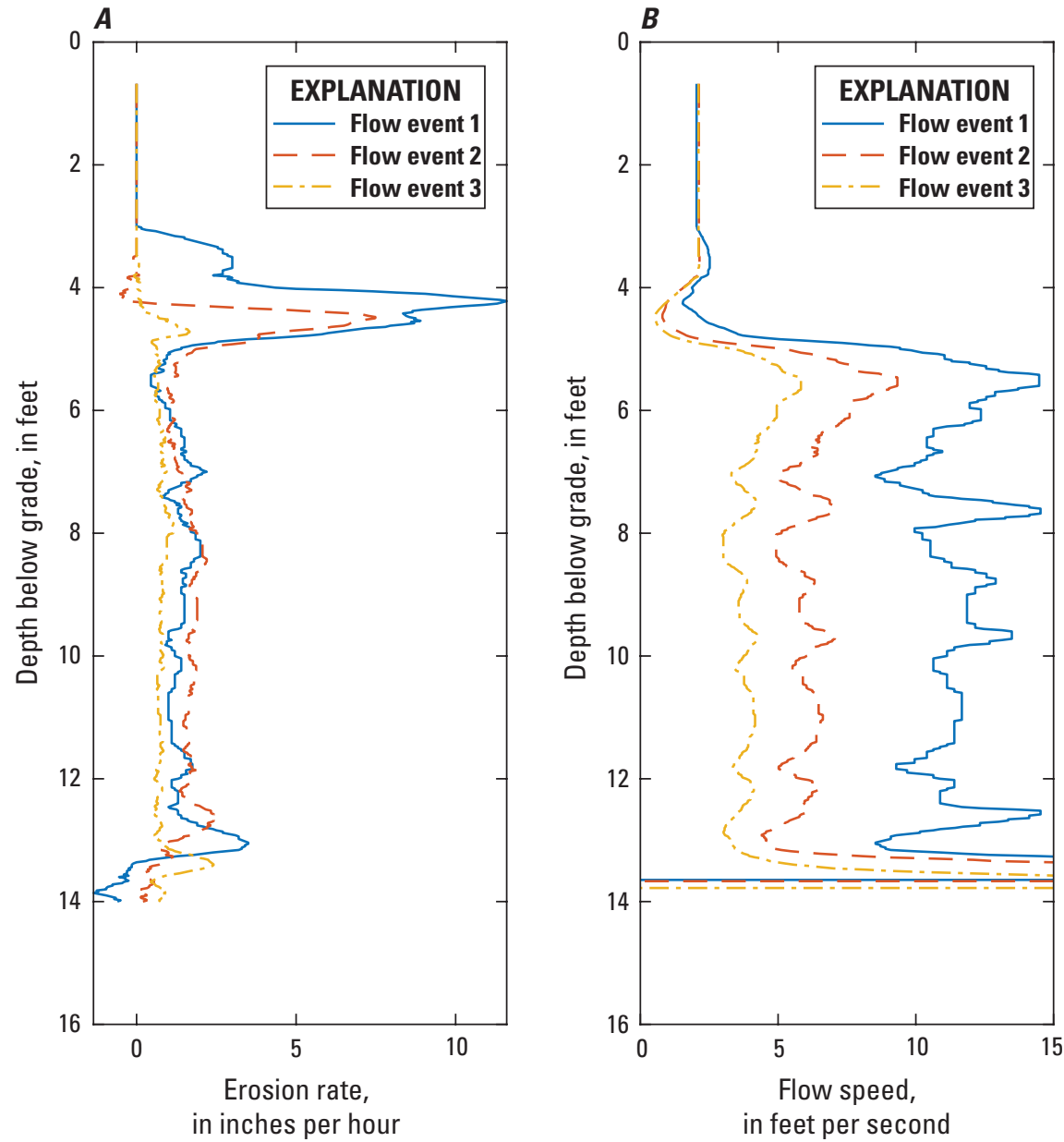

Figure 1.21. Site SAC7: $A$, computed erosion rate versus depth below grade; and $B$, mean flow speed versus depth below grade. 

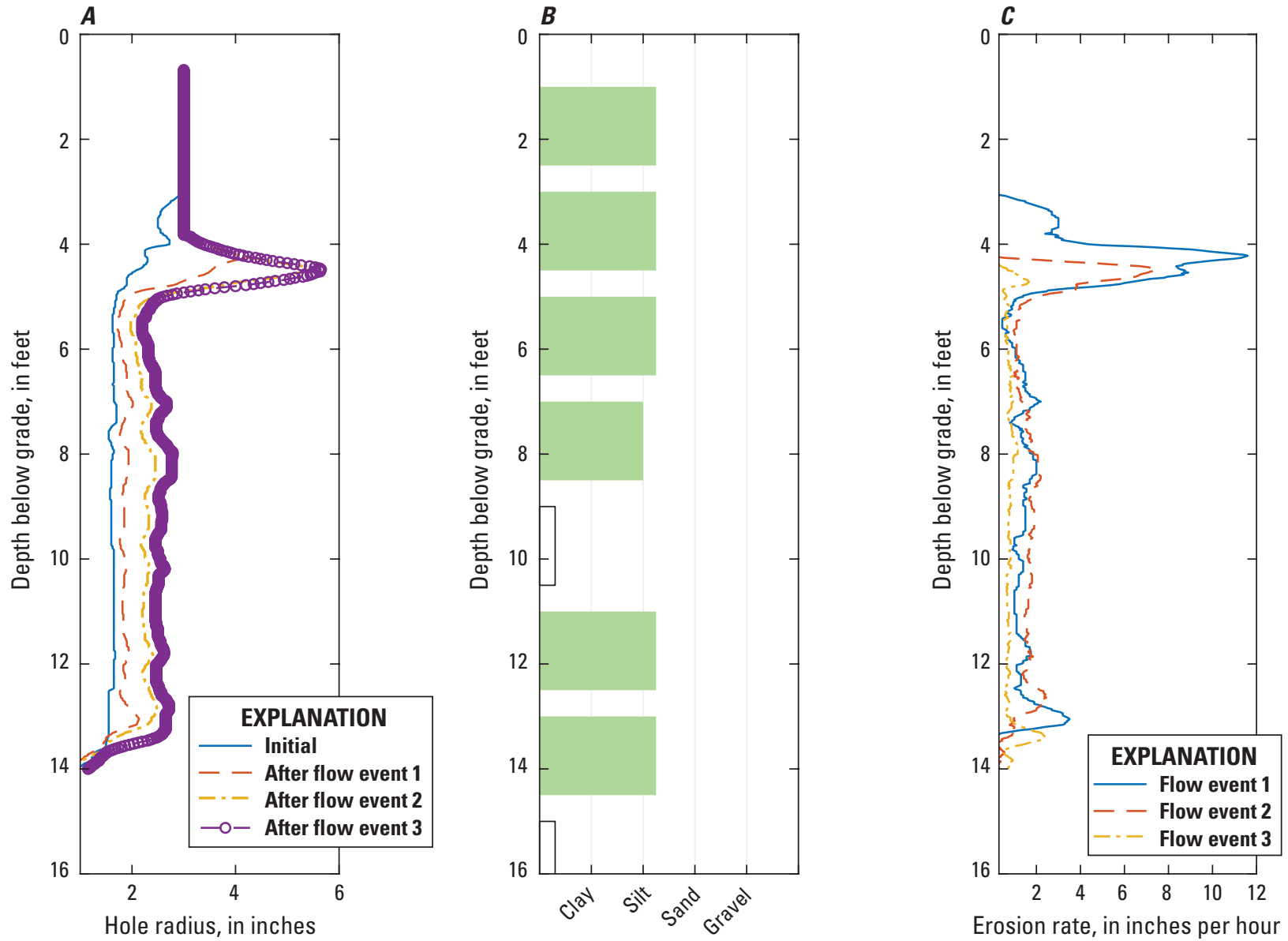

Figure 1.22. Site SAC7 borehole: $A$, mean profiles, $B$, lithology, and $C$, erosion rate. In the lithology plot, a white box indicates a Shelby tube sample. Clays are purple, silts are green, sands are red, and gravels are black. 


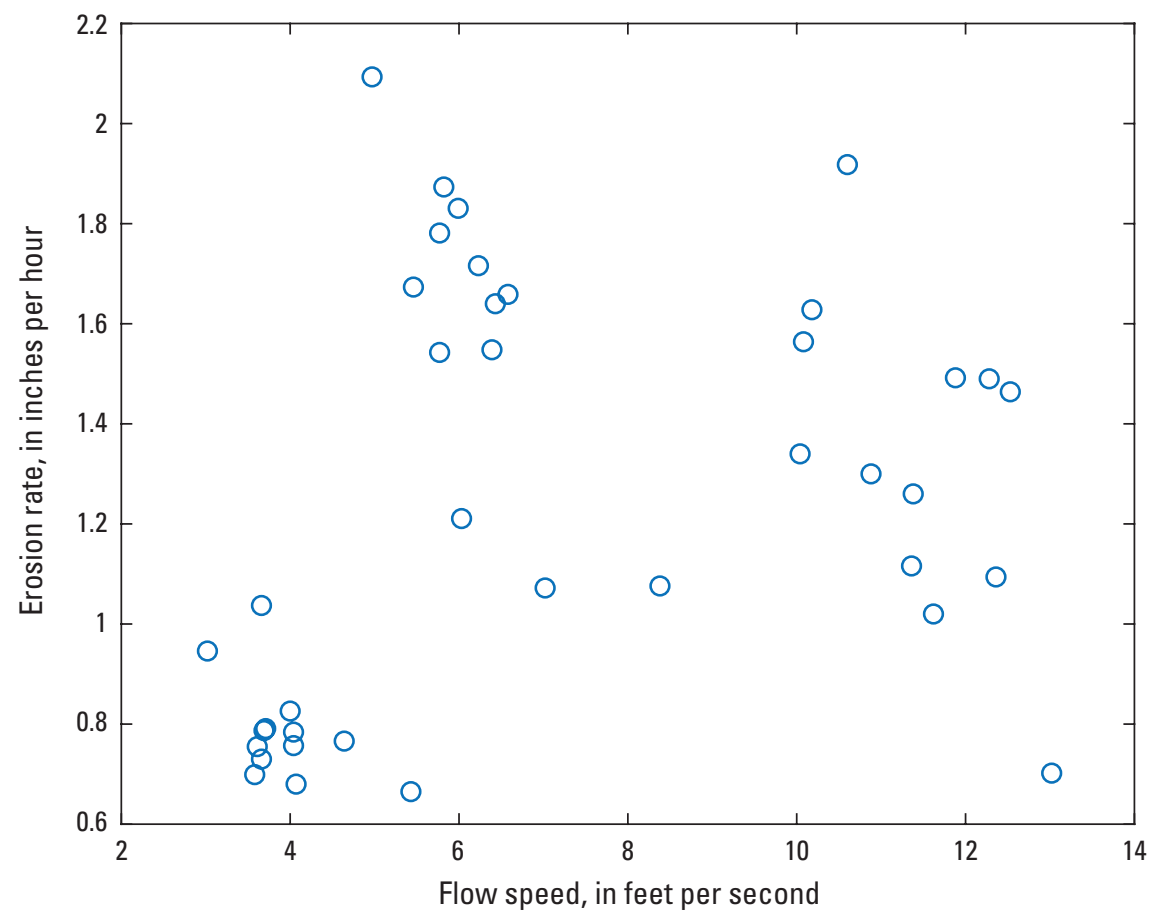

Figure 1.23. Erosion rate versus flow speed at site $\mathrm{SAC7}$ based on all data collected between 5.5- and 12.5-feet-below grade. Each point represents one 6-inch layer of soil.

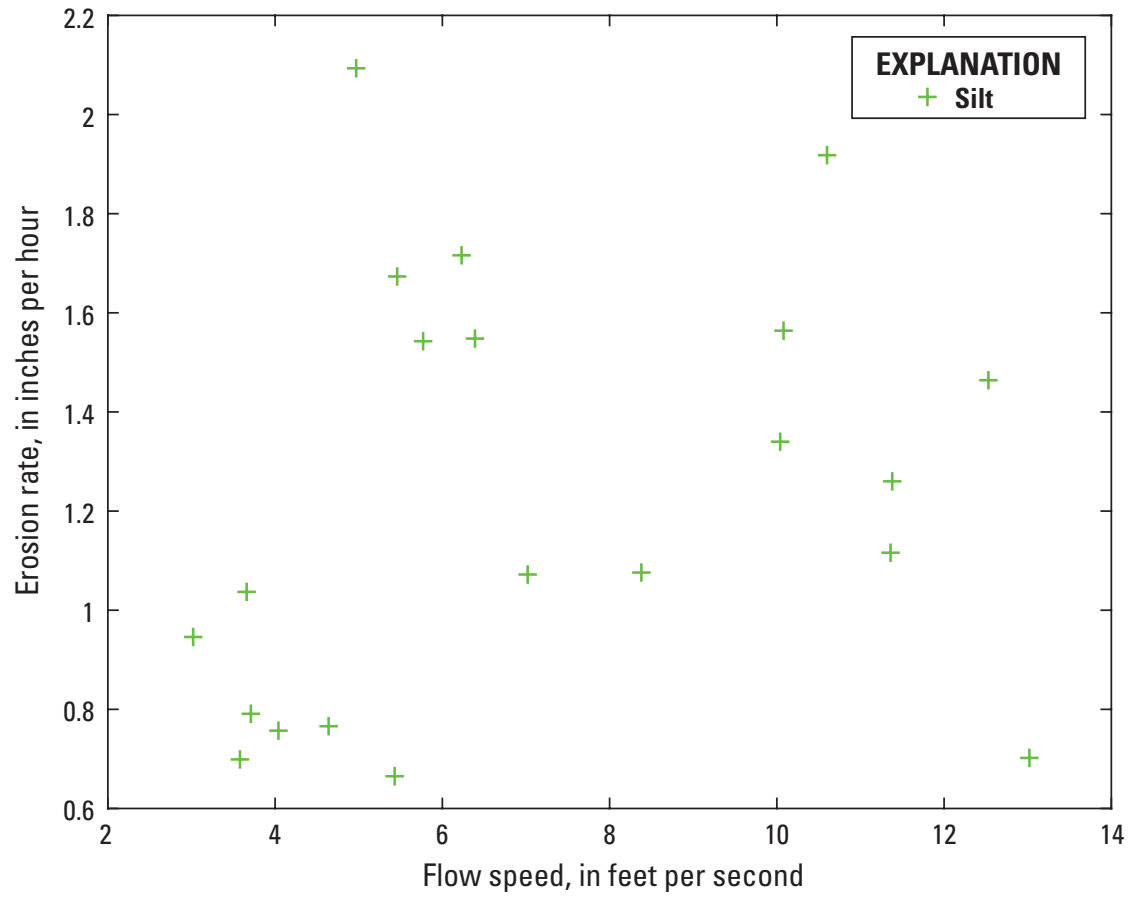

Figure 1.24. Erosion rate versus flow speed and sediment classification at site SAC7 based on all data collected between 5.5- and 12.5-feet-below grade. 


\section{Site SAC3}

The first (and largest) discharge at site SAC3 eroded the bottom of the hole substantially. Flow speed exceeded $10 \mathrm{ft} / \mathrm{s}$ in one part of the hole during this test, but there is little evidence of correlation between velocity and erosion rate. The entire test section was classified as sandy soils.
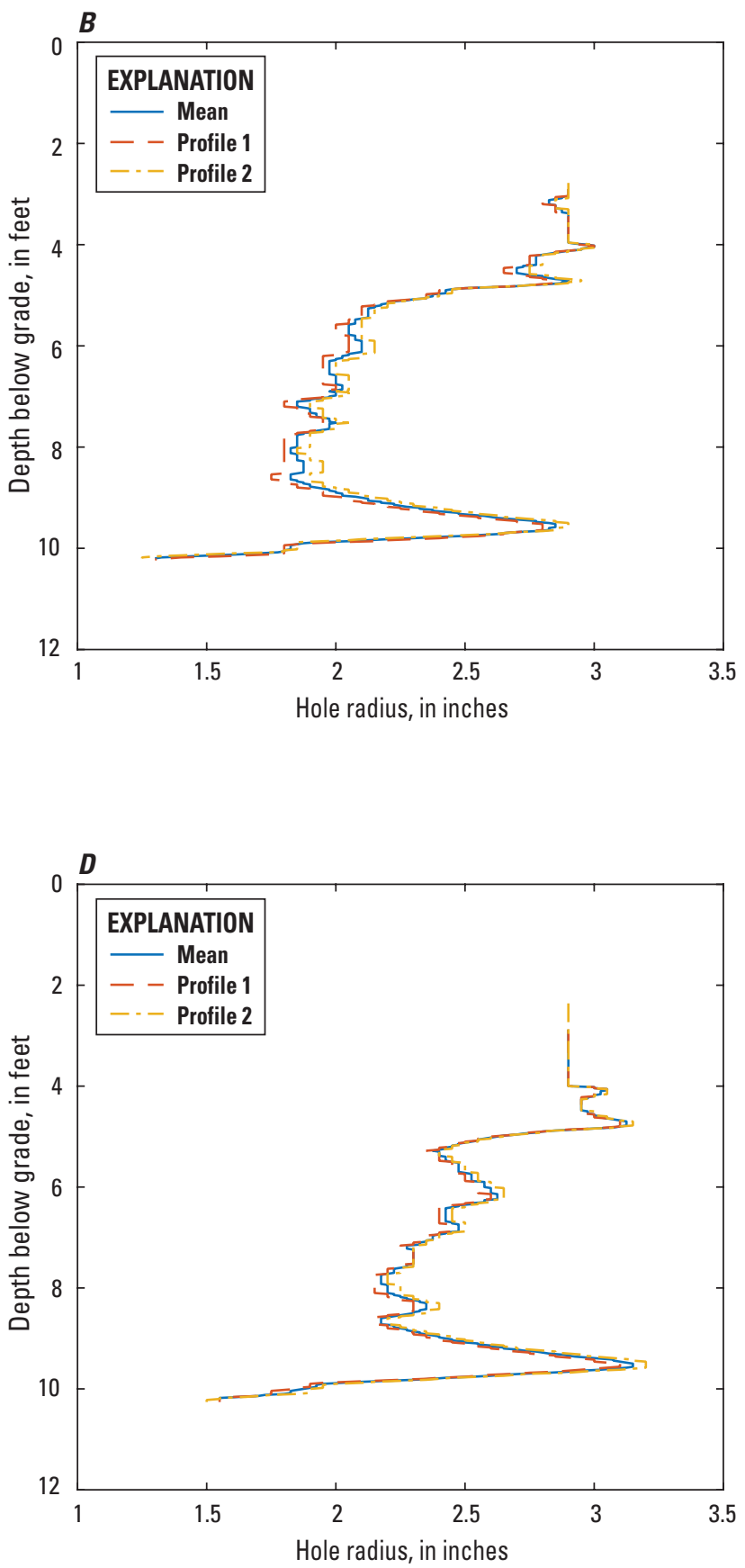

Figure 1.25. Results at site SAC3: $A$, shows the two profiles acquired before testing and the mean of the two results; $B$, shows the condition after flow event $1 ; C$, shows the conditions after flow event 2 ; and $D$, shows the conditions after flow event 3 . The mean was computed only for depths represented in all surveyed profiles. 


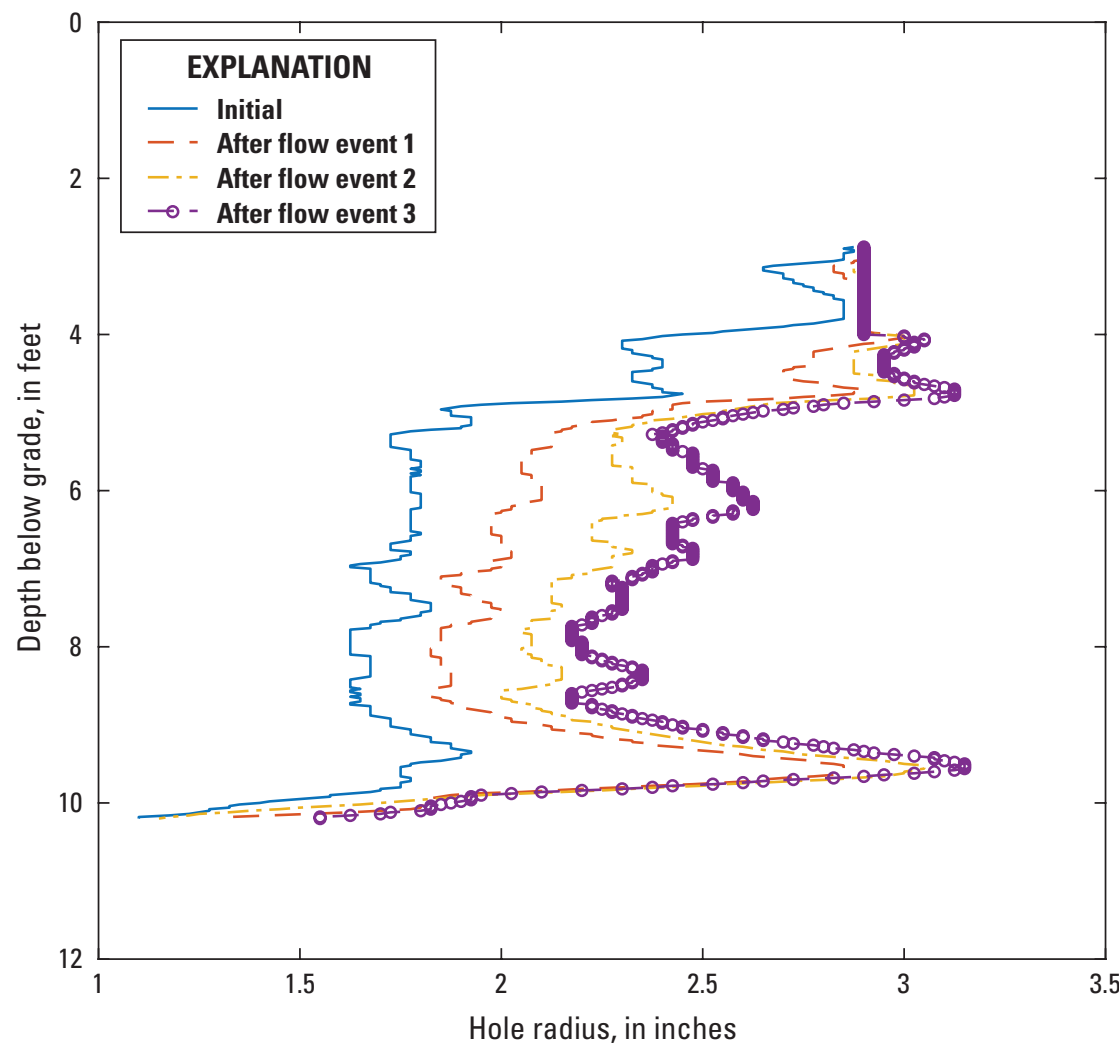

Figure 1.26. The evolution of mean profiles for each condition at site SAC3: Initial and after flow events 1,2, and 3. No diameter correction was applied because it appears that there was bentonite sealant inside the casing at the start of the test. 

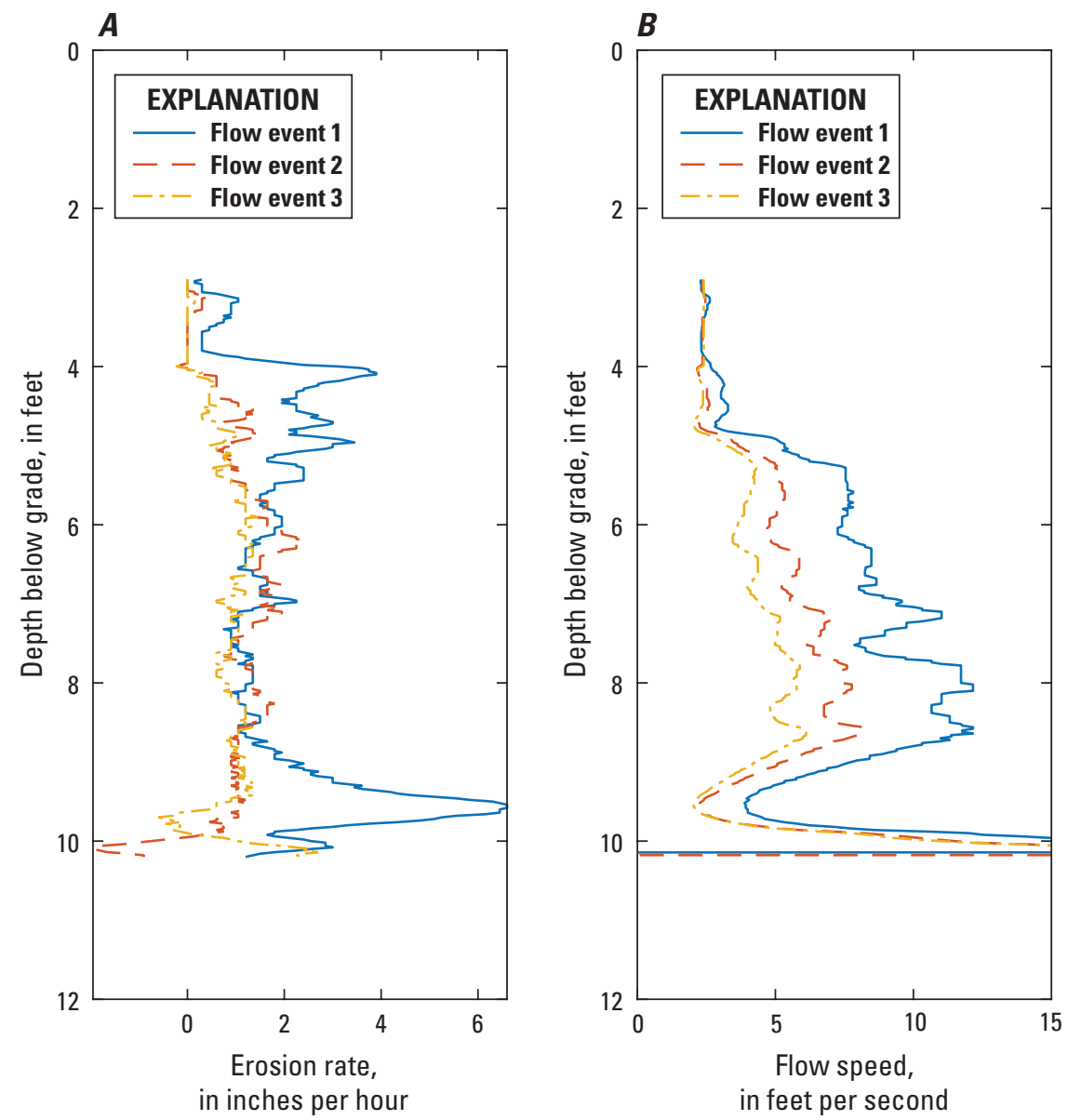

Figure 1.27. Site SAC3: $A$, computed erosion rate versus depth below grade; and $B$, mean flow speed versus depth below grade. 

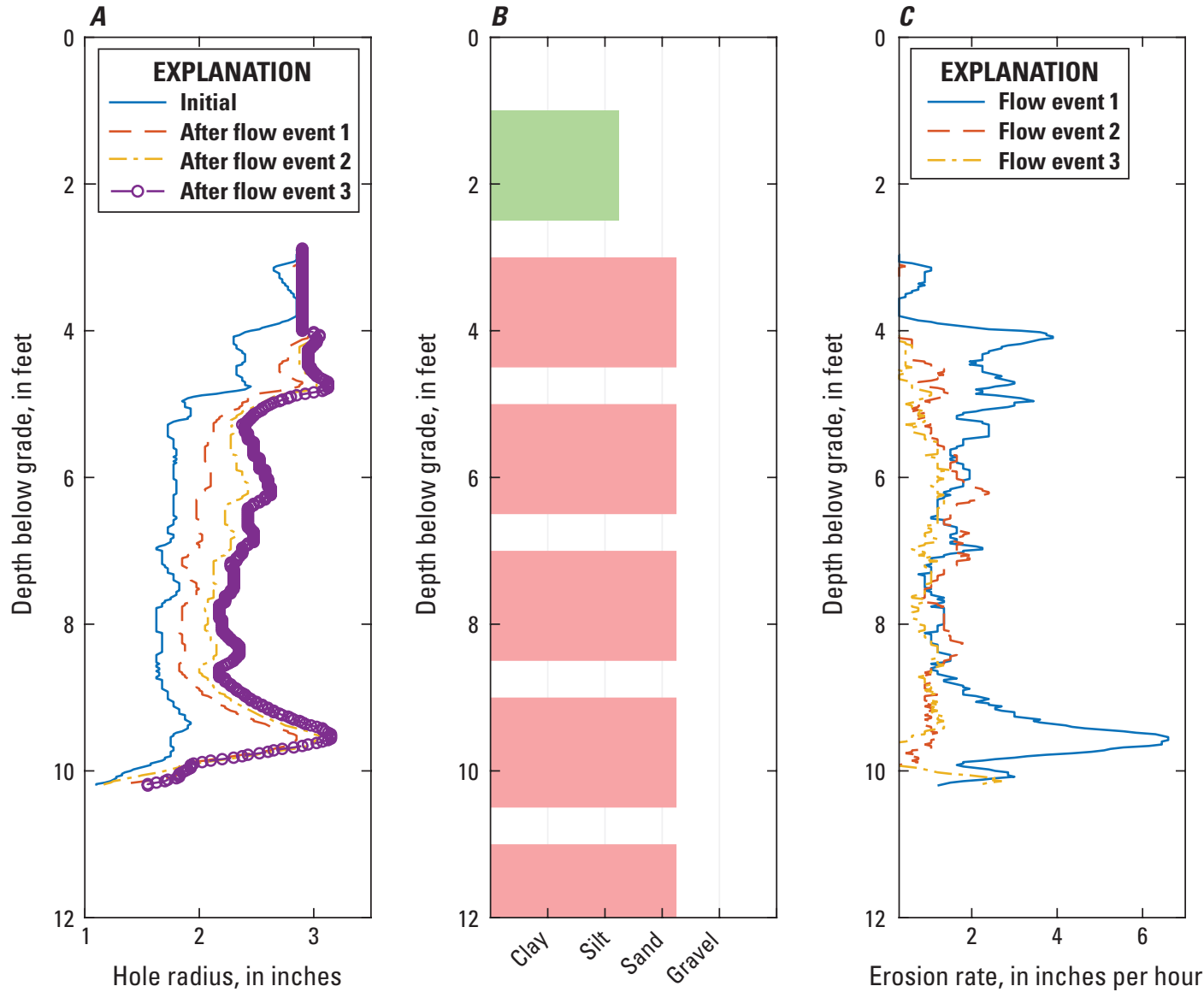

Figure 1.28. Site SAC3 borehole: $A$, mean profiles, $B$, lithology, and $C$, erosion rate. Clays are purple, silts are green, sands are red, and gravels are black. 


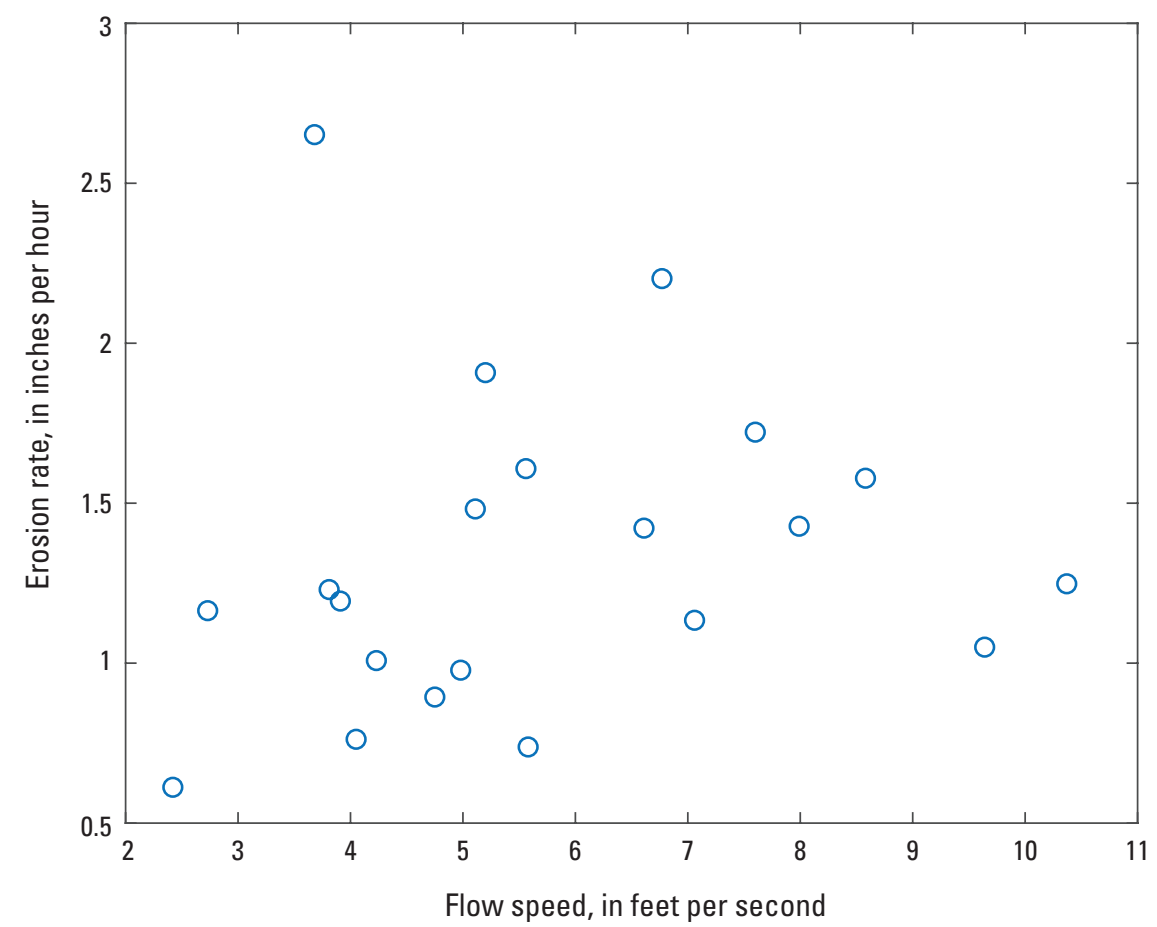

Figure 1.29. Erosion rate versus flow speed at site SAC3 based on data collected between 4.5- and 8.5-feet-below grade. Each point represents one 6-inch layer of soil.

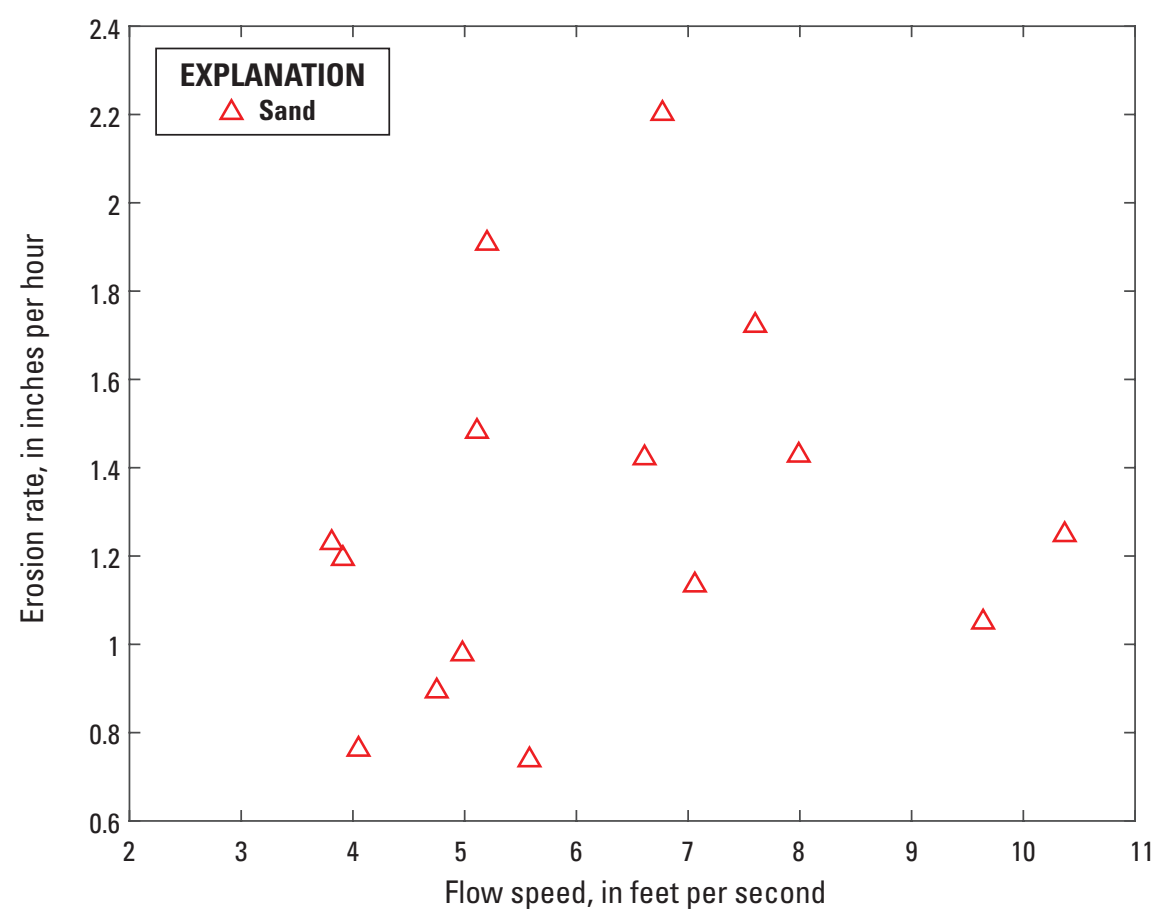

Figure 1.30. Erosion rate versus flow speed and sediment classification of site SAC3 based on data collected between 4.5- and 8.5-feet-below grade. 


\section{Site LAR2}

The lithology at site LAR2 was a mixture of sands and silts. The hole was shallow to stay above the water table, and the test section, selected to avoid regions near the hole bottom and casing, extended only from 4.5- to 7.5-ft-below grade. Maximum flow speed in this region reached $8 \mathrm{ft} / \mathrm{s}$ and the peak erosion rate was $4 \mathrm{in} / \mathrm{hr}$, with evidence of correlation between the two variables. The second and third tests revealed very little erosion but did reveal one problem with the testing procedure: It is really not possible to identify a critical velocity required for initiation of erosion because the minimum measurable erosion rate is nonzero.
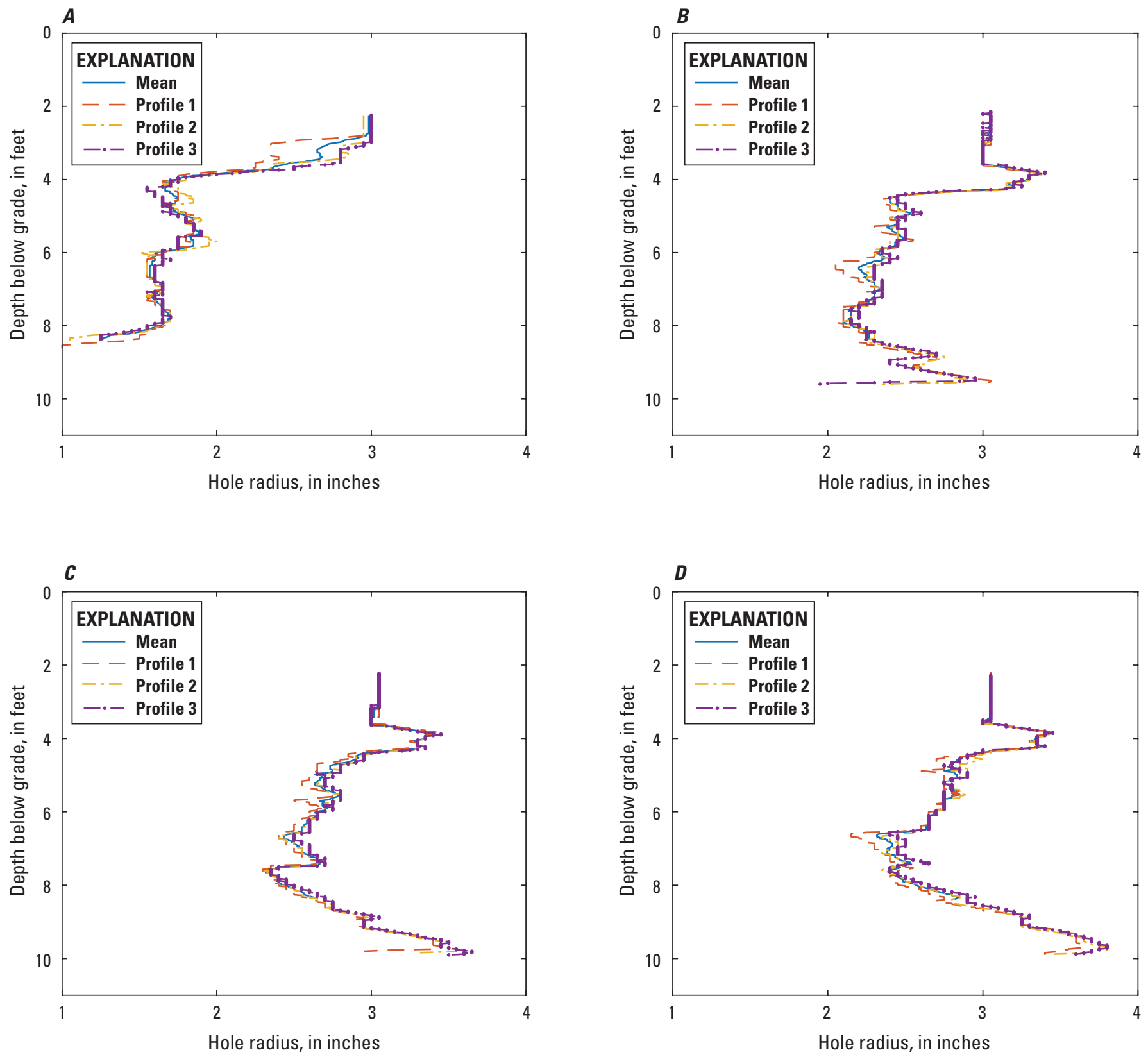

Figure 1.31. Results at site LAR2: $A$, shows the three profiles acquired before testing and the mean of the three results; $B$, shows the condition after flow event $1 ; C$, shows the conditions after flow event 2; and $D$, shows the conditions after flow event 3 . The mean was computed only for depths represented in all surveyed profiles. 


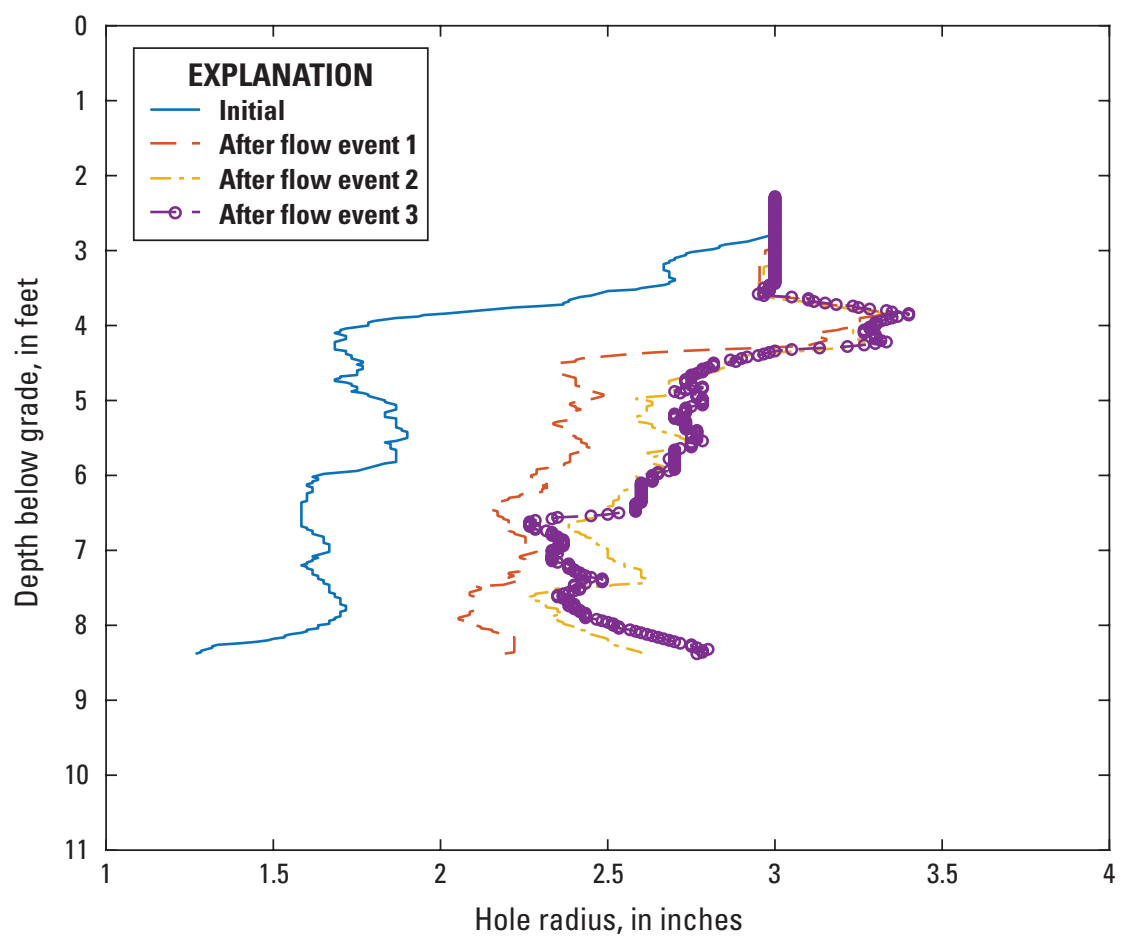

Figure 1.32. Evolution of mean profiles for each condition at site LAR2: Initial and after flow events 1, 2, and 3. A correction of 0.1 inch was applied to force the diameters to match within the casing. 

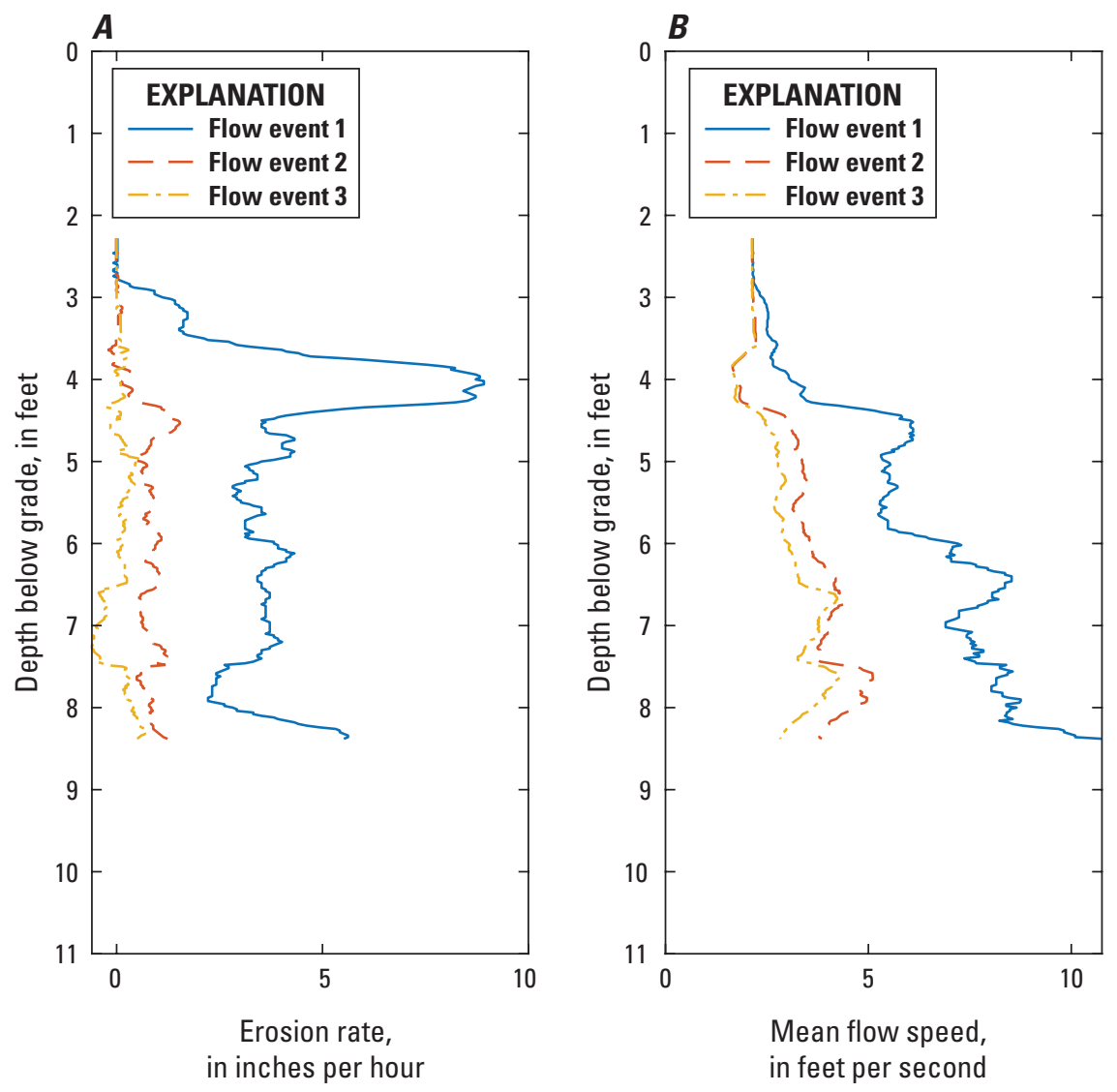

Figure 1.33. Site LAR2: $A$, computed erosion rate versus depth below grade; and $B$, mean flow speed versus depth below grade. 

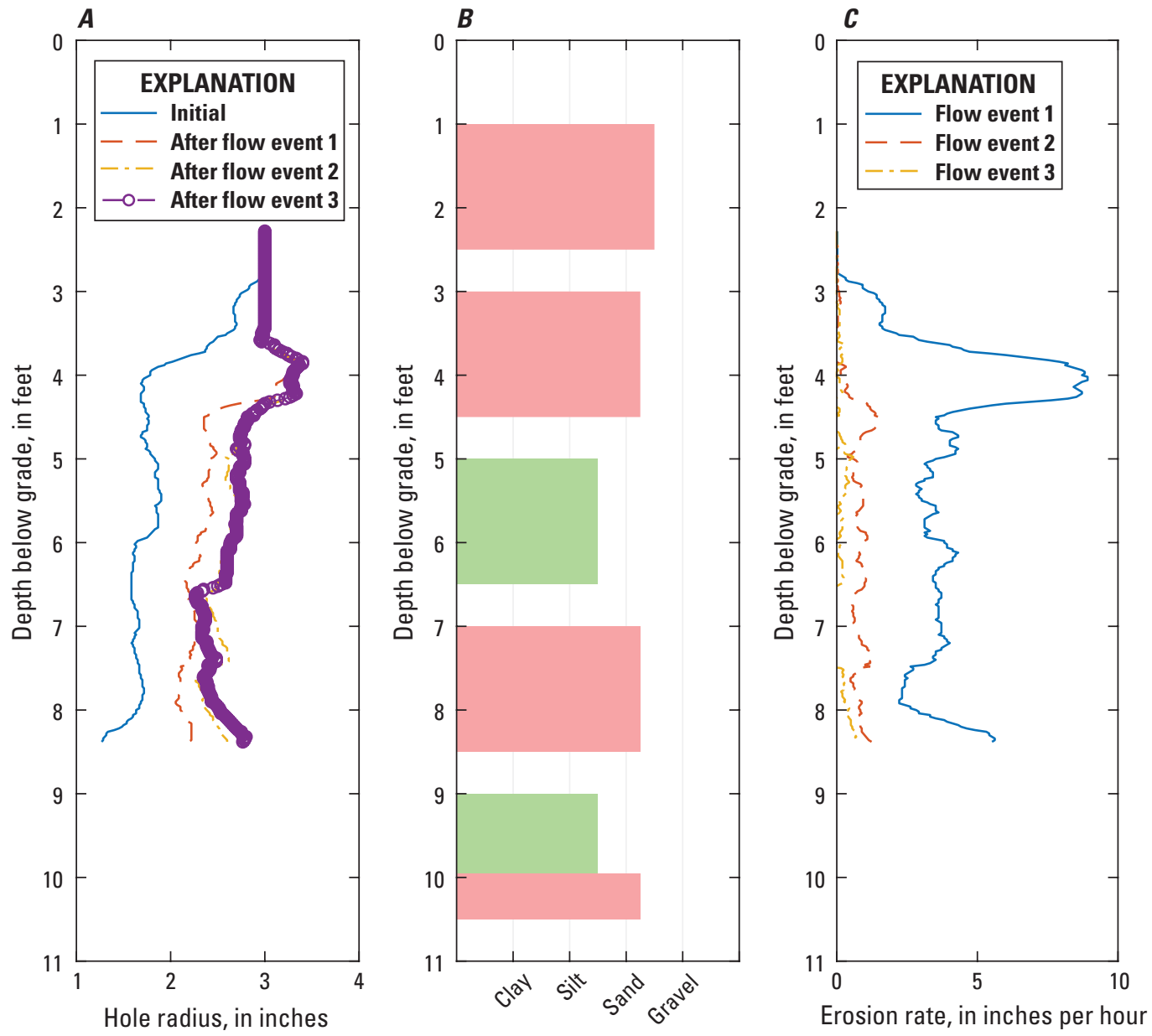

Figure 1.34. Site LAR2 borehole mean: $A$, profiles, $B$, lithology, and $C$, erosion rate. Clays are purple, silts are green, sands are red, and gravels are black. 


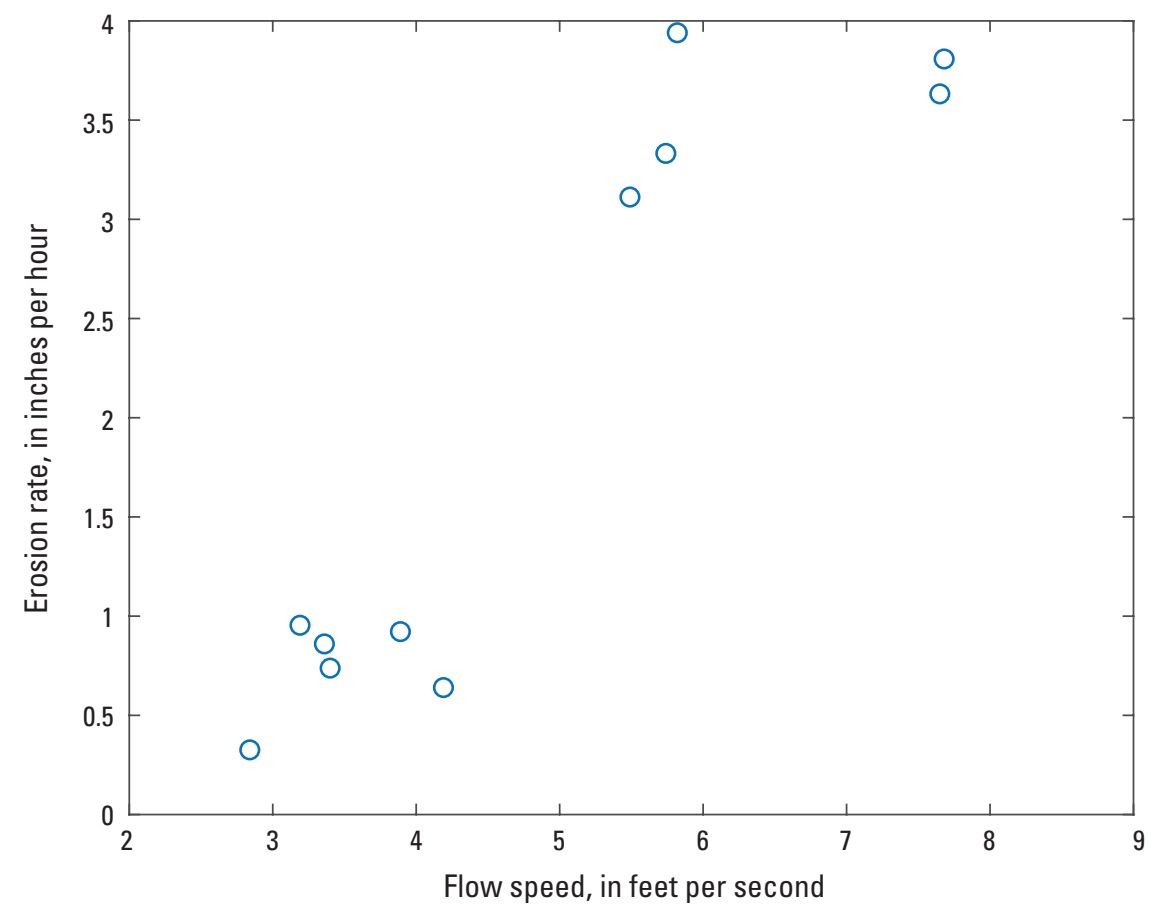

Figure 1.35. Erosion rate versus flow speed at site LAR2 based on data collected between 4.5- and 7.5-feet-below grade. Each point represents one 6-inch layer of soil.

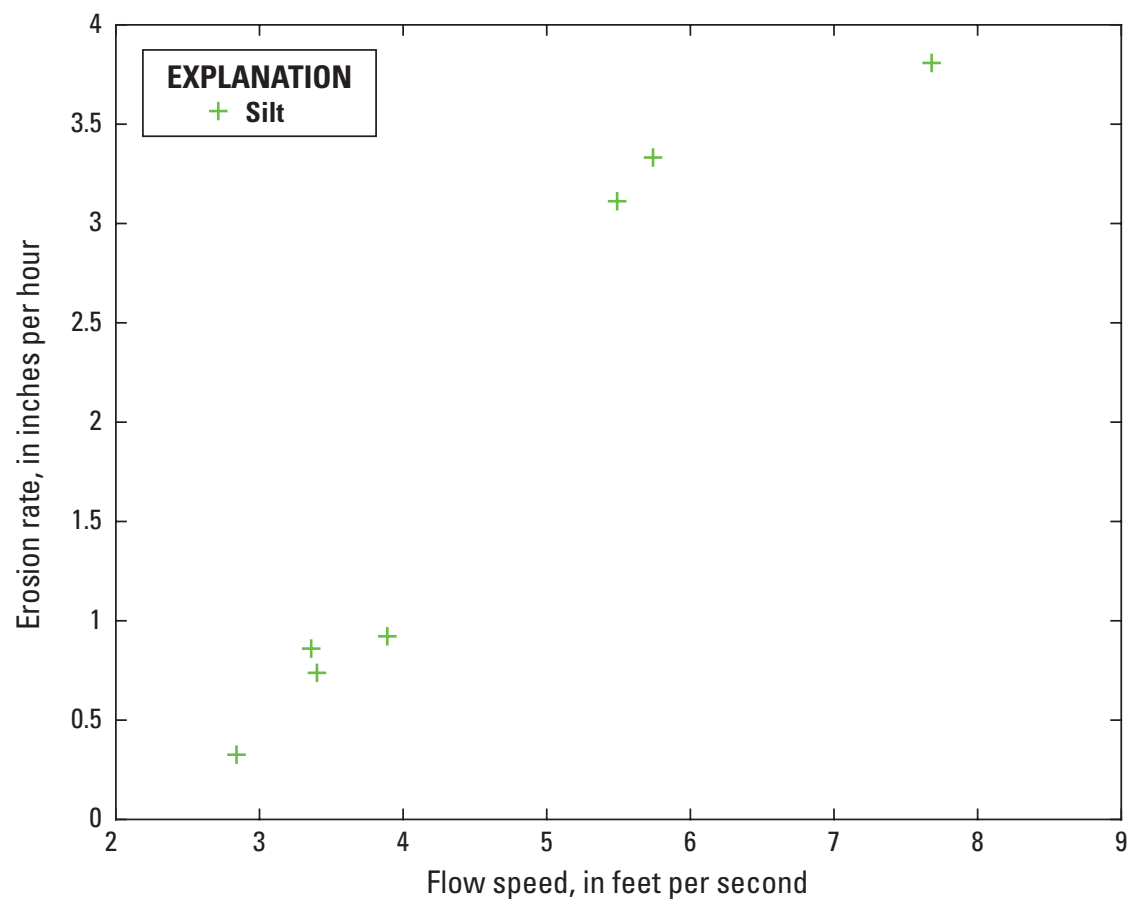

Figure 1.36. Erosion rate versus flow speed and sediment classification based on data collected between 4.5- and 7.5-feet-below grade, at site LAR2. 


\section{Site LAR5}

The entire borehole at site LAR5 was classified as sand, and the erosion rate was low despite flow speeds approaching $8 \mathrm{ft} / \mathrm{s}$. The second test, with lower discharge, resulted in near-zero erosion, indicating a critical velocity of $5-6 \mathrm{ft} / \mathrm{s}$
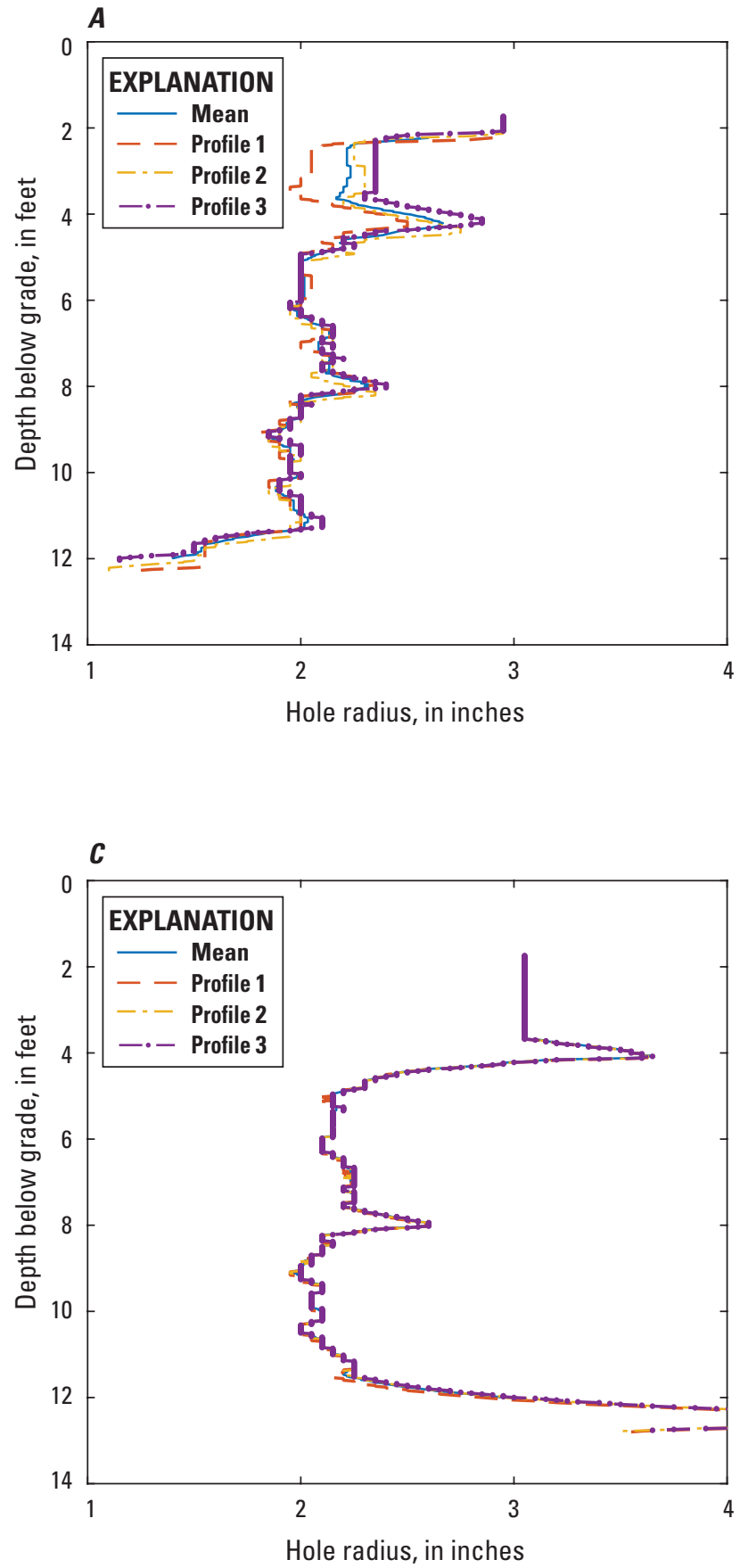

for initiation of erosion. Little correlation is evident between erosion rate and flow speed, although at very low erosion rates the signal-to-noise ratio becomes worse.
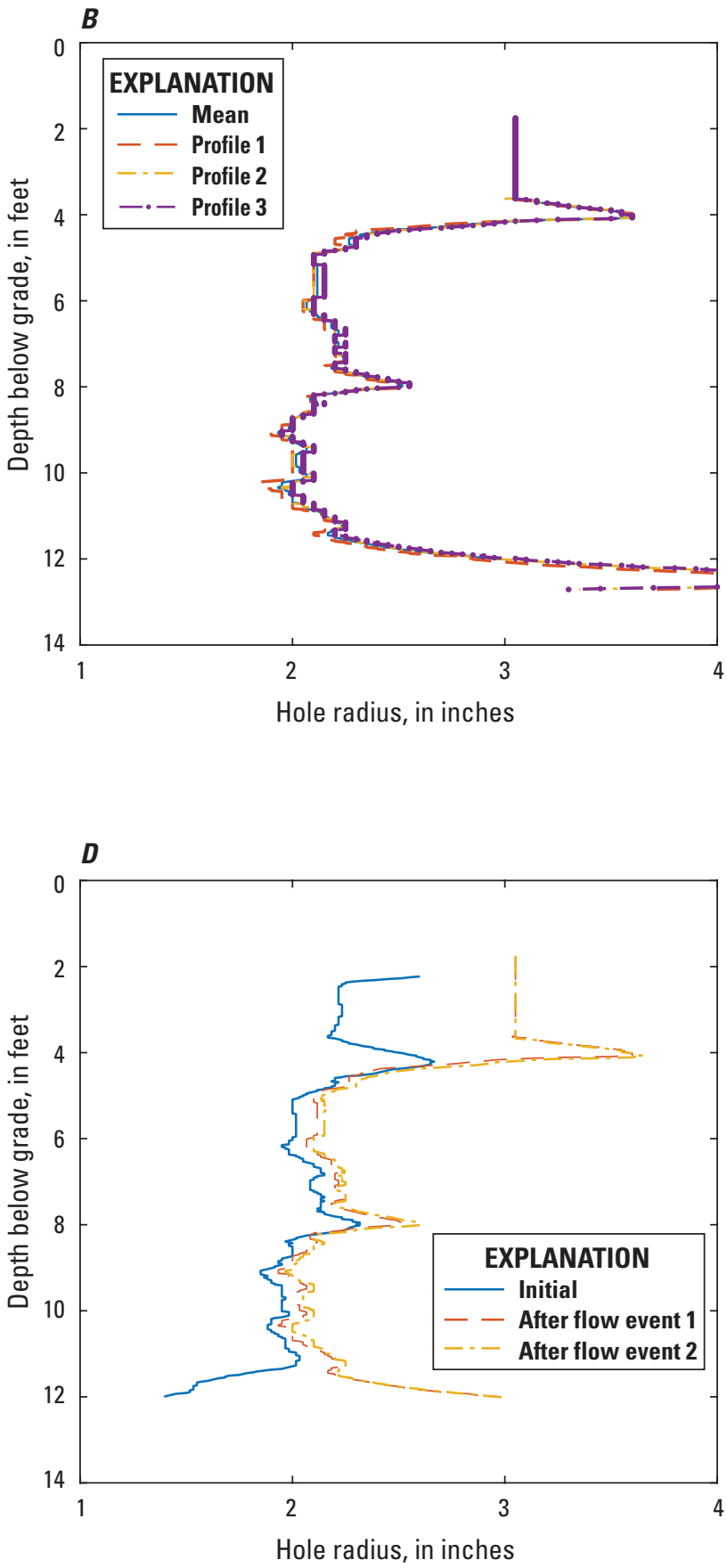

Figure 1.37. Results at site LAR5: $A$, shows the three profiles acquired before testing and the mean of the three results; $B$, shows the condition after flow event $1 ; C$, shows the condition after flow event 2 ; and $D$, shows the mean profiles with no correction. The mean was computed only for depths represented in all surveyed profiles. 

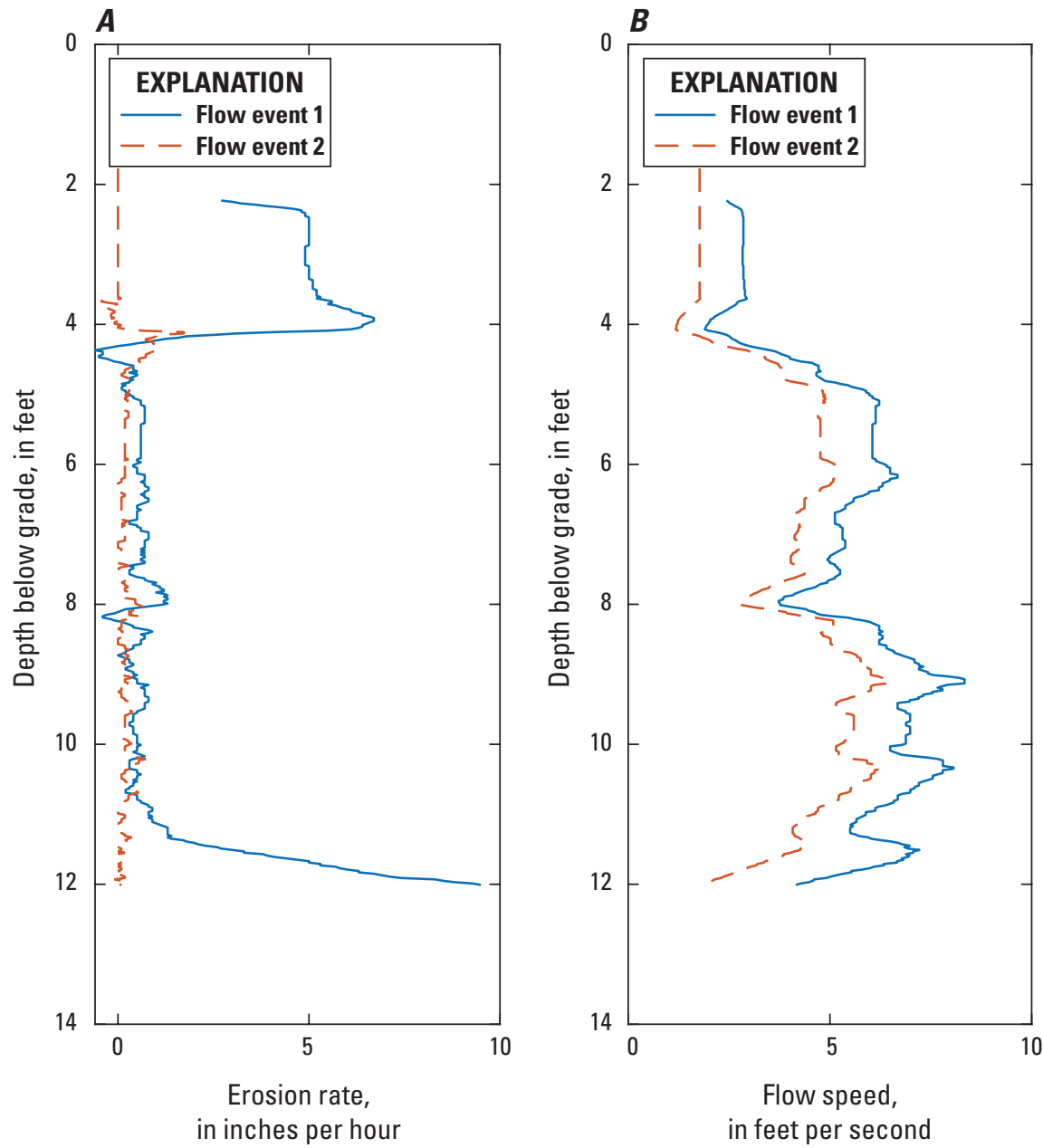

Figure 1.38. Site LAR5: $A$, computed erosion rate versus depth below grade; and $B$, mean flow speed versus depth below grade. 

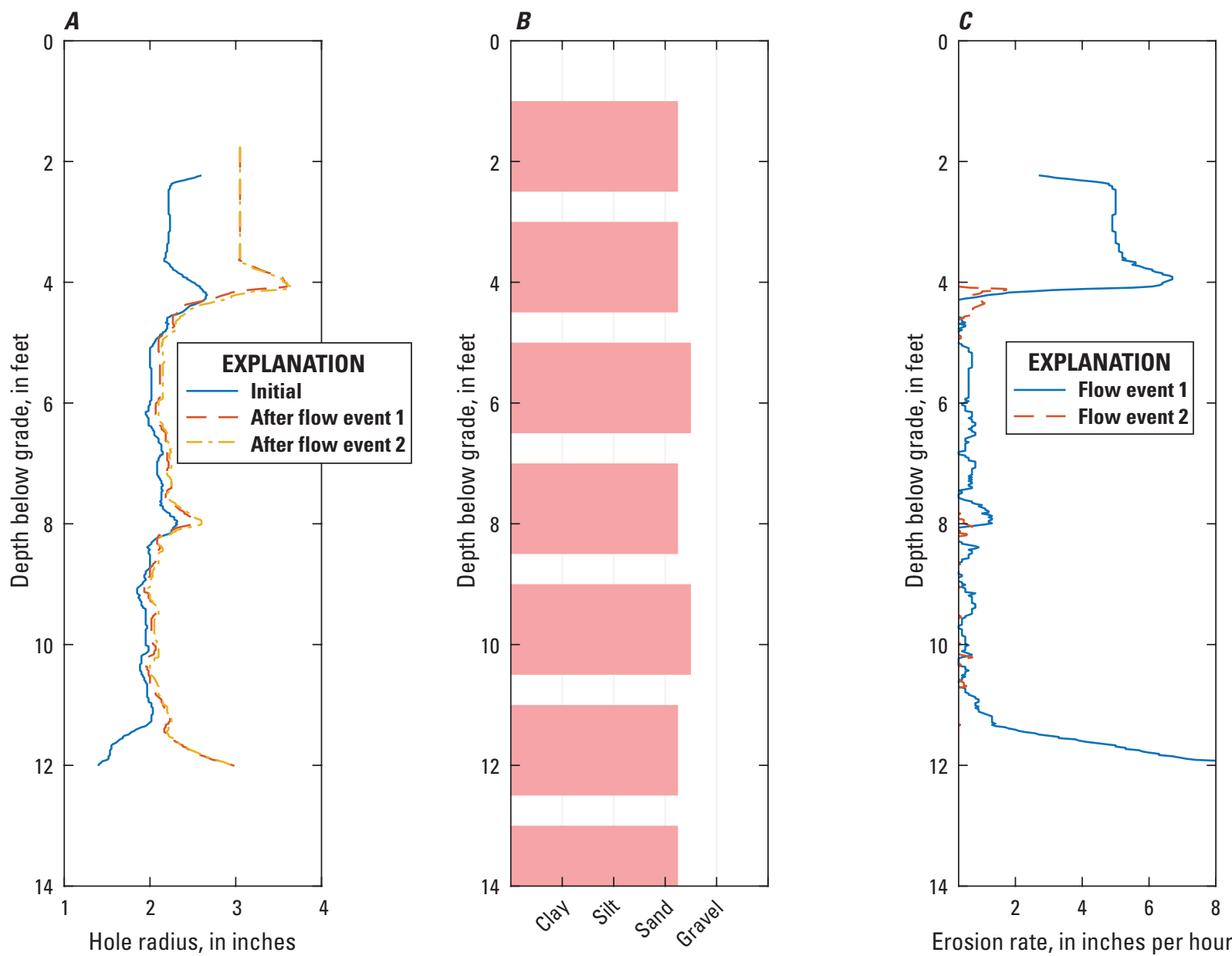

Figure 1.39. Site LAR5 borehole: $A$, mean profiles, $B$, lithology, and $C$, erosion rate. Clays are purple, silts are green, sands are red, and gravels are black. 


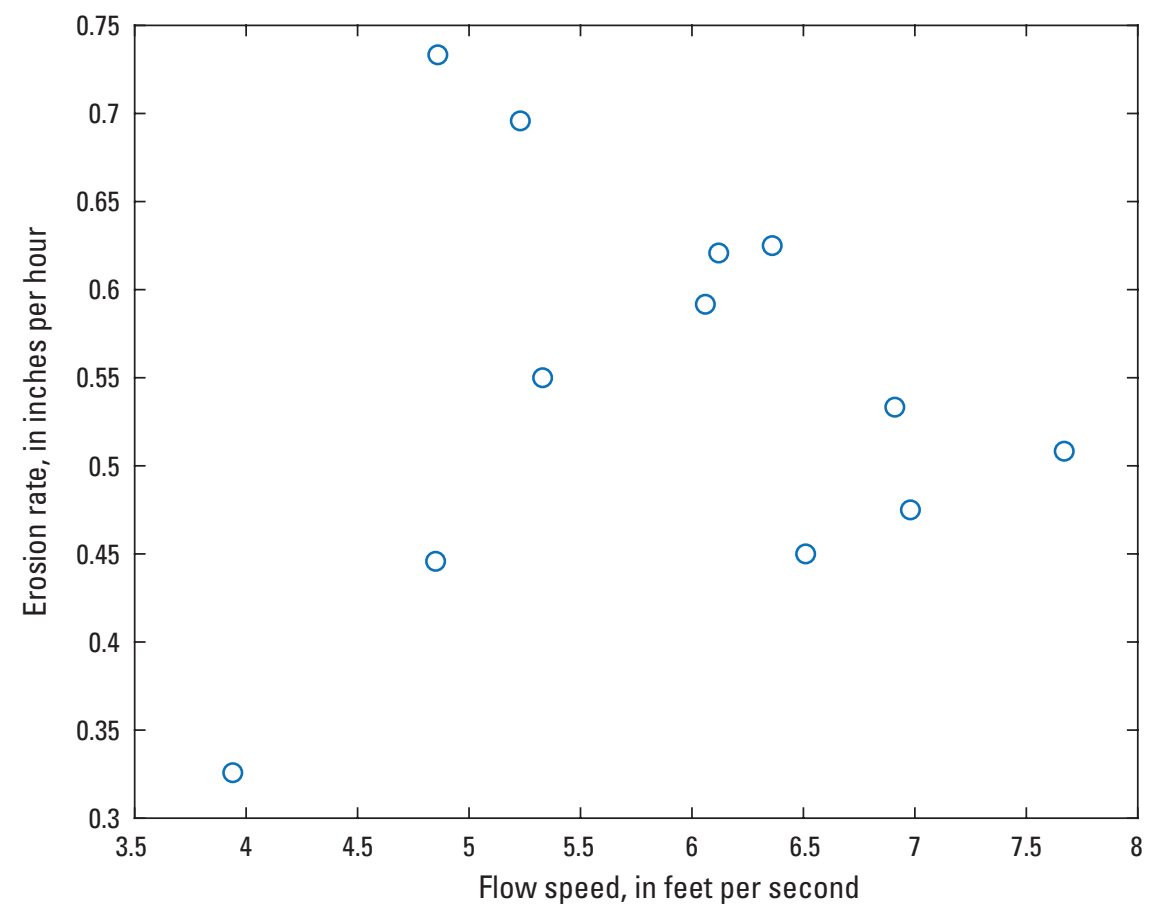

Figure 1.40. Erosion rate versus flow speed at site LAR5 based on data collected between 5- and 10.5-feet-below grade. Each point represents one 6-inch layer of soil.

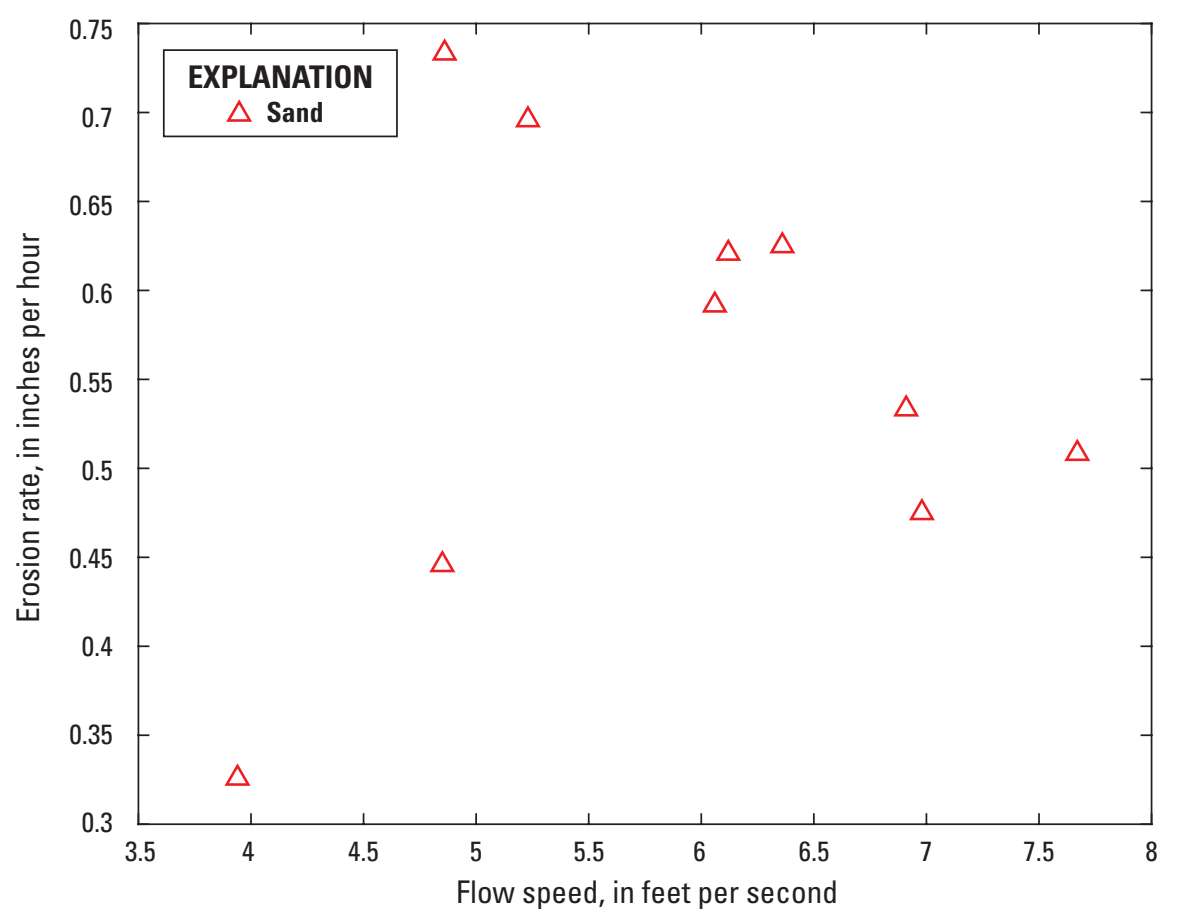

Figure 1.41. Erosion rate versus flow speed and sediment classification based on data collected between 5 - and 10.5 -feet-below grade, at site LAR5. 


\section{Site LAR6}

Although the entire hole at site LAR6 was classified as sand, erodibility was highly variable along the length of the hole. In some regions, testing doubled the diameter of the hole, whereas others saw near-zero change. The first two tests featured low discharge, the third test featured very high discharge, and the fourth test featured slightly less discharge. Maximum flow speed was close to $20 \mathrm{ft} / \mathrm{s}$, but because of the strong vertical variations in erodibility, there is little correlation between flow speed and erosion rate when considering the borehole as a whole. Unlike the other test sites, the drilling conducted to reveal lithology did not match the observed lithology of the hole drilled for the erosion test. This complicates interpretation of the results. 

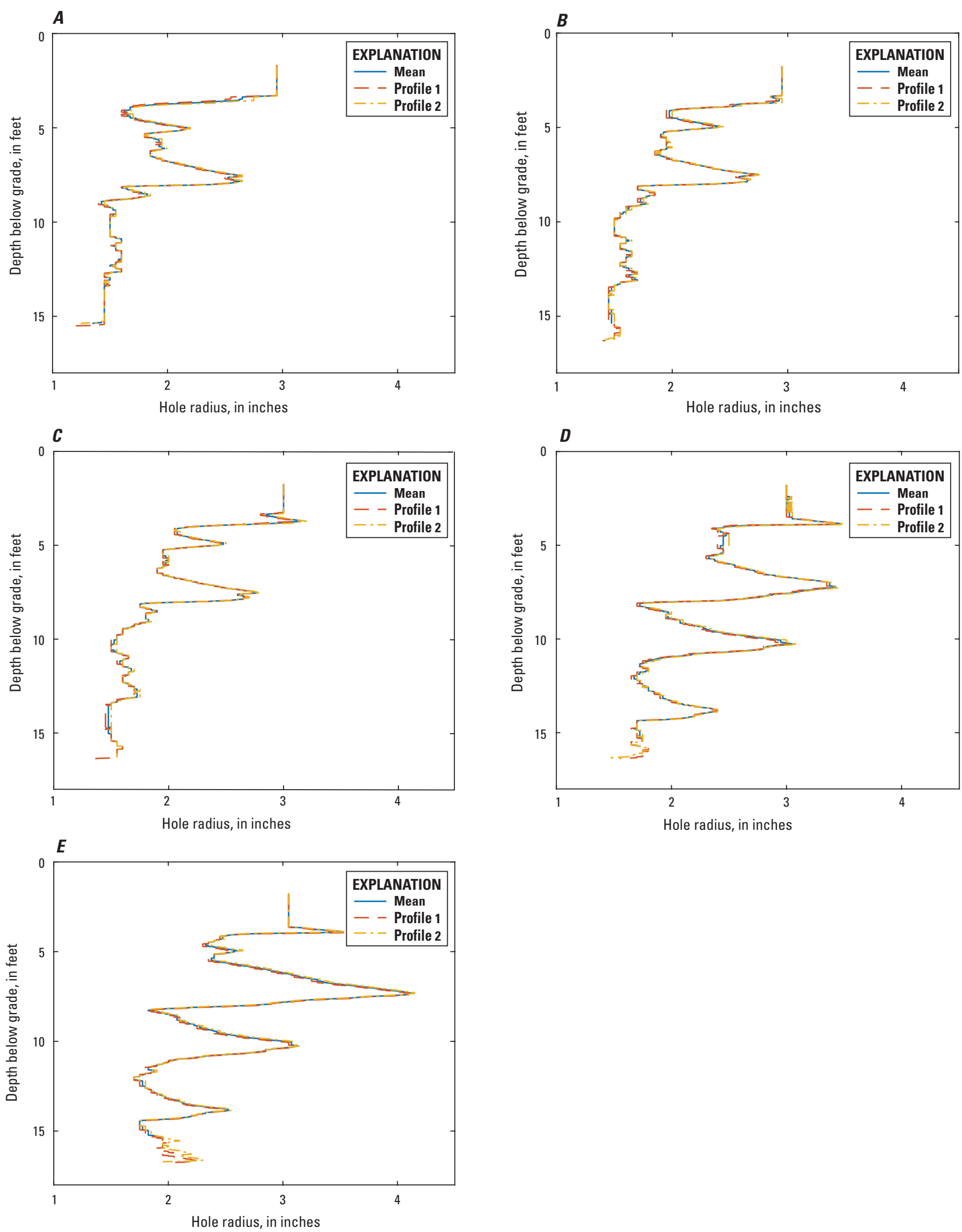

Figure 1.42. Results at site LAR6: $A$, shows the two profiles acquired before testing and the mean of the two results; $B$, shows the condition after flow event $1 ; C$, shows the condition after flow event 2; $D$, shows the condition after flow event 3 ; and $E$, shows the condition after flow event 4 . The mean was computed only for depths represented in all surveyed profiles. 


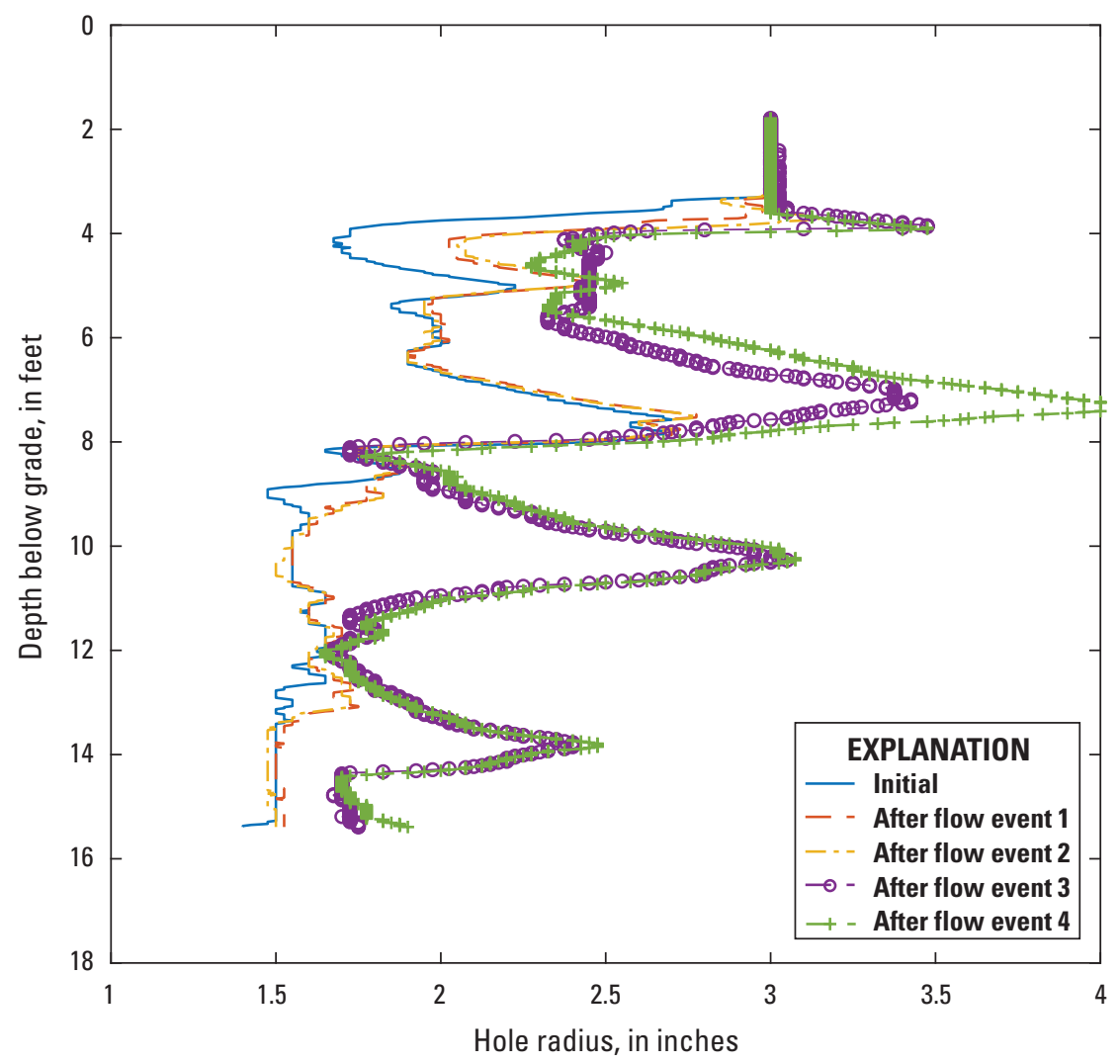

Figure 1.43. Mean profiles with radius correction for each condition at site LAR6: Initial and after flow events 1, 2,3, and 4. 

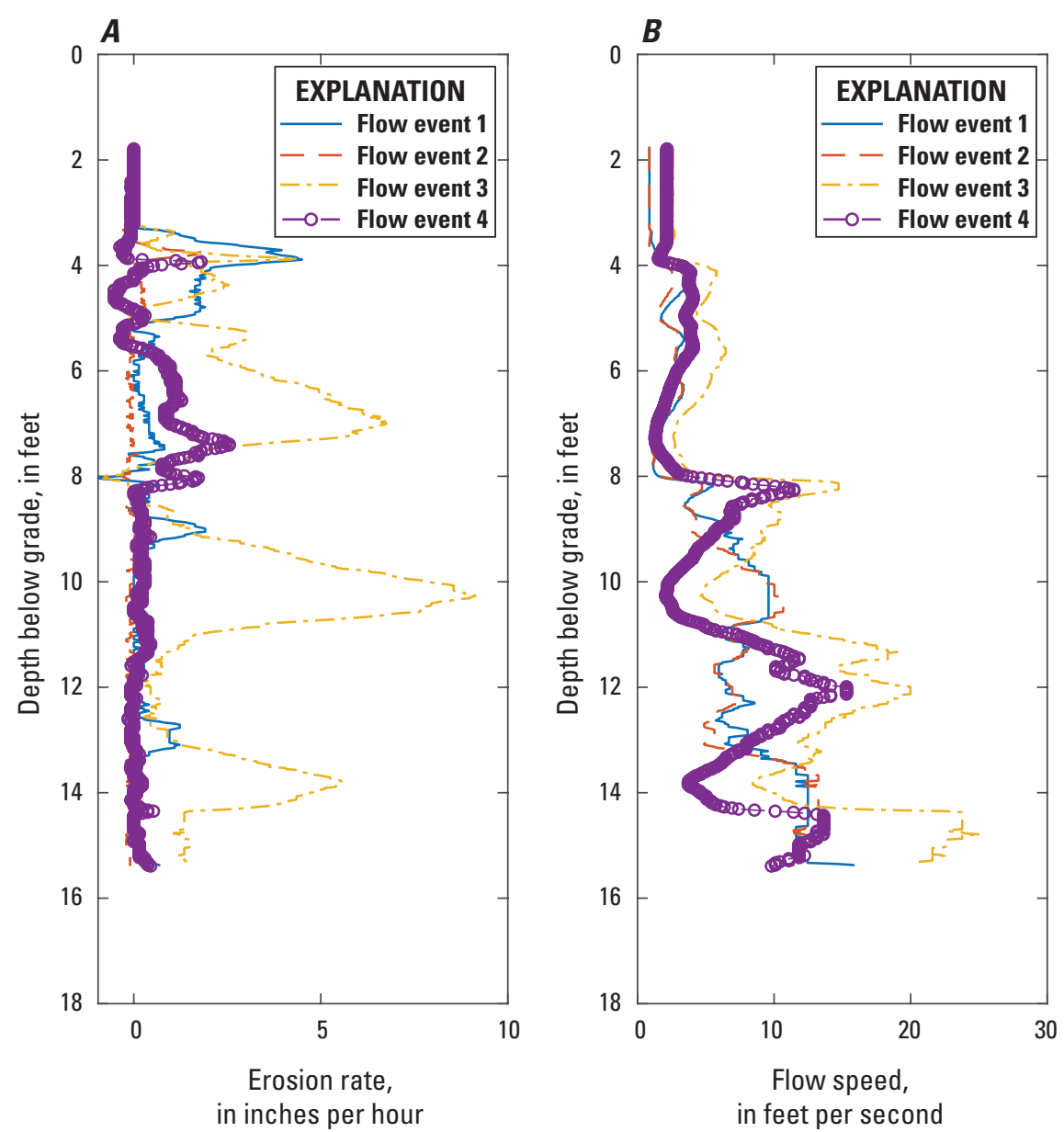

Figure 1.44. Site LAR6: $A$, computed erosion rate versus depth below grade; and $B$, mean flow speed versus depth below grade. 

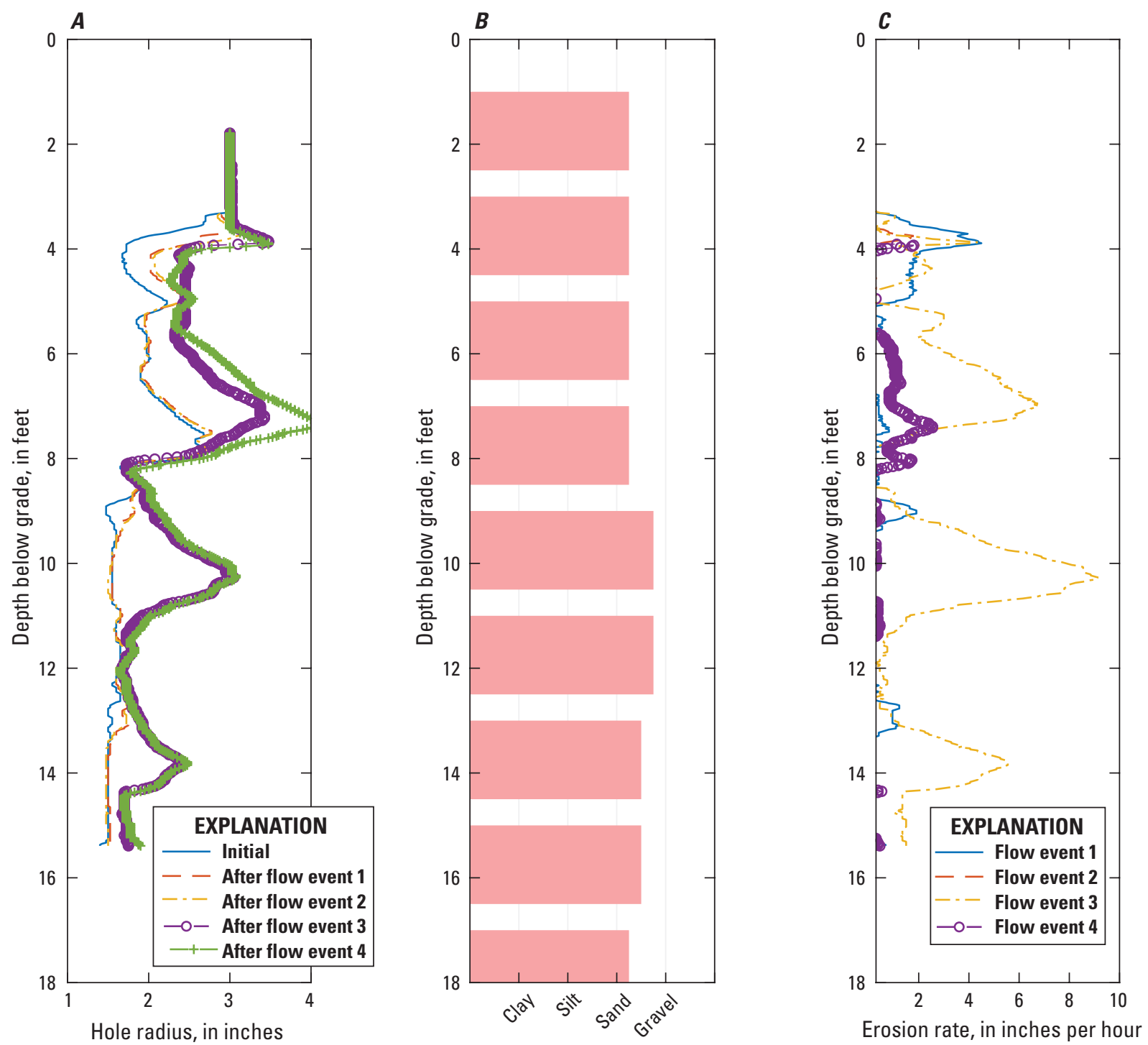

Figure 1.45. Site LAR6 borehole: $A$, mean profiles, $B$, lithology, and $C$, erosion rate. Clays are purple, silts are green, sands are red, and gravels are black. 


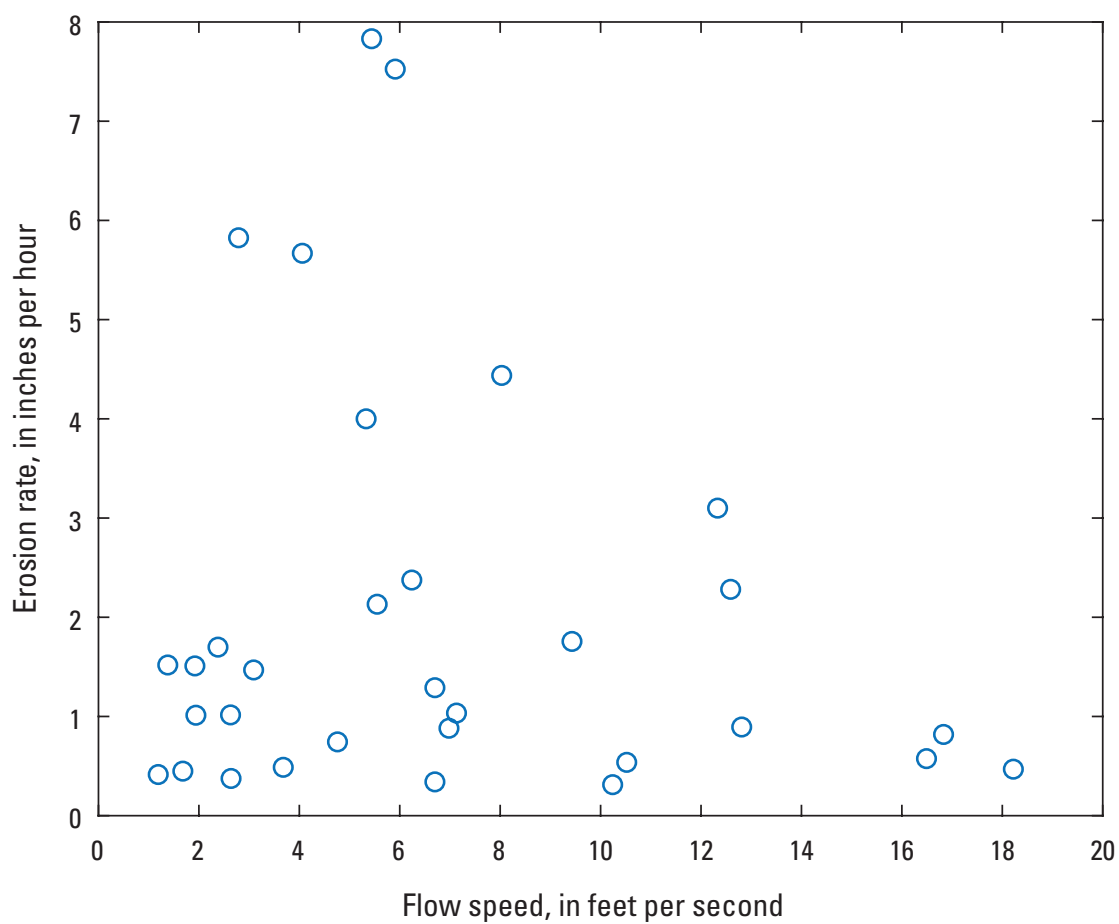

Figure 1.46. Erosion rate versus flow speed and sediment classification at site LAR6 based on data collected between 4.5- and 14-feet-below grade. Each point represents one 6 -inch layer of soil. Note that at this site, the observed lithology appeared to differ from what was encountered when drilling for the borehole erosion test.

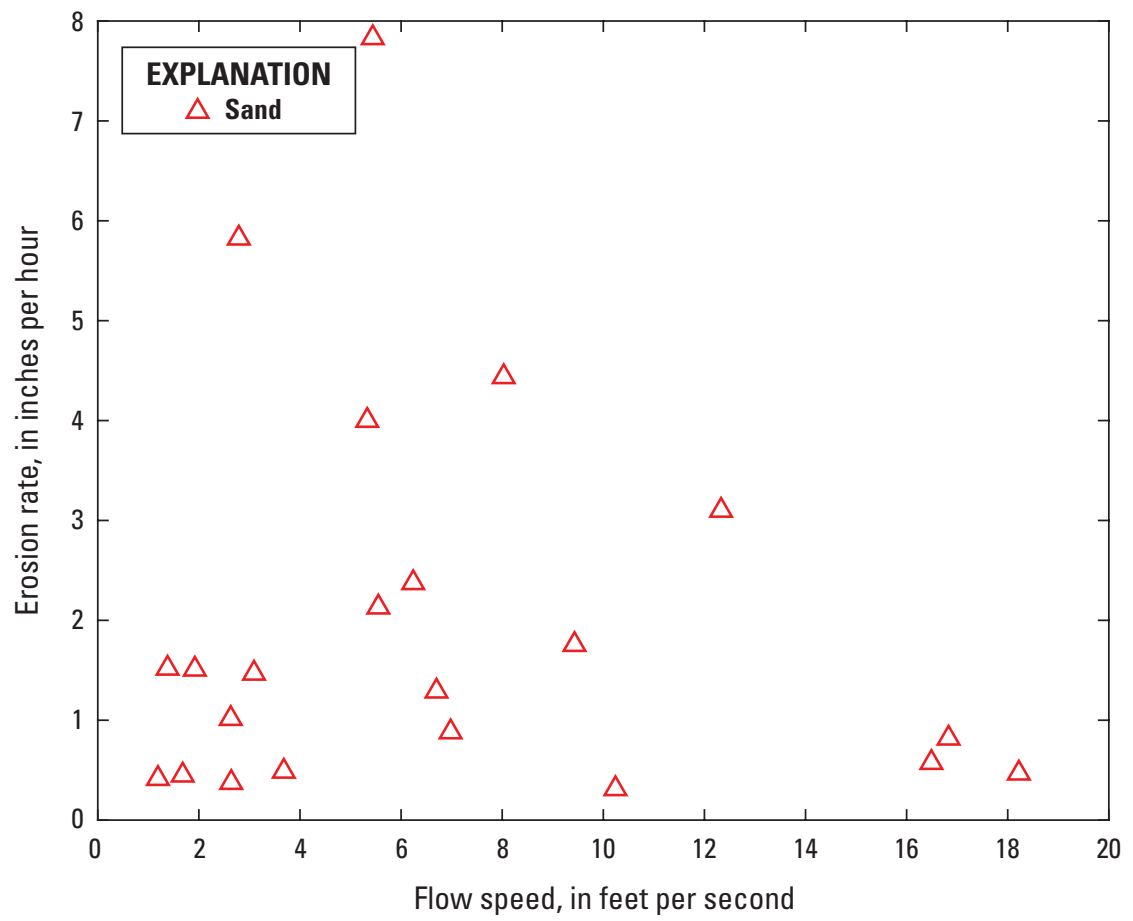

Figure 1.47. Erosion rate versus flow speed and sediment classification at site LAR6 based on data collected between 4.5- and 14-feet-below grade. 


\section{Site LAR10}

Site LAR10 featured a mixture of sand, silt, and clay soils. A thin layer of soil near 7-ft-below grade eroded so much that it was excluded from erosion rate versus flow speed plots because it violates the assumption of vertical flow along the hole walls. Regions of sand and silt above this showed low erosion rates even when subjected to high flow speeds (near $20 \mathrm{ft} / \mathrm{s})$.
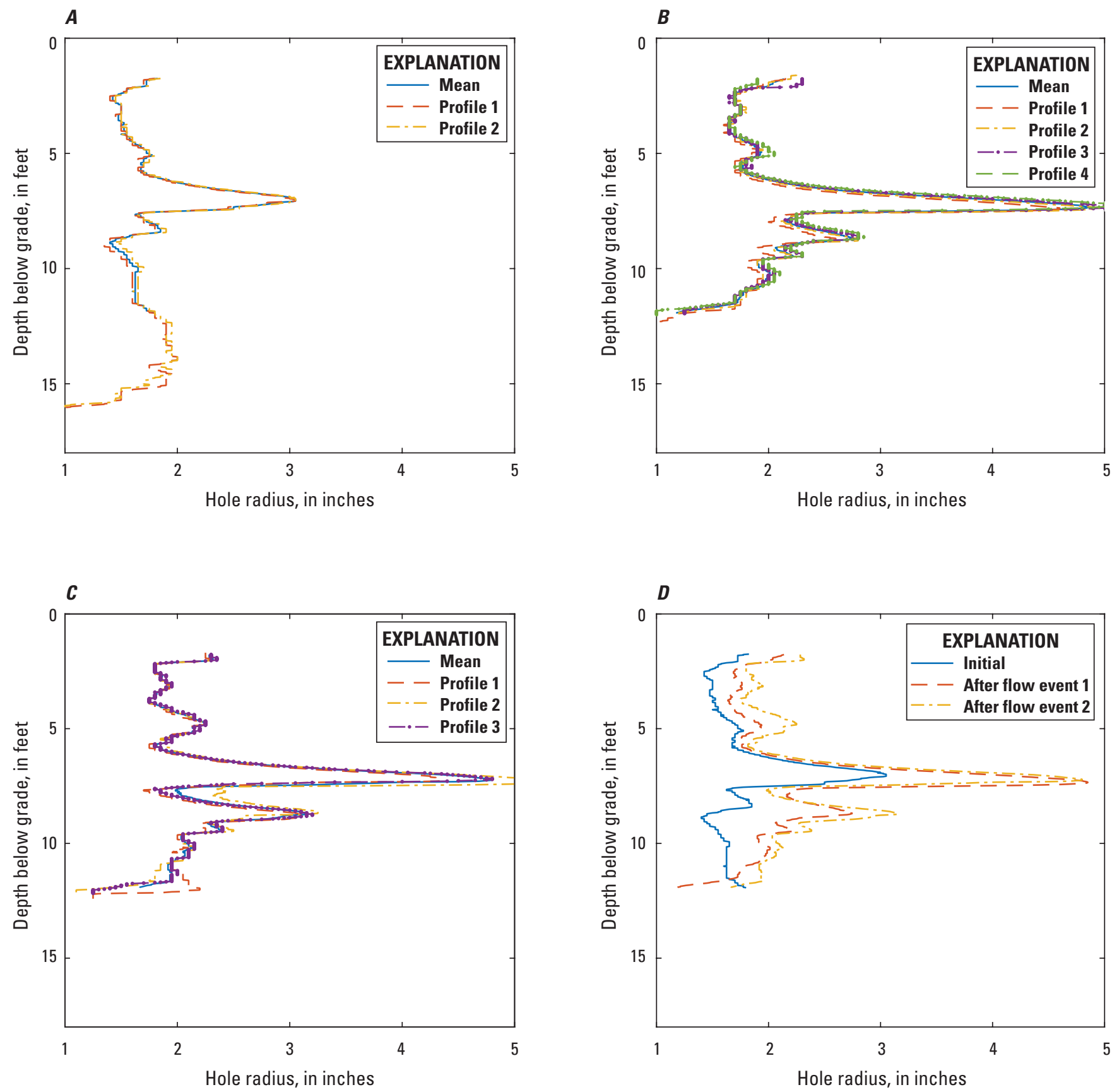

Figure 1.48. Results at site LAR10: $A$, shows the two profiles acquired before testing and the mean of the two results; $B$, shows the condition after flow event $1 ; C$, shows the condition after flow event 2 ; and $D$, shows the mean profiles with radius correction. The mean was computed only for depths represented in all surveyed profiles. 

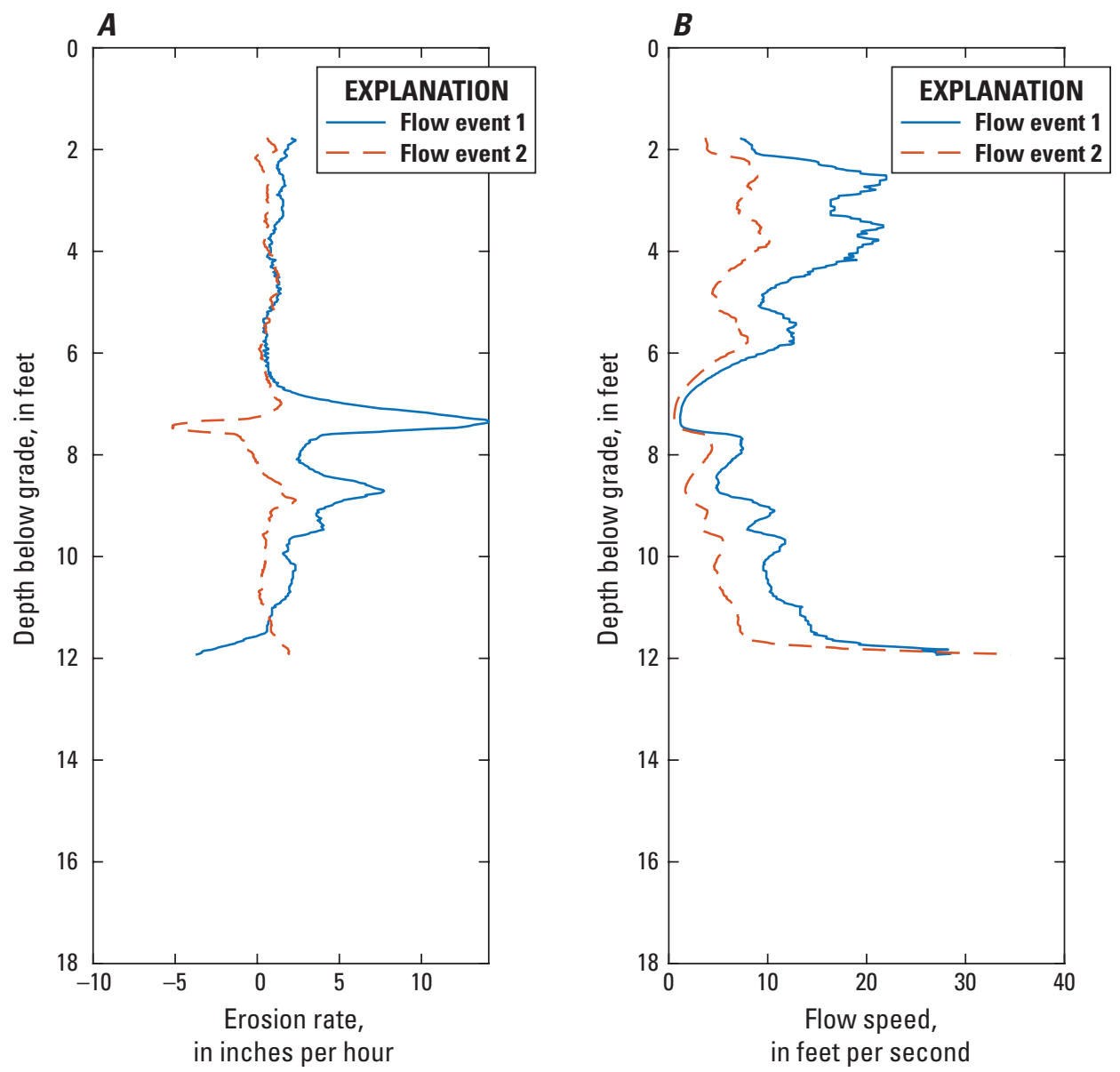

Figure 1.49. Site LAR10: $A$, computed erosion rate versus depth below grade; and $B$, mean flow speed versus depth below grade. 

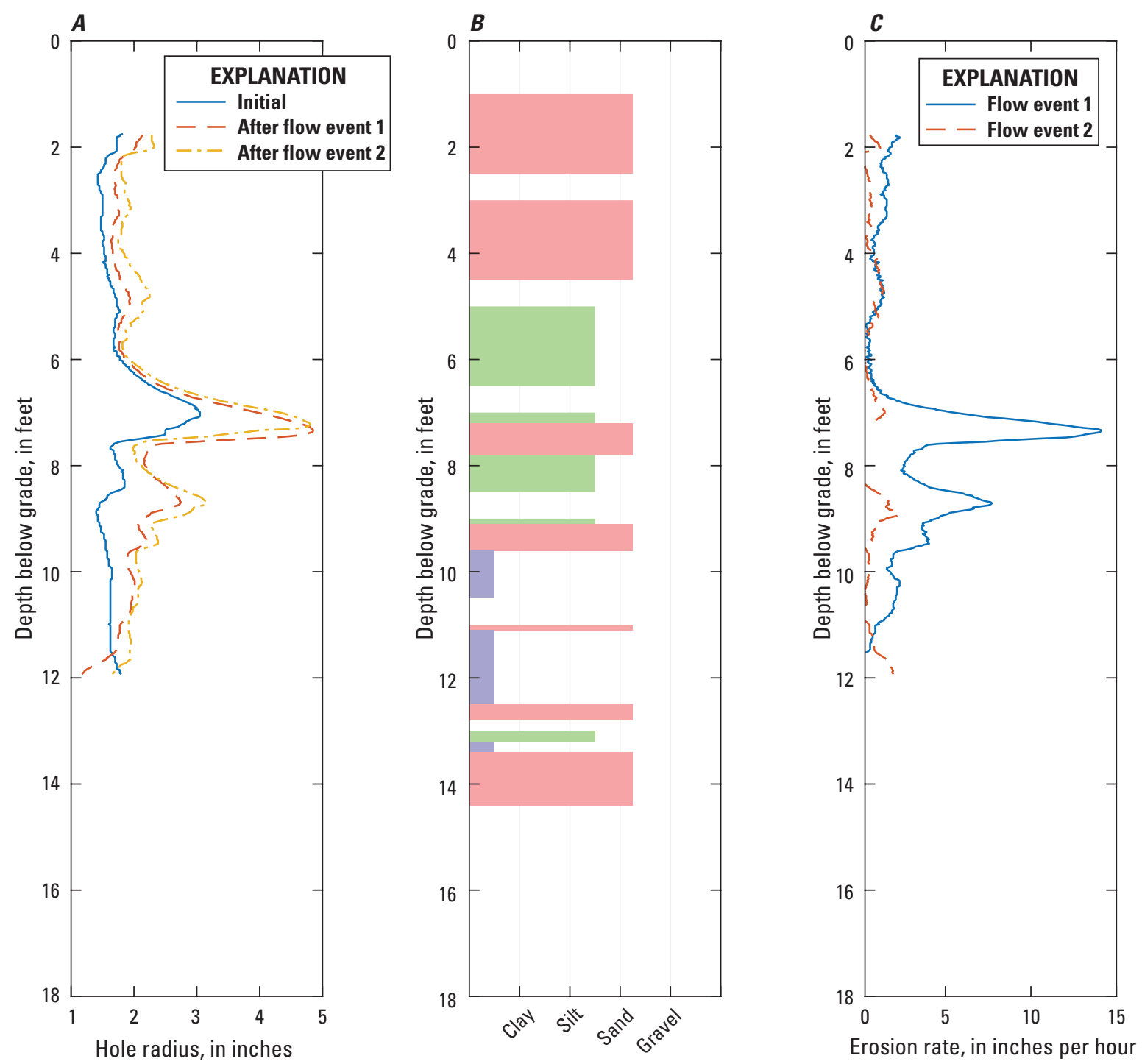

Figure 1.50. Site LAR10 borehole: $A$, mean profiles, $B$, lithology, and $C$, erosion rate. Clays are purple, silts are green, sands are red, and gravels are black. 


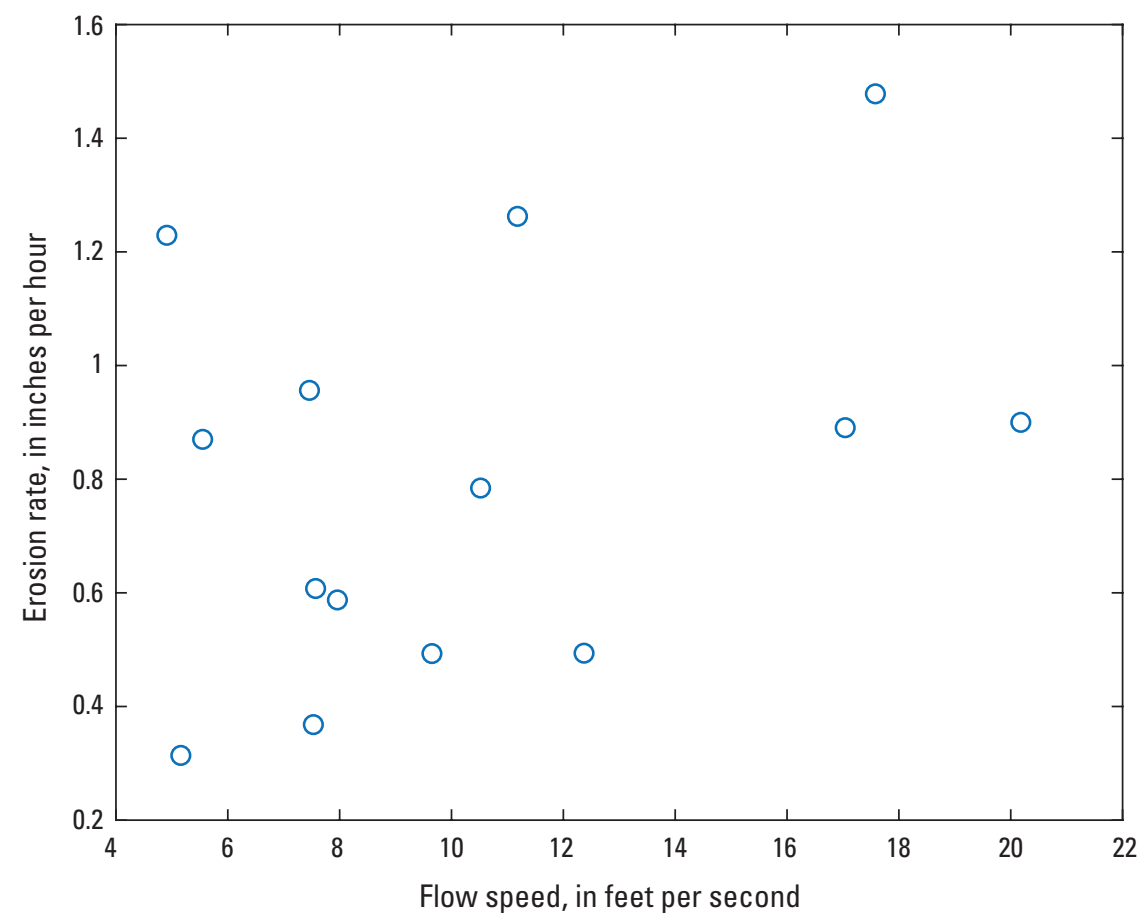

Figure 1.51. Erosion rate versus flow speed at site LAR10 based on data collected between 3- and 6.5-feet-below grade. Each point represents one 6-inch layer of soil.

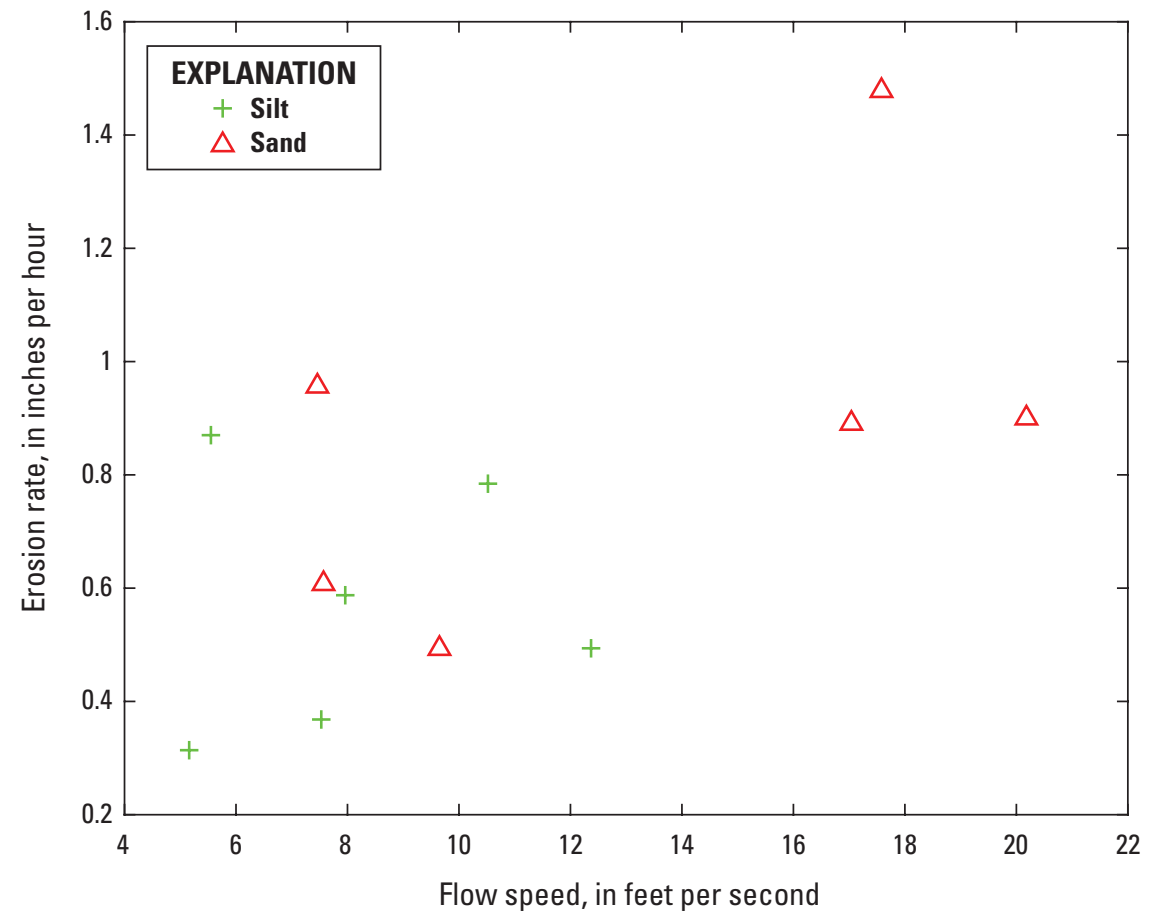

Figure 1.52. Erosion rate versus flow speed and sediment classification based on data collected between 3- and 6.5-feet-below grade, for site LAR10. 


\section{Site LAR3}

This site featured a clay layer above the top of the casing, which was underlain by sands. The surveyed profiles suggested either some slumping within the hole, or sections of the hole that are not round, resulting in computed negative erosion rates in the first of the three tests. The third test displayed negligible erosion, suggesting a critical velocity above $5 \mathrm{ft} / \mathrm{s}$, at least for part of the hole. Some correlation between erosion rate and flow speed is evident.
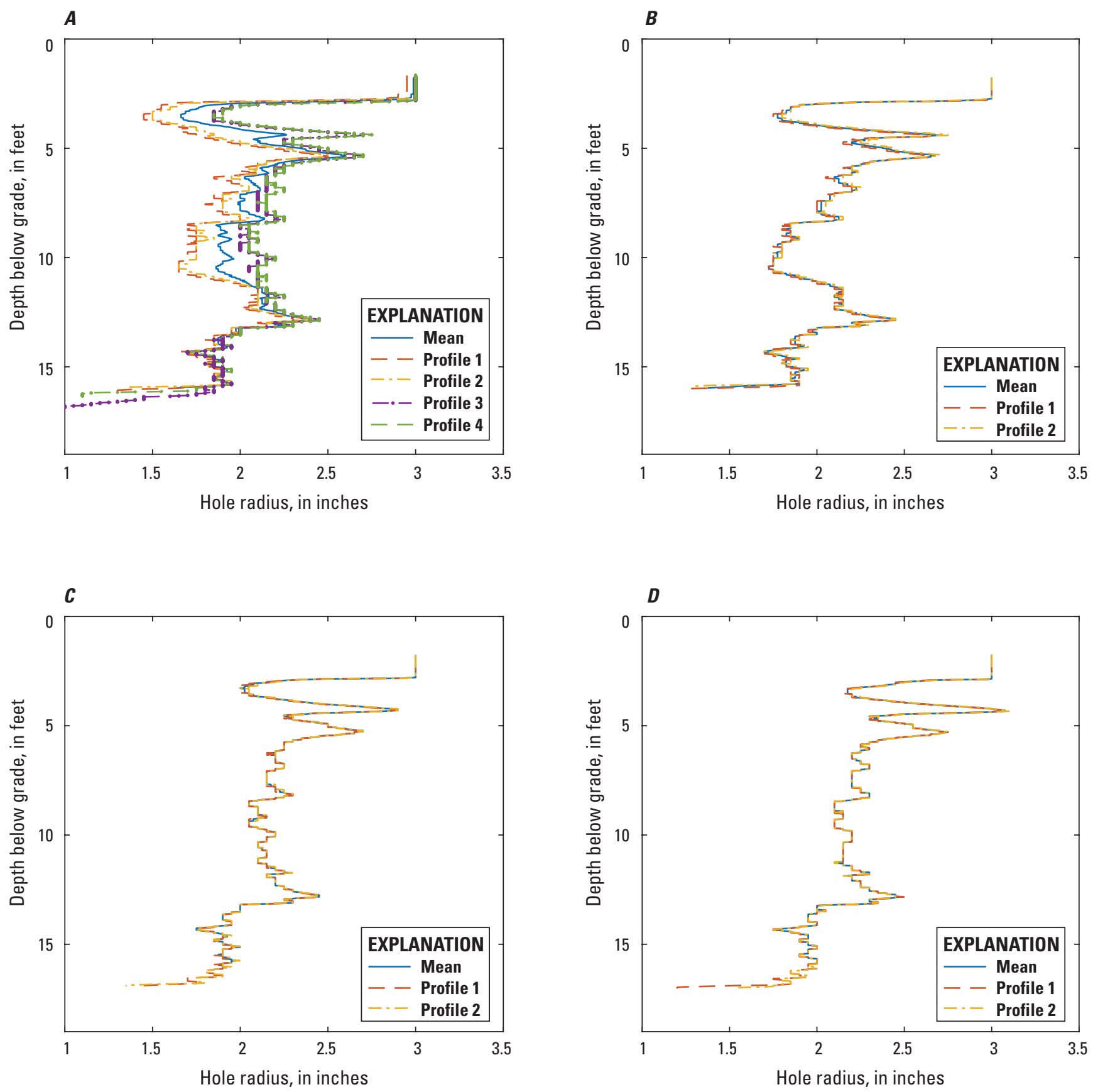

Figure 1.53. Results at site LAR3: $A$, shows the four profiles acquired before testing and the mean of the four results; $B$, shows the condition after flow event $1 ; C$, shows the condition after flow event 2 ; and $D$, shows the condition after flow event 3 . The mean was computed only for depths represented in all surveyed profiles. 


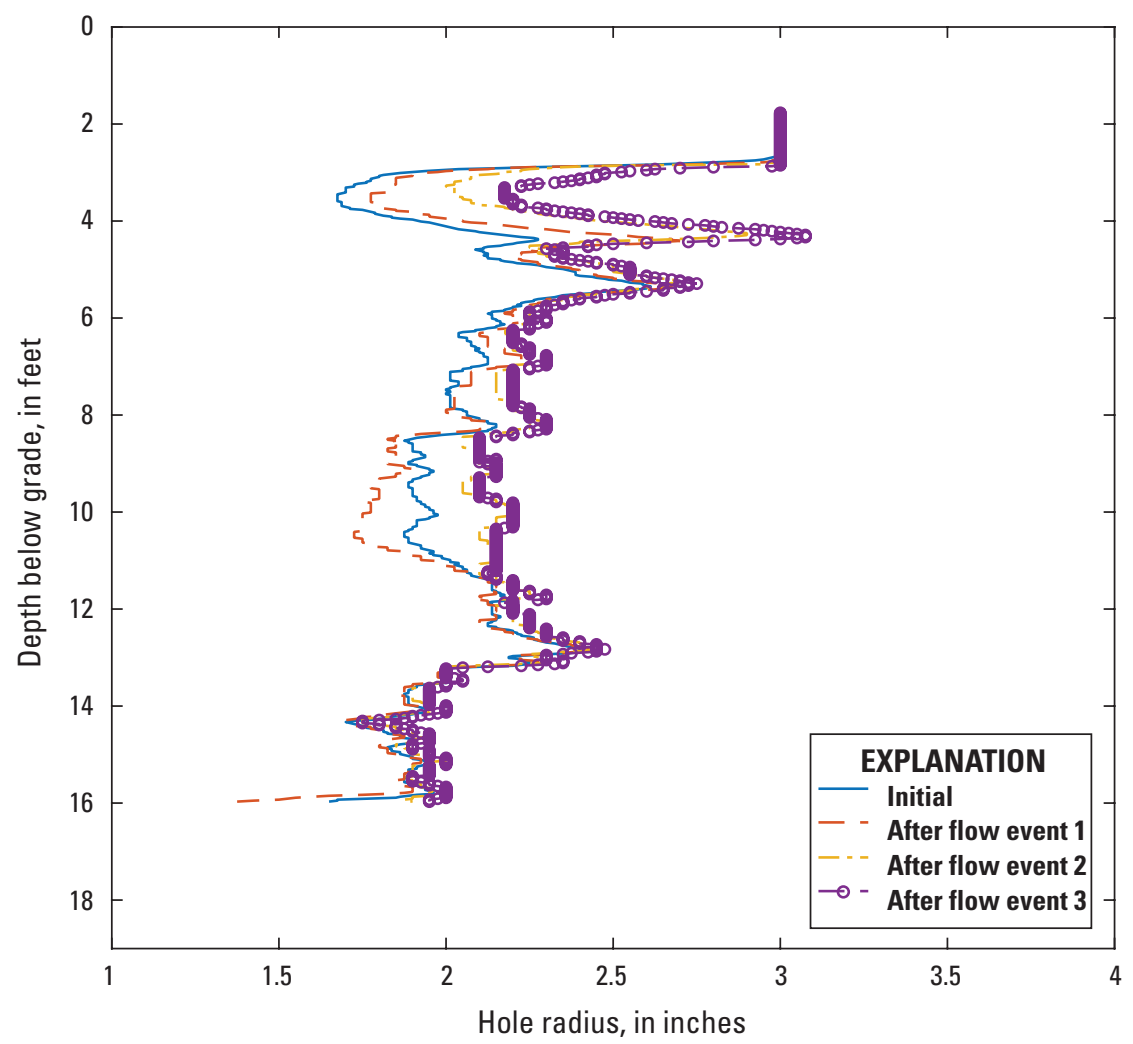

Figure 1.54. Mean profiles for each condition at site LAR3: Initial, after flow events 1, 2 , and 3 . A correction of 0.03 inch was applied to force diameters to match within the casing. 

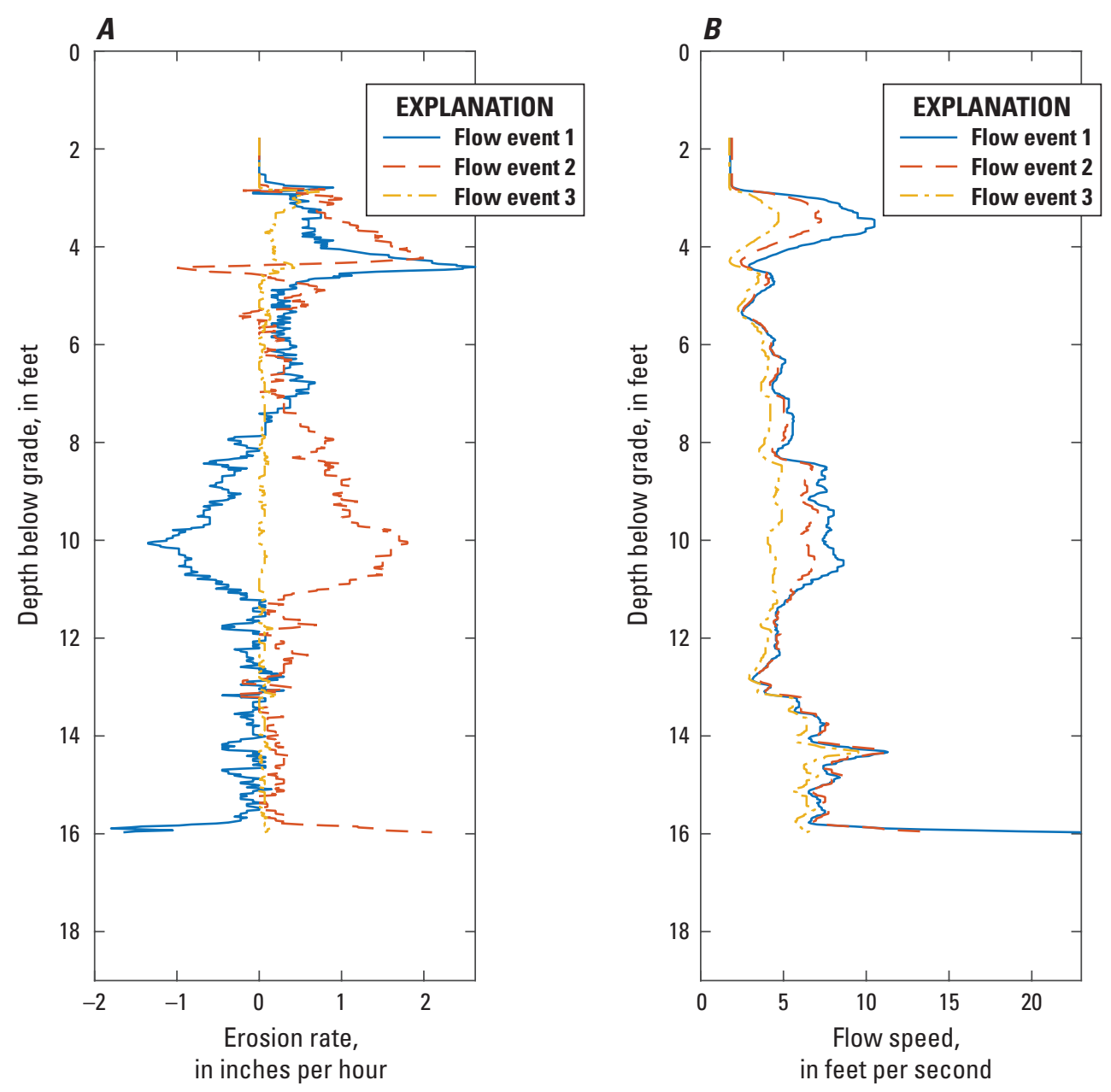

Figure 1.55. Site LAR3: $A$, computed erosion rate versus depth below grade; and $B$, mean flow speed versus depth below grade. 

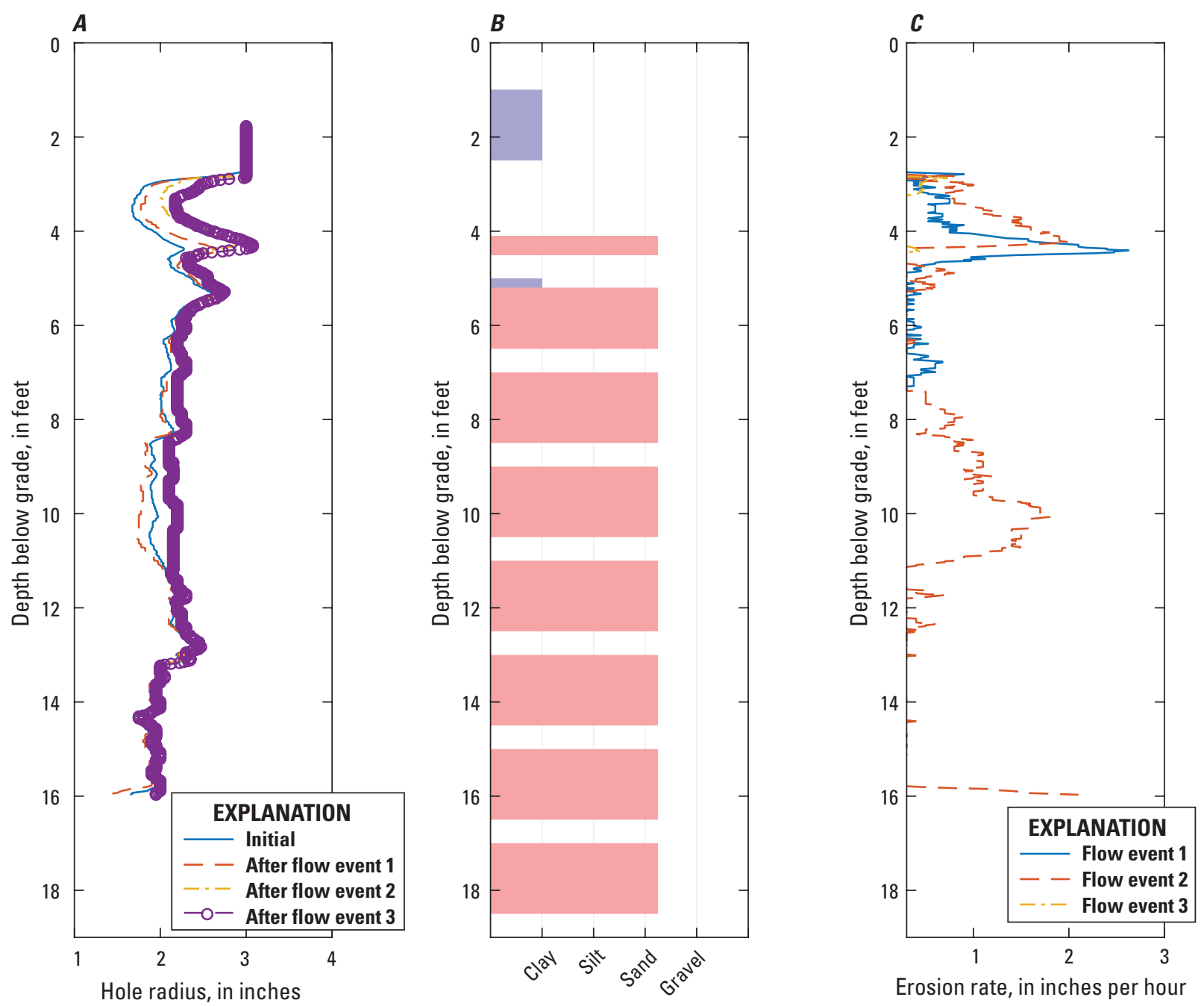

Figure 1.56. Site LAR3 borehole: $A$, mean profiles, $B$, lithology, and $C$, erosion rate. Clays are purple, silts are green, sands are red, and gravels are black. 


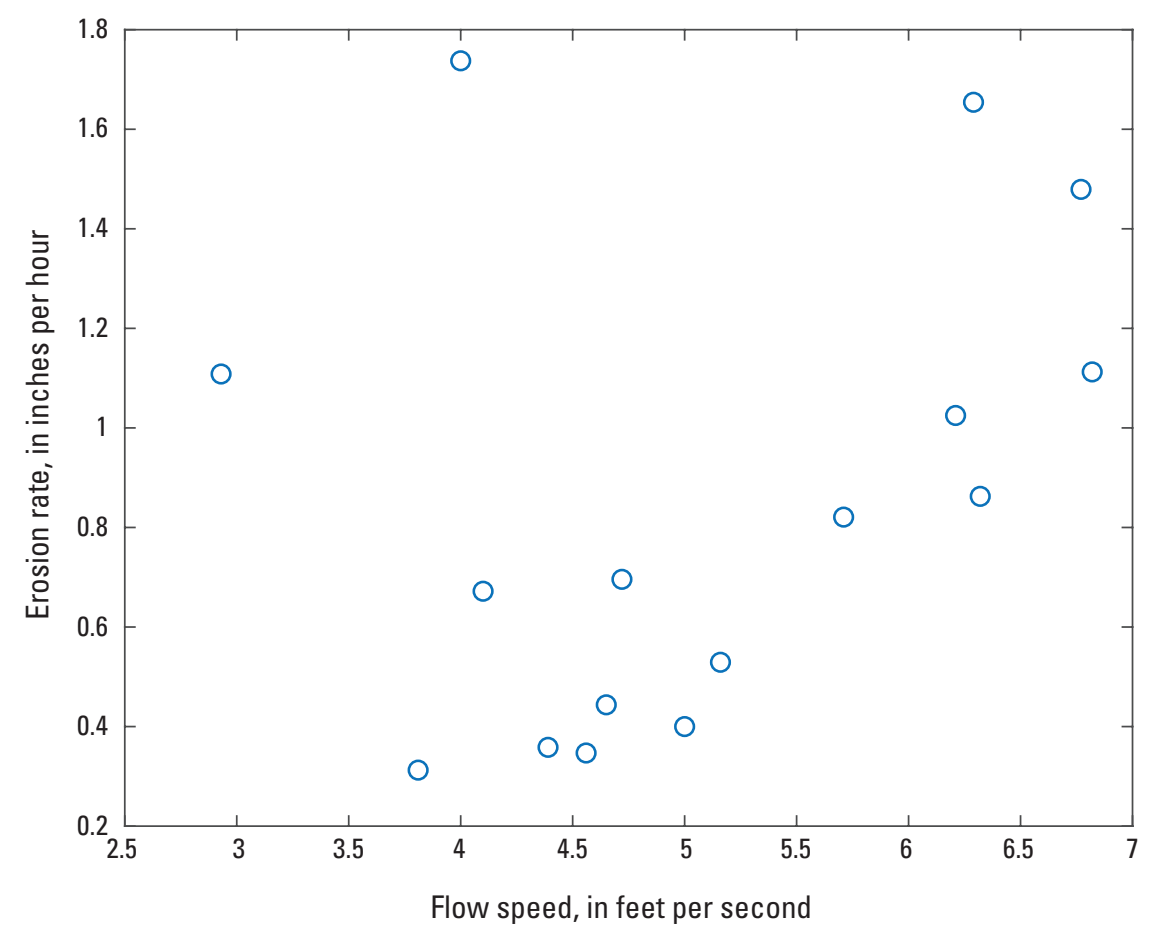

Figure 1.57. Erosion rate versus flow speed at site LAR3 based on data collected between 4- and 15-feet-below grade. Each point represents one 6-inch layer of soil.

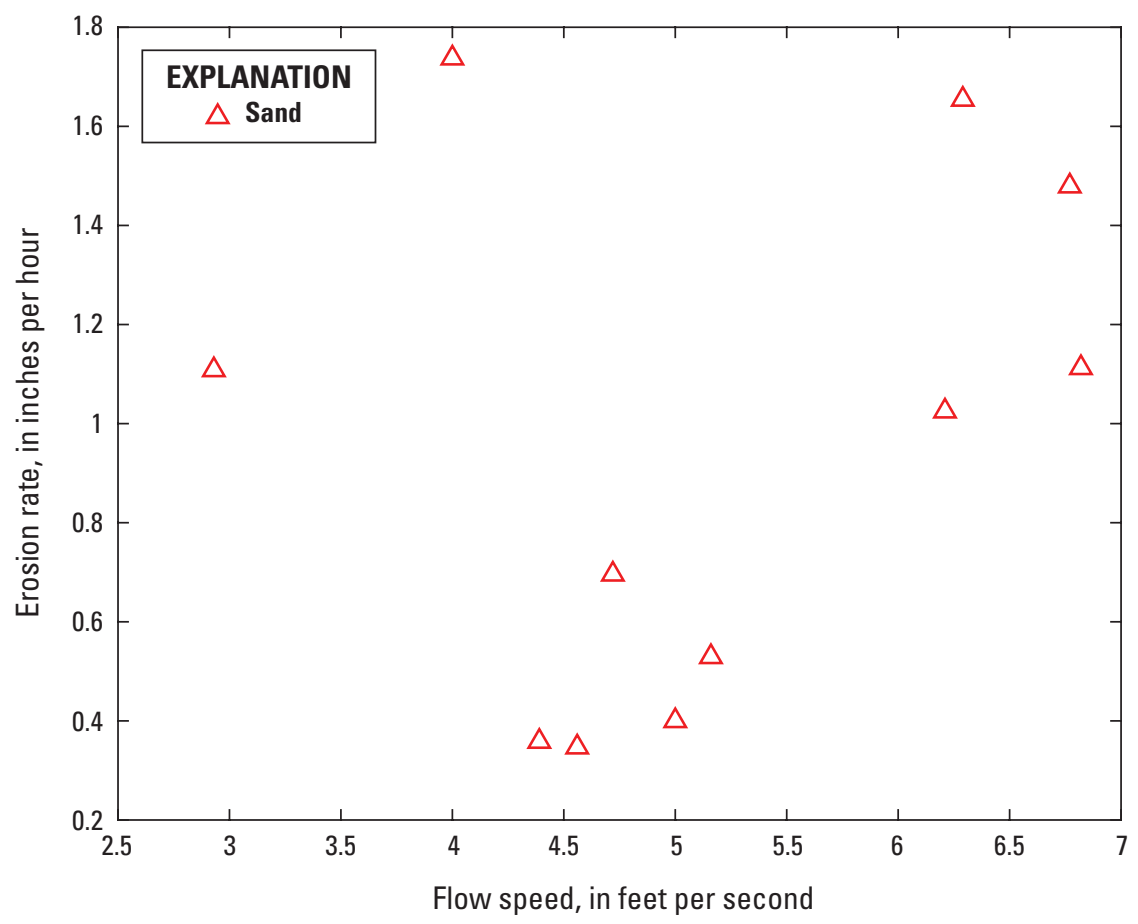

Figure 1.58. Erosion rate versus flow speed and sediment classification based on data collected between 4- and 15-feet-below grade, at site LAR3. 


\section{Site SAC9}

The test at site SAC9 included only one discharge in a hole dominated by clays. Peak flow speed exceeded $10 \mathrm{ft} / \mathrm{s}$, but peak erosion rate occurred where flow speed was closer to $4 \mathrm{ft} / \mathrm{s}$, again revealing how considerably the erodibility can vary vertically, even for the same soil type.

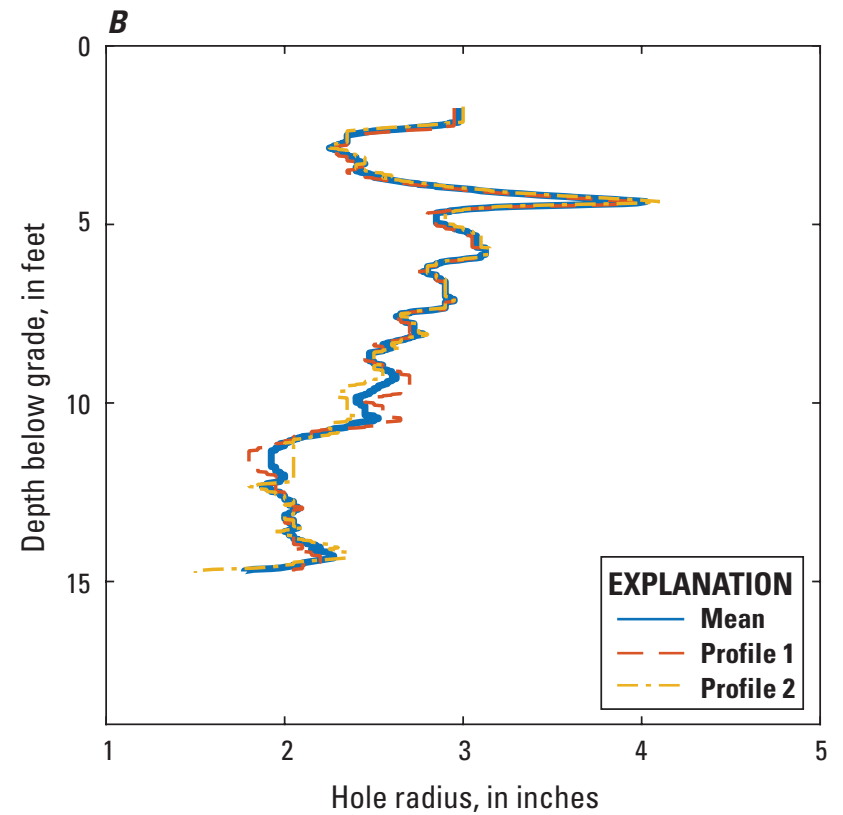

Figure 1.59. Results at site SAC9: $A$, shows the three profiles acquired before testing and the mean of the three results; and $B$, shows the condition after flow event 1 . The mean was computed only for depths represented in all surveyed profiles.

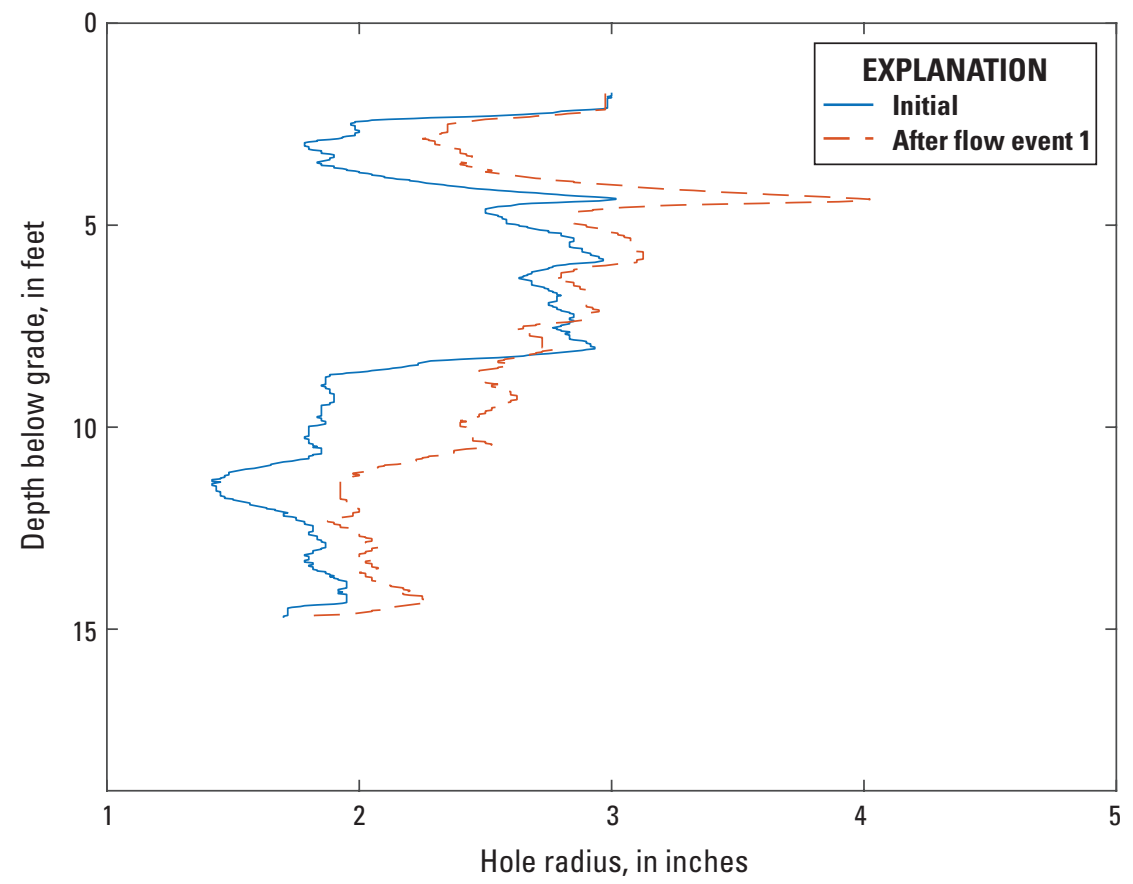

Figure 1.60. Mean profiles for each condition at site SAC9: Initial and after flow event 1 . A correction of 0.02 inch was applied to force profiles to match inside the polyvinyl chloride casing. 

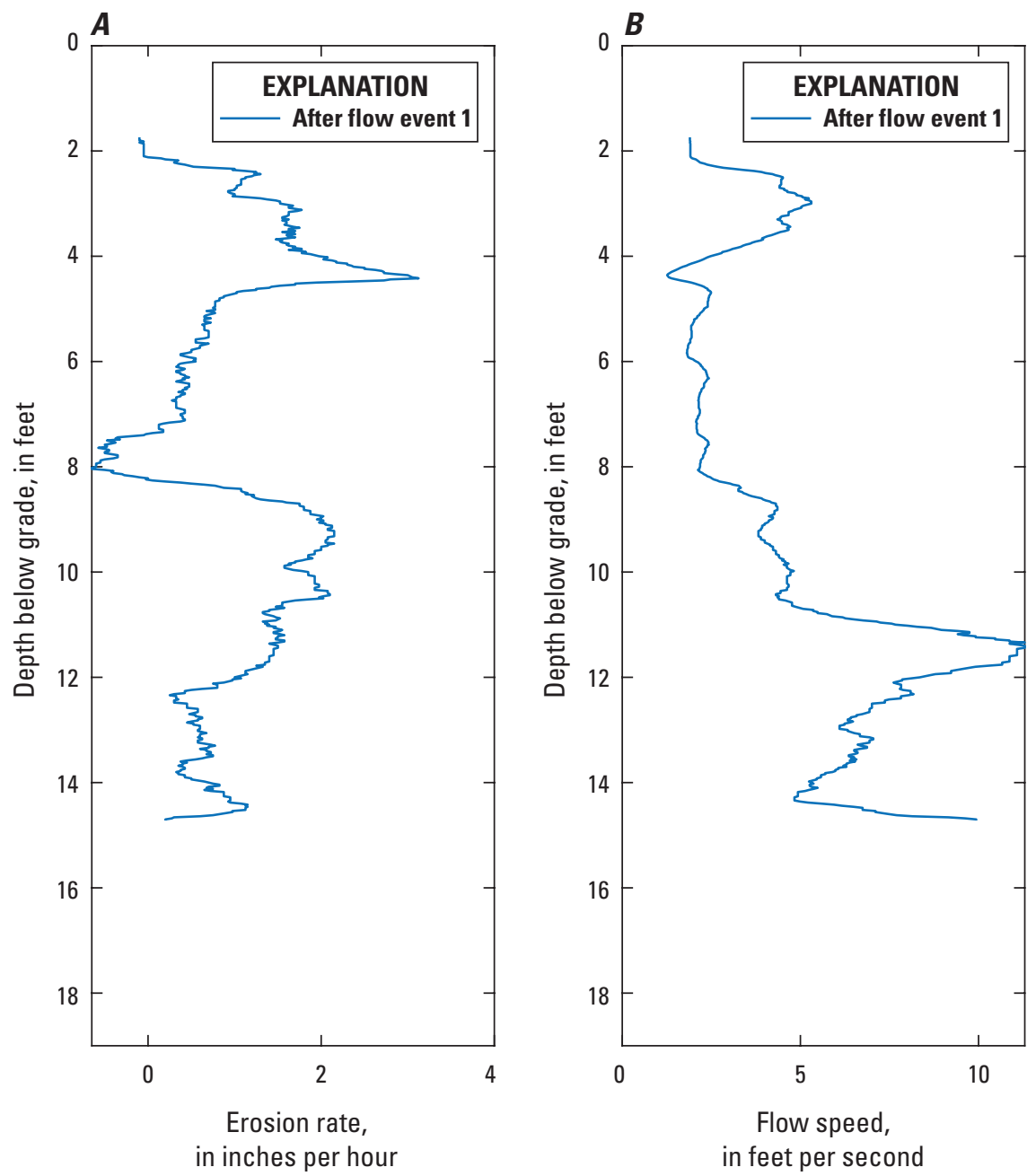

Figure 1.61. Site SAC9: $A$, computed erosion rate versus depth below grade; and $B$, mean flow speed versus depth below grade. 

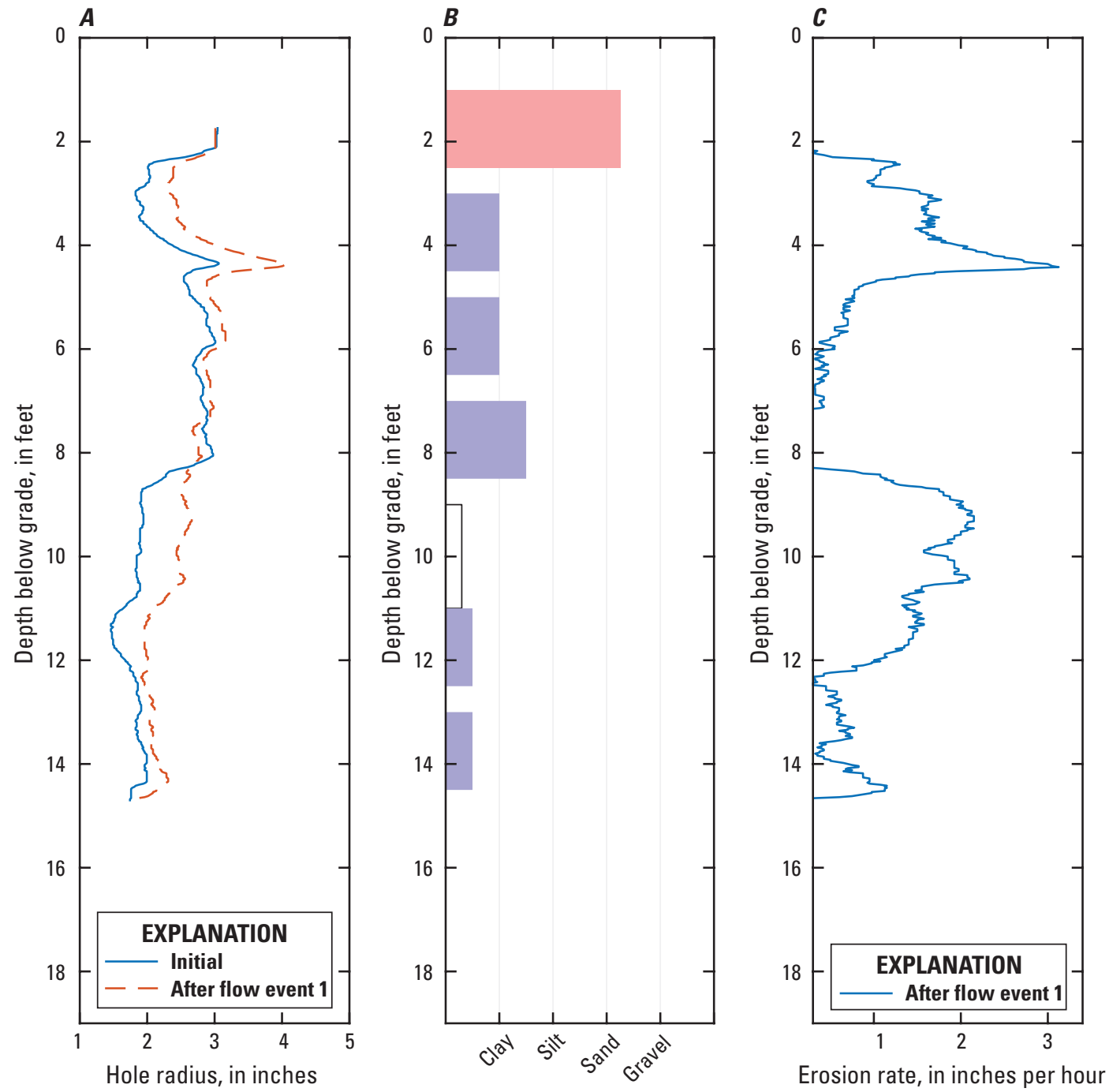

Figure 1.62. Site SAC9 borehole: $A$, mean profiles, $B$, lithology, and $C$, erosion rate. In the lithology plot, a white box indicates a Shelby tube sample. Clays are purple, silts are green, sands are red, and gravels are black. 


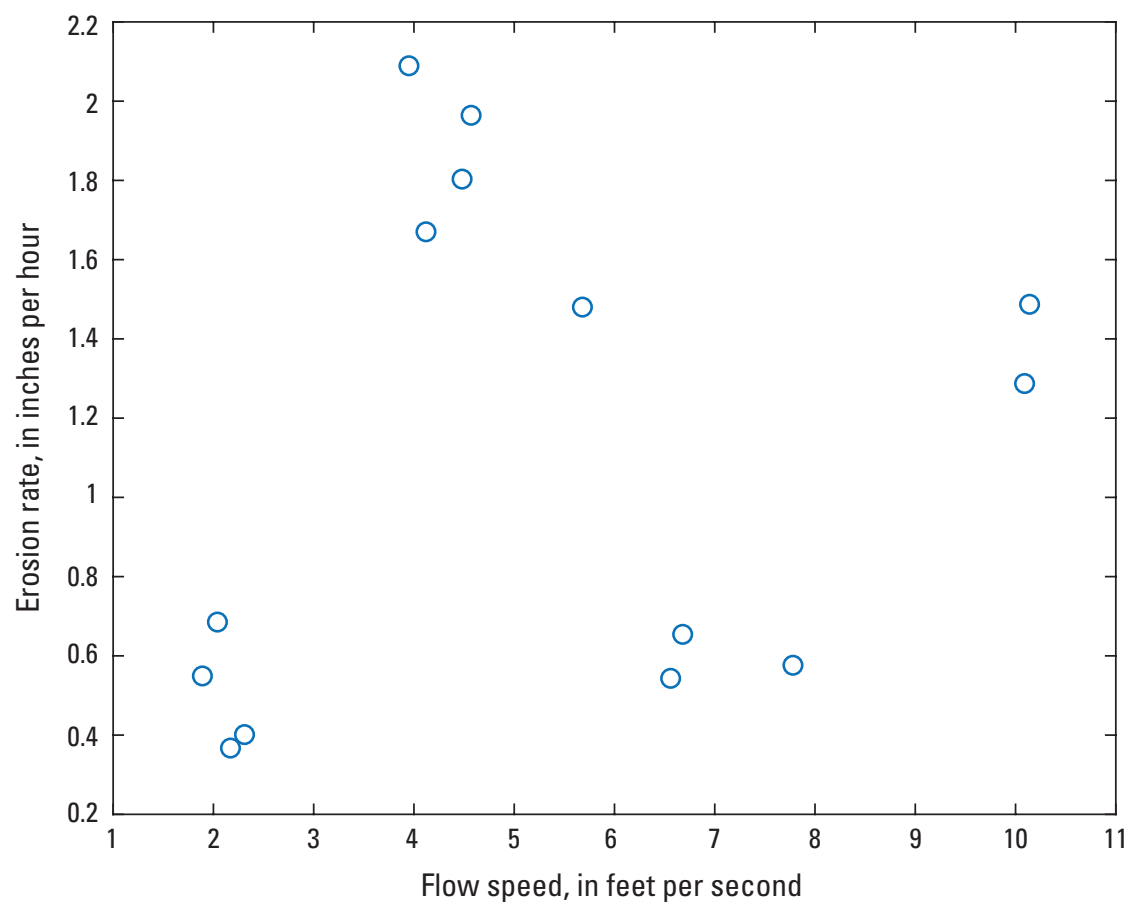

Figure 1.63. Erosion rate versus flow speed at site SAC9 based on data collected between 5- and 14-feet-below grade. Each point represents one 6-inch layer of soil.

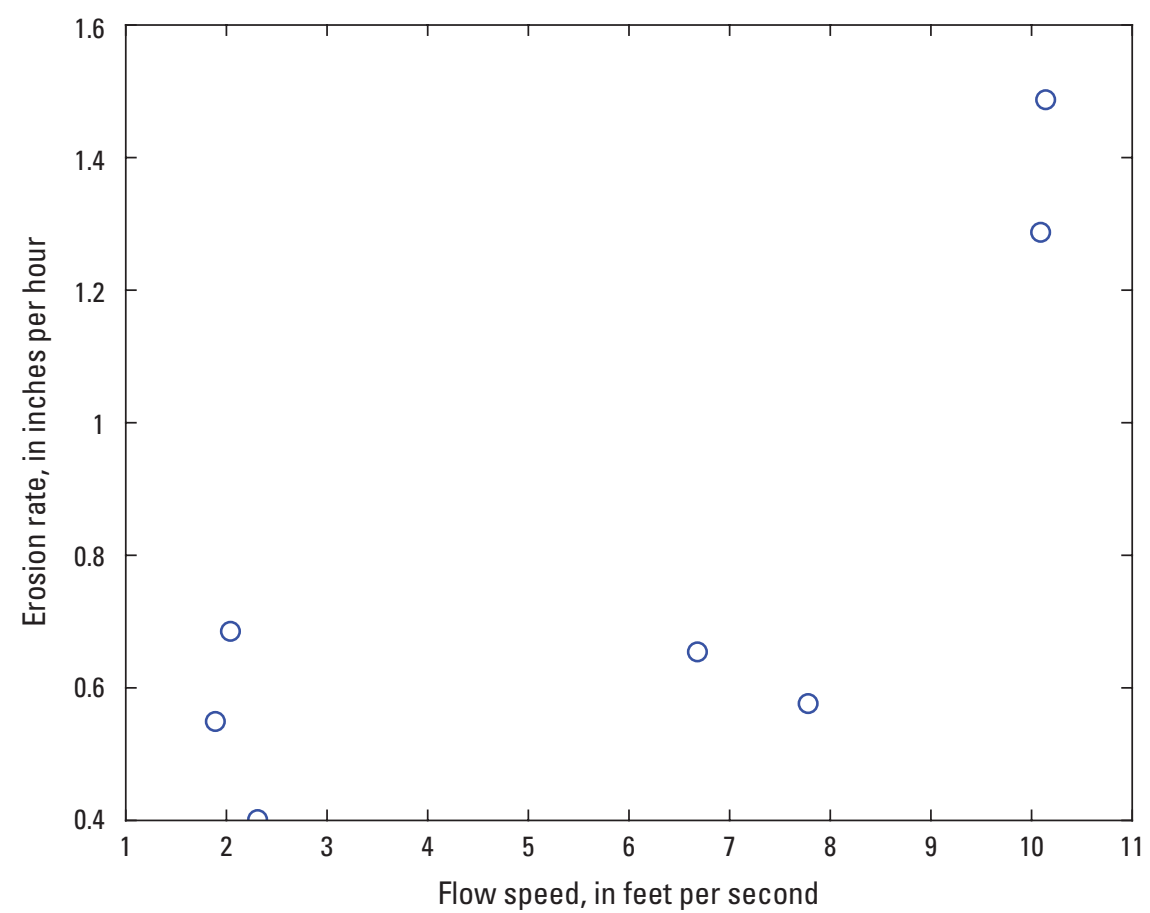

Figure 1.64. Erosion rate versus flow speed and sediment classification for site SAC9 based on data collected between 5- and 14-feet-below grade. 


\section{SAC3 Test with Drilling Mud (SAC3B2)}

A second test was performed at site $\mathrm{SAC} 3$, using drilling mud. Compared to the earlier test at the same site, computed erosion rates were considerably lower. The erosion rate was negligible except in the first test with the largest discharge.
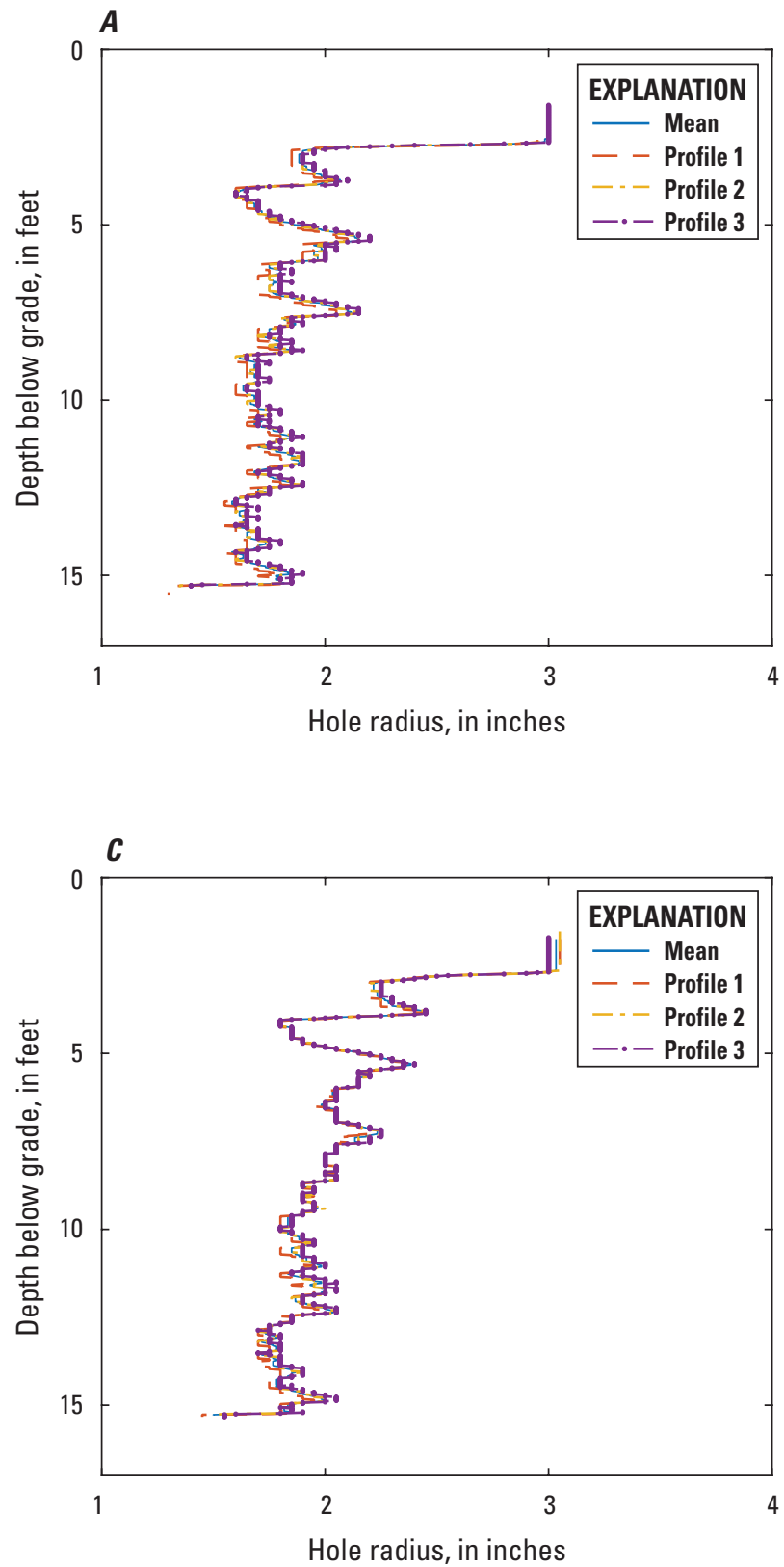

Erosion rates were reduced from a maximum of greater than $2 \mathrm{in} / \mathrm{hr}$ for the test with water to less than $0.9 \mathrm{in} / \mathrm{hr}$ when drilling mud was used.
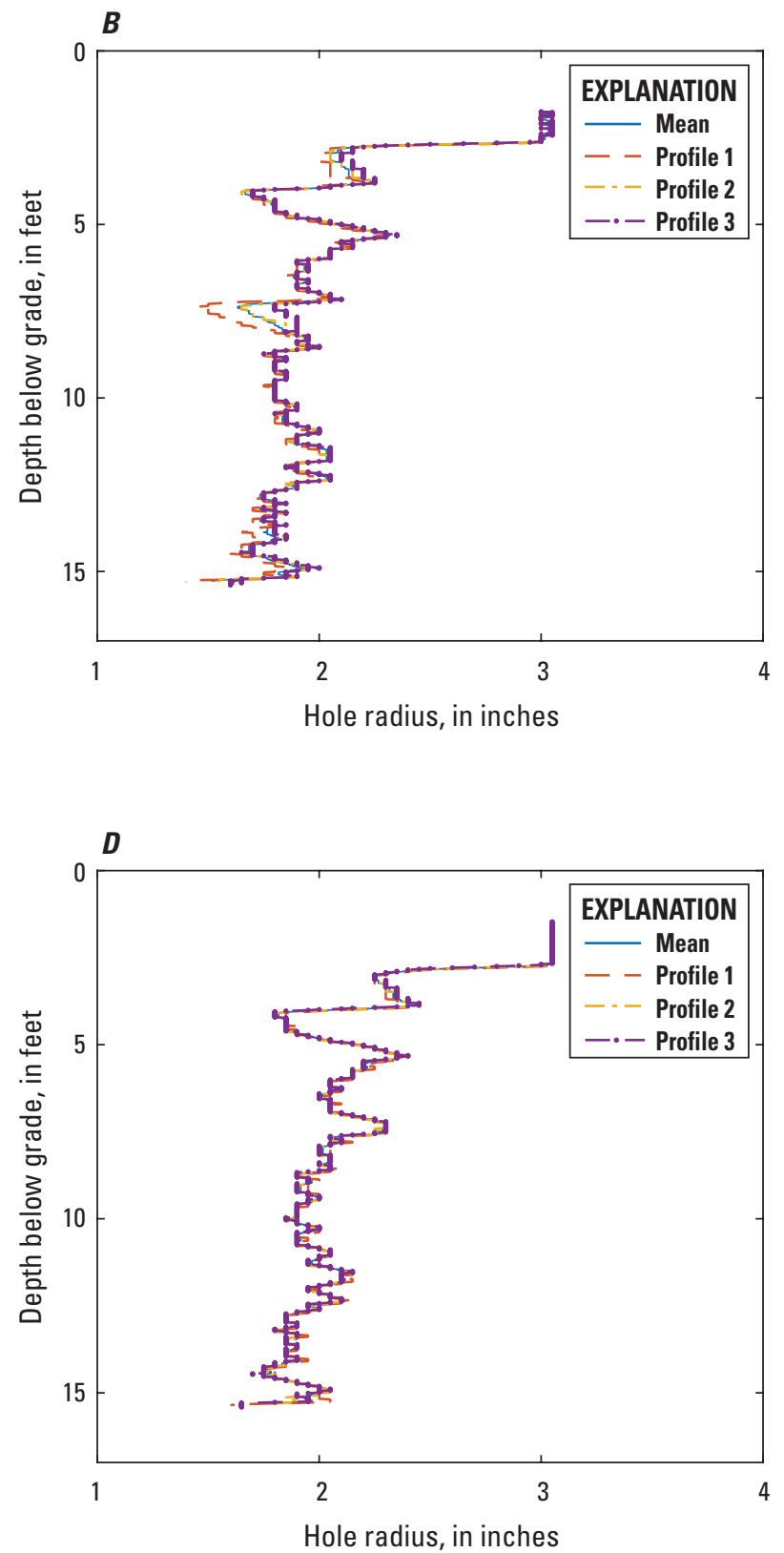

Figure 1.65. Results for the test at site SAC3B2, which was a repeat of the test at site SAC3B, including the use of drilling mud instead of water: $A$, shows the three profiles acquired before testing and the mean of the three results; $B$, shows the condition after flow event $1 ; C$, shows the conditions after flow event 2; and $D$, shows the conditions after flow event 3 . The mean was computed only for depths represented in all surveyed profiles. 


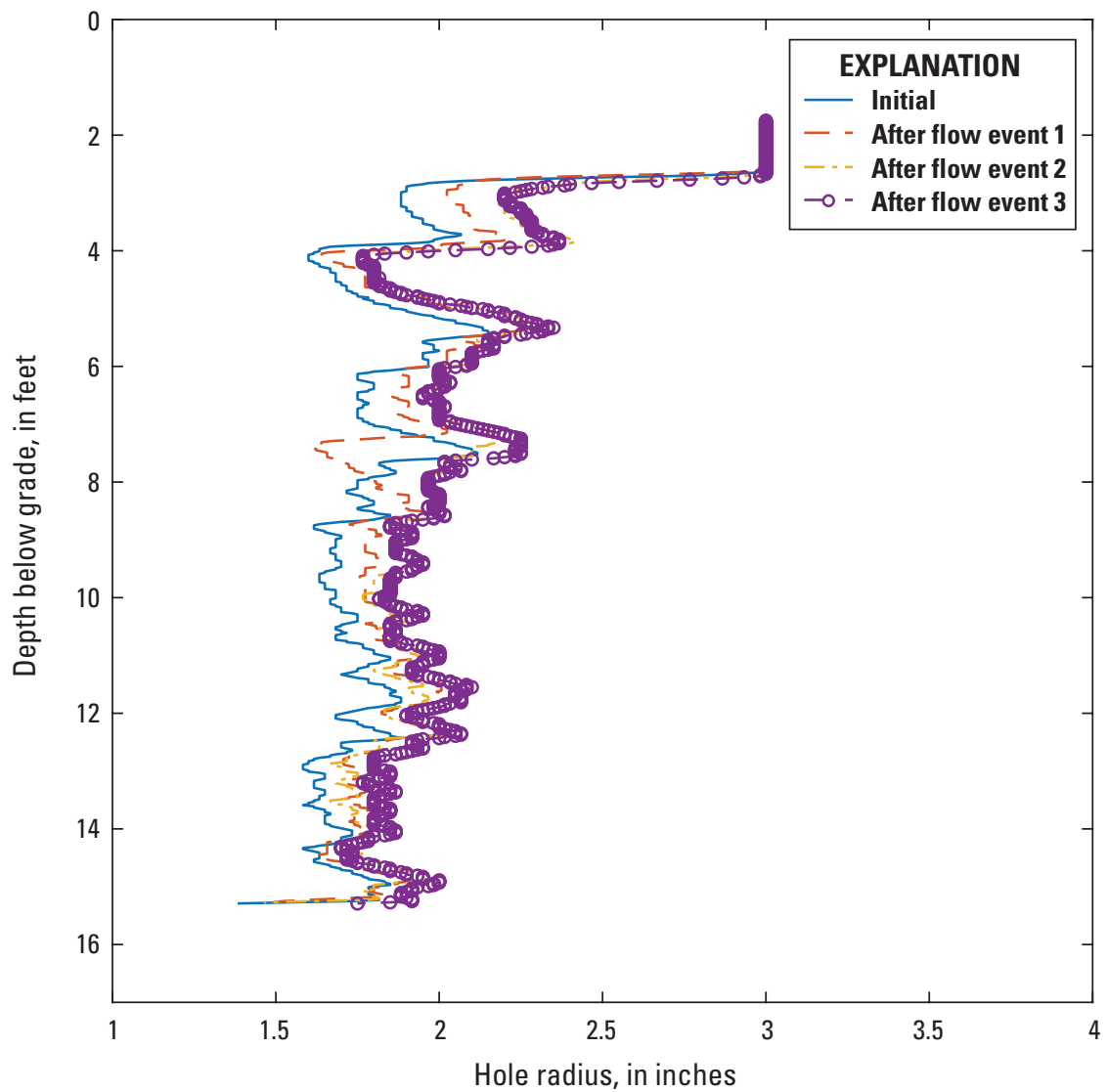

Figure 1.66. The evolution of mean profiles for each condition at site SAC3B2, with use of drilling mud: Initial, and after flow events 1, 2, and 3. A correction of 0.1 inch was applied to force diameters to match within the polyvinyl chloride casing. 

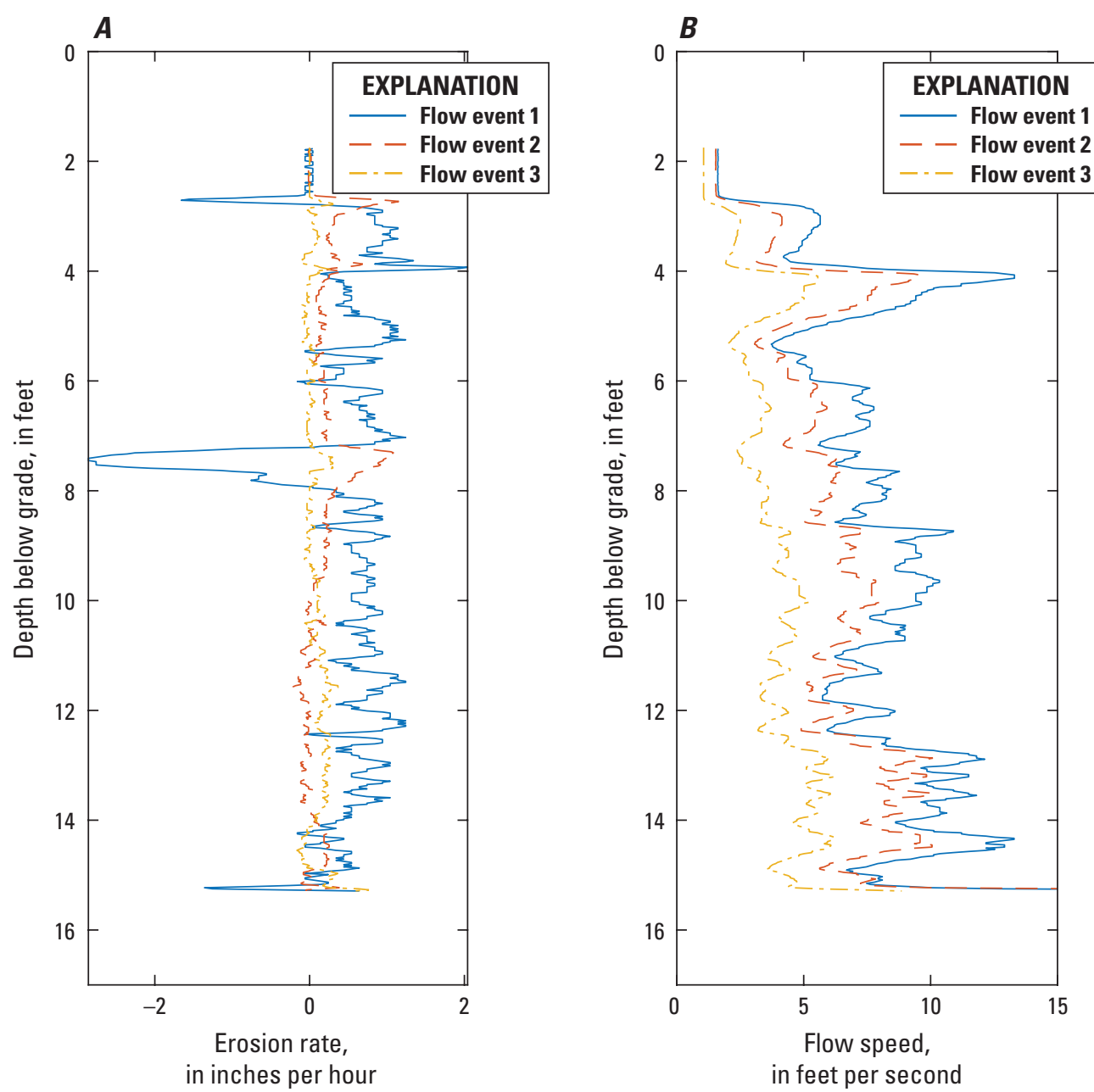

Figure 1.67. Site SAC3B2: $A$, computed erosion rate with drilling mud versus depth below grade; and $B$, mean flow speed versus depth below grade. 

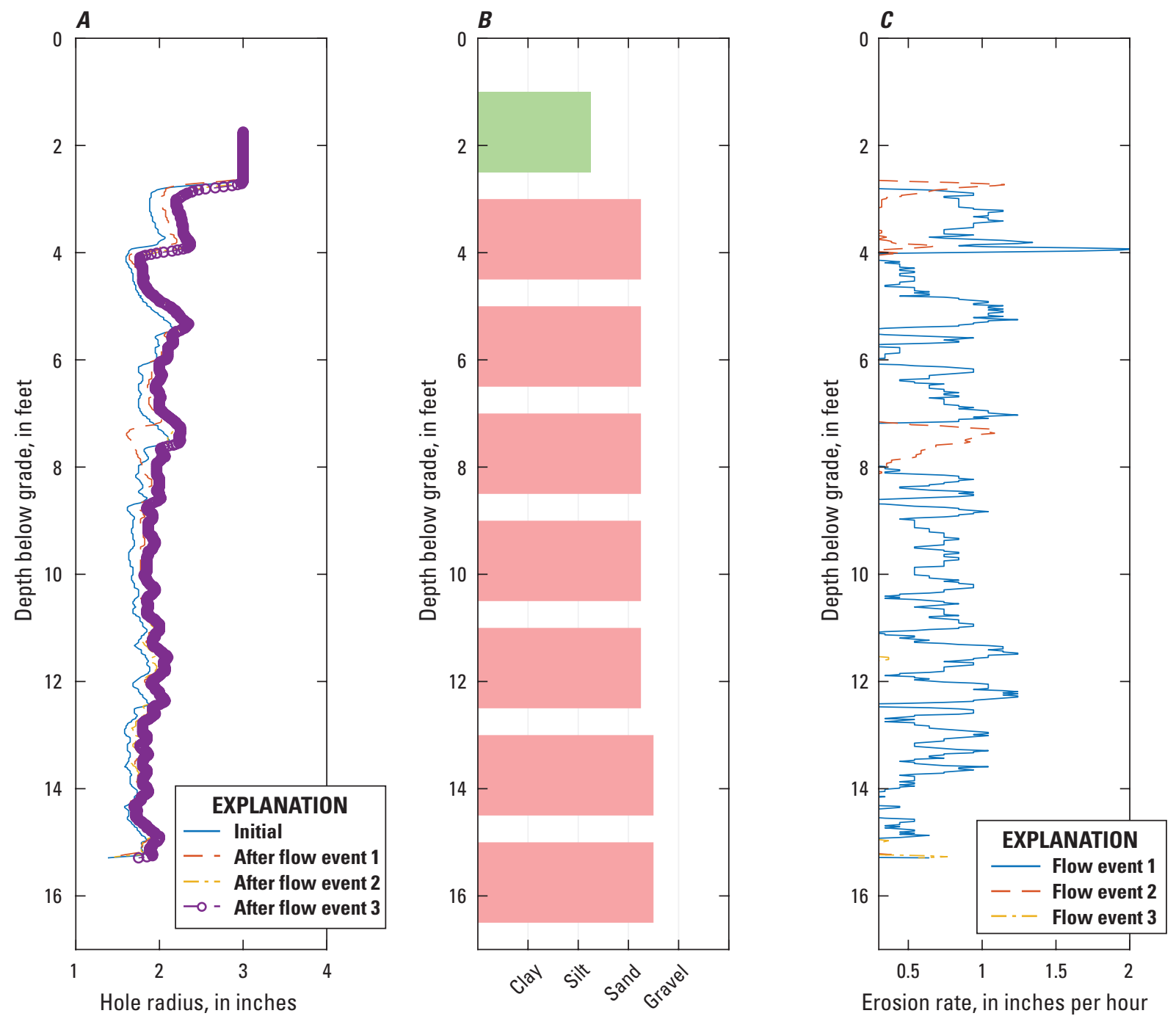

Figure 1.68. Site SAC3B2 borehole: $A$, mean profiles, $B$, lithology, and $C$, erosion rate. Clays are purple, silts are green, sands are red, and gravels are black. 


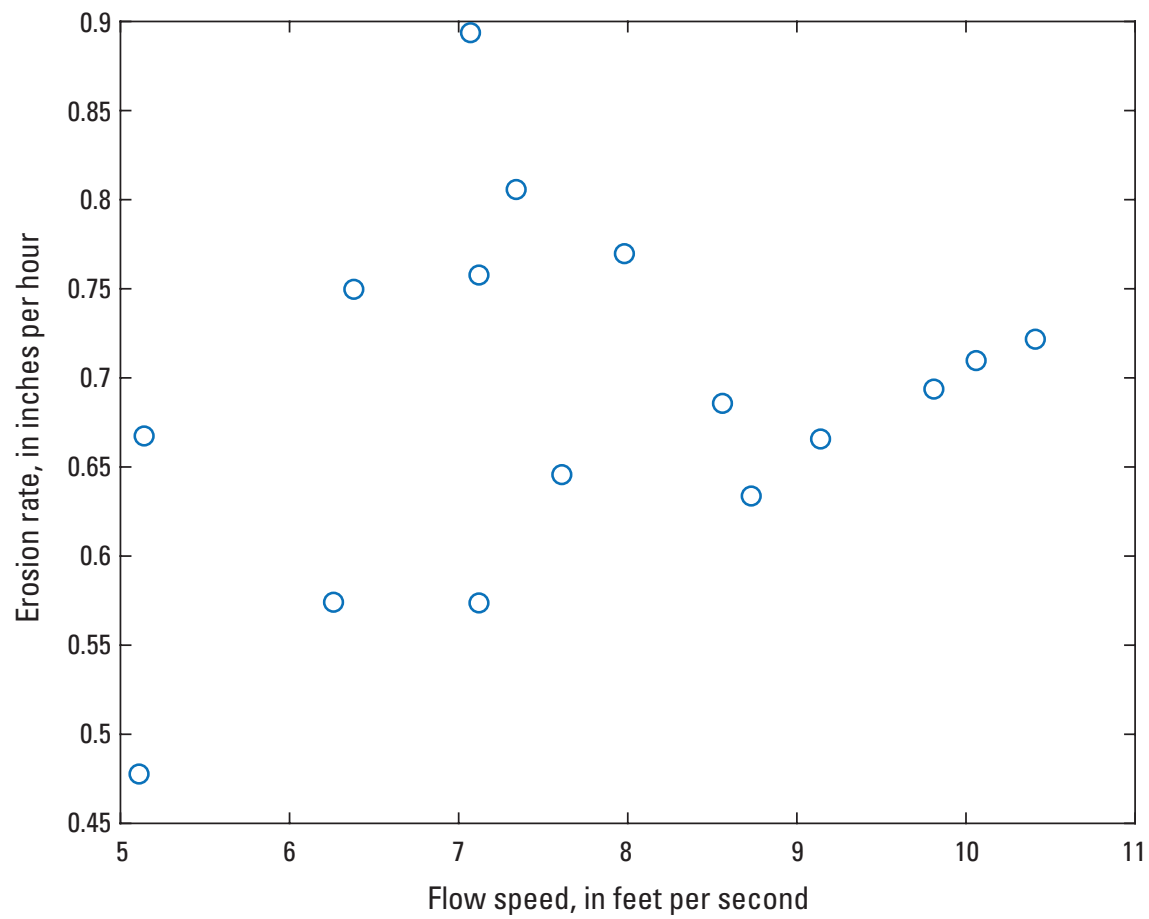

Figure 1.69. Erosion rate with drilling mud versus flow speed and sediment classification at site SAC3B2, based on data collected between 5.5- and 14-feet-below grade. Each point represents one 6-inch layer of soil.

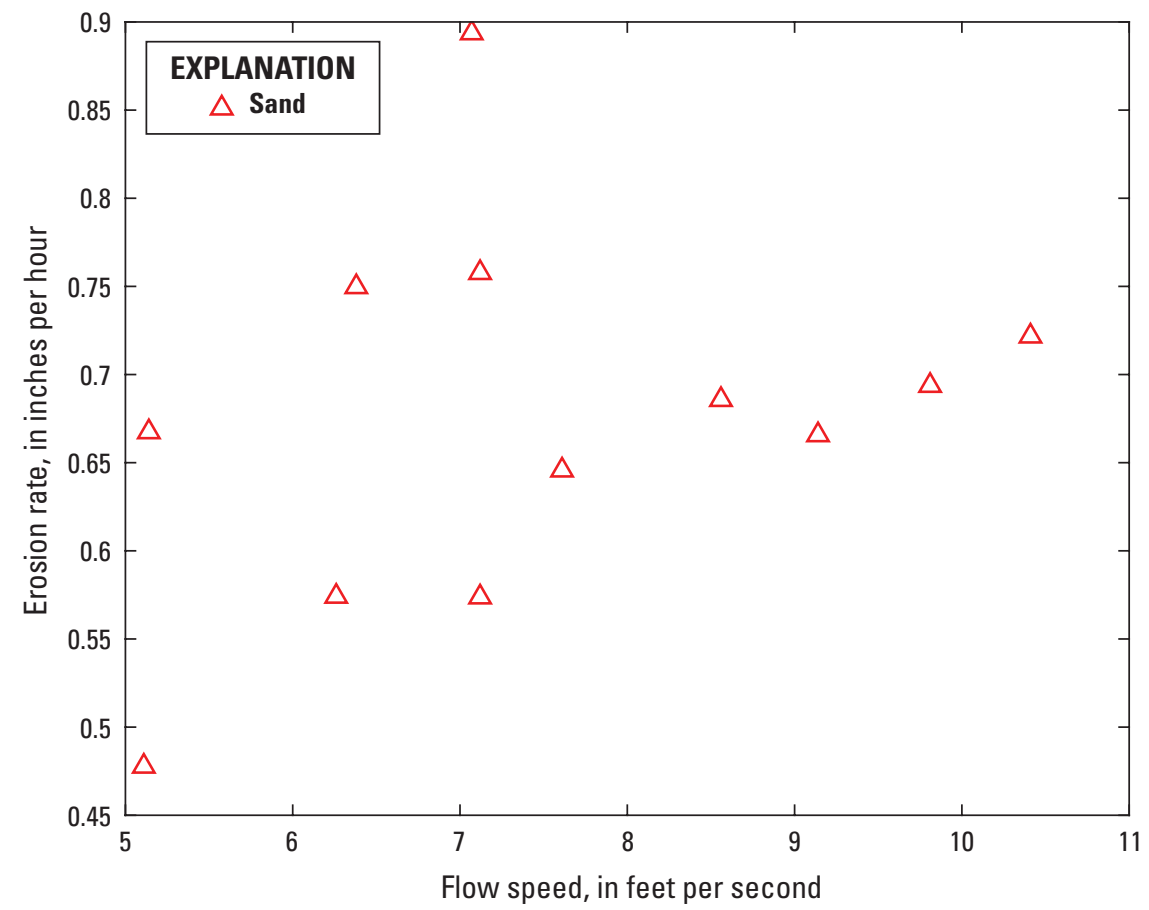

Figure 1.70. Erosion rate with drilling mud versus flow speed and sediment classification based on data collected between 5.5- and 14-feet-below grade, at site SAC3B2. 


\section{Appendix 2. Flowmeter and Water Level Logging}

The borehole erosion tests (BETs) require knowledge of the discharge out of the drilling rod, which can vary during the test as the hole erodes. Water also is lost during the test, and any water loss within the hole during testing means that discharge varies with altitude above the bottom of the hole. This makes flow speed dependent on altitude and time, even for a hole of constant (over its length) diameter. Many tests featured thick layers of sand and there was concern that water would be lost to these layers during tests.

The testing procedure involved pumping water in a loop to attempt to conserve mass. The water was provided in a shaker tank holding up to 1,000 gallons (gal); this supplied a centrifugal pump, powered by a diesel engine that pumped water through a system of pipes and hoses up to the top of the drilling rig, where it entered the drilling rod. An electromagnetic flowmeter was installed within this plumbing network, to measure discharge.

The water exiting the drilling rod flowed upwards out of the drilled hole and into a 70-gal receiving tank, which housed another pump to lift the water back into the shaker tank, completing the circuit (fig. 2.1). Some water remained in the drilled hole, the receiving tank, and the plumbing system at the end of each test and appears as a loss of water in addition to any water lost during the test.

The flowmeter (fig. 2.2) output fluctuated during each test. The display on the flowmeter was recorded at 1-minute intervals for each test. Later, digital loggers for water level and discharge were utilized to, more frequently, document time-dependence in discharge and water level.

The flowmeter outputs digital and analog signals. One of the analog outputs is 4-20 milliamperes ( $\mathrm{mA}$ ) of current, with the lower bound corresponding to zero flow and the upper bound corresponding to the user-selected maximum discharge. The flowmeter utilized is designed for up to 200 gallons per minute ( $\mathrm{gal} / \mathrm{min}$ ) but will measure and display larger values. The analog output can be set to output $20 \mathrm{~mA}$ for lower discharges if the user selects this to get higher resolution of low flows. No temperature correction was applied to the data, and it was not possible to check the validity of the flowmeter output with the equipment available in the field.

An Arduino microprocessor was used to log the analog output from the flowmeter, at 1 hertz (Hz; fig. 2.3). This was not successful in every instance; during the first use, the flowmeter was set to output $20 \mathrm{~mA}$ at $60 \mathrm{gal} / \mathrm{min}$, so higher flow rates were not captured. Power to the microprocessor failed on another occasion, and a bad wiring connection led to no data in two other instances. But for 7 of the BETs, the datalogger captured $1-\mathrm{Hz}$ data to reveal time dependence in the discharge. Figure 2.4 provides one example. The mean and the standard deviation of the discharge, where $1 \mathrm{~Hz}$ data are available, is shown in table 2.1.
The shaker tank that served as the water reservoir for the experiments has a width of 6 feet (ft), length of $7 \mathrm{ft}$, and depth of $3.5 \mathrm{ft}$, for a total volume of approximately 1,000 gal. A Hobo datalogger (Onset Computer Corporation) equipped with a pressure sensor (resolution 0.002 pound per square inch $\left(\mathrm{lb} / \mathrm{in}^{2}\right)$ and a typical error of 0.1 percent of full-scale reading of $13 \mathrm{ft}$ of pressure head) was suspended above the bottom of the tank to observe change in water depth during five of the later tests; it is not vented so is affected by barometric pressure changes, which were assumed negligible during any given test. Pressure data were recorded at $0.1 \mathrm{~Hz}$, converted to pounds per square foot, and divided by a constant 62.4 pounds per cubic foot $\left(\mathrm{lb} / \mathrm{ft}^{3}\right)$ to convert to water depth in feet. The total depth was not of interest, but rather the change in depth during a test, so water temperature was not considered.

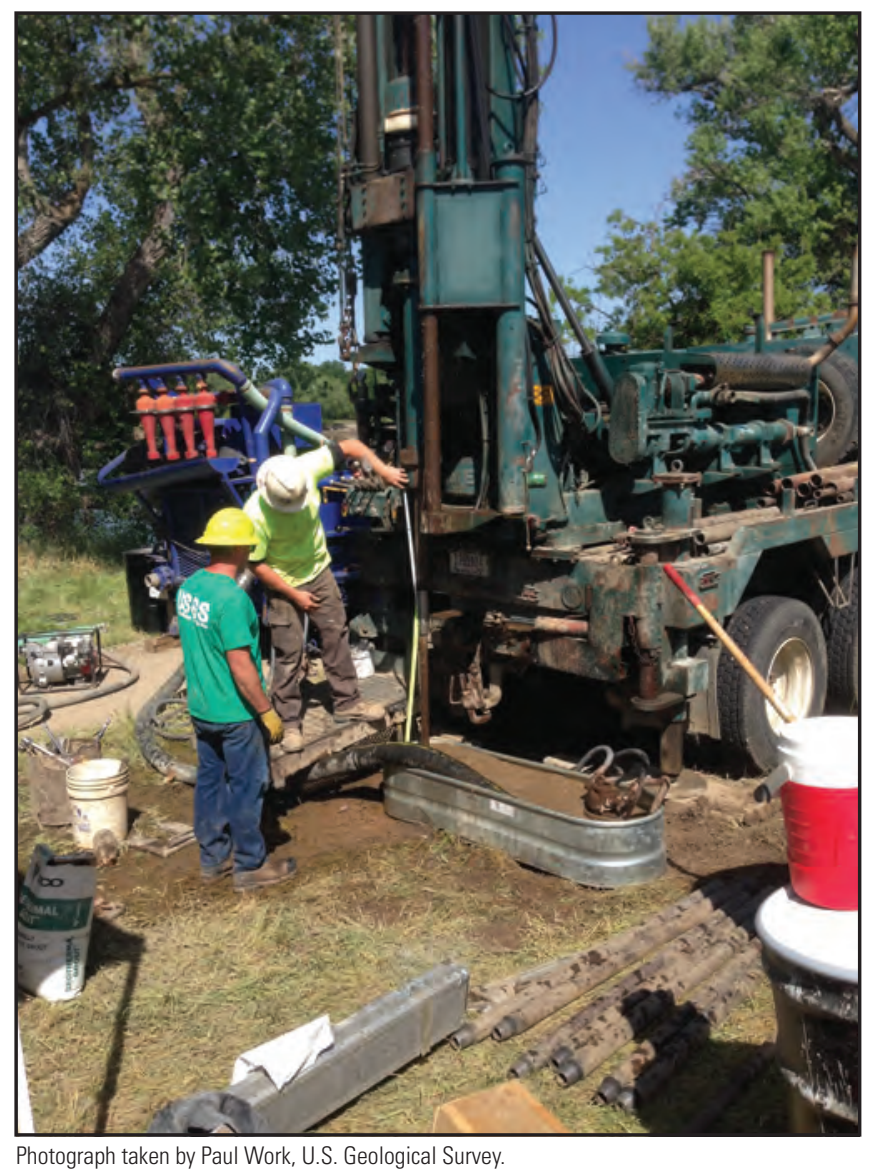

Figure 2.1. A drill rig being prepared for a borehole erosion test. Water is pumped from the blue shaker trailer in the background and travels through a flowmeter, into the top of the drilling rod, down the hole, and back up into the gray receiving tank. It then is pumped back into the shaker tank. 


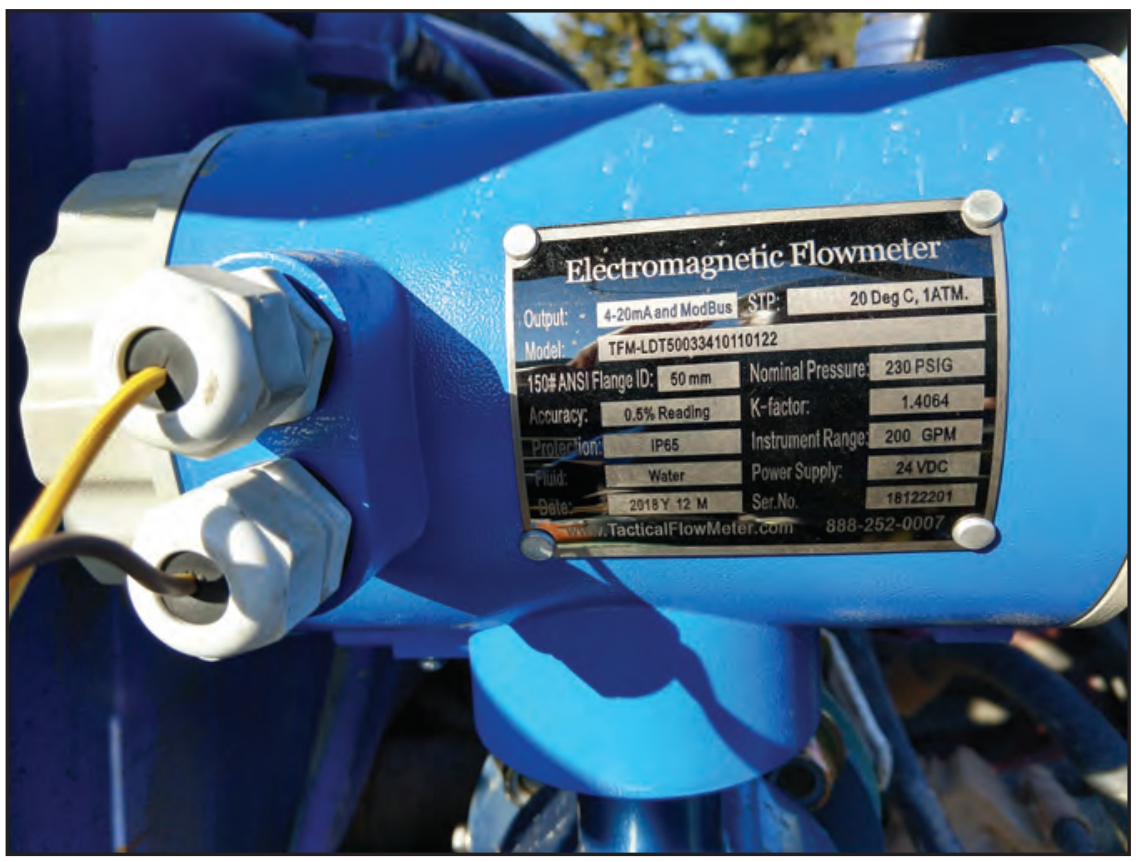

Site LAR9, (Photograph taken on April 13, 2019, by Paul Work, U.S. Geological Survey.)

Figure 2.2. The flowmeter that was used to monitor discharge during each test.

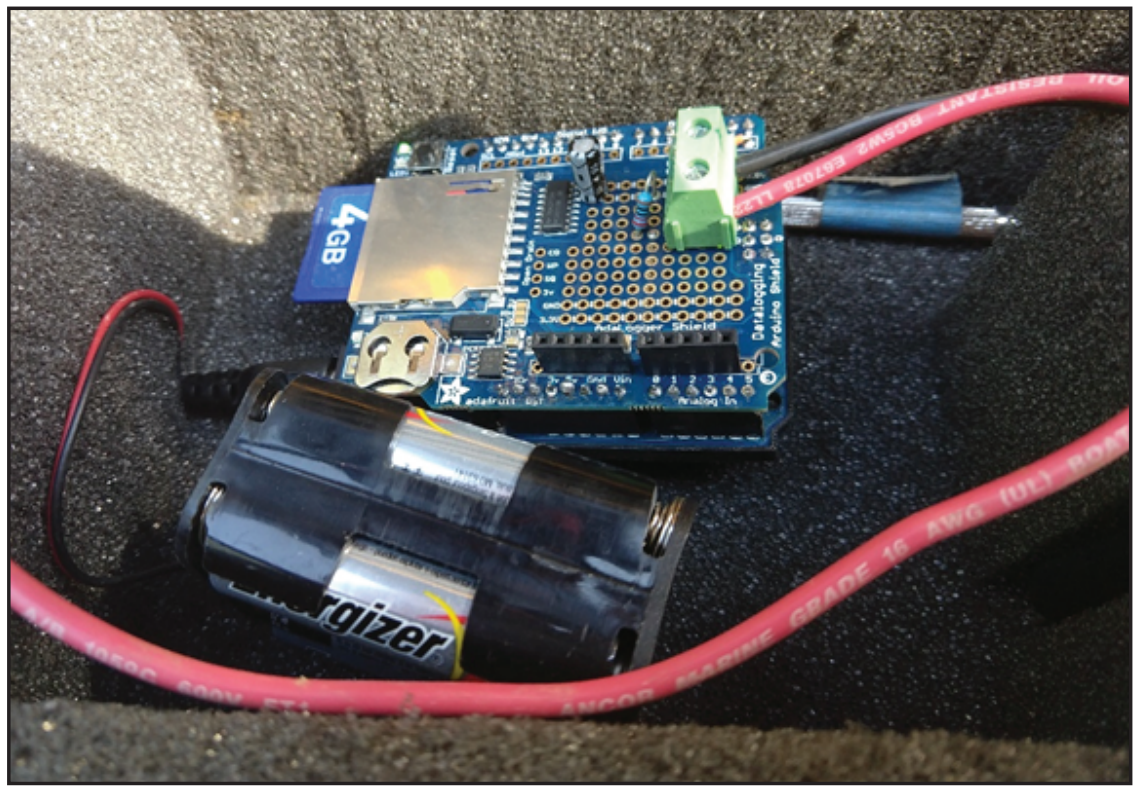

Photograph taken by Paul Work, U.S. Geological Survey.

Figure 2.3. The datalogger that was used to monitor flowmeter analog output. Red and black wires carry 4-20 milliamperes output from the flowmeter. 


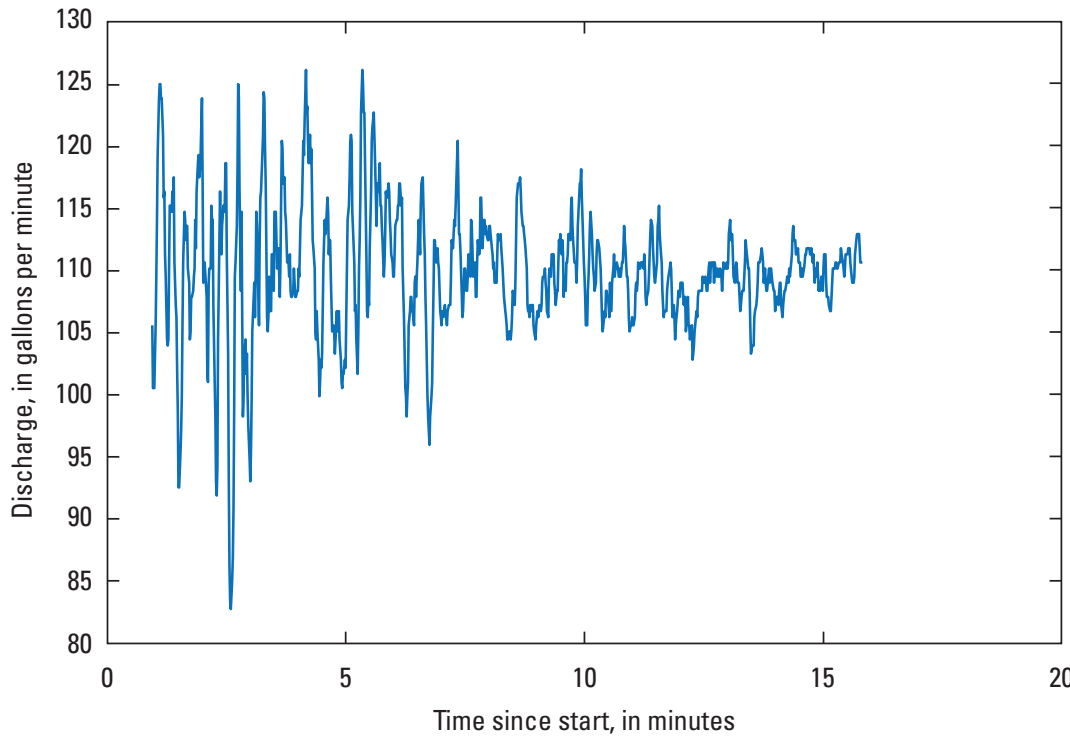

Figure 2.4. Time-dependence in discharge as reported by a flowmeter at 1 hertz at site SAC1 on May 2, 2019. This result is for the third experiment of the day. Mean and standard deviation of the discharge are 110 and 5.3 gallons per minute, respectively. Time zero corresponds to when the logger began recording; the flow started about 1 minute later.

Table 2.1. Summary of discharges and water volume losses for each borehole erosion test.

[Site locations are shown in table 1. Abbreviations: gal/min, gallon per minute; —, tests did not include digital discharge measurements or measured water levels to compute volume changes]

\begin{tabular}{|c|c|c|c|c|c|}
\hline $\begin{array}{c}\text { Number of } \\
\text { flows }\end{array}$ & $\begin{array}{c}\text { Mean flow } \\
\text { (gal/min) }\end{array}$ & $\begin{array}{l}\text { Duration } \\
\text { (minute) }\end{array}$ & $\begin{array}{l}\text { Standard } \\
\text { deviation } \\
\text { (gal/min) }\end{array}$ & $\begin{array}{c}\text { Water loss } \\
\text { (gallon) }\end{array}$ & Notes \\
\hline \multicolumn{6}{|c|}{ LAR9 } \\
\hline \multirow[t]{2}{*}{2} & 96 & 10 & - & - & - \\
\hline & 141 & 10 & - & - & - \\
\hline \multicolumn{6}{|c|}{ LAR12 } \\
\hline 1 & 155 & 10 & - & - & - \\
\hline \multicolumn{6}{|c|}{ LAR7 } \\
\hline \multirow[t]{2}{*}{2} & 55 & 10 & 3.6 & - & Datalogger captured flow 1 only. \\
\hline & 112 & 10 & - & - & - \\
\hline \multicolumn{6}{|c|}{ SAC1 } \\
\hline \multirow[t]{3}{*}{3} & 121 & 10 & 8 & - & - \\
\hline & 127 & 15 & 7 & - & - \\
\hline & 110 & 15 & 5 & - & - \\
\hline \multicolumn{6}{|c|}{ SAC7 } \\
\hline \multirow[t]{3}{*}{3} & 145 & 10 & - & - & - \\
\hline & 151 & 15 & - & - & - \\
\hline & 150 & 20 & - & - & - \\
\hline \multicolumn{6}{|c|}{ SAC3 } \\
\hline \multirow[t]{3}{*}{3} & 148 & 10 & - & - & - \\
\hline & 154 & 10 & - & - & - \\
\hline & 157 & 10 & - & - & - \\
\hline
\end{tabular}


Table 2.1. Summary of discharges and water volume losses for each borehole erosion test.-Continued

[Site locations are shown in table 1. Abbreviations: gal/min, gallon per minute; 一, tests did not include digital discharge measurements or measured water levels to compute volume changes]

\begin{tabular}{|c|c|c|c|c|c|}
\hline $\begin{array}{l}\text { Number of } \\
\text { flows }\end{array}$ & $\begin{array}{l}\text { Mean flow } \\
\text { (gal/min) }\end{array}$ & $\begin{array}{l}\text { Duration } \\
\text { (minute) }\end{array}$ & $\begin{array}{l}\text { Standard } \\
\text { deviation } \\
\text { (gal/min) }\end{array}$ & $\begin{array}{l}\text { Water loss } \\
\text { (gallon) }\end{array}$ & Notes \\
\hline \multicolumn{6}{|c|}{ LAR2 } \\
\hline \multirow[t]{3}{*}{3} & 153 & 10 & 28 & - & - \\
\hline & 152 & 20 & 16 & - & - \\
\hline & 152 & 20 & 14 & - & - \\
\hline \multicolumn{6}{|c|}{ LAR5 } \\
\hline \multirow[t]{2}{*}{2} & 150 & 10 & - & 34 & \multirow{2}{*}{ Leaky shaker tank for test 2 . } \\
\hline & 131 & 11 & - & 114 & \\
\hline \multicolumn{6}{|c|}{ LAR6 } \\
\hline \multirow[t]{4}{*}{4} & 61 & 11 & - & 23 & - \\
\hline & 62 & 15 & - & 21 & - \\
\hline & 184 & 10 & - & 67 & - \\
\hline & 153 & 20 & - & 77 & - \\
\hline \multicolumn{6}{|c|}{ LAR10 } \\
\hline \multirow[t]{2}{*}{2} & 150 & 10 & 31 & 630 & \multirow{2}{*}{ Bentonite seal around trough on ground failed. } \\
\hline & 114 & 15 & 11 & 370 & \\
\hline \multicolumn{6}{|c|}{ LAR3 } \\
\hline \multirow[t]{3}{*}{3} & 127 & 10 & 35 & 54 & No digital flow log for second discharge. \\
\hline & 134 & 15 & - & 46 & - \\
\hline & 123 & 45 & 24 & 50 & - \\
\hline \multicolumn{6}{|c|}{ SAC9 } \\
\hline 1 & 135 & 20 & 20 & - & - \\
\hline \multicolumn{6}{|c|}{ SAC3B2 } \\
\hline \multirow[t]{3}{*}{3} & 115 & 10 & 57 & 144 & - \\
\hline & 109 & 30 & 38 & 69 & - \\
\hline & 75 & 30 & 15 & 18 & - \\
\hline
\end{tabular}

Figure 2.5 shows the change in depth and volume in the shaker tank versus time for a series of four tests at site LAR6 on May 17, 2019. The amount of water lost during each test was in the range of $20-80 \mathrm{gal}$, and the corresponding rates of loss ranged from 1.2 to $4.0 \mathrm{gal} / \mathrm{min}$. With test flow rates typically in the 100-150 gal/min range, rates of loss were small enough that discharge within the hole was assumed constant and equal to the mean of the time-dependent discharge record. Discharge and water volume-change data for all (BETs) appears in table 2.1. 


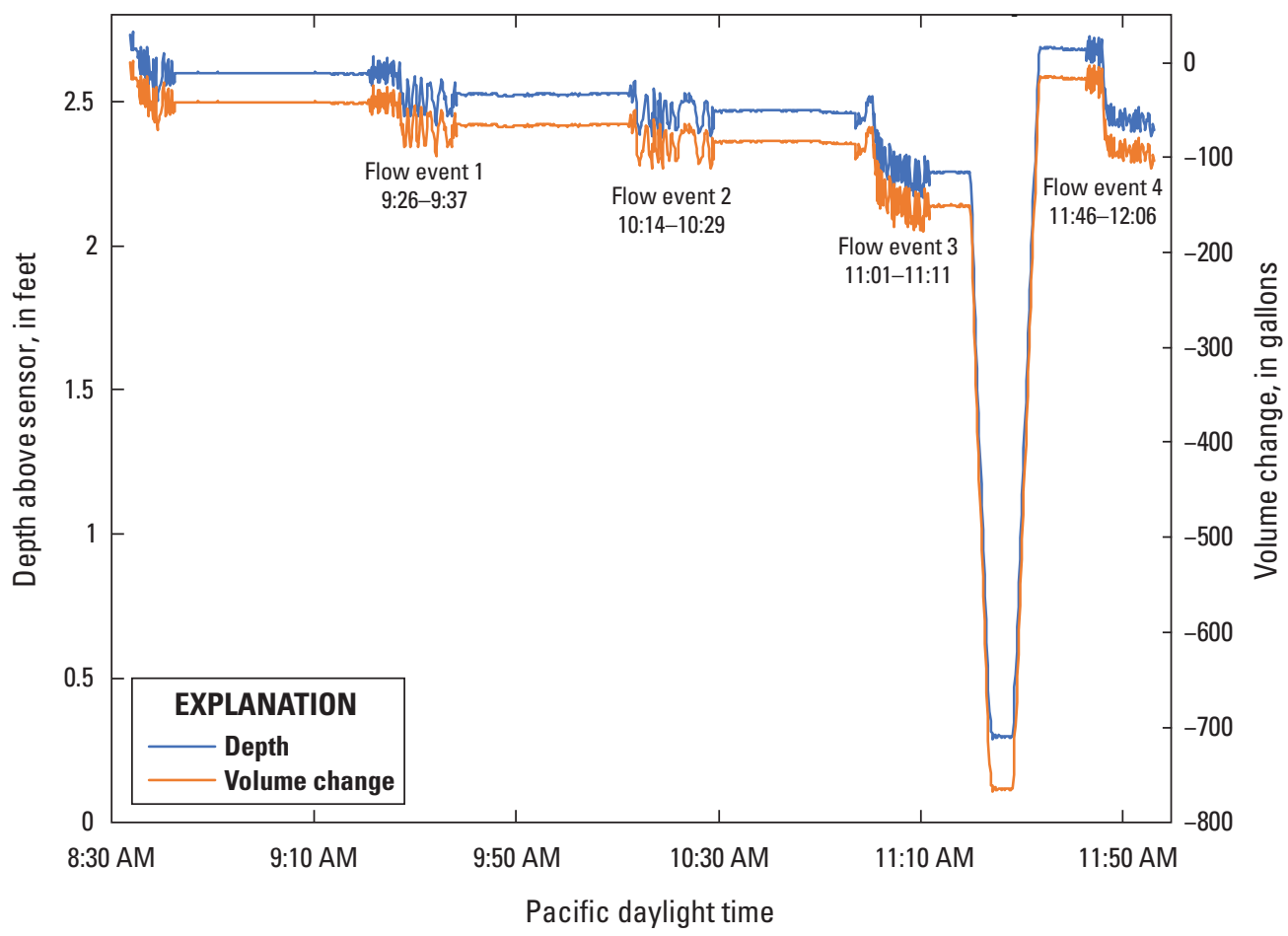

Figure 2.5. Measured depth and volume changes in the water-supply tank in the shaker trailer during a test at site LAR6 on May 17, 2019. The times for the start and end of each flow event are shown beneath or above each flow event. The datalogger was pulled from the tank and reinstalled at a slightly different altitude between flow events 3 and 4 . 
For more information concerning the research in this report, contact the Director, California Water Science Center

U.S. Geological Survey

6000 J Street, Placer Hall

Sacramento, California 95819

https://ca.water.usgs.gov

Publishing support provided by the U.S. Geological Survey

Science Publishing Network, Sacramento Publishing Service Center 


\section{$\frac{\mathbb{2}}{\mathrm{C}}$}

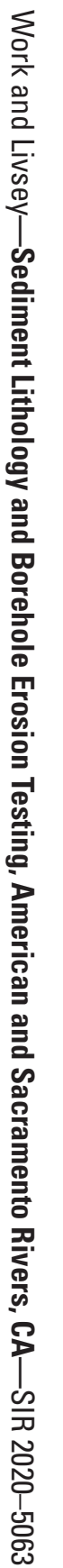

